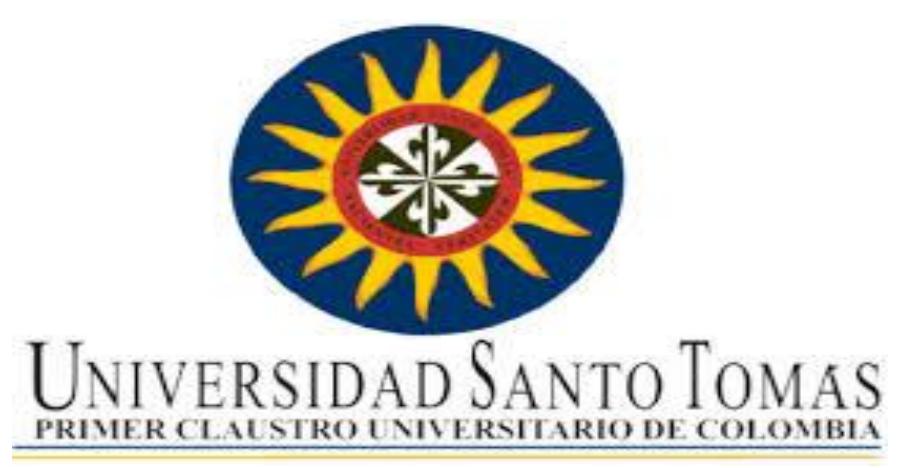

\title{
CHILE, MERCADO LABORAL Y SISTEMA DE PENSIONES 2006 - 2010: ILUSTRACIÓN DE LA REFORMA PREVISIONAL DE 2008
}

\section{LUIS ROBERTO ARISMENDI ECHEVERRY}

\author{
Universidad Santo Tomás
}

Facultad de Economía, Maestría en Protección Social

Bogotá, Colombia 


\section{CHILE, MERCADO LABORAL Y SISTEMA DE \\ PENSIONES 2006 - 2010: ILUSTRACIÓN DE LA \\ REFORMA PREVISIONAL DEL 2008}

\section{LUIS ROBERTO ARISMENDI ECHEVERRY}

Tesis o trabajo de investigación presentada(o) como requisito parcial para optar al título de

\section{Magíster en Protección Social}

Directora:

Mg. Sandra Milena Barrios Pulido

Universidad Santo Tomás

Facultad de Economía, Maestría en Protección Social

Bogotá, Colombia 


\section{Dedicatoria}

A Dios, el ser supremo que me guía en cada paso de mi vida y hace posibles todos mis logros a través de su bendición.

A mis padres Roberto y Nancy y a mi hermano Diego, por su afecto y apoyo

de forma incondicional. 


\section{Agradecimientos}

Quiero expresar mis más sinceros agradecimientos en primer lugar a Dios, porque es el ser primordial para mí desde mi formación familiar y quien ha permitido que alcance los objetivos propuestos. A mis padres y hermano porque a lo largo del tiempo hemos construido un sólido núcleo familiar que nos ha permitido salir adelante y construir un buen futuro siempre manteniendo nuestra unión.

Finalmente deseo agradecer a las Doctoras Sandra Barrios e Ivonne Ordóñez porque han sido un apoyo incondicional a lo largo del desarrollo de este trabajo académico, por su paciencia, por sus oportunas sugerencias y porque sin su guía no hubiese sido posible culminar esta investigación. 


\section{TABLA DE CONTENIDO}

1. CAPÍTULO 1. El sistema de pensiones chileno en 2006 y 2010

1.1 Estructura del Sistema de pensiones de Chile.... .24

1.2 Financiamiento del sistema pensional 35

1.3 Cifras de cobertura y resultados del sistema pensional chileno en el periodo 2006$2010 \quad 37$

1.4 Conclusiones .52

2. CAPÍTULO 2: Panorama del mercado laboral años 2006 y 2010 .55

2.1 Antecedentes históricos del Mercado Laboral en Chile 56

2.2 Instituciones y Actores del mercado laboral en Chile 61

2.3 Cifras y datos estadísticos relevantes del mercado laboral en Chile .66

2.4 La informalidad laboral en Chile. .85

2.5 Conclusiones 102

3. CAPÍTULO 3: Una Reforma Previsional Integral en medio de la crisis económica mundial 104

3.1 Aspectos centrales de la Reforma Previsional de 2008 111

3.2 Institucionalidad del Sistema Previsional chileno 123

3.3 Resultados esperados de la reforma... 128

3.4 Desafíos pendientes posteriores a la reforma 147

3.5 Conclusiones. 152

4. Recomendaciones aplicables al caso de Colombia 154

5. BIBLIOGRAFÍA. 158 


\section{LISTA DE TABLAS}

Tabla 1. Tipo de pensión, monto promedio a pagar y cantidad de pensiones emitidas año 2013 .36

Tabla 2. Número de afiliados por Tipo (Dependientes), Sexo y A.F.P (año 2005) ..................38

Tabla 3. Número de afiliados por Tipo (Independientes), Sexo y A.F.P (año 2005)............... 38

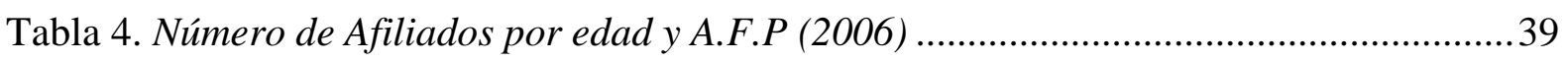

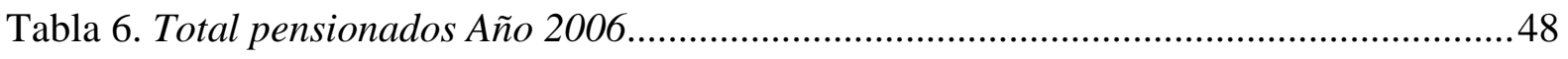

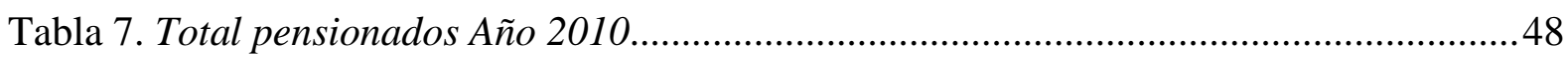

Tabla 8. América Latina y el Caribe: principales indicadores del mercado laboral urbano, 2004-2014 (porcentajes) .71

Tabla 9. América Latina: principales indicadores del mercado laboral urbano por sexo. Enero a septiembre, 2013 y 2014 (porcentajes). .76

Tabla 10. América Latina: principales indicadores del mercado laboral urbano por grupos etarios. Enero a septiembre, 2013 y 2014 (porcentajes).

Tabla 11. América Latina y el Caribe. Principales indicadores del mercado laboral por ámbito geográfico según sexo y país. Año 2013 o último año disponible (porcentajes)..... .80

Tabla 12. Tasa de desocupación promedio en Chile años 2006-2010 .82

Tabla 14. Caracterización de los trabajadores formales e informales. Definición OIT . .89

Tabla 15. Tasas de informalidad por género, nivel educativo y tramos de edad. Definición OIT. Año 2010 .90

Tabla 16. Evolución de la tasa de desocupación por sexo 1990 - 2006 .93 


\section{LISTA DE FIGURAS}

Figura 1. Asalariados que aportan al sistema de pensiones por país, años 2010 y 2014. (Porcentaje) 12

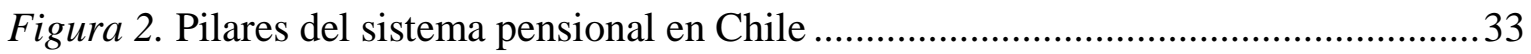

Figura 3. Número de Afiliados totales al sistema pensional. Año 2006 ............................. 42

Figura 4. Número de Afiliados totales al sistema pensional. Año 2010 ............................42

Figura 5. Número de Cotizaciones efectivas totales al sistema pensional. Años 2006 a 2010

Figura 6. Número de Cotizaciones efectivas totales por grupo etario. Año 2006 ...............45

Figura 7. Número de Cotizaciones efectivas totales por grupo etario. Año 2010 ..............45

Figura 8. Número de Cotizaciones efectivas totales por actividad económica. Año 200646

Figura 9. Número de Cotizaciones efectivas totales por actividad económica. Año 201047

Figura 10. Evolución de cobertura pensional en el periodo 1981-2009.............................49

Figura 11. Número de pensiones totales (por tipo de pensión) 1982-2009 .........................50

Figura 12. Número de pensiones por modalidad 1986-2012 ….......................................51

Figura 13. Producto Interno Bruto (PIB) Vs Ocupación en Chile (1986-2009). Cifras en

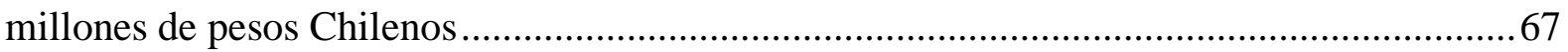

Figura 14. Evolución de Tasa de Empleo por quintil de ingreso - Chile ............................68

Figura 15. Evolución de Tasa de Empleo por años de escolaridad - Chile .........................69

Figura 16. Salario por hora según años de escolaridad .................................................. 70

Figura 17. Evolución del PIB, Tasa de Desempleo y nivel de Empleo. Periodo 1996-2009

Figura 18. América Latina y el Caribe: tasa de desocupación urbana. Enero a septiembre, 2013 y 2014 (porcentajes) .73

Figura 19. América Latina y el Caribe: Tasa de participación urbana. Enero a septiembre, 2014 y 2013 (porcentajes)

Figura 20. América Latina y el Caribe: Tasa de ocupación urbana. Enero a septiembre, 2014 y 2013 (porcentajes). .75

Figura 21. América Latina: variación interanual del salario real medio en el sector formal,

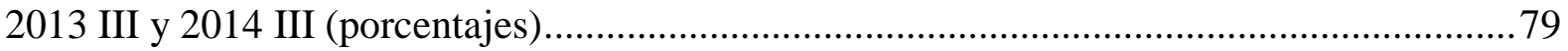

Figura 22. Cotizantes por actividad económica al sistema pensional 2006 ......................84

Figura 23. Cotizantes por actividad económica al sistema pensional 2010 ......................85

Figura 24. Evolución del nivel de informalidad laboral en el periodo 1998-2006..............87 
Figura 25. Formalidad e informalidad por componentes. 14 países de América Latina. Entre 2009 y 2013

Figura 26. Informalidad en el empleo como proporción del empleo total - Total Nacional Vs. Sector Construcción 2010-2013

Figura 27. Evolución de la Tasa de participación por sexo 1990 - 2009........................... 92

Figura 28. Evolución de la tasa de desocupación por sexo 1990 - 2006 ............................94

Figura 29. Total de trabajadores asalariados y no asalariados 1990 a 2009 ....................... 95

Figura 30. Asalariados según su situación contractual 2006 - 2009 (porcentaje) ..............96

Figura 31. Asalariados según tipo de vinculación contractual 2006 - 2009 (porcentajes) 97

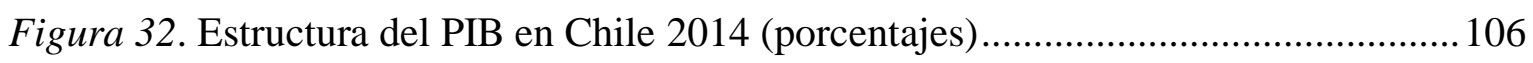

Figura 33. Evolución histórica del PIB 2010 - 2015. Cifras en millones de U\$\$........... 107

Figura 34. Gasto del PIB por sector años 2011 - 2014. Cifras en millones de U\$\$........ 109

Figura 35. Producto Interno Bruto por clase de actividad económica años 2011 - 2014.

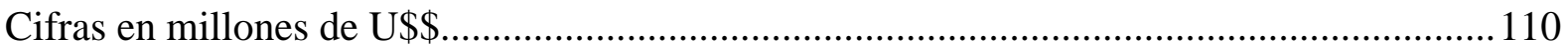

Figura 36. Gasto del PIB por grandes sectores años 2011 - 2016 (porcentajes) .............111

Figura 37. Objetivos para abordar la Reforma Previsional ............................................ 116

Figura 38. Beneficios para las mujeres con la aplicación de la reforma ..........................121

Figura 39. Estructura institucional del Sistema Previsional año 2006 .............................124

Figura 40. Estructura institucional del Sistema Previsional propuesto y aplicado en la

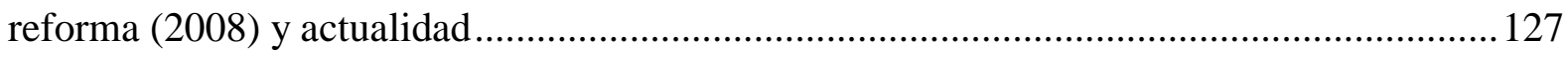

Figura 41. Resultados esperados de la reforma ............................................................. 130

Figura 42. Propuestas en materia fiscal de la Reforma previsional ............................... 131

Figura 43. Compromisos fiscales con el sistema........................................................ 133

Figura 44. Balance general de audiencias públicas para la Reforma Previsional ............137

Figura 45. Número de beneficiarios por pensión básica solidaria de vejez e invalidez (2009 $-2016)$

Figura 46. Afiliados voluntarios según periodo de afiliación y género 2009 - 2016 .......144

Figura 47. Número de pensiones de viudez pagadas a cónyuges hombres (2008 - 2016)

Figura 48. Porcentaje de obligatoriedad de cotización a los trabajadores independientes 


\section{INTRODUCCIÓN}

El presente trabajo hace parte del programa de Maestría en Protección Social y se encuentra enmarcado en la línea de Economía de la Protección Social. Las pensiones hacen parte fundamental del sistema de protección social al funcionar como garantes de ingreso en la vejez para las personas (Filgueira, 2014); respecto a las pensiones, las cuales se encuentran compuestas en su estructura básica de sistema por cobertura, financiamiento, institucionalidad y equidad (Robles, 2013), se hace de especial interés en este documento abordar todos estos aspectos antes nombrados pero haciendo énfasis en cómo estos, se ven reflejados antes, durante y después de la aplicación de la Reforma Previsional integral del año 2008.

La cobertura es fundamental para cualquier sistema o programa en materia de protección social, puesto que sirve como instrumento de medición del funcionamiento del propio sistema y a la vez ayuda a estructurar sólidamente los demás elementos que componen un sistema, en este caso "el sistema pensional", porque mientras exista cobertura, necesariamente debe existir una contribución monetaria definida y percibida a través de los salarios que permita alimentar el financiamiento y garantizar la sostenibilidad del sistema en el tiempo (Rofman \& Lucchetti, 2006).

Dada la importancia de la cobertura en el sistema de pensiones, el presente documento se abordó sustentado en la siguiente problemática de investigación: ¿Cuáles son los factores económicos que afectan la cobertura pensional en Chile para el periodo 2006-2010?, es de gran interés para el autor, describir y hacer una reflexión sobre la incidencia que por acontecimientos tan importantes como la Reforma Previsional de 2008, llega a tener la cobertura pensional para alimentar las arcas del Estado y contribuir al progreso de los sectores productivos de la economía chilena. Otro factor fundamental en esta investigación es el mercado laboral, su estructura, tendencia, remuneración salarial, las tasas de empleo y desempleo así como el nivel de informalidad; con relación a este último, es un factor clave en el desempeño del sistema de seguridad social general y un condicionante del comportamiento del mercado laboral (Coloma \& Rojas, 2012).

El tema de las pensiones, especialmente lo que concierne a la cobertura es de suma importancia para el bienestar y el desarrollo de un país y su población. Su relevancia principalmente radica en las implicaciones de tipo fiscal, social y económico que tiene sobre la población de un país, que para el presente análisis es Chile. 
La cobertura universal en pensiones, ha sido frecuentemente debatida en América Latina por expertos en temas políticos y económicos. quienes generalmente abordan el tema mencionando que el problema de la cobertura, hunde sus raíces principalmente en la sostenibilidad financiera del sistema y de haber sido concebido como un sistema de reparto y no ser modificado por uno de capitalización individual, a lo que Ortiz y Moreno (2010) mencionan como errado, puesto que el problema no es financiero, sino más bien los problemas de base del sistema son la poca articulación que los gobiernos tienen para responder a las dinámicas de transición demográfica, las políticas de empleo y el incremento de la productividad. Lo anterior se suma a la falta de voluntad política del gobierno para realizar y cumplir a cabalidad los acuerdos que incluyan a los trabajadores de los diversos sectores de la economía para que sea un proceso más participativo, debido a que normalmente cuando se presentan prioridades en la economía, la partida de gasto elegida para cubrir las obligaciones fiscales es la del gasto social, en la cual se reducen sus montos y como consecuencia de esto se genera una inminente emergencia social y consigo vienen los problemas de legitimidad para el gobierno debido a que ha reducido o incumplido con lo pactado a los pensionados.

En este trabajo se destaca la importancia de analizar la cobertura universal en pensiones, dado que realmente es una opción que de articularse adecuadamente, garantiza un ingreso mínimo y sostenible a todos los ciudadanos jubilados o en edad de hacerlo, contrarresta la responsabilidad que se asigna al Estado con las pensiones asistenciales como consecuencia de los incrementos en la calidad de vida de la población y finalmente con una organización definida las finanzas públicas del sistema garantizarían su sostenibilidad a través del tiempo. También es propicio destacar la importancia que tiene en el ámbito de la cobertura en pensiones el comportamiento y las políticas que se generan para el mercado de trabajo, puesto que según Uthoff (2011): los descensos en la población en edad de trabajar (joven) sumado con los descensos en la fecundidad y el aumento en la esperanza de vida de la población, hace que el mercado de trabajo sea más excluyente y se produzca una mayor tasa de dependencia intergeneracional que a su vez exija una mayor demanda de servicios de protección social, esto sin dejar de lado el hecho de incentivar a que se generen contratos de trabajo y empleos estables que retomen el principio básico de protección de los trabajadores y sus familias contra riesgos como, invalidez, vejez, enfermedad y muerte; y que como respuesta a esa estabilidad también existan remuneraciones salariales adecuadas para contribuir al sistema y a la densidad de cotización (Rofman \& Lucchetti, 2006). 
Bajo la descripción introductoria realizada por el autor, la cobertura se transforma a lo largo del documento en una parte importante que entra a examinar si realmente se presentaron cambios sustanciales antes y después de la reforma no solo en términos de cobertura, sino también, en términos del sistema general de pensiones, que en el marco de la protección social debe ser garante de bienestar y generación de ingresos en la vejez como producto de años juiciosamente laborados y aportados al sistema de protección social, el cual desde su esencia debe procurar siempre por el bienestar de la población y por la estabilidad de las condiciones económicas y sociales en las cuales las personas se desenvuelven para contribuir de forma conjunta a la nación por medio de la vía salarial.

Las contribuciones provenientes de los salarios deben reflejar la proporción en la cual el Estado retribuye a sus cotizantes los aportes realizados por ellos, procurando siempre otorgar el mayor nivel de bienestar posible y realizando un control eficaz que permita monitorear la evasión o elusión de aportes (Uthoff, 2006), deficiencias que afectan enormemente los sistemas de protección social y de pensiones respectivamente, tanto en el corto como en el largo plazo.

Si se habla en términos comparativos entre el sistema chileno de pensiones respecto de sus similares del continente, tomando como referencia a Robles, Cecchini, \& Filgueira (2014) se puede encontrar que el nivel de cobertura promedio para los adultos mayores en Chile ronda el 63\% para el año 2014, este indicador sitúa a Chile en la tercera plaza en cuanto a cobertura pensional, superado únicamente por Uruguay y Brasil con más del 80\% de cumplimiento en este indicador. 


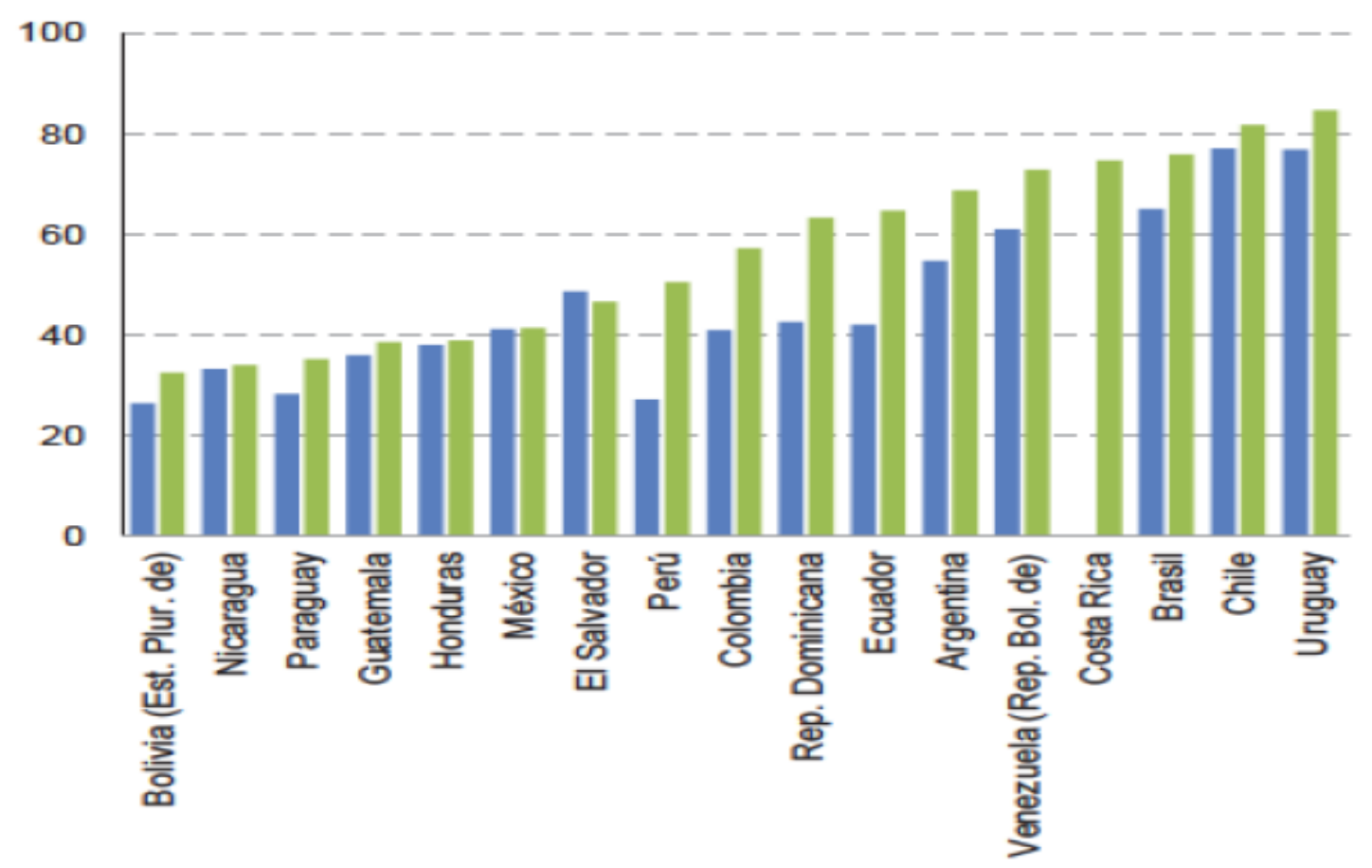

Figura 1. Asalariados que aportan al sistema de pensiones por país, años 2010 y 2014. (Porcentaje)

Fuente: (Robles et al., 2014, p. 34)

En cuanto al aporte que realizan los trabajadores al sistema de pensiones, se puede observar que Chile tanto en el año 2010 como en el 2014, mantuvo su nivel de cotización e incluso lo aumentó aunque en una cantidad muy pequeña, sin embargo, se encuentra entre los dos países en los cuales sus trabajadores cotizan más al sistema de pensiones registrando un $78 \%$, siendo superado únicamente por Uruguay con $82 \%$ aproximadamente, esta diferencia porcentual es realmente escasa y de hecho si se observara por cantidad real de trabajadores Brasil y Chile serían los mayores contribuyentes al sistema de pensiones vía recurso humano del mercado laboral.

Se destaca en términos de transformación e innovación en el sistema de protección social, los "esfuerzos sinérgicos impulsados por algunos países de la región [...] para conformar verdaderos sistemas o sub-sistemas de protección social dirigidos a la primera infancia, donde se incorpora también el componente de cuidado" (Cecchini, 2016, p. 19). Ejemplos clave son los de Brasil (Brasil Carinhoso), Chile (Chile Crece Contigo), Colombia (De cero a siempre) y, más recientemente, Uruguay (Uruguay Crece Contigo) (UNICEF, 2013). Con este tipo de medidas y programas orientados a la población infantil, se busca que la previsión y prevención 
sea una medida básica que contribuya al bienestar de la niñez y de este modo se consolide de una mejor manera la estructuración de un sistema integrado de protección social.

Un grupo de países ha generado diversas estrategias convertidas en mecanismos de protección social orientadas a la población cesante, que buscan minimizar la afectación que genera el desempleo (o su aumento gradual) en el mercado laboral y en el sistema de Seguridad Social. Entre ellos está Uruguay (seguro de desempleo e inclusión de trabajadores del sector rural y el servicio doméstico), aunque también esto es comprobable en países como Argentina, Chile y Brasil.

América Latina y el Caribe han apostado desde hace más de una década a un sostenido esfuerzo por incrementar la cobertura de la protección social. Ello se manifiesta al menos en cuatro áreas de la política social: jubilaciones, pensiones y otras transferencias monetarias a los adultos mayores, transferencias monetarias a familias con hijos, acceso a servicios y aseguramiento de salud y finalmente, protección al trabajador (seguro de enfermedad y seguro de desempleo, sumado a las políticas de derechos laborales-indemnización, horas extras, licencias, etc.) (Robles et al., 2014). En cuanto a estos cuatro aspectos, que van desde la universalidad a la focalización y del usuario emisor al benefactor, se está revaluando según el impacto que tiene en la sociedad y en las políticas establecidas para cada nación.

Chile tiene una larga historia en cuanto a la aplicación de políticas sociales. Fue uno de los países pioneros en América Latina en ampliar la cobertura gratuita de la salud y la educación. Además, Chile comenzó tempranamente a implementar políticas de seguridad social para los trabajadores urbanos asalariados del sector formal. (Robles, 2013, p. 7)

La Caja del Seguro Obrero Obligatorio Chileno se fundó en el año de 1924. Hacia el año 1950 ya se sabía de la existencia de tres entidades creadas para ofrecer seguridad social a los trabajadores independientes, dos para las fuerzas miliares y policía y otros dos para brindar cobertura a varios sectores de trabajadores asalariados (Robles, 2013). Desde los años 50 y a lo largo de este periodo, en Chile se implementó diferentes políticas orientadas a la maternidad y la protección de la niñez. Estas políticas justifican las considerables caídas en las tasas de mortalidad y desnutrición infantil que se evidenció en Chile.

Hacia el año de 1980 en Chile se desarrolla un conjunto de reformas que se dieron con el propósito de impactar los sectores económicos y sociales, entre estas se destaca la privatización 
de los servicios de Salud y Educación así como disminuir el gasto destinado a los temas sociales.

En lo que se refiere al sistema de seguridad social, para el año de 1981 se sustituyó el sistema de reparto por un modelo de capitalización individual, en este mismo año se crean las Administradoras de Pensiones (AFP) y adicionalmente el sistema público de pensiones se mantuvo sin modificaciones exclusivamente para un $4 \%$ de la población chilena en el momento. Por otra parte para la población que no contaba con un ingreso mínimo, se creó la Garantía Estatal de Pensión Mínima (GEPM).

El Programa de Pensiones Asistenciales (PASIS) se creó en 1975 con el fin de universalizar el acceso a la seguridad social para las personas sin cobertura. Sin embargo, el PASIS cubría una parte muy limitada de la población y representaba un monto de ingresos muy bajo, equivalente al 40,7\% de la GEPM (Mesa, 2004).

Como base en estas reformas, las pensiones utilizarían como mecanismo de financiación en las cuentas individuales, empleando tres modalidades: retiro programado, renta vitalicia y una modalidad que combina las dos anteriores. Otro cambio fundamental en las pensiones se dio porque las variables del sistema pensional estarían dadas por Unidades de Fomento (UF), las cuales tenían como objetivo sanear un problema histórico del sistema pensional público que era la afectación al poder adquisitivo en la economía.

Las edades de jubilación estaban establecidas así: para los hombres a los 65 años y las mujeres a los 60. Con el nuevo sistema privado en materia pensional se generó una gran diferencia con el sector público que consistía básicamente en otorgar todo el manejo del sistema a las administradoras de fondos de pensiones (AFP), las cuales estaban fuertemente reguladas por el Estado y recibían giros directos del mismo con el fin de mantener bajo control el funcionamiento del sistema.

La transición previsional -desde un esquema de reparto a otro de capitalización individualdejó al Estado encargado tanto de la supervisión y fiscalización del sistema de pensiones de AFP como de un rol en la administración y pago de los beneficios del antiguo sistema público civil de pensiones; la administración, cálculo y pago de los Bonos de Reconocimiento; la administración y pago de las pensiones del esquema público previsional de las Fuerzas Armadas y de Carabineros; la administración y pago de la GEPM del sistema de AFP; y la 
administración del sistema público asistencial, que provee de pensiones no contributivas a los indigentes y personas carentes de previsión (Mesa, 2004).

Con la reforma de 1981 se generó una mayor focalización de recursos hacia los grupos poblacionales menos favorecidos, no obstante, la afectación para los grupos de edades intermedias (25-35 años) en cuanto a la cobertura del Sistema Previsional seguía en descenso a razón de que los montos salariales eran insuficientes para que el trabajador pudiese garantizar una pensión acorde a las prestaciones que le correspondían.

“Los compromisos asumidos por el Estado durante la transición generan fuertes presiones sobre las finanzas públicas, traducidas en déficits previsionales que se mantienen en el orden de 5\% del PIB” (Arenas, 2010, p. 26), fue una de las principales conclusiones que floreció de la implementación de dicha reforma.

La Encuesta de Protección Social (EPS) en 2002 fue un instrumento estadístico estructurado y aplicado por parte de varios frentes de la economía; que incluyó, entes del gobierno, Academia y Banca Multilateral. Todo el año 2001 se trabajó en el diseño metodológico y el contenido que debía llevar para que se aproximara lo más posible a la realidad y la percepción que tienen de esta los ciudadanos, dicha encuesta fue avalada por los principales líderes del gabinete de gobierno chileno.

Esta encuesta se trazó como objetivo esencial, realizar un estudio de la densidad (cantidad) de cotizaciones por género y validar la cantidad de afiliados que en cifras reales contribuían al sistema, para con esta información poder calcular tasas de reemplazo, proyecciones y estimaciones de los efectos fiscales que produciría la implementación de la Garantía de Pensión Estatal mínima y estaba autorizado por un proyecto de ley que le soportaba.

Las reformas en materia pensional llevan implícitas cambios en la legislación del sistema, los cuales generan afectación en el largo plazo para la población, como por ejemplo, el hecho de que una mujer empiece a laborar con 22 años, recibirá un bono por hijo (si es apta para recibir el beneficio) cuando tenga entre 62 a 65 años, es decir, en cuarenta años como mínimo. También es importante destacar acerca de los efectos en términos fiscales que inciden en las reformas, tales como las alzas en los porcentajes de cotización para empresas y trabajadores.

En los últimos 30 años, las reformas a los sistemas de pensiones han tenido como característica principal, una marcada contraposición entre el sistema de reparto y el de capitalización individual y entre la administración del sistema pública o privada (Mesa, 2001; 
2008). En este contexto, América Latina ha estado inmersa en un debate de ideologías sobre cómo el Estado concibe al sistema pensional colocando como primicia la realidad social del país, dejando de lado las cifras y registros numéricos que se han recolectado a través de los años y que finalmente han sido la herramienta principal para el diseño de diversas políticas no solo en materia pensional sino también en cuanto al sistema de protección social.

La Reforma Previsional chilena de 2008 sustituyó este debate de naturaleza ideológica. Puesto que demostró que el Estado es un actor estrictamente necesario para estructurar el funcionamiento del sistema pensional, respecto al esquema de capitalización individual se evidencia que cumple un papel complementario para el financiamiento público de las pensiones solidarias.

En general las reformas a las políticas públicas en el Estado se planifican en etapas consecutivas: estudio y diagnóstico; diseño de propuestas; elaboración del proyecto de ley; tramitación ante el Congreso de la República; se hace el proceso de aprobación e implementación, luego de esto se genera una evaluación para analizar los alcances e impacto y pulir los detalles que se consideren necesarios. Sin embargo, con la Reforma Previsional se adquiere un aprendizaje relacionado con la democracia que muestra cómo la implementación de una policía pública debe ser transversal, esto quiere decir, que el desarrollo de sus fases debe ser simultáneo para que a través del tiempo y por las condiciones del entorno en el cual se desenvuelve, dichas fases se complementen entre sí.

El sistema de pensiones al año 2010 se componía a partir de tres elementos: un pilar redistributivo, un pilar de cuentas individuales obligatorias y finalmente un pilar voluntario. Las cuentas individuales se crearon en el año de 1981 y se caracterizan por tener una contribución definida o fija al sistema. Para acceder a las contribuciones definidas, se debía cumplir con la condición de que la edad de retiro para los hombres es de 65 años y de 60 para las mujeres (OCDE, 2015). A partir de esas edades, los beneficios generados por los aportes al sistema realizados durante todos los años laborados se pueden reclamar ante la entidad pensionadora en cualquier momento. No se constituye como un requisito u obligación dejar de lado la actividad laboral para acceder a la pensión.

Sistemas básicos y suplementarios. La Pensión Básica Solidaria (PBS) se autoriza a partir de los 65 años de edad y se encuentra dirigida al $60 \%$ de la población con mayores índices de pobreza, aquí se encuentran incluidos todos los ciudadanos que hayan vivido en el país un mínimo de 20 años y al menos cuatro o cinco años antes de la solicitud para obtener pensión. 


\section{Cálculo de beneficios - Contribución definida}

La contribución de los trabajadores para el sistema de capitalización individual debe ser del $10 \%$ de los ingresos. De esta contribución se debe deducir los cargos administrativos y que en promedio son aproximadamente el 1,55\% de los ingresos, adicionalmente, los trabajadores deben contribuir con una prima del $1,49 \%$ por concepto de seguros en caso de discapacidad y sobrevivencia (asociada con muerte accidental).

En el momento de la jubilación, el capital acumulado a través de los años trabajados se puede destinar para comprar una renta vitalicia inmediata u obtener un ingreso temporal con renta vitalicia diferida, también se tiene la alternativa de retiros (por medio de iniciativas de ahorro) programados para las personas que han logrado acumular una suma considerable de capital a través de sus aportes al sistema pensional.

La pensión suplementaria o mejor conocida como Pensión Básica Solidaria (PBS) tiene como objetivo mejorar la calidad de vida de los trabajadores de bajos ingresos cuando se retiran del mercado laboral para obtener pensión. La modalidad de retiro programado y anticipado permite realizarse a cualquier edad, siempre y cuando el capital acumulado en la cuenta de cotización del trabajador sea considerablemente superior a lo establecido por el sistema.

A partir de julio del 2012, esta condición cambia a un 80\% de la Pensión Máxima con Aporte Solidario (PMAS), La segunda condición es alcanzar una tasa de reemplazo del $70 \%$ de los ingresos de los 10 años anteriores al desembolso de la pensión. (OCDE, 2015, p. 98)

\section{Impuesto sobre la renta personal y contribuciones a la seguridad social}

\section{Impuesto a los trabajadores}

En el 2010, todos los pensionados pagaron un 7\% de sus ingresos para solventar la atención en salud que requerían, Pero desde noviembre del 2011, los jubilados que hacen parte del $60 \%$ más pobre y que son beneficiarios del pilar redistributivo, ya no contribuyen al sistema para aumentar la cobertura y el gasto en salud. Además, los pensionados que pertenecen al cuarto quintil de ingresos aportan apenas un 5\% de los ingresos por pensión a la cobertura de salud y el resto, pagan el 7\%. (OCDE, 2015, p. 99) 
Las brechas en términos contributivos de los hombres y mujeres en ALC, correlacionadas con las altas tasas de transición, los altos índices de informalidad y las bajas tasas de empleo, tendrán un impacto significativo sobre la futura adecuación de los ingresos por jubilación. . En casi todos los sistemas, los historiales contributivos incompletos tienen como resultado menores derechos a pensión. (OCDE, 2015, p. 23)

Es de alta importancia que en los esquemas contributivos, los primeros años laborales de un trabajador signifiquen los de una cotización constante y juiciosa con el fin de evitar impactos negativos representados a través del tiempo por un valor más alto de cotización y un mayor periodo para alcanzar la jubilación de la persona.

El análisis de los datos de dos estudios piloto realizados por el Banco Interamericano de Desarrollo (BID) en 2008 en Lima (Perú) y Ciudad de México (México) sugieren, por ejemplo, que las brechas o diferencias encontradas tienden hacia una distribución uniforme durante la vida laboral, lo cual es consecuente con los frecuentes cambios de los mercados laborales de estos países.

El autor de este documento considera que es oportuno observar dos visiones o perspectivas de interpretación de los sistemas pensionales. Por un lado se encuentra la visión pro-mercado, la cual sustenta su base teórica en la consecución y sostenibilidad de los recursos de los fondos pensionales y del propio sistema, incluyendo la cotización constante como un requisito para poder acceder a los servicios de seguridad social establecidos en un país según sea el caso.

Esta visión se encuentra muy presente en las instancias de las entidades multilaterales (Banco Mundial, CEPAL, ONU, OCDE y FMI entre otros) que enfocan sus programas de desarrollo de mercado con un tinte social, en muchas ocasiones y como el caso de Chile los modelos diseñados por estas entidades son compuestos por pilares (Rofman, Apella, \& Vezza, 2013), que si bien atienden un segmento grande de una problemática específica (desigualdad de ingresos o pobreza), siempre van encaminados hacia la rentabilidad financiera que define la aplicación o no de estos modelos en los distintos sectores de la economía.

La otra visión expuesta es desde la perspectiva del Derecho, visto como la idea de que la prestación y satisfacción de un servicio social requerido se debe ver atendida por la entidad pública o privada y que pase a un segundo plano la sostenibilidad y los rendimientos financieros. Cabe destacar que esta visión no desconoce las implicaciones que trae para la economía y para el Estado el hacerse cargo de garantizar una buena parte del gasto social de 
cara a la población, pues la afectación al presupuesto público vía gasto fiscal es grande y debe ser constantemente controlado para evitar crisis presupuestales que afecten el desempeño del sistema pensional y la prestación de servicios del mismo.

Una vez expuestas ambas visiones, el autor se inclina por la segunda visión en pro de los derechos de la población aunque no en su totalidad, esto quiere decir que, el diseño de un sistema pensional y de una posible reforma debe ser un mix que combine elementos fundamentales de ambas visiones, como la garantía de pensión de la población en respuesta a los pagos realizados durante su vida laboral y de acuerdo a su capacidad de pago vía salarios, el sostenimiento financiero del sistema a través de las AFP teniendo como referente un ente regulador de estas (en Chile es la SAFP) para que sean legisladas, vigiladas y se cree un ambiente de competencia legal, adicionalmente debe tener un sistema de incentivos de ahorro pensional dedicado especialmente para los más jóvenes, fomentando así la cotización al sistema pensional y aumentando la cobertura del mismo.

Por último, el sistema pensional debe estar muy bien relacionado con el mercado laboral, pues de los salarios de los afiliados y de sus contribuciones se alimenta el ahorro en la vejez, por lo que, es necesario que la dinámica de ambos sistemas se encuentre bajo un esquema que permita planear en la medida de lo posible los cambios que puedan generarse de cara al sistema pensional en la población.

En este trabajo el autor se propuso el siguiente objetivo general: "Identificar cuáles son las limitaciones del mercado laboral que han impedido lograr la cobertura universal en el sistema pensional de chile, antes y después de la Reforma Previsional de 2008". Dentro de este objetivo macro, se encuentran propuestos cuatro objetivos específicos de la siguiente manera:

- Realizar una caracterización general del sistema pensional chileno, teniendo en cuenta los años antes (2006) y después (2010) de la reforma pensional del 2008.

- Ilustrar cómo ha sido la dinámica y evolución del mercado laboral chileno durante el periodo 2006-2010.

- Describir el proceso, los resultados, los actores participantes y los desafíos pendientes que se generaron tras la implementación de la reforma pensional del 2008 en Chile y la forma en la cual se desarrolló el proceso para alcanzar el proceso de reforma. 
- Presentar un análisis que permita aportar unas conclusiones a partir de los resultados obtenidos en la investigación y que se puedan interpretar como recomendaciones en políticas pensionales y de mercado laboral.

Estos objetivos específicos fueron abordados de forma secuencial para dar un panorama de la estructura que componía el sistema pensional y el mercado laboral chileno de la época, así como el proceso de Reforma Previsional. Toda la información que se presentó en su mayoría fue proveniente de documentos oficiales, encuestas, datos y micro datos consultados a través de los portales institucionales del gobierno de Chile; en contadas ocasiones hubo algunos datos, comentarios y cifras que son elaboración propia del autor con el objetivo de enriquecer el análisis del tema pensional.

Este documento siguió un enfoque mixto, de alcance descriptivo, transversal comparativo en dos momentos del tiempo que corresponden a los 2006 y 2010, mediante el análisis de un estudio de caso, el país de Chile, y de tipo narrativo en el cual se señala la composición del sistema pensional, el mercado laboral y la Reforma Previsional integral del año 2008 de forma detallada según la información disponible.

El objeto de estudio central de este documento es el sistema de pensiones chileno entre los años 2006 a 2010. El sistema de este país se caracteriza por ofrecer un nivel de cobertura de más del $60 \%$ de su población lo hace que esté situado entre los 3 mejores de América Latina (Bertranou, 2001), superado por un escaso margen por Uruguay y Brasil. Pero Chile no es ajeno a la grave afectación que genera un alto nivel de informalidad (más del $45 \%$ de la economía) y de desigualdad de ingresos por encima del 52\% para el año 2010 (Banco Mundial, 2016). Otras variables de igual importancia a la cobertura, son el financiamiento y las prestaciones que otorga el sistema pensional como reconocimiento a las remuneraciones hechas por los afiliados a partir de los ingresos percibidos a través de su trabajo (SAFP, 2010).

Respecto al financiamiento, este opera con dos regímenes, que son: el de capitalización individual, en el cual los afiliados ahorran obligatoriamente una porción de su salario y estos aportes van direccionados a una cuenta de ahorro individual en la cual anualmente se generan rendimientos que servirán para ir acumulando el monto total exigido por los fondos pensionales para adquirir el beneficio de su jubilación y el Pilar solidario en el cual se manejan todas las pensiones asistenciales u otorgadas por el Estado para las personas que no alcanzan a pensionarse dentro de la edad y las semanas de cotización establecidas (Guardia, 2012), incluye los asuntos de género por desigualdad de ingresos y las medidas que toma el Estado para 
impulsar la cotización pensional a través de programas de focalización que permitan la integración de más mujeres al mercado laboral.

Respecto a las prestaciones económicas que otorga, el sistema maneja una serie de bonos que se traducen en los tipos de pensiones que se pueden otorgar, como por ejemplo, los bonos de pensión básica solidaria (BPS) son las pensiones asistenciales, que antiguamente se llamaron PASIS (SAFP, 2014), están los bonos de reconocimiento por hijo (nacido vivo) y otras modalidades que serán explicadas al detalle a lo largo del desarrollo del documento. La procedencia y naturaleza de los datos es cuantitativa y cualitativa, tomando fuentes de información secundaria, la elaboración de algunas figuras y tablas son elaboración propia, tomando como referencia los datos disponibles por parte de las entidades del gobierno chileno, quienes gracias a su accesibilidad han permitido ser un medio público de consulta y han logrado dar viabilidad al desarrollo de esta investigación.

Este estudio se caracteriza por realizar un análisis cualitativo y descriptivo, a partir de la narración de lo sucedido en el Sistema Previsional chileno para los años 2006 y 2010, teniendo en cuenta la aplicación de la Reforma Previsional del año 2008, que incluye cifras, documentos oficiales y las estructuras detalladas de cada uno de los sistemas de interés para desarrollar la investigación. También se relata el contexto económico, político y social de la época, buscando ambientar al lector sobre la situación coyuntural que indujo al Estado chileno a tomar el camino de la reforma.

Se describen a detalle el sistema de pensiones y el mercado laboral chileno junto con la Reforma Previsional que tuvo lugar en el año 2008 y como anexo final, de forma muy breve se generan una serie de reflexiones que permitan ser vistas como herramientas para el mejoramiento del mercado laboral y que sirvan como impulso al sistema de pensiones, dependiendo el país que se quiera evaluar, aunque en la esencia del sistema de seguridad social Chile guarda ciertas similitudes con Colombia y por esta razón se hace más fácil comparar (en el caso que se quisiera llegar a hacer) a los dos sistemas de protección social de estos países, aunque es claro que la comparación no es un objetivo de esta investigación. 


\section{CAPÍTULO 1. El sistema de pensiones chileno en 2006 y}

\section{0}

El sistema de pensiones chileno ha sido pionero y a la vez referencia en cuanto a normatividad y desempeño institucional para distintos países de América Latina, los cuales a lo largo de los años han intentado replicar institucionalmente este modelo en muchos casos sin el mayor de los éxitos y con bastantes vacíos técnicos o financieros. Estos vacíos o brechas que resultaron de la aplicación de una réplica de modelo pensional por cotizaciones individuales (capitalización individual) se tomó el punto de partida para realizar ajustes en materia de seguridad social que fortalecieran las prestaciones sociales a que tenían derecho los trabajadores, sin embargo, en las primeras décadas del Siglo XX (Holzmann \& Hinz, 2006), los sectores más beneficiados por la protección social fueron: la industria, la manufactura y algunos subsectores específicos del sector minero y por supuesto la defensa nacional (los militares) quienes desde inicios de los sistemas de seguridad y de pensiones han gozado de importantes beneficios y de un régimen especial que los cobija. De hecho este último sector de la población fue quien gobernó durante más de 20 años en Chile, por medio de la dictadura de Augusto Pinochet en la que en materia de protección social se unifican las más de 132 cajas de previsión social que existían en el sistema de seguridad chileno a razón de que los beneficios que percibían los trabajadores estaban establecidos de acuerdo a su nivel jerárquico dentro del sector en el cual laboraran (Arellano, 1991).

Chile ha pasado por dos grandes reformas dentro de su sistema pensional, la de 1981 y la de 2008, esta última aún sigue realizando ajustes graduales con propuestas que permitan una mayor y mejor empleabilidad de los recursos económicos y así mismo incentivar a la cotización por parte de los jóvenes para garantizar la sostenibilidad del sistema pensional en el tiempo a través de diversas alternativas de contribución y los beneficios que estos representan para algunos grupos focales en Chile.

\section{¿Qué es un sistema de pensiones?}

El Sistema General de Pensiones es la forma como el Estado y la estructura privada y pública se sincronizan para garantizar protección a las personas, producto de las cotizaciones realizadas a través del salario durante su vida laboral. Este sistema tiene como objetivo garantizar a la población, el amparo contra las contingencias derivadas de la vejez, invalidez o muerte, mediante el reconocimiento de una pensión y prestaciones determinadas en la Ley (SAFP, 
2010), su constitución se encuentra bastante ligada al enfoque beveridge dado en Inglaterra en los años 40 del siglo XX.

Actualmente los sistemas pensionales se encuentran divididos en tres subsistemas, los cuales determinan su funcionamiento (CEPAL, 2016): un primer subsistema es el de reparto o pass as you go (PAYGO), en el que se encuentra una cotización definida como porción del salario devengado por el trabajador, de esta forma se acumula un saldo determinado por las semanas obligatorias de cotización y la edad mínima para jubilarse, que a nivel mundial el promedio de esta se encuentra en 58 años para mujeres y 61 para hombres (Lo Vuolo, 2005).

De forma seguida se encuentra el subsistema de capitalización y ahorro individual, el cual opta por establecer un ahorro voluntario (según la capacidad de ingresos del afiliado) que van destinados a una cuenta de ahorro individual en la que para pensionarse se requiere haber reunido el monto necesario exigido para poder obtener el ingreso en la vejez (Uthoff, 2006), bajo esta modalidad de régimen pensional, es posible acceder a retiros programados o pensiones por vejez anticipada que es cuando el trabajador ya ahorró lo suficiente en su cuenta previsional y a falta de unos pocos años para alcanzar la edad de jubilación, el gobierno y el fondo de pensiones autorizan su mesada pensional tras haber hecho previamente el estudio actuarial que avala esta solicitud de pensión.

Un tercer subsistema aflora producto de combinar algunos elementos de los dos subsistemas anteriores (de reparto y de capitalización individual) y que opta por tener un sistema de pilares (Banco Mundial, 2014), en el que se atacan diversas problemáticas divididas por sectores, como lo son; la pobreza, desigualdad de ingresos, desigualdad de género, desempleo, entre otras; todo esto encaminado a formar un sistema de pensiones que permita ajustarse a la dinámica y las tendencias de la población.

\section{¿Cuáles son los elementos básicos que componen un sistema pensional?}

Los sistemas pensionales se componen por 4 elementos principales según el Banco Mundial (2014): la cobertura, el financiamiento, su estructura institucional y las prestaciones que otorga a sus afiliados.

Estos elementos se pueden medir de la siguiente manera: la cobertura se puede estimar por medio de los aportes que realizan de forma mensual los afiliados a través de sus salarios o ingresos por su actividad económica desempeñada, el financiamiento se mide a través del ejercicio que realizan las Administradoras de Fondos de Pensiones (AFP), consolidando todos 
los aportes de empleadores y trabajadores, el nivel de competencia que fija el gobierno nacional para estas entidades, de tal forma que exista la posibilidad para que los afiliados escojan libremente la entidad a la cual quieren pertenecer, también el sistema se financia por medio de aportes provenientes del Estado y de su ejecución presupuestal, específicamente de su gasto fiscal (Berstein, 2010).

La estructura institucional de cada sistema varía de acuerdo al país que se observe, puesto que cada uno tiene una forma particular de instaurar contribuciones, obligatoriedades y beneficios prestacionales para su población objetivo. Esta estructura es sumamente importante, porque de ella depende la solidez del sistema para abordar las altas y bajas que puede presentar el sistema de pensiones a lo largo del tiempo, en momentos tan diferentes como la austeridad y la bonanza (CEPAL, 2015).

Las prestaciones o beneficios que otorga un sistema pensional a sus afiliados son un determinante clave en el desarrollo del propio sistema, puesto que se tienen que generar una serie de incentivos que resulten fiables y atractivos a la población, especialmente a los más jóvenes para hacer que estos coticen al Sistema Previsional, impulsando la solidaridad intergeneracional (Arellano, 1991). Dentro de las opciones que puede tener un sistema pensional sobre sus prestaciones sociales, se encuentran opciones tan diversas como los retiros programados, tasa de contribución menor para el empleado, exenciones tributarias para las empresas que vinculen un cierto número de personas al mercado laboral, pensiones de tipo asistencial y hasta programas focalizados en población objetivo como los bonos de reconocimiento por hijos (Biblioteca del Congreso Nacional de Chile, 2005).

\subsection{Estructura del Sistema de pensiones de Chile}

En este capítulo se describe la forma en la que quedó constituido el Sistema Previsional chileno posterior a la segunda reforma integral sucedida en el año 2008, junto con su estructura institucional, prestaciones sociales que otorga, formas de financiamiento y cobertura del mismo para la población.

En el tiempo posterior a la aplicación de la reforma, el sistema de capitalización individual se mantuvo como uno de los pilares más fuertes del Sistema Previsional, sin embargo, se plantea la puesta en marcha de otros pilares que puedan reducir los fenómenos de pobreza, desigualdad de género y que a su vez incentiven la cotización de una mayor cantidad de 
afiliados al sistema, amplíe la competencias entre las AFP y se permita flexibilizar el mercado de inversiones que regula a dichas entidades.

La utilización o implementación de "pilares" en los sistemas pensionales actuales están ligados en su mayoría a la reducción o mitigación de una problemática social a gran escala, pero se hace con un determinado pilar, cuya finalidad es trabajar en dicha problemática de forma aislada, muchas veces, para contrarrestar los efectos que se podrían desprender de la toma de medidas drásticas como por ejemplo, la reducción de un determinado rubro del presupuesto nacional o algunos fondos destinados a atender una circunstancia particular de forma temporal que si bien afectaría a toda la economía (de forma potencial), lo que se busca es que afecte de forma directa al pilar o destino para el que fue creada, como los casos en los que se realizan acciones para contrarrestar las desigualdades existentes en los ingresos de la población de adultos mayores y que se debe procurar generar la menor afectación posible a las generaciones venideras.

\section{Pilares del Sistema pensional chileno en 2010}

El sistema de pensiones está estructurado en base a tres pilares: un primer pilar de prevención de la pobreza, un pilar de contribución de origen obligatorio y un tercer pilar de ahorro voluntario.

A través de estos componentes se desea alcanzar que los trabajadores puedan obtener y conservar una calidad de vida parecida a la que poseían cuando se encontraban en su etapa laboral activa y por otro, se busca reducir o eliminar (si es posible) la incidencia de pobreza y escasez de recursos que se producen en la tercera edad o en condiciones de incapacidad. El Pilar solidario es el que tiene como objetivo intentar prevenir pobreza cuando la población se encuentra en altas condiciones de vulnerabilidad. Este pilar está estructurado por una pensión no contributiva, la pensión básica solidaria (PBS), y el aporte previsional solidario (APS), instrumento empleado para complementar el ahorro obligatorio realizado a través del sistema de AFP, también hay incentivos tributarios para motivar a que los trabajadores realicen aportes voluntarios adicionales por medio de una serie de instrumentos financieros: cuentas de ahorro previsional voluntario administradas por las propias AFP, fondos mutuos, productos de seguro de vida con ahorro y que beneficia las cuentas individuales.

El esquema está diseñado de manera tal que los ahorros destinados a estos productos se encuentran exentos de impuesto a la renta en aquellos años en que los depósitos son 
realizados. Los intereses generados por estos ahorros también están exentos de impuestos pero las pensiones financiadas con estos recursos son consideradas como ingreso para efecto de este tipo de impuesto. Los individuos pueden retirar sus ahorros voluntarios antes de jubilarse, pero pagando los impuestos correspondientes y un castigo por retiro anticipado. (Berstein, 2010, p. 132)

Enseguida se describe cómo está estructurado cada uno de los tres pilares atrás nombrados, los cuales forman la base del Sistema Previsional de Chile.

\section{Pilar de Prevención de Pobreza}

Los ingresos provenientes de la fuerza de trabajo de la población y su posterior destinación para contribuir al sistema pensional durante los años (expresados en semanas) que reglamente el gobierno nacional, son los que finalmente otorgan la posibilidad a las personas de obtener o asegurar un ingreso en la vejez.

Sin embargo, esta situación tiende a volverse compleja cuando los trabajadores pasan largos periodos de tiempo para conseguir empleo y tener la posibilidad nuevamente de cotizar al sistema de pensiones, lo que trae como consecuencia final, que la persona que se haya visto en estas condiciones recibirá un monto de pensión menor que la de sus semejantes, dadas las condiciones de inestabilidad laboral que experimentó en determinado momento de su etapa productiva en el mercado laboral. El mismo caso ocurre con las personas que han estado laborando en el sector informal y que a su vez se integran al sistema pensional de forma tardía.

Una de las evidencias claras que dejó la Reforma Previsional del año 2008 fue que buena parte de la población contribuía al Sistema Previsional de forma intermitente, lo que en consecuencia producía un monto de dinero insuficiente para la jubilación. Esta situación era abordada mediante un diagnóstico a partir de análisis multidimensionales que arrojaban resultados como los presentados anteriormente.

Antes de implementarse la reforma del año 2008 para combatir la pobreza en la vejez se utilizaban dos programas básicos: la pensión mínima garantizada por el Estado (PMGE), la cual permitía una base a las pensiones de las personas que contaran con al menos 20 años de aportes al sistema, y las pensiones asistenciales (PASIS) para individuos sin derecho a pensión bajo ningún concepto registrado en el sistema. 
Pero sin lugar a dudas la principal medida tomada en esta reforma fue la implementación del sistema de pensión solidaria (SPS), y el aporte previsional solidario (APS), que reemplazaría, a las formas anteriores de pensiones asistenciales existentes, la pensión asistencial (PASIS) y la pensión mínima garantizada (PMG), esta nueva pensión solidaria cubrirá vejez, invalidez y sobrevivencia. El sistema de pensiones solidario (SPS), cobija a todas las personas que no hayan contribuido al sistema de capitalización, si bien se podría pensar que este sistema de pensión solidario (SPS), es similar a la pensión Asistencial (PASIS) existente antes de la reforma, el monto de dinero recibido con el nuevo sistema es significativamente superior: el PASIS entregaba 45.000 pesos chilenos y el SPS entrega 75.000 pesos chilenos, estos recursos serán entregados a partir del 1 de julio de 2009, por su parte el Aporte Previsional Solidario (APS), reemplaza a la pensión mínima garantizada (PMG), y este aporte complementa las pensiones autofinanciadas en el sistema privado y se entregará a los jubilados cuyas pensiones alcancen un monto inferior a los 150000 pesos chilenos a septiembre del 2009. Este valor se incrementaría gradualmente, el monto ascendería a los 225000 pesos chilenos a partir del 1 de julio del 2012, se estima que para el 2010 este aporte beneficiaría al 60\% de la población más vulnerable (Berstein, 2010).

Si bien es cierto la introducción del Pilar solidario ayuda a disminuir la pobreza en la vejez, la crítica que recibe este pilar es que no representa la esencia de los modelos de protección social modernos, sino que se limita a ser un sistema en el cual el Estado entrega subsidios (de forma asistencial) a una parte de la población menos favorecida y que estas medidas no atacan el problema real que son las desigualdades que potencian los regímenes de capitalización individual.

Este apoyo estatal no será universal, pero sí se espera que cubra la menos al 60\% de la población de menores ingresos para el año 2012, y son mayores en monto y cubertura a las existentes antes de la reformas implementadas por las presidenta Michelle Bachelet. Los beneficiarios de este sistema deberán cumplir con las siguientes condiciones: ser mayor de 65 años, pertenecer al $60 \%$ de la población de menores ingresos y tener un periodo mínimo de permanencia en el país de 20 años y de cuatro de los últimos cinco de la solicitud.

Se afirma que este Pilar solidario no recibe aporte del empleado, ni del empleador, sino que es financiado directamente por el Estado, lo que va en contravía de la definición de solidaridad en la que se aprecia esta desde diferentes perspectivas, como la solidaridad intergeneracional, en la cual los jóvenes aportan para el sostenimiento de los adultos mayores. 
Referente a los beneficios a los cuales tienen derecho los individuos en el Sistema Previsional es importante mencionar que dentro de este primer pilar enfocado a erradicación de la pobreza en la vejez, se presentan falta de incentivos para el ahorro de las personas, especialmente en cuyos casos han estado inmersos en el sector informal del mercado laboral, dichos desincentivos al ahorro están producidos principalmente por la fuerte relación que tiene la contribución con el segundo Pilar de solidaridad en el que los ingresos de las personas que tienen la posibilidad de cotizar en mayor medida al sistema se ven reducidos para poder impulsar los montos de las personas que tienen un caso contrario, ya sea por desempleo o por carencia de ingresos de cualquier tipo.

\section{Pilar Contributivo Obligatorio}

Este pilar está constituido por una contribución definida y se encuentra administrado por empresas privadas (A.F.P) de giro único, que se encuentra funcionando desde 1981. Con la reforma de 2008 se han realizado ajustes tendientes a perfeccionar el funcionamiento del Pilar contributivo, sobre todo en la frecuencia de cotización de los usuarios. La contribución del sistema pensional está relacionada de forma directa con la cantidad histórica de aportes de una persona (y la frecuencia con que lo hace, monto y momento) que le da derecho a recibir un determinado paquete de beneficios.

Para incrementar la frecuencia en la cotización pensional el gobierno chileno opta a partir de la reforma de 2008 implantar la contribución de carácter obligatorio para una gran parte de los trabajadores independientes, se incentivan por medio de subsidios a la cotización a través de la contratación formal de trabajadores jóvenes y se introducen herramientas para observar las cotizaciones anteriores que se adeudan al sistema en procura de su saneamiento (Banco Mundial, 2014).

Como característica singular de los sistemas de pensiones que poseen contribución definida está la incidencia que tienen los aportes pensionales en el interés compuesto, dado que si estos se realizan a una edad temprana y durante una buena cantidad de años, así mismo será el crecimiento de las pensiones finales que pueda obtener un trabajador. Por esta razón es que el gobierno nacional incluye en la Reforma Previsional un subsidio que financia una parte del aporte previsional que hacen los jóvenes mensualmente al sistema y que también a su vez incentiva el financiamiento del costo del aporte al sistema de pensiones a los empleadores que contraten personas con edades entre 18 y 35 años (Berstein, 2010). 
El sistema de pensiones se basa, desde sus inicios, en la capitalización individual obligatoria del ahorro previsional de los afiliados, esto es, que cada trabajador efectúa mensualmente un aporte previsional del $10 \%$ de su remuneración.

Estos aportes son acumulados en una cuenta de capitalización individual que aumenta de acuerdo a los aportes que realiza el trabajador y a la rentabilidad obtenida con la inversión de sus fondos. El dinero acumulado en la cuenta es de propiedad de cada trabajador afiliado y opera como patrimonio independiente de la AFP.

Tras la Reforma Previsional y a partir de 2012, los trabajadores independientes, que reciben rentas a través de boletas de honorarios o boletas de servicios a terceros, también se incorporan al sistema de ahorro obligatorio. Cabe recordar que en Chile no era obligatorio para los trabajadores independientes cotizar al sistema de pensiones. Así, entre 2012 y 2014 según lo que enuncia la reforma, estos trabajadores cotizarían voluntariamente por el 40\%, 70\% y 100\% de sus ingresos base de cotización y a partir de 2015 todos ellos se integrarán al sistema de pensiones, con sus derechos y obligaciones según el proyecto de ley que dio lugar a la reforma.

Por otra parte, la reforma también estableció un beneficio para los jóvenes que aportan para su pensión: el subsidio previsional destinado. Este busca incrementar los ahorrados en edades tempranas de los afiliados considerando que estos son más importantes en el aumento de las pensiones que aquellos aportados en edades más adultas. Los trabajadores que pueden beneficiarse de dicha medida son los siguientes:

- Aquellos que tengan entre 18 y 35 años.

- Tengan una remuneración salarial igual o inferior a 1,5 salarios mínimos mensuales.

- Haber cotizado constantemente durante 24 meses al sistema.

- Para las mujeres se creó el bono por hijo, el cual aumenta el valor de la pensión de la mujer por cada hijo nacido vivo o tomado en adopción.

\section{Pilar Voluntario}

En el Pilar voluntario los trabajadores disponen de múltiples opciones para realizar su afiliación a la entidad A.F.P de su preferencia para que maneje sus montos de cotización y los rendimientos financieros que de estos se desprenden. Las instituciones que se encuentran avaladas por el gobierno para tener manejo de los aportes del sistema de ahorro previsional (APV) son: Administradoras de Fondos de Pensiones; Administradoras de Fondos Mutuos; 
Administradoras de Fondos de Inversión; Administradoras de Fondos para la Vivienda; Compañías de Seguros de Vida; Bancos e Intermediarios de Valores siempre y cuando sus planes de inversión y manejo financiero sean aprobados por la Superintendencia de Valores y Seguros. Esta amplia gama de opciones permite que los usuarios escojan entre un gran número de alternativas de administración de fondos con diversas combinaciones de riesgo y retorno esperado y adicionalmente genera incentivos al ahorro (CEPAL, 2015).

El sistema de capitalización individual permite realizar aportes (cotizaciones) al sistema de pensiones con el fin de aumentar gradualmente el monto de la pensión a recibir. Sin embargo, esta alternativa tomo una importancia mayor en cuanto se dio la ampliación institucional y de productos que existían en el sistema a través de una reforma importante sucedida en el año 2002 que contribuyó a una mayor liquidez de este ahorro pensional.

Desde ese momento el crecimiento de la población que se afilió al Pilar de ahorro voluntario ha venido mostrando un comportamiento creciente y sostenido y transformando como principal desafío de este pilar la generación de incentivos para ahorrar en la vejez de los sectores de ingresos medios ya que el beneficio tributario que ofrece este pilar estuvo dirigido a un sector muy específico de la población chilena.

La reforma implementada por Bachelet, buscando ampliar la cobertura de este pilar a sectores de ingresos medios, propone la creación del Ahorro Previsional Voluntario Colectivo (APVC), además de introducir mayores incentivos tributarios para hacerla más atractiva y se introduce la figura del cotizante voluntario.

Respecto a las instituciones que regulan el funcionamiento del Sistema Previsional chileno se encuentran: las Administradoras de Fondos de Pensiones (AFP), Compañías de seguro, Comités asesores, Consejo Consultivo Previsional, Comisión de Usuarios, Consejo Técnico de Inversiones, Comisiones calificadoras (en materia de riesgo de inversión y de actividades laborales), Comisiones de Ergonomía (de salud en el trabajo) y Comisiones de Invalidez. Las pensiones básicas solidarias de vejez e invalidez conforman una parte del "Pilar solidario" de la reforma de pensiones, cubriendo a las personas que no efectuaron ahorros para financiar su pensión. El sistema solidario considera además el Aporte Previsional Solidario (APS) de vejez e invalidez.

Estas novedosas fórmulas sustituyeron las pensiones asistenciales y la garantía estatal de pensión mínima, que eran mecanismos con los que se generaba cobertura a la población de más 
bajos ingresos. Según la Superintendencia de Administradoras de Fondos de Pensiones las condiciones para acceder a alguna de las pensiones que tiene disponible el sistema son según SAFP (2010):

\section{Pensión Básica Solidaria (PBS) de Vejez e Invalidez:}

Se encuentra dirigida a la población que no tenga derecho (por ingreso y cantidad de cotizaciones) a pensión alguna. La ley establece el pago de la Pensión Básica Solidaria (PBS) como mecanismo para las personas que nunca realizaron aportes al Sistema Previsional o que su cantidad de cotización fue intermitente y baja.

\section{Requisitos para Obtener una PBS:}

De Vejez:

- Tener 65 años o más.

- Tener 20 años de residencia en Chile a partir de los 20 años de edad.

- Haber vivido en Chile 4 de los últimos 5 años antes de la solicitud de pensión.

- Integrar un grupo familiar perteneciente al $60 \%$ de menores ingresos de la población.

De Invalidez:

- Estar declarado como inválido por la Comisión Médica de Invalidez.

- No tener derecho a pensión en algún régimen previsional.

- Tener entre 18 años y menos de 65 años.

- Haber vivido en Chile 5 de los últimos 6 años antes de la solicitud de pensión.

- Integrar un grupo familiar perteneciente al $60 \%$ más pobre de la población.

Para calificar entre el 60\% más pobre se requiere tener un puntaje igual o menor a 1206 puntos en el Puntaje de Focalización Previsional, que es un mecanismo para censar a la población nacional dentro de los estándares de ingreso.

Aporte Previsional Solidario (APS) de Vejez e Invalidez. 


\section{APS de Vejez:}

Es dirigida a la población que tengan acceso y derecho a una o más pensiones, regidas por el Decreto Ley 3500 de 1980 y también que su monto pensional sea menor a la pensión máxima de aporte solidario (PMAS) y cuyo monto se encontraba establecido para el año 2012 en $\$ 291.778$.

\section{APS de Invalidez:}

Está destinada a personas declaradas como inválidas, que no reciben pensiones de otros regímenes previsionales.

\section{Requisitos para Obtener un APS:}

De Vejez:

- Tener como mínimo 65 años de edad.

- Tener derecho a alguna pensión en algún régimen previsional.

- Durante el primer año de aplicación de la reforma el pensionado debía ser parte de un grupo familiar perteneciente al 40\% más pobre de población, porcentaje que en 2012 subió al $60 \%$ de la población más pobre.

- Tener 20 años de residencia en Chile, desde los 20 años de edad, y 4 de los últimos 5 años en Chile. Con 20 años de aportes en sistemas de pensiones en el país se cumple este requisito.

De Invalidez:

- Tener entre 18 y 65 años de edad.

- Haber sido declarado inválido por las Comisiones Médicas de la Superintendencia de Pensiones.

- Durante el primer año de aplicación de la reforma el pensionado debía ser parte de un grupo familiar perteneciente al 40\% más pobre de población, porcentaje que en 2012 subió al 60\% de la población más pobre.

- Acreditar residencia en Chile en 5 de los últimos 6 años desde que se solicita el beneficio.

Rentabilidad de los Fondos de Pensiones: 
Las administradoras de pensiones pueden hacer gestión de cinco fondos de pensiones, dicha tarea comprende el recaudo de las cotizaciones del afiliado, la realización de aportes a las cuentas individuales y la inversión de los montos generados como consecuencia del recaudo.

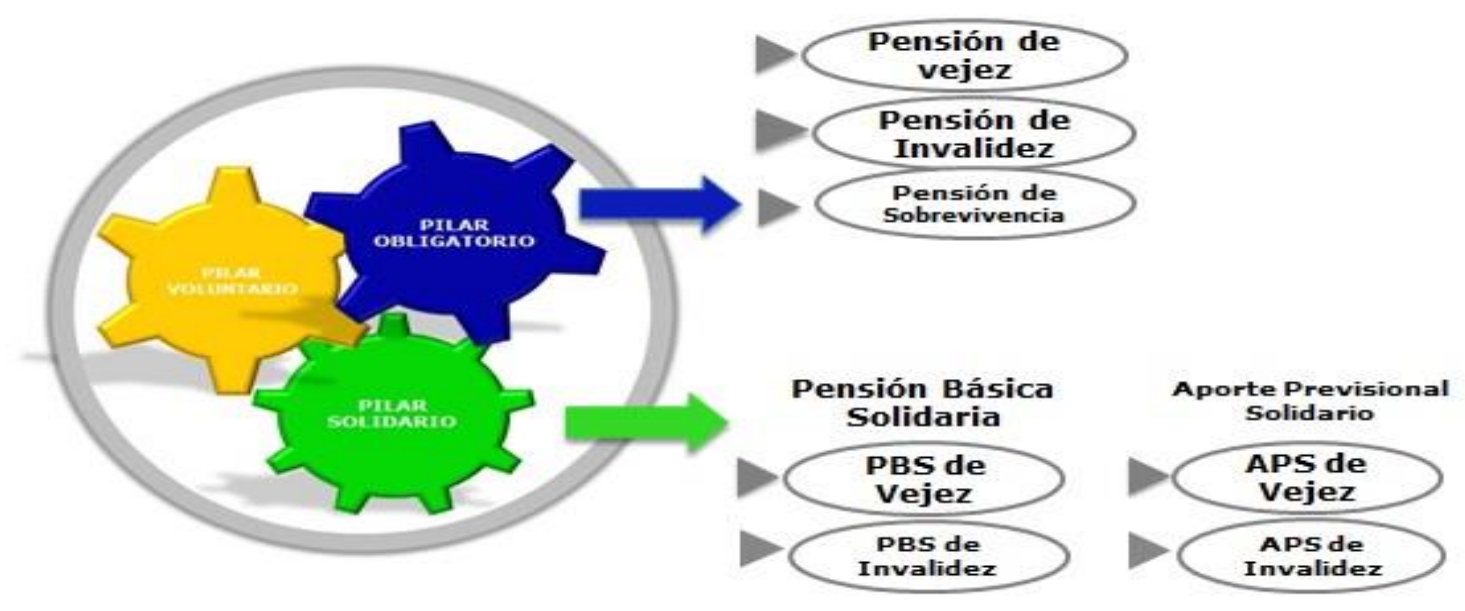

Figura 2. Pilares del sistema pensional en Chile

Fuente: (Subsecretaría de Previsión Social, s.f., párr. 5)

Como todo sistema pensional, el implementado en Chile tiene por objetivo proveer de ingresos suficientes a las personas que por elección, edad u obligación (condiciones de salud) se retiran de la vida laboral y buscan en los aportes pensionales que realizaron una solución para solventar sus gastos. El sistema chileno está basado en dos alternativas principales, el ahorro y la capitalización individual, por medio de las AFP los trabajadores de las empresas cotizan de forma obligatoria y los trabajadores independientes (cuenta propia) lo hacen de forma voluntaria y de acuerdo a su capacidad de ingresos, de este modo según el volumen y los montos de cotización así mismo será el monto pensional obtenido a futuro.

Las personas están en total libertad de elegir la AFP que desee para que maneje su ahorro previsional, también puede elegir la modalidad bajo la cual desea estar; sea ahorro programado, renta vitalicia, retiro programado o renta vitalicia diferida, adicionalmente el trabajador puede cambiarse de administradora de pensiones en el momento en el cual lo desee.

La contabilidad que se genera en las AFP es totalmente diferente a la de los fondos de inversión en donde se colocan los recursos de los afiliados, esto para separar y controlar el 
dinero de la cuenta de capitalización individual cuyos recursos son propiedad del cotizante y es un recurso monetario independiente al de cada administradora de pensiones.

El rol que toma el Estado es subsidiario (garante) y ejerce a su vez la función de contralor del sistema, apoyado en organismos de control tales como las Superintendencias de AFP y de Valores y seguros, quienes recaudan los recursos del afiliado y los invierten en los fondos con el fin de obtener beneficios futuros para el trabajador.

La Reforma Previsional de 2008 con la estructuración del sistema pensional a través de la Ley 20255 estableció que los trabajadores que tengan remuneración salarial por honorarios variables (boletas de honorarios) deberán cotizar de forma obligatoria al sistema de pensiones a partir del año 2012, y desde el año 2015 podrán adquirir el derecho a pensionarse y a la seguridad laboral (seguridad y salud en el trabajo).

\section{¿Qué servicios reciben por cotizar los trabajadores con boletas honorarios?}

- Pensiones (AFP): vejez, invalidez y sobrevivencia

- Seguro de Invalidez y Sobrevivencia, 10061 cobertura brindada será directamente proporcional al pago hecho por el trabajador.

- Seguridad Laboral: protección y atención prioritaria en el caso de un accidente de trabajo (con causa u ocasión del trabajo), accidente de trayecto, y/o enfermedad profesional. Cobertura de 60 días por cada cotización mensual realizada al sistema.

- Salud (Fonasa/Isapre): atención mediante la libre elección (compra de bonos), y pago del subsidio de incapacidad laboral. Cobertura mensual para atención médica, y para licencia médica se requerirán 6 meses continuos o discontinuos de cotizaciones, en un año considerando al menos 12 meses de afiliación al sistema (AFP y Salud).

- Otros beneficios: derecho a recibir asignación familiar (subsidios y servicios variados para el grupo familiar del trabajador y a afiliarse a una caja de compensación.

\section{Seguro de Invalidez y Sobrevivencia (SIS)}

Teniendo en cuenta que la mayor parte de la población de los trabajadores se encuentra en un riesgo medio de invalidez o fallecimiento, las AFP están en la obligación de adquirir un plan de seguros para sus afiliados y que equivale al 1,15\% de la remuneración salarial mensual del trabajador y que complementa el ahorro hecho por la persona a través de sus cotizaciones. 
A pesar de que el género femenino muestra un menor porcentaje de siniestralidad que el masculino, las primas por invalidez y fallecimiento es la misma para todas las personas, sin embargo, en cuanto a la cotización por este concepto la diferencia en las mujeres respecto a los hombres es de aproximadamente del 0,20\% en las cuentas individuales de capitalización.

\subsection{Financiamiento del sistema pensional}

Los aportes que el trabajador debe hacer al sistema es de un $17 \%$ y los aportes provenientes del fondo de pensiones se fijaron en un $10 \%$ de la remuneración salarial bruta (Biblioteca del Congreso Nacional de Chile, 2005). Al realizarse en el último algunos ajustes sobre dicha base de aportes, se impulsó el libre cambio entre usuarios de una AFP a otra distinta.

Se afirma que el sistema es privado, pero es de gran importancia recordar que el Estado lo regula y soporta una fuerte carga financiera: I) cubre el elevado déficit del sistema público que se quedó con solo el 16\% de los asegurados totales, pero con el $96 \%$ de los pensionados totales; II) otorga un bono de reconocimiento (BR) a los asegurados en el sistema privado en el momento de la jubilación, que es igual al valor de las cotizaciones previamente pagadas al sistema público, indizado a la inflación, y obtiene un interés anual del 4\%; III) aporta la diferencia necesaria para pagar una pensión mínima a los que carecen de fondos suficientes en su cuenta individual; IV) financia las pensiones de asistencia social, el subsidio de desempleo y las asignaciones familiares (SAFP, 2010).

\section{Principales prestaciones que ofrecen las diferentes modalidades de retiro}

El sistema pensional que se encontraba vigente en el año 2005 admitía varios tipos de pensiones, entre los que se encuentran (SAFP, 2010):

- Contratación de una renta vitalicia: el afiliado contrata con una compañía de seguros de vida, el pago de una renta mensual, para este, y en caso de fallecimiento para su beneficiario, si selecciona esta opción, el afiliado deja de tener la propiedad de sus fondos.

- Retiro Programado: Permite al afiliado recibir una pensión pagada por la AFP, esta irá con cargo al monto que ha logrado acumular a lo largo de su vida laboral, se calcula año a año, teniendo en cuenta el saldo de la cuenta individual, la rentabilidad 
del fondo y la expectativa de vida del afiliado junto con sus potenciales beneficiarios en caso de fallecimiento.

- Renta temporal con renta vitalicia diferida: es una opción intermedia entre las dos anteriores, porque da al afiliado la posibilidad de solicitar anticipadamente los montos cotizados al sistema, sin embargo, los intereses de estos serán pagos en los meses siguientes según sea el interés compuesto vigente que exista en el sistema al momento de hacer la solicitud para pensión.

- Pensiones anticipadas: para quienes adelantan su jubilación para antes de los 60 años en el caso de las mujeres o 65 años en el caso de los hombres, siempre y cuando cumplan con los requisitos y montos exigibles para poder solicitar la mesada pensional.

- Pensión mínima garantizada por el Estado: que se paga cuando los fondos acumulados no alcanzan a financiar un valor mínimo de la pensión y el Estado aporta los recursos faltantes para hacerlo posible. (Biblioteca del Congreso Nacional de Chile, 2005, p. 5)

La reforma que se realizó (en 1981) por el gobierno de Chile permite que las pensiones se ajusten de acuerdo al valor de la inflación, puesto que su valor queda definido en Unidades de Fomento (UF) al momento de seleccionar la opción de retiro que prefiera el afiliado.

Tabla 1. Tipo de pensión, monto promedio a pagar y cantidad de pensiones emitidas año 2013

\begin{tabular}{|c|c|c|c|c|c|c|}
\hline \multirow{2}{*}{$\begin{array}{l}\text { Tipo de } \\
\text { pensión }\end{array}$} & \multicolumn{2}{|c|}{ Retiro programado } & \multicolumn{2}{|c|}{ Renta vitalicia } & \multicolumn{2}{|c|}{ Total } \\
\hline & Número & $\begin{array}{c}\text { Monto } \\
\text { promedio } \\
\end{array}$ & Número & $\begin{array}{c}\text { Monto } \\
\text { promedio }\end{array}$ & Número & $\begin{array}{c}\text { Monto } \\
\text { promedio }\end{array}$ \\
\hline Vejez edad & 292.522 & $\$ 122.435$ & 110.990 & $\$ 260.660$ & 414.602 & \$ 168.891 \\
\hline $\begin{array}{l}\text { Vejez } \\
\text { anticipada } \\
\text { Invalidez }\end{array}$ & 25.224 & $\$ 338.469$ & 216.237 & $\$ 248.073$ & 243.532 & \$ 261.118 \\
\hline $\begin{array}{l}\text { Definitiva } \\
\text { total } \\
\text { Invalidez }\end{array}$ & 62.943 & $\$ 122.206$ & 27.668 & $\$ 294.988$ & 99.108 & $\$ 198.413$ \\
\hline $\begin{array}{l}\text { Definitiva } \\
\text { parcial }\end{array}$ & 9.323 & $\$ 131.589$ & 2.944 & $\$ 262.949$ & 12.653 & $\$ 174.155$ \\
\hline Viudez & 67.352 & $\$ 121.062$ & 78.987 & $\$ 173.011$ & 155.009 & $\$ 150.126$ \\
\hline Orfandad & 32.674 & \$ 47.372 & 20.543 & \$ 58.128 & 53.601 & $\$ 51.720$ \\
\hline Otras & 8.624 & $\$ 57.213$ & 6.814 & $\$ 90.625$ & 16.075 & $\$ 72.317$ \\
\hline Total & 498.662 & $\$ 127.241$ & 464.183 & $\$ 230.452$ & 994.580 & $\$ 183.538$ \\
\hline
\end{tabular}

Fuente: elaboración propia con base en Equipo Observatorio Social (2013) 
Si bien el número de pensiones emitidas por edad cumplida son sustancialmente más altos que la cantidad de pensiones de vejez anticipadas, como se puede observar, el monto promedio a recibir por parte de un pensionado por vejez es prácticamente un $25 \%$ menor al monto que recibe un pensionado por anticipación. El monto promedio de una pensión en Chile quedó fijada en 183.538 pesos chilenos para el año 2013, en total se generaron 994.580 pensiones de distinta índole dentro del sistema.

\subsection{Cifras de cobertura y resultados del sistema pensional chileno en el periodo 2006-2010}

La cobertura pensional en América Latina ha dado lugar para un amplio debate sobre la forma de preparar a un territorio para una reforma estructural, que permita brindar una verdadera protección a los trabajadores y sus familias. A tal punto ha llegado el tema, que muchos países han optado por hacer ajustes graduales a sus sistemas pensionales y otros tantos, entre ellos Chile, se han decantado por generar unas reformas integrales en periodos específicos que buscan contrarrestar un conjunto de problemáticas históricas previamente definidas, tal como la desigualdad de género en el mercado laboral, las brechas de cotización a pensiones y seguridad social que existen entre ambos sexos, la pobreza, el desempleo juvenil, entre otros factores que afectan de forma directa la cotización y por ende la cobertura al sistema pensional de las personas.

Un elemento común que tienen todos estos aspectos que afectan la cobertura pensional y al sistema de pensiones en general es la redistribución de ingreso en la población de forma equilibrada, lo anterior se produce porque al existir una mejor distribución en los ingresos, esto producirá en el mediano plazo una cotización más activa por parte de los ciudadanos en la medida en que la prestación u obtención de un servicio se vea reflejado en sus contribuciones y lo que consecuentemente podría aliviar la pobreza extrema de las regiones más afectadas.

El término "cobertura" dentro del sistema de protección social hace referencia a la proporción de personas que reciben un beneficio dentro de un determinado grupo referencial y este se denomina como "población objetivo" (Rofman \& Lucchetti, 2006).

Es importante dejar claro que al comparar las coberturas alcanzadas antes de la reforma y posterior a su realización, no se evidencian cambios significativos en los porcentajes de cobertura alcanzados, así en 1975 se alcanzaron coberturas del $62 \%$, comparadas con 
coberturas en el sistema de capitalización del $62.5 \%$, es de recalcar que en este régimen nuevo, era obligatoria la vinculación de todos los trabajadores al sistema.

Se presenta un breve compilado de cifras para el año 2005 en materia de cobertura pensional, desglosado por género, AFP a la que pertenece cada una de las cantidades de afiliados a modo de introducción a las cifras grandes de los años 2006 y 2010 que enmarcan un antes y un después en lo que significó para Chile la reforma integral del año 2008.

Tabla 2. Número de afiliados por Tipo (Dependientes), Sexo y A.F.P (año 2005)

\begin{tabular}{|l|r|r|r|}
\hline \multirow{2}{*}{ A.F.P. } & \multicolumn{3}{|c|}{ TIPO Y SEXO } \\
\cline { 2 - 4 } & \multicolumn{3}{|c|}{} \\
\hline BANSANDER & 634.884 & 358.937 & 275.947 \\
\hline CUPRUM & 478.317 & 273.064 & 205.253 \\
\hline HABITAT & 1.712 .523 & 915.885 & 796.638 \\
\hline PLANVITAL & 397.521 & 230.424 & 167.097 \\
\hline PROVIDA & 2.984 .289 & 1.699 .109 & 1.285 .180 \\
\hline SANTA MARIA & 934.413 & 502.207 & 432.206 \\
\hline TOTAL & $\mathbf{7 . 1 4 1 . 9 4 7}$ & $\mathbf{3 . 9 7 9 . 6 2 6}$ & $\mathbf{3 . 1 6 2 . 3 2 1}$ \\
\hline
\end{tabular}

Fuente: elaboración propia con base en Superintendencia de Pensiones de Chile (2016)

Tabla 3. Número de afiliados por Tipo (Independientes), Sexo y A.F.P (año 2005) 


\begin{tabular}{|l|r|r|r|}
\hline \multirow{2}{*}{\multicolumn{1}{c|}{ A.F.P. }} & \multicolumn{3}{|c|}{ TIPO Y SEXO } \\
\cline { 2 - 4 } & & & \\
\hline BANSANDER & INDEPENDIENTES & Masculino & Femenino \\
\hline CUPRUM & 641.258 & 362.073 & 279.185 \\
\hline HABITAT & 489.833 & 279.236 & 210.597 \\
\hline PLANVITAL & 1.769 .809 & 945.494 & 824.315 \\
\hline PROVIDA & 402.589 & 233.370 & 169.219 \\
\hline SANTA MARIA & 3.126 .661 & 1.781 .232 & 1.345 .429 \\
\hline TOTAL & 964.356 & 519.461 & 444.895 \\
\hline
\end{tabular}

Fuente: elaboración propia con base en Superintendencia de Pensiones de Chile (2016)

De acuerdo a lo evidenciado en las tablas anteriores que corresponden a la cantidad de afiliados por A.F.P, por tipo y por sexo, se puede observar que existen dos A.F.P que sobresalen de las demás en cuanto al número total de afiliados, que son "HÁBITAT" y "PROVIDA" porque ocupan tanto en los afiliados de tipo dependiente como en los independientes, el 23\% y el $43 \%$ del total de afiliados captados en el sistema pensional.

Si se observa desde el ítem de afiliados por sexo, se aprecia que el panorama es exactamente el mismo, con estas dos A.F.P con la mayor concentración de afiliados del sistema. Lo anterior sin entrar en materia de cálculos profundos sobre la rentabilidad y la utilidad que de esta actividad sustraen los fondos de pensiones, además invita a corroborar que de acuerdo a la caracterización del sistema presentada anteriormente, estas dos instituciones pensionales están obteniendo mayores utilidades que generaban a partir del gran número de afiliados que estaban en capacidad de captar, tal como se mostró en la tabla anterior.

Tabla 4. Número de Afiliados por edad y A.F.P (2006) 


\begin{tabular}{|c|c|c|c|c|c|c|c|}
\hline EDAD & & & & F.P. & & & \\
\hline (años) & BANSANDER & CUPRUM & HABITAT & PLANVITAL & PROVIDA & SANTA MARIA T & TOTAL \\
\hline Hasta 45 & 486.738 & 345.900 & 1.377 .970 & 260.597 & 2.312.968 & 682.236 & 5.466 .409 \\
\hline 46 & 15.476 & 12.723 & 37.675 & 12.486 & 75.581 & 27.259 & 181.200 \\
\hline 47 & 14.865 & 12.486 & 36.261 & 12.799 & 72.781 & 26.149 & 175.341 \\
\hline 48 & 14.319 & 12.287 & 34.363 & 11.152 & 69.932 & 24.578 & 166.631 \\
\hline 49 & 13.060 & 11.717 & 32.460 & 10.373 & 63.720 & 22.591 & 153.921 \\
\hline 50 & 12.011 & 10.788 & 28.925 & 9.599 & 58.370 & 20.371 & 140.064 \\
\hline 51 & 10.896 & 10.153 & 26.394 & 8.703 & 52.832 & 18.469 & 127.447 \\
\hline 52 & 10.114 & 10.106 & 25.816 & 8.531 & 51.358 & 17.693 & 123.618 \\
\hline 53 & 9.040 & 9.020 & 22.393 & 7.804 & 45.022 & 15.677 & 108.956 \\
\hline 54 & 8.066 & 8.545 & 20.003 & 6.946 & 40.648 & 14.150 & 98.358 \\
\hline 55 & 7.212 & 7.578 & 18.383 & 6.508 & 37.201 & 13.029 & 89.911 \\
\hline 56 & 6.438 & 6.859 & 16.837 & 5.925 & 34.264 & 11.805 & 82.128 \\
\hline 57 & 5.898 & 6.149 & 15.492 & 5.646 & 31.721 & 11.009 & 75.915 \\
\hline 58 & 5.288 & 5.581 & 13.898 & 5.285 & 28.173 & 10.103 & 68.328 \\
\hline 59 & 4.684 & 4.801 & 12.496 & 4.729 & 25.067 & 9.101 & 60.878 \\
\hline 60 & 3.423 & 3.740 & 9.619 & 3.857 & 20.251 & 6.730 & 47.620 \\
\hline 61 & 2.904 & 2.964 & 7.560 & 3.251 & 16.126 & 5.530 & 38.335 \\
\hline 62 & 2.320 & 2.256 & 6.555 & 2.856 & 13.540 & 4.645 & 32.172 \\
\hline 63 & 2.053 & 1.840 & 5.686 & 2.653 & 12.153 & 4.098 & 28.483 \\
\hline 64 & 1.655 & 1.463 & 4.653 & 2.326 & 10.445 & 3.444 & 23.986 \\
\hline 65 & 1.000 & 826 & 3.064 & 1.545 & 7.735 & 1.967 & 16.137 \\
\hline 66 & 589 & 539 & 1.787 & 1.035 & 5.040 & 1.359 & 10.349 \\
\hline 67 & 411 & 324 & 1.376 & 811 & 4.220 & 1.050 & 8.192 \\
\hline 68 & 388 & 246 & 1.192 & 694 & 3.606 & 926 & 7.052 \\
\hline 69 & 274 & 149 & 1.026 & 555 & 3.081 & 892 & 5.977 \\
\hline 70 & 260 & 148 & 924 & 575 & 2.998 & 756 & 5.661 \\
\hline Mas de 70 & 1.869 & 645 & 6.964 & 5.339 & 27.828 & 7.524 & 50.169 \\
\hline \begin{tabular}{|l|} 
S/I (SIN \\
INFORMACIÓN) \\
\end{tabular} & 7 & 0 & 37 & 9 & 0 & 1.215 & 1.268 \\
\hline TOTAL & 641.258 & 489.833 & 1.769 .809 & 402.589 & 3.126 .661 & 964.356 & 7.394 .506 \\
\hline
\end{tabular}

Fuente: elaboración propia con base en Superintendencia de Pensiones de Chile (2016)

El rango de edad que concentra la mayor parte de los afiliados en el sistema pensional chileno se encuentra ubicado entre los 46 y los 49 años respectivamente, posterior a los 49 años se observa que aunque la cifra de captación de afiliados es relativamente alta, esta va 
disminuyendo de forma gradual conforme se avanza en los rangos de edad por obvias razones (a mayor edad, el costo de afiliación de un individuo va creciendo considerablemente), como por ejemplo, que las personas afiliadas al sistema que tienen 60 años o más están realizando ahorros voluntarios (APV) para obtener su ingreso de jubilación en la mayor brevedad de tiempo posible. Es importante destacar que como se había mencionado antes, las dos A.F.P que tienen en su poder a la mayoría de afiliados, destaca por supuesto en todos los rangos de edad desde los 45 hasta los 70 años de edad.

\section{Formas de medir la cobertura pensional}

Una primera forma de medir la cobertura pensional, resulta de calcular el número total de afiliados al sistema pensional sobre el total de la población económicamente activa (PEA que para el caso chileno muestra un resultado de aproximadamente el 90,4\%, en el año 2006, teniendo en cuenta que según las cifras de la Superintendencia de las administradoras de fondos de pensiones (de ahora en adelante SAFP).

En el año 2006 se registraron un total de 7.683 .451 millones de personas afiliadas al sistema pensional de Chile, para el año 2010 este porcentaje fue de 88,4\% con 8.751 .08 afiliados totales. La segunda forma de estimar la cobertura pensional, se genera al calcular la cantidad o densidad de cotización de la población que actualmente contribuye al sistema pensional chileno en el año 20006 registró un 24,1\%, en el año 2010 las contribuciones por densidad de cotización a pensiones fueron de $27,9 \%$.

Una tercera y última forma de medición de cobertura que se aborda en este trabajo se obtiene a través del número total de pensionados y el total de la población mayor de 60 años (adultos mayores) que para el caso de Chile en 2006 evidencia un resultado de 42,8 \% de población en edad de jubilación que se encuentra cubierta con un ingreso en su vejez, el resultado mostrado para el año 2010 representa una disminución de 5 puntos porcentuales en esta cifra ubicándose en $37,2 \%$.

En esta sección del documento se encontraran las cifras y datos sobre el sistema pensional chileno en los años 2006 a 2010, la razón de estos dos años de referencia es porque marcan el antes y el después de la reforma integral al sistema de pensiones del año 2008 realizada por la presidenta Michelle Bachelet. Después que se muestren al detalle dichas cifras, se emite un análisis por parte de los autores, a modo de comentario final, acerca de la tendencia en el comportamiento del sistema pensional de acuerdo a los datos hallados. 


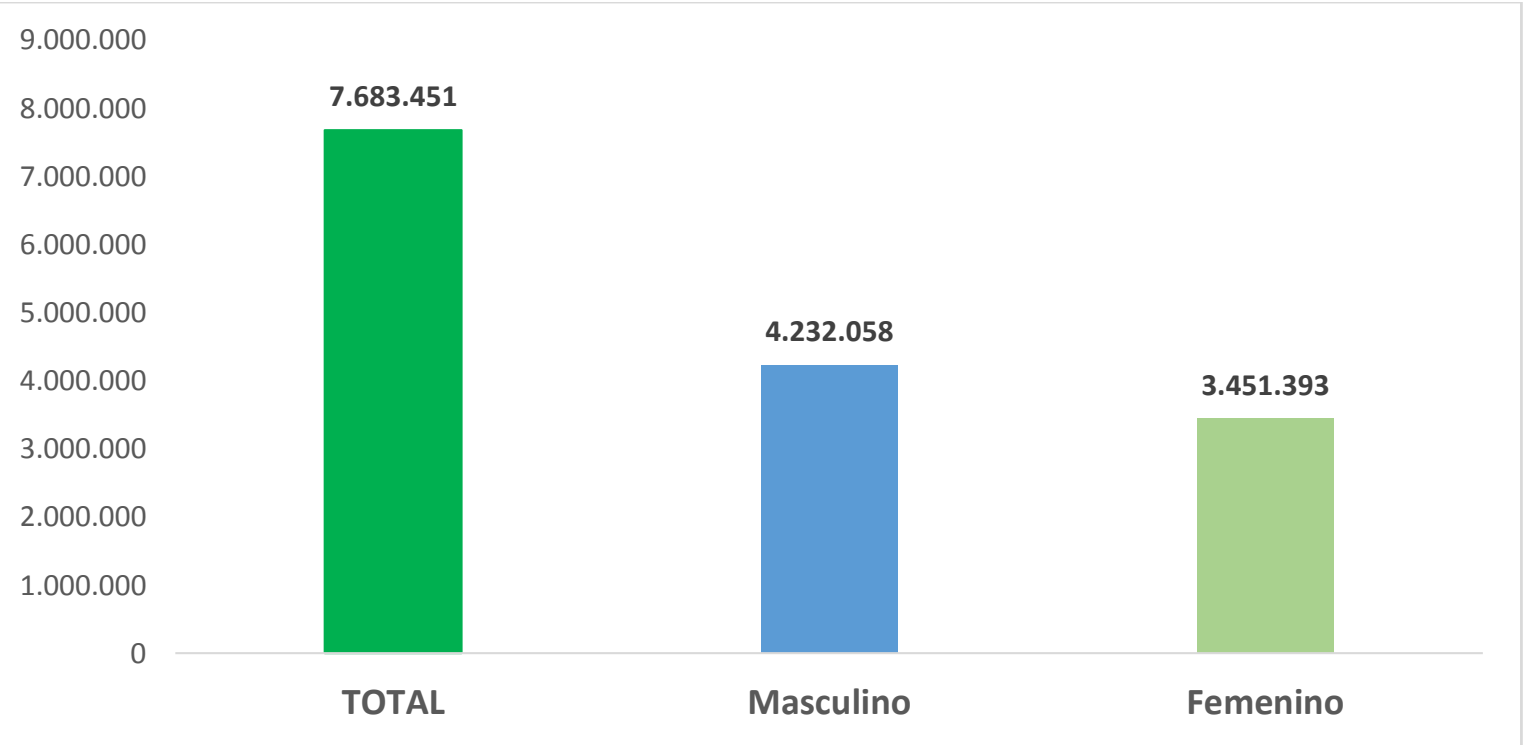

Figura 3. Número de Afiliados totales al sistema pensional. Año 2006

Fuente: elaboración propia con base en SAFP (2016)

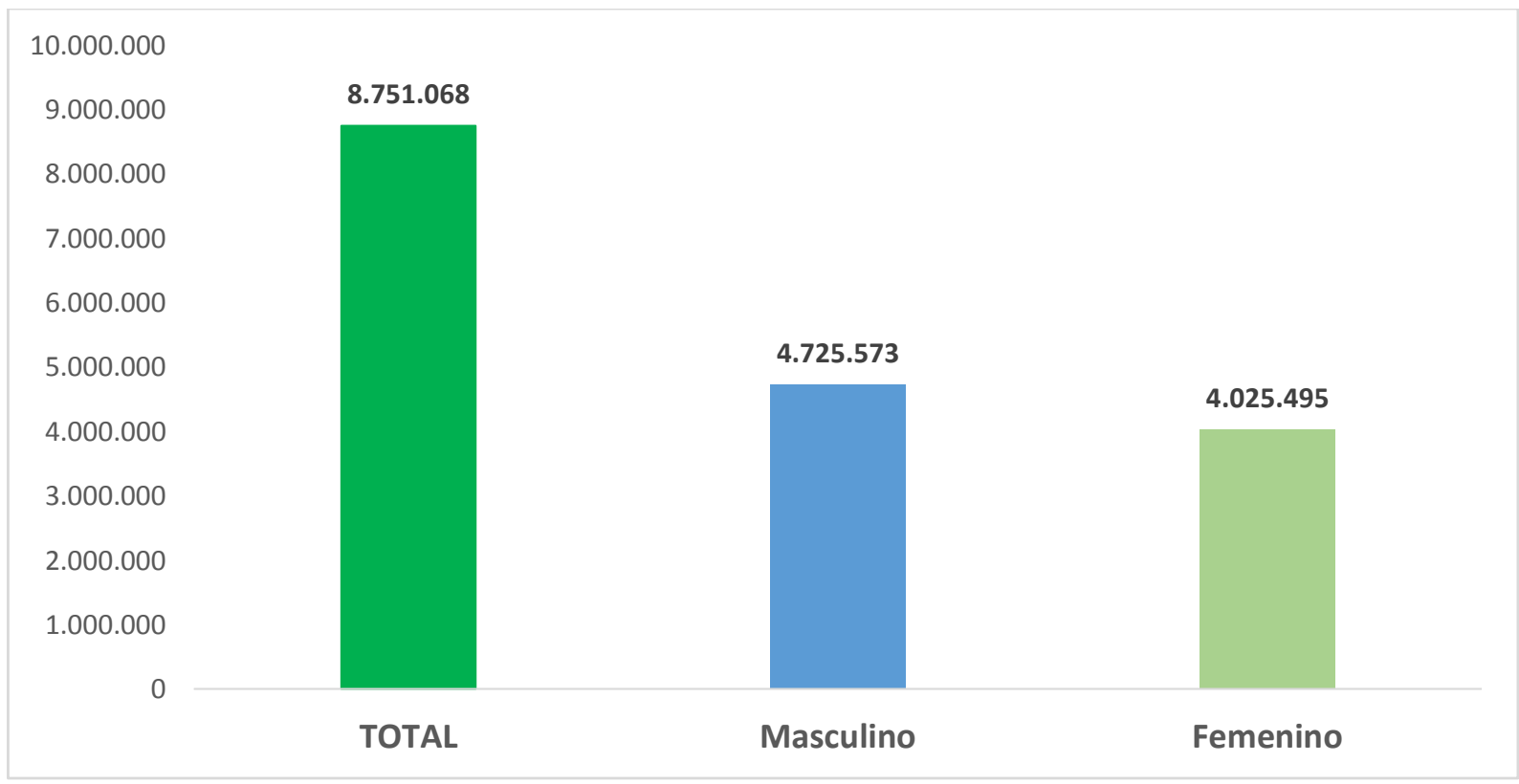

Figura 4. Número de Afiliados totales al sistema pensional. Año 2010

Fuente: elaboración propia con base en SAFP (2016)

En términos de afiliados totales, sistema pensional chileno para los años 2006 y 2010 ha mostrado una tendencia creciente aunque de forma gradual, presentando que en promedio los afiliados en este lapso aumentaron en 500.000, pero siempre manteniéndose la diferencia de más hombres que mujeres registrados como afiliados al sistema de pensiones. En el aumento 
total en afiliación de un año a otro fue de 1.100.000, traduciéndose esto en una mejora en la implementación de planes para mejorar la cobertura pensional en las diferentes regiones del país e impulsar el sistema pensional para que más mujeres pudiesen afiliarse, cotizar y finalmente recibir su mesada pensional, pues esta era una de las más grandes dificultades que en principio estaba impactando al sistema pensional en Chile.

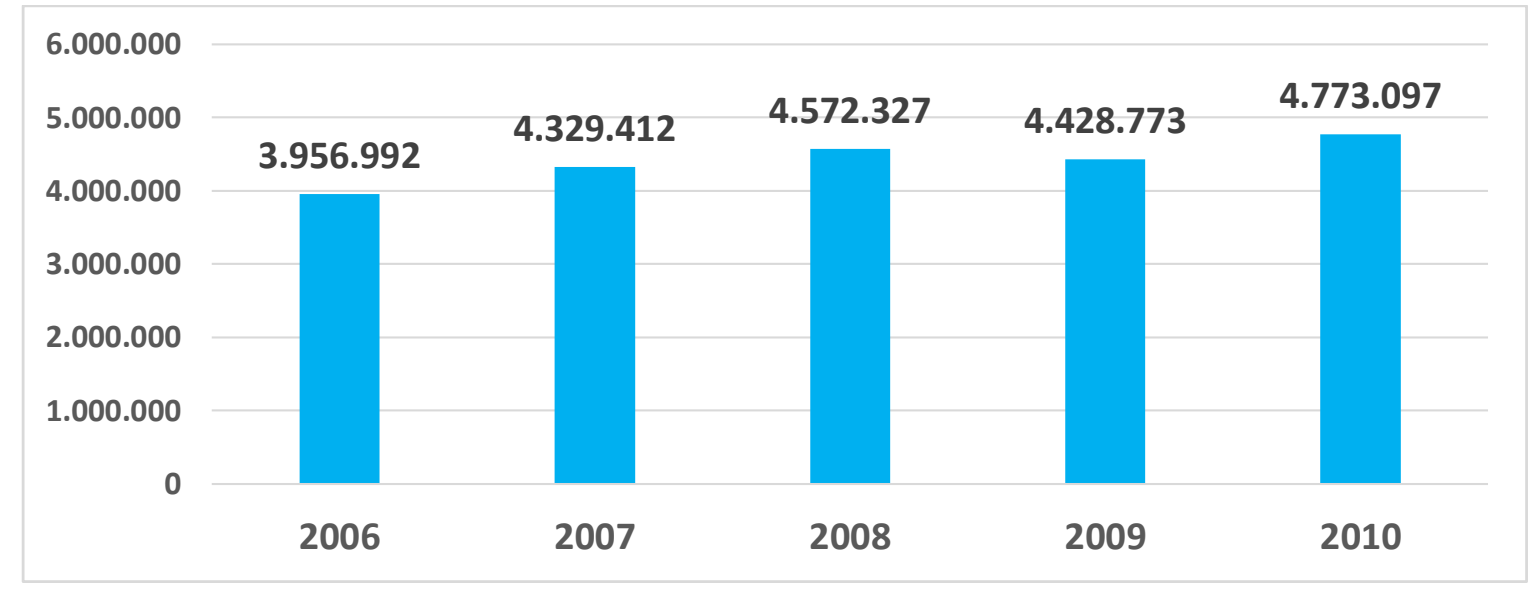

Figura 5. Número de Cotizaciones efectivas totales al sistema pensional. Años 2006 a 2010

Fuente: elaboración propia con base en SAFP (2016)

Si se observan los cotizantes en Chile, el panorama es considerablemente más reducido que en las afiliaciones al sistema, esto explicado porque en estos años las iniciativas para el fortalecimiento del empleo juvenil y femenino apenas se estaban reformando, de esta forma, los incentivos e impulsos para que estos sectores específicos de la población contribuyeran activamente al sistema de seguridad social, no estaban tan adelantados como sí lo era en sectores productivos de la economía chilena como el industrial y minero-energético (Uthoff, 2002).

En términos numéricos, como se puede ver, la cotización a pensiones en Chile para este periodo representaba apenas un 50\% de la afiliación total del sistema. Esta problemática de baja cotización al sistema ha estado generada en su mayor parte porque los ingresos provenientes del salario de los trabajadores no les estaban siendo suficientes para ahorrar el monto establecido para obtener la mesada pensional y esto hacía que los trabajadores no se vieran incentivados para cotizar a un sistema del cual nunca irían a percibir contraprestación económica alguna (Organización Mundial de la Salud, 2010). 
En el caso particular de las mujeres, debido al ciclo natural que muchas de ellas llevan a cabo, entiéndase el contraer matrimonio y formar un núcleo familiar, implicaba que ellas al momento de tener hijos y dedicarse a su crianza, se veían en la obligación de retirarse del mercado laboral por un tiempo prudencial mientras esta época de crianza pasaba, aunque en muchos casos las mujeres que se retiran del mercado laboral no regresan a este, ya sea porque sus cónyuges no les permiten hacerlo o porque ha pasado mucho tiempo y su remuneración salarial no va a ser igual porque la carencia de mayor formación profesional y la experiencia laboral que no se obtuvo en este tiempo, son dos factores por los que el mercado laboral tiende a excluirlas de forma indirecta.

Por lo anterior es que en Chile el gobierno se tomó muy en serio la iniciativa de generar formas y facilidades de trabajo para que las mujeres pudieran contribuir más activamente al sistema de seguridad por medio de la generación de ingresos a partir de la participación en el mercado laboral. También es destacable el hecho de que las cotizaciones fueron más reducidas en el año 2009, de hecho, fue el único año de los cinco mostrados que presentó una reducción respecto a su antecesor.

Esto fue generado porque a través de la reforma integral de 2008 se incentivaron traslados masivos de un sistema a otro (de reparto a capitalización individual y viceversa) por lo cual muchas personas quedaron a la deriva mientras se decidían al sistema que iban a pertenecer o en su defecto el sistema en que el gobierno nacional decidiera que debían estar, esta última situación desencadenó una incertidumbre generalizada en la población chilena, por ello en este año 2009 los aportes a pensiones fueron menores a los registrados en otros años, mientras se lograba definir la articulación del sistema y cómo se iba a direccionar a partir de la reforma. 


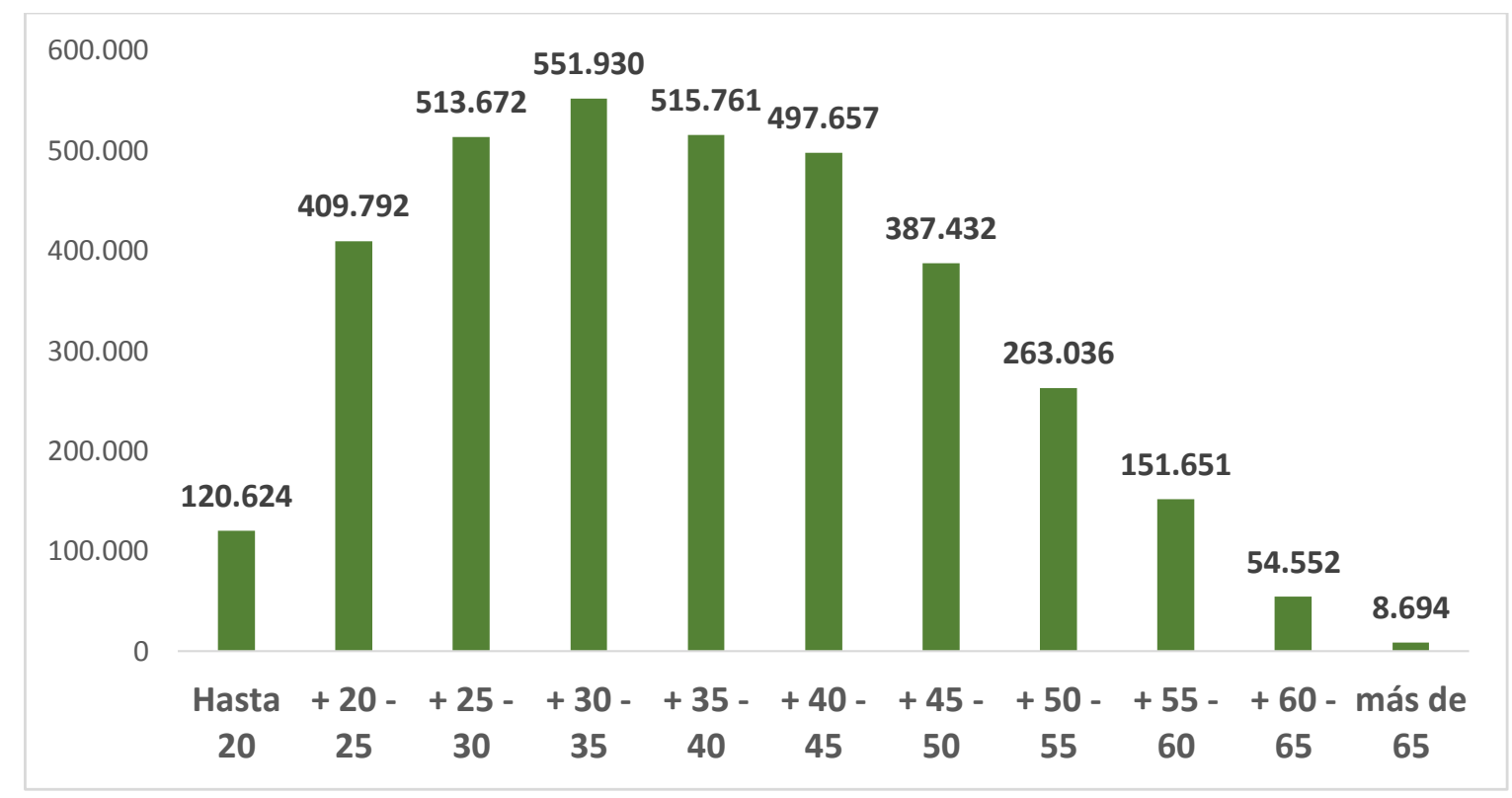

Figura 6. Número de Cotizaciones efectivas totales por grupo etario. Año 2006

Fuente: elaboración propia con base en SAFP (2016)

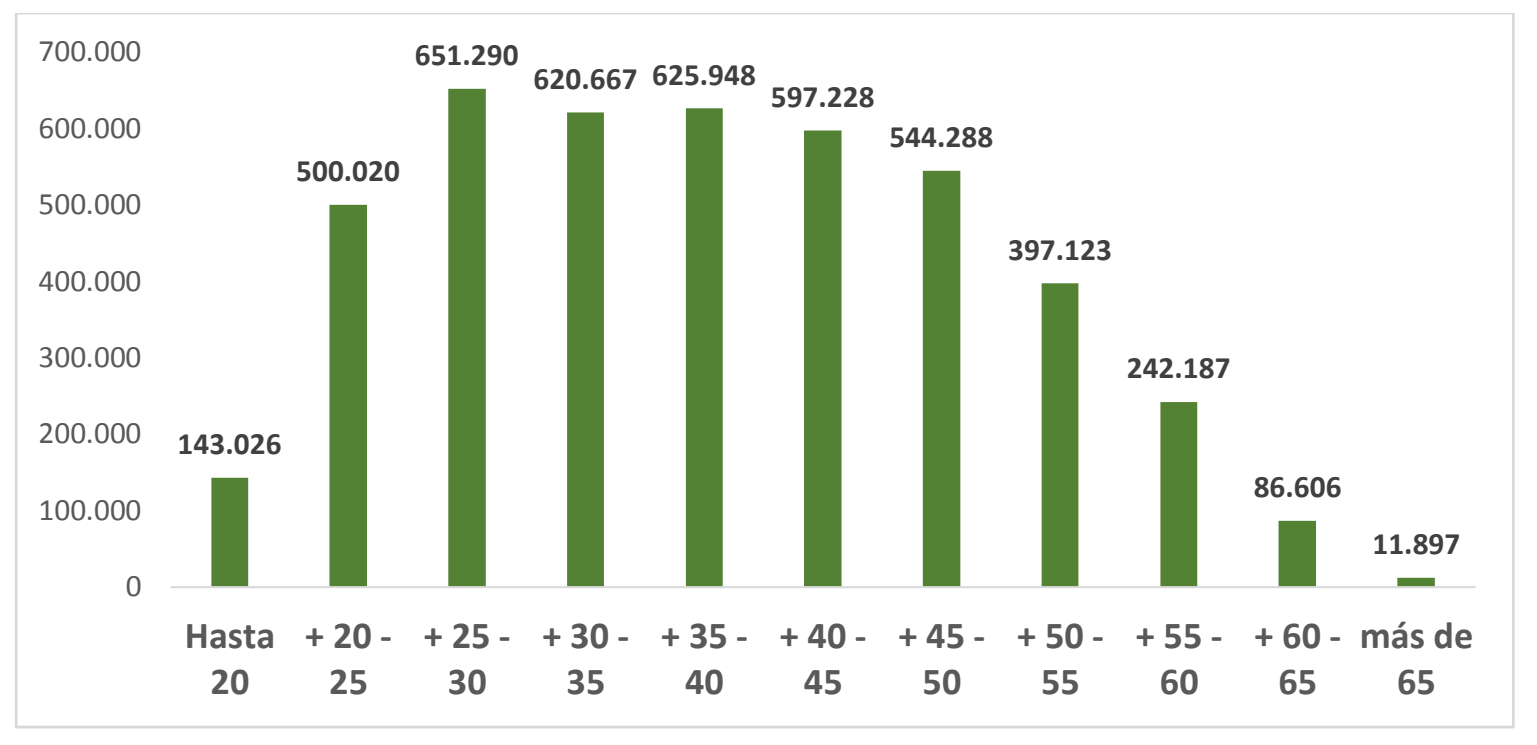

Figura 7. Número de Cotizaciones efectivas totales por grupo etario. Año 2010

Fuente: elaboración propia con base en SAFP (2016)

En el año 2006 el grupo de edad que registra una mayor cantidad de cotizaciones al sistema pensional de Chile se encuentra ubicado entre los 30 a 35 años, con más de medio millón de cotizaciones efectivas registradas durante el año. Si se observa el año 2010 hubo un crecimiento considerable de los grupos de edad más representativos en cuanto a cotizaciones, en este año particularmente quienes cotizaron en mayor cuantía fueron las personas de 25 a 30 años con 
más de 650.000 cotizaciones realizadas, seguidos muy de cerca por los grupos de 30 a 35 y de 35 a 40 años (Helmsdorff, 2008).

Lo anterior fue producido porque tras la reforma integral al sistema chileno de pensiones del 2008 se impulsaron varios programas que fortalecieron la inserción laboral para el grupo etario de 25 a 30 años, contribuyendo así a que se diera un aumento en las arcas del recaudo chileno; adicionalmente se generó un apalancamiento del empleo femenino (programas derivados del gran programa "Chile trabaja") y generación de ingresos adicionales destinados a las madres de bajos ingresos, para que pudieran tener posibilidades de cotizar al sistema de protección social mediante un empleo que garantizara calidad de vida aceptable para ellas y sus familias.

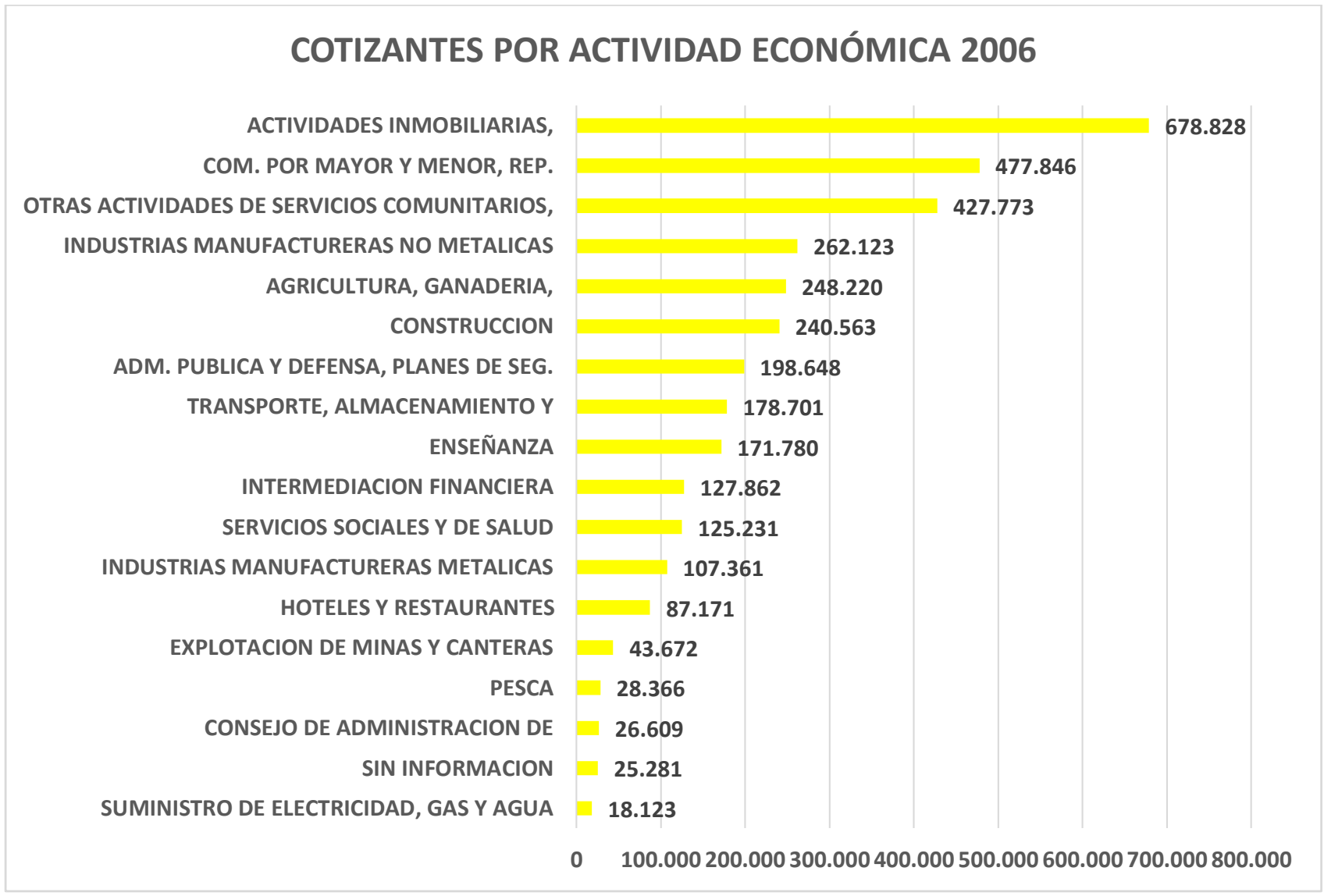

Figura 8. Número de Cotizaciones efectivas totales por actividad económica. Año 2006

Fuente: elaboración propia con base en SAFP (2016)

Las actividades de tipo inmobiliario fueron las que registraron el mayor número de cotizaciones para el año 2006 al sistema pensional, seguida por las actividades comerciales. Cabe destacar que para este año aún no se había dado la burbuja inmobiliaria que afectó el 
mercado estadounidense y golpeó colateralmente las economías latinoamericanas, quizá esta fue una de las razones para que las actividades inmobiliarias mostraran unas diferencias tan marcadas en términos de cotización respecto a las demás actividades de la estructura productiva.

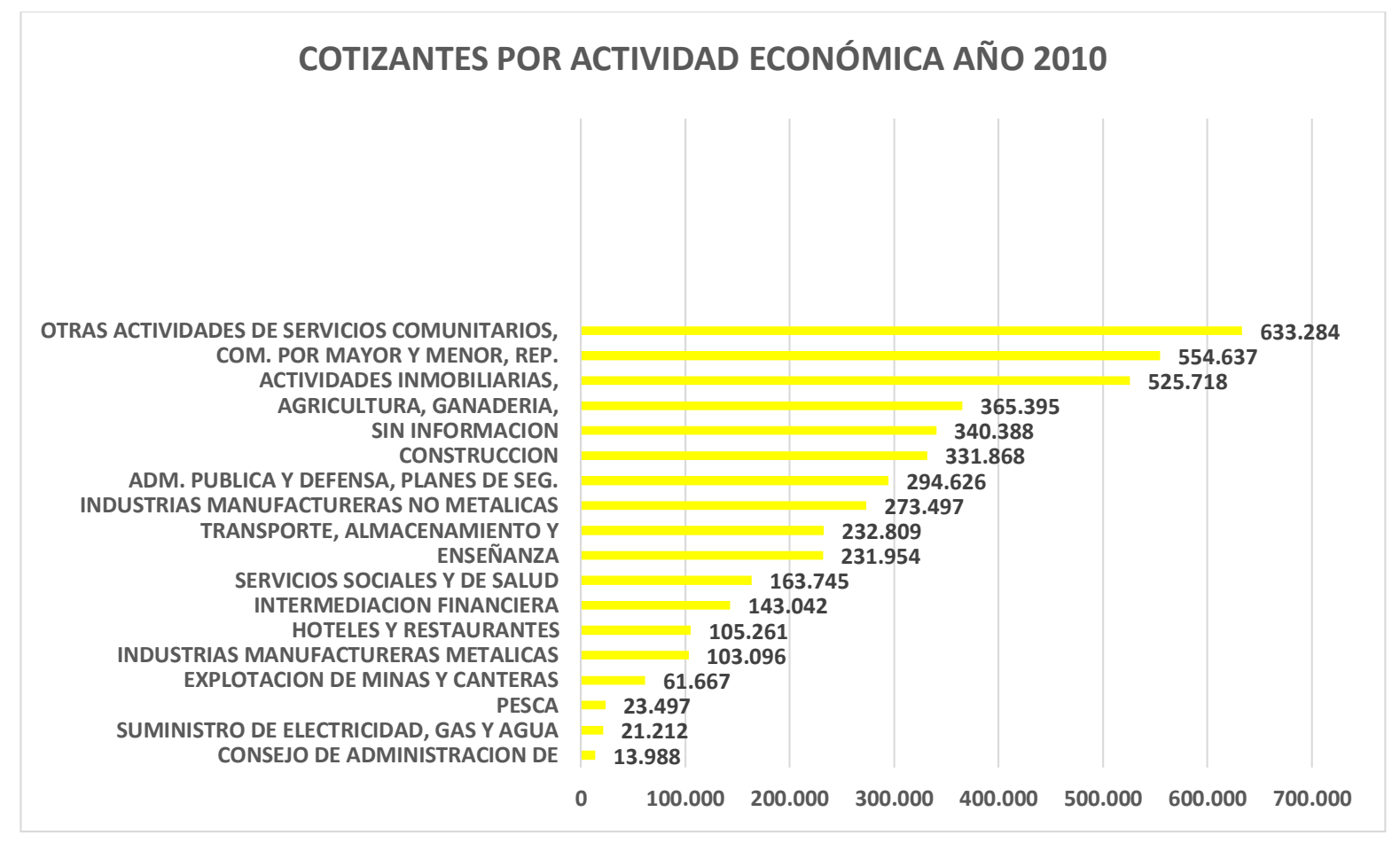

Figura 9. Número de Cotizaciones efectivas totales por actividad económica. Año 2010

Fuente: elaboración propia con base en SAFP (2016)

El panorama en el año 2010 tuvo un cambio realmente importante, fue el hecho de que la cotización a pensión estuviera impulsada en su mayor parte por las actividades gubernamentales, públicas y sindicales, tendientes en su mayoría a atender los programas sociales que tenía en funcionamiento el gobierno para este año, dichos sectores en la figura anterior se denominan "otras actividades de servicio comunitario". Esto supone un direccionamiento de las contribuciones hacia el sector público y un aumento en la implementación de programas de asistencia social que atendieran las principales problemáticas sociales del momento centralizando la prestación de esta ayuda en poblaciones focalizadas que se establecían por parte del gobierno nacional para delimitar el uso de recursos disponibles para este tipo de iniciativas. 


\begin{tabular}{|l|r|r|r|r|r|r|}
\hline A.F.P. & HOMBRE & MUJER & TOTAL & HOMBRE & MUJER & TOTAL \\
\hline BANSANDER & 12.266 & 12.655 & 24.921 & 30.889 & 4.586 & 35.475 \\
\hline CUPRUM & 4.896 & 8.077 & 12.973 & 26.364 & 5.261 & 31.625 \\
\hline HABITAT & 29.095 & 30.630 & 59.725 & 52.897 & 8.743 & 61.640 \\
\hline PLANVITAL & 17.825 & 14.399 & 32.224 & 16.411 & 2.568 & 18.979 \\
\hline PROVIDA & 69.171 & 60.368 & 129.539 & 72.338 & 11.453 & 83.791 \\
\hline SANTA MARIA & 28.744 & 34.040 & 62.784 & 38.258 & 6.746 & 45.004 \\
\hline TOTAL & 161.997 & 160.169 & 322.166 & 237.157 & 39.357 & 276.514 \\
\hline
\end{tabular}

Fuente: elaboración propia con base en SAFP (2016)

Tabla 6. Total pensionados Año 2010

\begin{tabular}{|c|c|c|c|c|c|c|c|}
\hline \multirow[b]{3}{*}{ A.F.P. } & \multicolumn{6}{|c|}{ NÚMERO DE AFILIADOS PENSIONADOS POR } & \multirow[b]{3}{*}{ TOTAL } \\
\hline & \multicolumn{3}{|c|}{ VEJEZ EDAD } & \multicolumn{3}{|c|}{ VEJEZ ANTICIPADA } & \\
\hline & HOMB RE & MUJER & TOTAL & HOMBRE & MUJER & TOTAL & \\
\hline CAPITAL & 56.120 & 80.234 & 136.354 & 76.536 & 12.394 & 88.930 & 225.284 \\
\hline CUPRUM & 9.716 & 21.927 & 31.643 & 29.394 & 5.808 & 35.202 & 66.845 \\
\hline HAB ITAT & 46.930 & 55.660 & $\mathbf{1 0 2 . 5 9 0}$ & 58.582 & 9.496 & 68.078 & 170.668 \\
\hline MODELO & 10 & 2.639 & 2.649 & $\overline{0}$ & 1 & 1 & 2.650 \\
\hline PLANVIT & 25.234 & 24.236 & 49.470 & 16.519 & 2.602 & 19.121 & 68.591 \\
\hline PROVIDA & 97.422 & 110.873 & 208.295 & 80.821 & 12.327 & 93.148 & 301.443 \\
\hline TOTAL & 235.432 & 295.569 & 531.001 & 261.852 & 42.628 & 304.480 & \begin{tabular}{|l|}
835.481 \\
\end{tabular} \\
\hline
\end{tabular}

Fuente: elaboración propia con base en SAFP (2016)

Tanto en los años 2006 como 2010 la AFP que tuvo un mayor número de afiliados (pensionados) al sistema pensional fue PROVIDA, con cerca del $50 \%$ del total de personas afiliadas al sistema bajo esta condición. En términos generales, los pensionados chilenos fueron teniendo un alza en cuanto a la cantidad que de ellos cotiza al sistema de seguridad social, la mayoría de los registros obtenidos muestra que son muchas más la cantidad de personas que se pensionan por vejez anticipada que las que lo hacen por requisitos cumplidos de edad y semanas cotizadas. 
Dado esto, la evolución de afiliados y cotizantes se ha comportado de la siguiente manera: para el primer rubro en 1981 contaba con 1,4 millones y para el año 2009 contaba con 8,5 millones respectivamente, lo que se traduce en una variación anual del $7 \%$ de crecimiento promedio. Por el lado de la cotización se puede observar la misma tendencia de crecimiento, puesto que en el año de 1981 se contaba con 1,1 millones de personas que contribuían al Sistema Previsional, en el año 2009 fueron 4,4 millones los cotizantes, lo que significa un 5,4 $\%$ de aumento promedio por año.

Las marcadas diferencias a lo largo de todo el periodo analizado en la siguiente figura se sustentan principalmente en la morosidad del pago de las contribuciones al sistema, la pérdida de empleo en extensos periodos (desempleo relativamente elevado), demoras en la asignación o imputación de cotizaciones a los trabajadores de diversos sectores y también a errores en la información de afiliados de algunos años especialmente los de principios de la década de los 80.

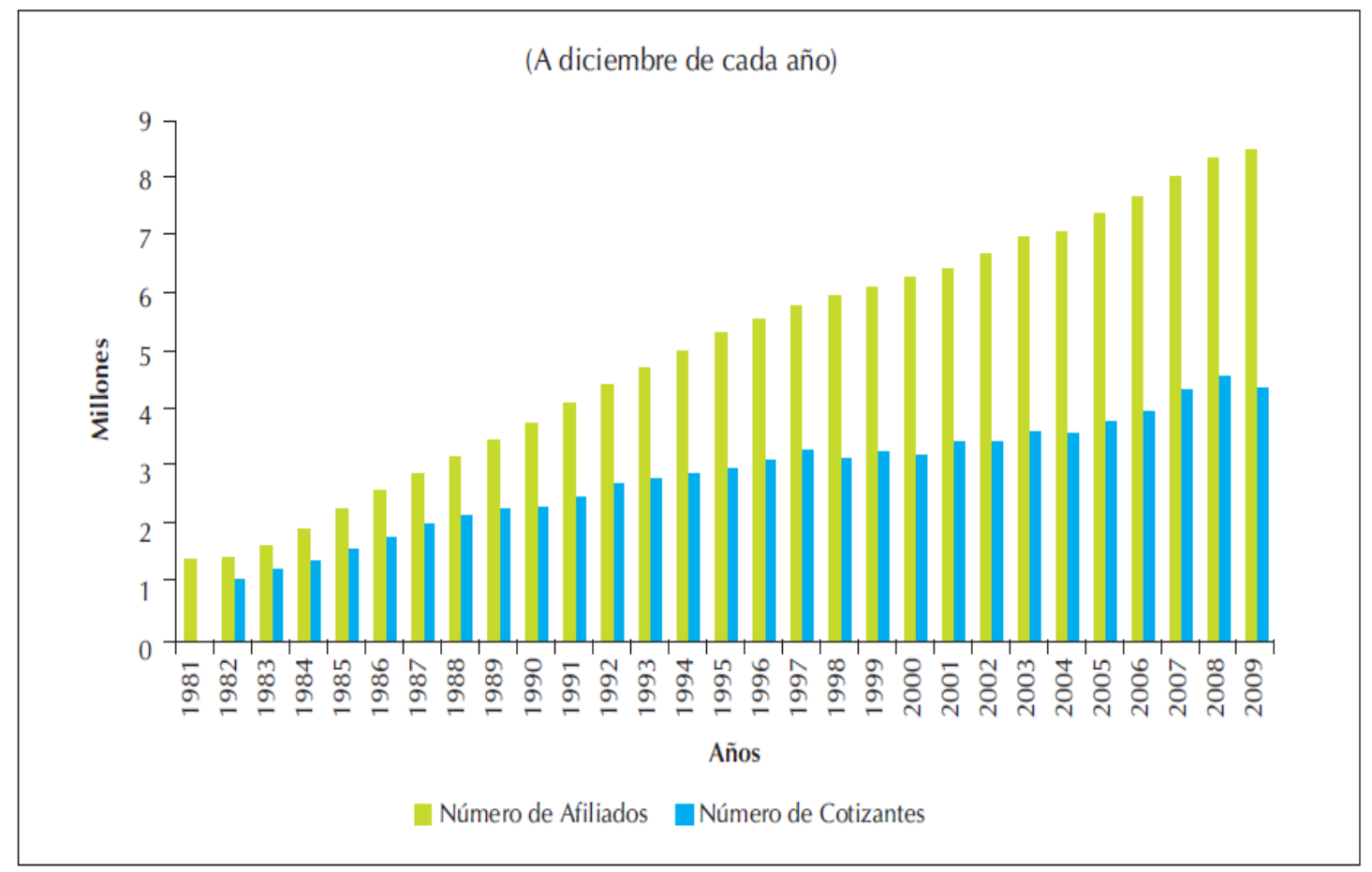

Figura 10. Evolución de cobertura pensional en el periodo 1981-2009

Fuente: Superintendencia de Pensiones de Chile (2010) 
En relación a las pensiones otorgadas por el Sistema Previsional cabe resaltar que las pensiones más relevantes históricamente en el sistema son las de viudez y orfandad, y las pensiones de vejez anticipada (desde 1998) que se han mantenido en crecimiento sostenido a través del periodo estudiado. Caso contrario presentan las pensiones por concepto de invalidez, esto debido a que a través de la creación de la comisión de invalidez del gobierno chileno se les da a estas personas una mayor atención y prioridad en la resolución de su situación pensional y así se pueden autorizar de forma más simplificada estos ingresos para la vejez. Lo anterior arroja un resultado de emisión de las pensiones tendiente al crecimiento entre un $7 \%$ y un $11 \%$ en promedio anual (Berstein, 2010).

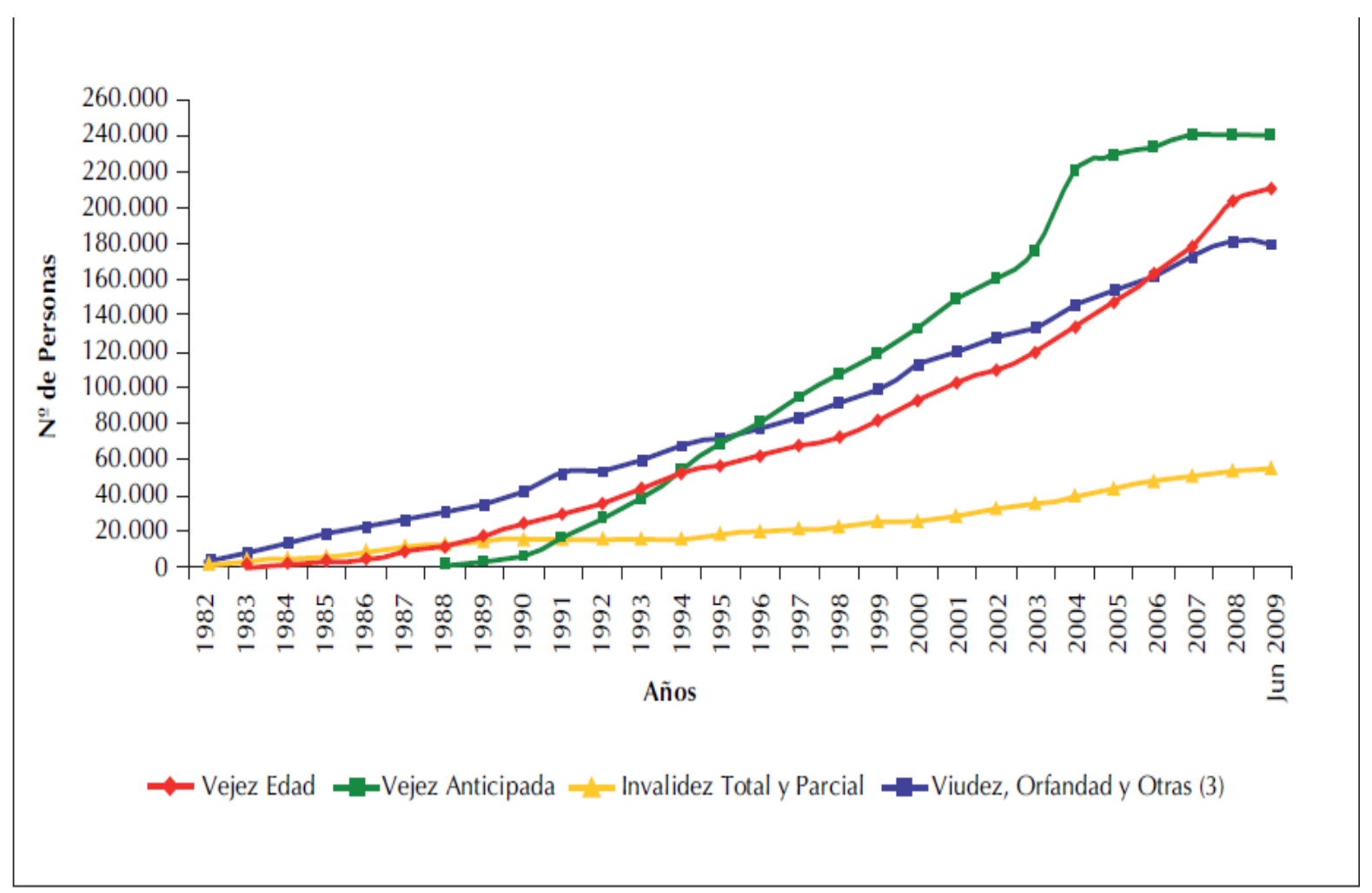

Figura 11. Número de pensiones totales (por tipo de pensión) 1982-2009

Fuente: Superintendencia de Pensiones de Chile (2010)

Las dos principales modalidades de pensión en el sistema chileno son el retiro programado y las rentas vitalicias, en la siguiente figura se puede observar el comportamiento histórico que han tenido a lo largo de los últimos 18 años. Las rentas vitalicias obtienen un mayor crecimiento gracias a la existencia de las pensiones de vejez anticipada, las cuales son representativamente más altas que cualquier otro tipo de pensión dentro del Sistema Previsional de Chile. El crecimiento de las modalidades de pensión han sido de $25 \%$ para las rentas vitalicias y del 15 
\% para el retiro programado (Berstein, 2010), esta diferencia se explica principalmente porque existe una marcada desigualdad para los trabajadores que desean acceder a la pensión por modalidad de renta vitalicia, puesto que en esta modalidad el monto de contribución debe ser igual o un tanto más elevado que el de la pensión básica solidaria, lo que supone una dificultad especialmente para los sectores de ingresos medios que no cuentan con posibilidades de incrementar su monto de cotización por carecer de ingresos adicionales para hacerlo.

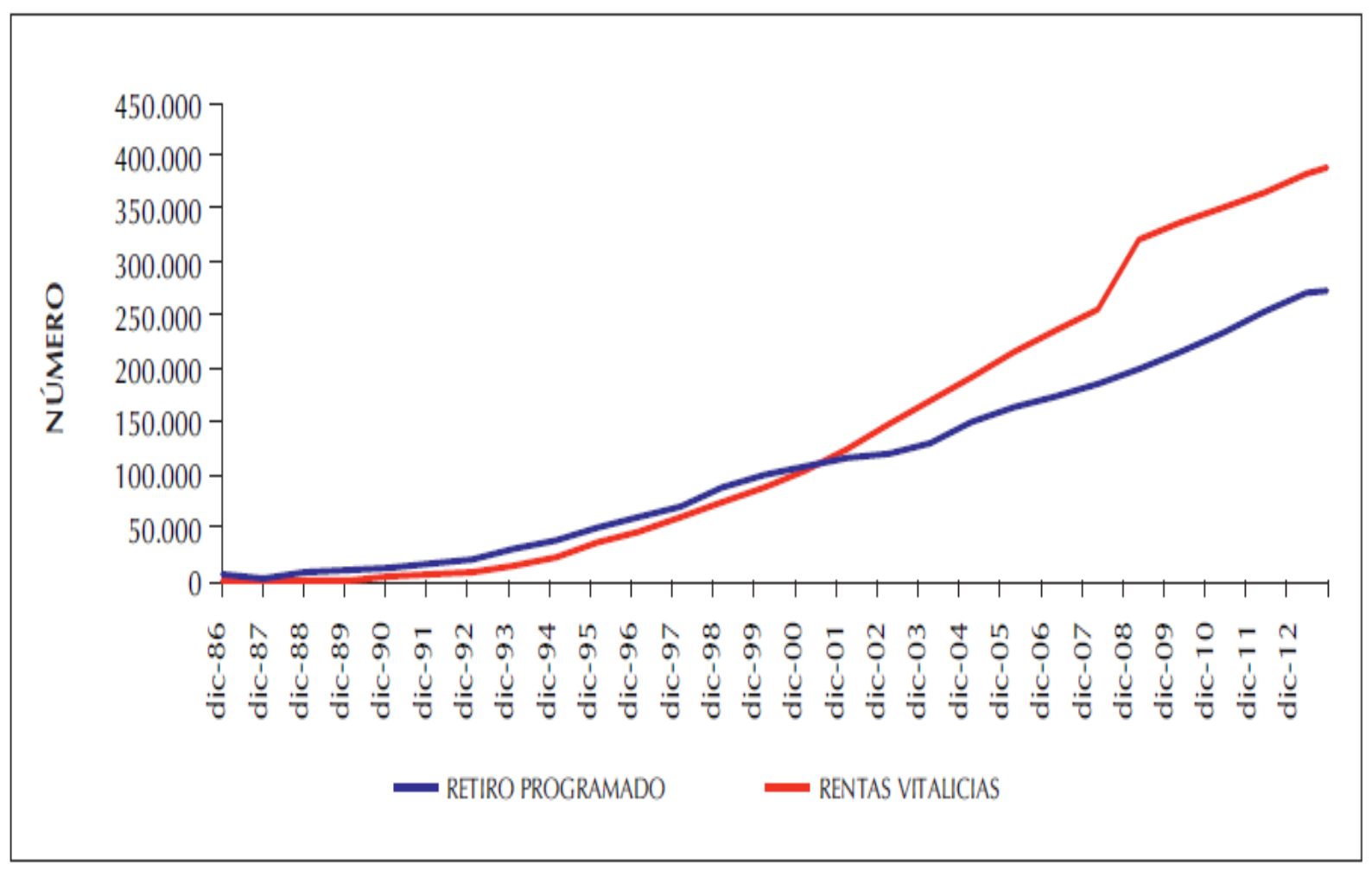

Figura 12. Número de pensiones por modalidad 1986-2012

Fuente: Superintendencia de Pensiones de Chile (2010)

El consolidado de cifras y datos mencionados a lo largo del presente capítulo son instrumento para comprender de una manera más precisa la estructura que se tenía del Sistema Previsional chileno tanto antes como después de la aplicación de la Segunda Reforma Integral del año 2008; y adicionalmente se ilustran unas estadísticas muy generales del Sistema Previsional después de los ajustes graduales que se han realizado en el periodo post-reforma. 


\subsection{Conclusiones}

Como conclusiones se podría decir sin temor a equivocarse que las razones que se adujeron para la realización de la reforma del Sistema Previsional en Chile durante la dictadura militar no lograron sus objetivos básicos. En primer lugar se buscaba una disminución de la carga fiscal, para el Estado; al respecto tendría que decirse que en el sistema de reparto, que era administrado por el Estado como se ha mencionado, se quedaron los pensionados, y los próximos a alcanzar esta; y al impedir el ingreso de nuevos cotizantes en el antiguo sistema, la única forma de cumplir con las obligaciones es la de seguir recurriendo a aportes del Estado, se suma a esto el Bono de Reconocimiento (BR), más los intereses anuales que el Estado entrega por cada año al fondo privado, cuando el empleado alcanza los requisitos para solicitar la pensión. No se debe olvidar que en el nuevo modelo el Estado también participa entregando recursos cuando lo ahorrado no alcanza para una pensión mínima, y por último también se destinan recursos fiscales para la pensión de asistencia social a la población más pobre.

Un segundo objetivo, que era aumentar las coberturas de afiliación, ya se mencionó que las coberturas alcanzadas antes y después de la reforma son muy similares, por lo tanto este objetivo tampoco se logró, si se valora desde la óptica de los fenómenos políticos y económicos de la época se logra entender muy bien por qué se realizó esa reforma tan radical y no se buscaron opciones de mejorar al sistema existente; hay estudios teóricos como el de la Fundación Sol (Narbona, 2015) en los que se evidencia que con ajustes básicos el sistema de reparto hubiera sido viable y sostenible, lo que se pretendía de fondo, con base en el pensamiento económico neoliberal que empezaba a invadir el mundo era dar al sector privado el manejo de unos recursos significativos para su lucro. Sin embargo, el fracaso se puede evidenciar en los posteriores ajustes que el sistema ha tenido que realizar, como el del año 2008 durante la administración de Bachelet, y en que el Estado no ha logrado disminuir sus contribuciones al Sistema Previsional, ahora a través de terceros como son las AFP.

Ahora bien, las formas en las cuales se aborda un tema como la medición de la cobertura en pensiones dentro del sistema de protección social determinan el panorama que tiene y que podría llegar a tener el ámbito pensional en los próximos años. Como se pudo ver la cobertura pensional ha venido creciendo gradualmente en Chile, sin embargo, esta crece a un ritmo considerablemente menor de lo que crecen las pensiones por vejez anticipada, estas son el beneficio más solicitado y otorgado por el Estado, debido a que las personas que generan 
ingresos sustancialmente altos en comparación a los demás trabajadores aportan mucho más al sistema de protección por medio del aporte previsional voluntario (APV). Los resultados mostrados en este primer capítulo evidencian que aunque se está realizando una gestión destacada en la implementación de políticas para garantizar el buen funcionamiento de las pensiones como también en materia de derecho que poseen los ciudadanos a un ingreso en la vejez, cada día se les garantiza a más personas una pensión digna que le permita vivir en unas condiciones viables para su sustento. A pesar de esto, aún queda bastante por hacer para que más trabajadores se vean motivados a cotizar a pensiones y acojan la cultura del ahorro para recibir un ingreso en la vejez y que sirva de sustento para gozar de un sistema de protección social que se ocupe del bienestar de sus contribuyentes.

Más adelante se podrá observar cómo el mercado laboral y el sistema de pensiones mantienen una relación sumamente estrecha sobre los derechos, las prestaciones a las cuales un usuario se hace acreedor, y cómo por medio del salario se sustenta gran parte del sistema de protección social. Se mantiene también la postura de que para realizar una Reforma Previsional Integral se debe tener una mezcla de elementos que combinen los derechos con la sostenibilidad financiera y que en el diseño del sistema esté implícito:

- Una planeación de la estructura del sistema pensional de cara a los retos que implican los cambios demográficos del país en donde funcione dicha estructura.

- Los sistemas pensionales y sus reformas deben estar de cara a sus afiliados porque en gran parte, el sistema se alimenta de sus aportes fruto de su trabajo o labor diaria.

- Debe ser equitativo en cierta proporción con las empresas, incentivando a que vinculen bajo más y mejores condiciones a la población, sin que eso signifique grandes exenciones tributarias que las eximan de las responsabilidades que tienen como parte del sistema productivo del país.

- Los sectores de población de las mujeres y los jóvenes merecen más atención por parte del gobierno, esto para incentivar que puedan cotizar al sistema pensional a través de una acertada inserción laboral y de contrarrestar lo más posible las asimetrías de ingreso que existen entre género, ya que si se piensa detenidamente, las mujeres son (en cantidad) más que los hombres y ante el envejecimiento de la población, sumado a la negativa de las mujeres para tener hijos, se está ingresando en una ruta en la cual será muy complicado garantizar la sostenibilidad del sistema pensional con el paso de los años. 


\section{CAPÍTULO 2: Panorama del mercado laboral años 2006 y}

\section{0}

En este capítulo se pueden observar los diferentes escenarios por los que ha pasado el mercado de trabajo (también es correcto decir "mercado laboral") en Chile en el periodo de estudio y se encuentra divido por los siguientes acápites: una primera sección en la cual se describen los antecedentes del mercado laboral en Chile así como la relación que existe entre los niveles de empleo y los salarios para contribuir a sistema de pensiones, una segunda que describe las actores y la institucionalidad que compone el sistema laboral; también se refiere a los niveles de formalidad e informalidad del empleo, esta última definida por Gálvez y Díaz (2015) de la siguiente manera:

Inserción endeble de los asalariados en el sistema productivo (producción de bienes y servicios), caracterizada por una multiplicidad de formas de manifestación, que se extiende al ámbito de la condición asalariada. [...] La inserción endeble se expresaría en la participación intermitente e inestable de los trabajadores en la actividad laboral, determinada centralmente por la ausencia de condiciones contractuales que garanticen una permanencia y dependencia continua: contratos de trabajo por tiempo determinado bajo distintas modalidades - a plazo fijo, por obra o faena, por tiempos parciales, subcontratos, relaciones civiles que ocultan subordinación como el trabajo a honorarios. (p. 10)

En Chile actualmente para medir la informalidad se tienen en cuenta una serie de factores relevantes tales como número de empleados de una empresa, condiciones contractuales del trabajador, cotización de aportes al Sistema de protección y seguridad social, tiempo de duración de la condición contractual pactada con el empleador, estructura productiva del país y niveles de empleo y desempleo actuales e históricos. Estos factores permiten establecer una estimación aproximada a los niveles de informalidad que presenta la economía chilena actualmente.

La información que se presenta en este capítulo está analizada previamente y cuenta con cifras que respaldan la información presentada. Seguidamente, se incluye una tercera sección que trata sobre las políticas en materia laboral que existen en Chile para poblaciones como los jóvenes y las mujeres, este último en miras a reducir las inequidades que en materia laboral se han presentado a lo largo del tiempo; y finalmente una breve reflexión a modo de posible 
respuesta por parte de los autores para contrarrestar las dificultades que padece el mercado laboral chileno.

\subsection{Antecedentes históricos del Mercado Laboral en Chile}

Al igual que en la mayoría de países de todo el planeta, la relación entre la tasa de empleo y los salarios en Chile ha sido sumamente fuerte, pues los aportes que realizan los trabajadores y empleadores al sistema de protección social se encuentran ligados a la capacidad de las personas para generar un ingreso que les permita sostenerse en el tiempo; en caso de carecer de ingresos, el Estado genera intervenciones por medio de programas sociales que impulsan el desarrollo y la productividad de las personas de bajos ingresos, con el fin de que puedan tener opciones de aportar ingresos a los diferentes sistemas del gobierno.

Por lo anterior es propicio mencionar que a lo largo de muchos años, el mercado laboral chileno ha experimentado periodos de profundas crisis y de cambios, en los que principalmente se ha buscado mejorar las condiciones salariales y de vida de los trabajadores, a la par que se intenta conciliar con los empleadores para equiparar los beneficios de ambas partes. Para lograr dicha conciliación, los gobiernos de las diferentes épocas por las cuales pasó la reforma laboral optaron por implementar (aunque no con el éxito esperado) varios planes laborales en los que se pudieran conocer más profundamente las exigencias de cada sector de la economía, que a saber, los sectores manufactureros, industriales, minero y agrícola son los que por la época demandaban mayores garantías para el ejercicio de su profesión.

Ahora, todas estas fases de negociación colectiva sucedidas desde el año 1927 hasta mitad de los años 60 (extendidas por más de cuatro décadas) entre la Central Unitaria de Trabajadores de Chile (CUT) y los empresarios apuntaban a mantener en un nivel aceptable los salarios que se otorgaban a los trabajadores, para evitar al máximo una posible afectación (por medio de huelgas o actividades sindicales) en los sectores productivos que sostenían la economía chilena; más si se tiene en cuenta la influencia que tenía la forma de gobierno de Francisco Franco (Dictadura española) y la Escuela de Chicago (Chicago Boys) en la dictadura de ultraderecha en Chile que optaba por impulsar una economía totalmente libre y abierta al mundo (Arellano, 1980).

Además, el mercado laboral chileno tuvo como rasgo distintivo una marcada flexibilización de las relaciones laborales (es decir, ampliación en las formas de contratación a los trabajadores 
sin que este proceso implique necesariamente hacer reducciones en sus prestaciones sociales); aunque en Chile esto implicó drásticos cambios en la contratación de trabajadores, pues los salarios se mantenían pero la cantidad de personal que podía ingresar de forma estable al mercado laboral era cada vez menor con el paso de los años, a raíz de este proceso de flexibilización laboral y contando con los cambios surgidos entre los años 1973 a 1981; periodo en el que vale la pena destacar los siguientes factores:

1. Con el gobierno de Augusto Pinochet vinieron grandes limitaciones y prohibiciones para ejercer la actividad sindical y la negociación colectiva por parte de los trabajadores con los empleadores. El sector productivo más afectado fue el industrial, debido a que las fábricas que producían bienes en la economía de Chile no ofrecían garantías tanto salariales como de salubridad a los empleados y esto traía como consecuencia frecuentes accidentes laborales, protestas, huelgas y ausentismo justificado por la vulneración de derechos fundamentales de los empleados; para contrarrestar esta disputa, los empleadores tenían un mínimo de días de ausentismo al puesto de trabajo en las fábricas, y en caso de que este se cumpliera procedían a despedir al trabajador de forma aparentemente "justa" bajo las condiciones que ellos, apoyados por el Estado, habían establecido para evitar perder el control sobre los asalariados.

2. Todos los gobiernos del periodo en mención estuvieron de acuerdo y en procura de hacer de Chile la Nación con el mercado de trabajo más flexible del mundo.

3. En la fase dictatorial (1973-1978) se crea el Plan Laboral, establecido como Decreto Ley y a su vez hoja de ruta para decidir sobre la marcha las políticas laborales del país y la acciones a llevarse a cabo sobre el mercado laboral. También se consideraba un instrumento que servía de escudo a los gobiernos de la época para justificar las acciones de transformación abrupta del mercado laboral, este Plan Laboral se extendió en Chile por más de cuatro décadas, adaptando formas distintas pero con una misma finalidad: el control social del mercado de trabajo.

4. Como parte del proceso de flexibilización laboral se presentó una afectación en los salarios de la población Chilena y más notoriamente en los sectores de la minería, agricultura e industrial; dado que eran los sectores del mercado laboral sobre los que el gobierno nacional realizaba más control para evitar los intentos de huelga o manifestación. 
Tras la imposición de la dictadura militar en Chile hacia el año de 1973, con la llegada de Augusto Pinochet al poder vale la pena destacar que se tomaron las siguientes medidas para ejercer presión sobre los asalariados de la época:

- Se establecieron normas que impedían el funcionamiento de los sindicatos, se expidió un Decreto Ley (D.L) que facilitaba el despido masivo de dirigentes y seguidores que hubiesen participado en las diferentes huelgas o manifestaciones en contra del gobierno Nacional chileno.

- Se congelaron todo tipo de ajustes y remuneraciones que se hicieran por concepto de prestaciones sociales, como por ejemplo, la pensiones.

- Existió la suspensión temporal y hasta nueva orden de las elecciones sindicales que representarían a los trabajadores ante las empresas.

- Se realizó el fusilamiento de líderes sindicales en varias regiones del país (Narbona, 2015).

Como es evidente, el gobierno chileno en diferentes oportunidades a lo largo de las últimas décadas (1973- 1983) utilizó mecanismos de reforma al empleo para controlar la actividad sindical, tales como la reducción salarial por periodos de huelga prolongada y la prohibición de negociación de muchos sectores del sector industrial con el Estado. Este tipo de acciones perjudicaron los intereses de los trabajadores vía salarios, dándole un mayor margen de manejo del ejercicio laboral a los empresarios sobre sus empleados (Narbona, 2015).

La lógica del gobierno de Augusto Pinochet (1973-1990) estaba determinada por lo que se denominaba "corporativismo nacionalista", que se caracterizaba principalmente por ejercer una forma de gobierno drástica que conducía a controlar el mercado y las libertades de elección de los individuos en la sociedad económica. Todo estaba apoyado por cuerpos sociales (instituciones) que se ocupaban de administrar el capital y el trabajo, operando bajo subordinación absoluta del Estado y con la finalidad de reducir las tensiones recurrentes entre empleadores y trabajadores, optando por mejorar las condiciones salariales de estos últimos; pero manteniéndolos como impulsadores de la productividad de los primeros (Piñera, 1990).

Posteriormente, llegó una de las reformas más fuertes en términos laborales para Chile gestada desde 1975 a 1979, en lo que se llamó “una revolución laboral, para la revolución liberal", dicha reforma constaba de la implementación del Plan Laboral al Mercado de Trabajo chileno, que pretendía en primera instancia convertir a Chile en la economía más flexible del 
mundo, esto implicaba que los productos importados carecieran de aranceles y que la producción nacional en Chile sería mucho menor por la prioridad que en materia comercial se le daba a los productos extranjeros. Adicionalmente, los acuerdos comerciales entre naciones fueron una tendencia muy marcada en la economía de Chile en los años 70 (Marcel \& Tapia, 2010).

El plan laboral dentro de sus acciones más importantes realizó las siguientes:

- Prohibió la negociación colectiva de derechos en instancias más allá de la empresa.

- Excluyó de la negociación colectiva a los trabajadores con contrato de aprendizaje, a trabajadores del sector de la construcción, a los trabajadores por contrato de obra (término fijo) o faena (obra o labor) y a los trabajadores del servicio público (entidades públicas).

- Se fijó un plazo máximo de 60 días por concepto de huelga, al terminar este plazo si el trabajador no retomaba sus actividades se consideraba despedido de su puesto de trabajo.

- Se permitió que grupos negociadores en temas laborales estuvieran representados por trabajadores sindicales y huelguistas que podrían participar en negociaciones.

Estas disposiciones legales significaron un gran avance en cuanto a negociación colectiva en el marco laboral; sin embargo, favoreció en gran medida al sector empresarial más que a los propios trabajadores de los diversos sectores productivos. Trasladando el tiempo a años más recientes, más exactamente en el año 2005, aún se tenía evidencia de que el código de trabajo que imperó en la dictadura de Augusto Pinochet se encontraba vigente "reestructurando la postura empresarial y fijando la negativa de retroceder en flexibilización laboral en el país" (Córdova, 2005: 132-133).

El periodo 1990-2014, muestra de hecho, solo dos procesos de reformas laborales y algunas iniciativas menores, que no alteran en lo esencial los pilares de la institucionalidad laboral de Pinochet e incluso, la profundizan. A fines de 2014 se inicia un nuevo proceso, que aún se encuentra dentro de los elementos que constituyen el plan laboral anteriormente citado. (Fundación SOL et al, 2013 como se citó en Narbona, 2015, p. 24) 
Así, la política inaugural del periodo de transición democrática fue la generación de una convivencia entre los actores sociales a través de "acuerdos marco" tripartitos, entre la recién creada Central Unitaria de Trabajadores (1990-1993), el gobierno y la Confederación de la producción y el comercio. En el periodo (1990-1993) se produjo una segunda reforma laboral integral que resultó ser efectiva en gran medida, dentro de esta se aprobaron cinco (5) proyectos estipulados dentro del Código de Trabajo (Narbona, 2015):

1. Sobre terminación de contratos

2. Centrales sindicales

3. Organizaciones sindicales y negociación colectiva

4. Contrato individual de trabajo

5. Asociaciones de funcionarios de la Administración Pública

Este grupo de proyectos y leyes que se reformaron, afectaron a unos grupos poblacionales sumamente importantes en la economía de Chile, con acciones tales como la ampliación de los derechos de la maternidad, las licencias para permisos de conciliación de trabajo/familias y la eliminación de jornadas laborales extendidas de hasta 70 horas que debían cumplir algunos trabajadores, se regularon los horarios de descanso mínimos para trabajadores del sector transporte y la creación de un sueldo básico y garantías laborales definidas para los trabajadores de casa.

Luego, en el periodo comprendido entre los años 2000-2010 se generaron una serie de reformas, las cuales conjuntamente apuntan a gestar la primera reforma sustancial al mercado de trabajo, dejando de lado los elementos de la dictadura y bajo el emblema de modernizar la actividad sindical y las relaciones laborales de los actores del mercado de trabajo. Posteriormente, el gobierno bajo la lógica de transformación sustancial del código de trabajo hace que las políticas laborales estén estrictamente fundadas por la institucionalidad (instituciones) que rige el mercado de trabajo para evitar una confrontación entre empresas y trabajadores que potencialmente pueda afectar la productividad nacional. En mitad de este mismo periodo según Campero (2007:34) como se citó en Narbona (2015), se hacen incorporaciones importantes para generar equidad y oportunidad en el mercado laboral chileno, por medio del desarrollo de contratos de trabajo por tiempo parcial, el teletrabajo y el contrato juvenil. 
Finalmente en el año 2005 se creó el seguro de cesantía, lo cual representa un avance importante en términos de aseguramiento y recaudo para el mercado de trabajo en Chile (Narbona, 2015) y en donde su funcionamiento básicamente se da por un aporte (tripartito) de trabajadores, Estado y patrones a un fondo común que está sujeto a la utilización por parte del trabajador ante cualquier circunstancia de terminación de contrato, pero dentro del cual los empleadores pueden descontar el valor de su aporte por concepto de los años de servicio en los que estuvo el empleado.

\subsection{Instituciones y Actores del mercado laboral en Chile}

Este apartado tiene como propósito ilustrar al lector sobre la institucionalidad y la terminología específica que comprende el mercado de trabajo en Chile, cabe destacar que aunque muchos de los términos que se van a nombrar a continuación suelen ser similares en los diferentes países de América Latina, es preciso mostrar su definición teórica para evitar confusiones a los largo del desarrollo de los diferentes temas.

Las diferentes instituciones aquí nombradas son las que por su función de entes reguladores y recopiladores de información del mercado laboral, permiten mostrar las cifras y algunos datos numéricos relevantes del comportamiento del mercado de trabajo en Chile. La institución más importante que vigila el comportamiento del empleo en Chile es el Ministerio de Trabajo y Previsión Social, de él se desprenden otras instituciones que complementan su labor en el territorio chileno:

\section{- CENTRAL UNITARIA DE TRABAJADORES DE CHILE (CUT)}

Es una multisindical chilena fundada en septiembre de 1988, se erige como la principal organización que trabaja por la sindicalización en Chile. Este organismo se dio como resultado de una fusión entre las organizaciones sindicales centrales de diferentes sectores laborales de la economía Chilena. La CUT brindó su apoyo y asesoría permanente al gobierno de la Unidad Popular que encabezó Salvador Allende hasta su derrocamiento el 11 de septiembre de 1973. El 4 de enero de 1972 se promulgó la Ley $\mathrm{N}^{\circ}$. 17.594, que concedió personalidad jurídica de la CUT y dio lugar a los mecanismos de financiamiento de sus actividades. La CUT alcanzó un papel importante en el rol decisorio de Chile para inicios de los años 70.

Tras el golpe de Estado del 11 de septiembre de 1973 sucedido al gobernante Salvador Allende, a la CUT se le canceló su personería jurídica por el Decreto Ley No 12 del 24 de 
septiembre de dicho año, lo que le impidió ejercer sus funciones legales e interferir en las decisiones políticas de la época.

\section{- INSTITUTO DE PREVISIÓN SOCIAL (IPS):}

El Instituto de Previsión Social (IPS) es un servicio público que se creó a partir del artículo 53 de la Ley 20.255 de Reforma al Sistema Previsional; de carácter descentralizado y que cuenta con una figura jurídica y recursos monetarios propios destinados al sostenimiento y financiamiento del sistema pensional y de este organismo del Estado.

El nuevo servicio tiene por objetivo la administración del sistema de pensiones solidarias y de los regímenes previsionales administrados anteriormente por el INP, y constituye un servicio público regido por el Sistema de Alta Dirección Pública, establecido en la ley $N^{\circ}$ 19.882. (Instituto de Previsión Social, s.f.a, párr. 3)

\section{- INSTITUTO DE SEGURIDAD LABORAL (ISL):}

Es la entidad pública que se encarga de administrar el Seguro Social contra accidentes de trabajo, riesgos laborales y enfermedades profesionales. Adicionalmente busca, a través de la implementación de varios programas y campañas, aumentar la calidad de vida de los trabajadores; teniendo en cuenta que pertenece al Ministerio de Trabajo y Previsión Social.

El Instituto de Seguridad Laboral, desde su condición de Servicio Público, contribuye a la construcción e instalación de una cultura de trabajo que promueve y garantiza a los trabajadores y trabajadoras el ejercicio de sus derechos en materia de seguridad y salud laboral, a través del despliegue de la Política Nacional de Seguridad y Salud en el Trabajo. (Instituto de Previsión Social, s.f.b, párr. 3)

\section{- MINISTERIO DE TRABAJO Y PREVISIÓN SOCIAL:}

El Ministerio del Trabajo y Previsión Social fue creado por el D. F. L. N 25 de 1959, del Ministerio de Hacienda.

Conforme al artículo 40 de la Ley 20255 de 2008 el Ministerio del Trabajo y Previsión Social se considera como el órgano superior de asesoría a la presidencia de la República en temas laborales y de protección social, aquí le corresponde estudiar y realizar propuestas para implementar (o mejorar según sea el caso) las normas de seguridad social, asignación de recursos y vigilar las actividades del sector pensional y previsional. 


\section{- SERVICIO NACIONAL DE CAPACITACIÓN Y EMPLEO (SENCE):}

Es un servicio del Estado que hace parte del Ministerio de Trabajo y Previsión Social. Se encarga de promover la generación de empleo en las empresas tanto a nivel público como privado, también hace gestiones para brindar capacitación a los trabajadores de menores ingresos, a los jóvenes y a las mujeres que no han podido acceder al mercado de trabajo (SENCE, s.f.).

\section{- SUPERINTENDENCIA DE PENSIONES:}

Es el organismo contralor que representa al Estado al interior del sistema chileno de pensiones. Es una entidad autónoma, cuya máxima autoridad es el Superintendente; se relaciona con el gobierno a través del Ministerio del Trabajo y Previsión Social, por intermedio de la Subsecretaría de Previsión Social, y tiene la capacidad para manejar el Sistema Previsional casi en su totalidad puesto que a cargo de esta también se encuentra la vigilancia de los fondos de inversión.

La Superintendencia de Pensiones fue creada por la Ley 20.255 de Marzo del 2008 como sucesora y continuadora legal de la Superintendencia de Administradora de Fondos de Pensiones, creada por el Decreto Ley $\mathrm{N}^{\circ} 3.500$, de 1980, que inició sus funciones a contar del $1^{\circ}$ de mayo de 1981. Se rige por un estatuto orgánico contenido en el Decreto con Fuerza de Ley N 101 de 1980, del Ministerio del Trabajo y Previsión Social. (Superintendencia de Pensiones, s.f., párr. 2)

\section{- SUPERINTENDENCIA DE SEGURIDAD SOCIAL}

Es una institución autónoma del Estado, también se relaciona con el gobierno a través del Ministerio de Trabajo y Previsión Social, esta reúne a las instituciones que fiscalizan y vigilan los recursos del Estado para garantizar un correcto funcionamiento del sistema (Asociación de Auditores Externos de Chile, s.f.).

Se inicia el 10 de diciembre de 1927, con la denominación de Departamento de Previsión Social. A partir de julio de 1945, se sustituyó su nombre por el de Dirección General de Previsión Social, y en el año 1953, se creó la Superintendencia de Seguridad Social, en reemplazo de dicha Dirección. (Asociación de Auditores Externos de Chile, s.f., párr. 2) 
De acuerdo a las instituciones ilustradas anteriormente es viable ahondar un poco más en cuanto a los tipos de contrato laboral que se dan actualmente en el mercado laboral de Chile, y de las prestaciones sociales que otorga:

\section{INGRESO MENSUAL MÍNIMO:}

Por 'salario mínimo' puede entenderse la suma mínima que deberá pagarse a un trabajador por su labor desempeñada o servicios prestados, dentro de un lapso de tiempo determinado, que está garantizada por la ley y puede fijarse para cubrir las necesidades mínimas del trabajador y de su familia, teniendo en consideración las condiciones económicas y sociales de los países. (Organización Internacional del Trabajo, s.f., párr. 1)

En Chile el salario mínimo representa el monto mensual mínimo que se obtiene por una jornada de trabajo y cuya duración no puede exceder las 45 horas semanales. Este ingreso es fijado mediante la implementación de una ley que se tramita por parte del Congreso y la cual es concertada con representantes de las empresas y las asociaciones de trabajadores; por lo general el 1 de julio de cada año se fija una nueva ley de salario mínimo en Chile.

\section{ENCUESTA DE CARACTERIZACIÓN SOCIOECONÓMICA NACIONAL (CASEN):}

Es el instrumento estadístico que utiliza el gobierno de Chile para medir los niveles de cobertura de los diferentes servicios públicos y sociales que presta a sus ciudadanos, y así mismo, a partir de los resultados obtenidos poder identificar las necesidades y los elementos de los cuales carecen los diferentes mercados de trabajo, salud, educación, entre otros.

\section{CONTRATO POR FAENA:}

Es un tipo de contrato que maneja únicamente su duración por el tiempo que dure la labor que se desarrolla, es decir, que una vez se cumpla el tiempo de ejecución del proyecto en el que se trabaja, el contrato finalizará.

\section{CONTRATO JUVENIL:}

Es un vínculo laboral que como su nombre lo indica está dirigido a la población de 18 a 30 años que cuenten con algún tipo de barrera social o económica que les impida acceder a un empleo formal. Este contrato es un avance sumamente interesante, pues cumple con la finalidad de reducir el desempleo juvenil en Chile, problema que aqueja a todos los mercados laborales 
de América Latina. Para impulsar esta iniciativa, el gobierno de Chile ofrece a sus jóvenes algunos incentivos que permitan aumentar la contribución que se realiza al Sistema de Seguridad Social y de Pensiones, por medio de subsidios a la cotización.

\section{CONTRATO POR OBRA:}

Según Narbona (2015) es un contrato de trabajo en el cual al trabajador se le remunera por cumplir en un tiempo establecido un proceso específico, y dentro de este contrato no se asumen obligaciones por concepto de prestaciones sociales, pues estas van a cargo del trabajador; es muy similar al contrato por prestación de servicios que se maneja en el mercado de trabajo colombiano.

\section{CONTRATO POR PLAZO FIJO:}

Es el contrato que está acordado por ambas partes (empleador y trabajador) y tiene un término fijo, aunque puede estar sujeto a una prórroga de común acuerdo.

\section{SEGURO DE CESANTÍA:}

"Es una protección económica en caso de desempleo, a la que tenemos derecho todos los trabajadores regidos por el Código del Trabajo y contempla una serie de criterios descritos a continuación: el trabajador está afiliado automáticamente, si su contrato laboral comenzó a partir del 2 de octubre de 2002. Esta afiliación es obligatoria y debe ser comunicada por el empleador a AFC Chile; si el contrato es previo a esa fecha, el trabajador se puede afiliar voluntariamente, para lo cual debe dirigirse a una sucursal de la AFC o hacerlo directamente en su lugar de trabajo o en www.afc.cl para cada afiliado.

AFC crea una Cuenta Individual de Cesantía (CIC), cuyos recursos acumulados son de propiedad de cada trabajador. Como complemento al ahorro individual, existe el Fondo de Cesantía Solidario (FCS), que es un fondo de reparto conformado con aportes del empleador y del Estado. El Seguro de Cesantía cubre también beneficios sociales, previsionales, de salud y asignación familiar según el Fondo por el cual se cobre el beneficio. (AFC Chile, s.f., párr. 1) 


\subsection{Cifras y datos estadísticos relevantes del mercado laboral en Chile}

El Ministerio del Trabajo y Previsión Social es la institución que regula la dinámica y las políticas en materia laboral en Chile. Antes de pasar a enseñar unas cifras concretas de la situación que vive el mercado laboral en Chile, es preciso poner en conocimiento dos conceptos claves para evitar dar lugar a confusiones:

\section{TASA DE EMPLEO:}

Se entiende como tasa de empleo a la cantidad de personas que se encuentran vinculadas laboralmente (empleadas) a alguna actividad legamente establecida, sin importar la clase de contrato laboral que esta posea.

\section{TASA DE OCUPACIÓN:}

Representa la cantidad de personas que se encuentran trabajando sobre la cantidad de personas que se encuentran disponibles para hacerlo.

Respecto a la dinámica reciente del mercado laboral en Chile se tienen los siguientes comportamientos: el país contaba en el año 2009 con un nivel de empleo (tasa de empleo) de 57,3\% sobre la PEA (población en edad de trabajar) (OCDE, 2010; CEPAL, 2010), mientras que para el año 2015 se tuvo un nivel de empleo del 65,2 \% (OCDE, 2015). El salario mensual medio es de 3.000 USD, lo que al año concretamente es 36.118 USD. Otro dato de importancia es que el porcentaje de personas que han estado desempleadas por un lapso de un año o más corresponde al 2,8, y en cuanto a riesgo de perder su empleo los chilenos únicamente tienen un $5,4 \%$; cifra considerablemente baja respecto a algunos países europeos en donde esta es cercana al $12 \%$. 


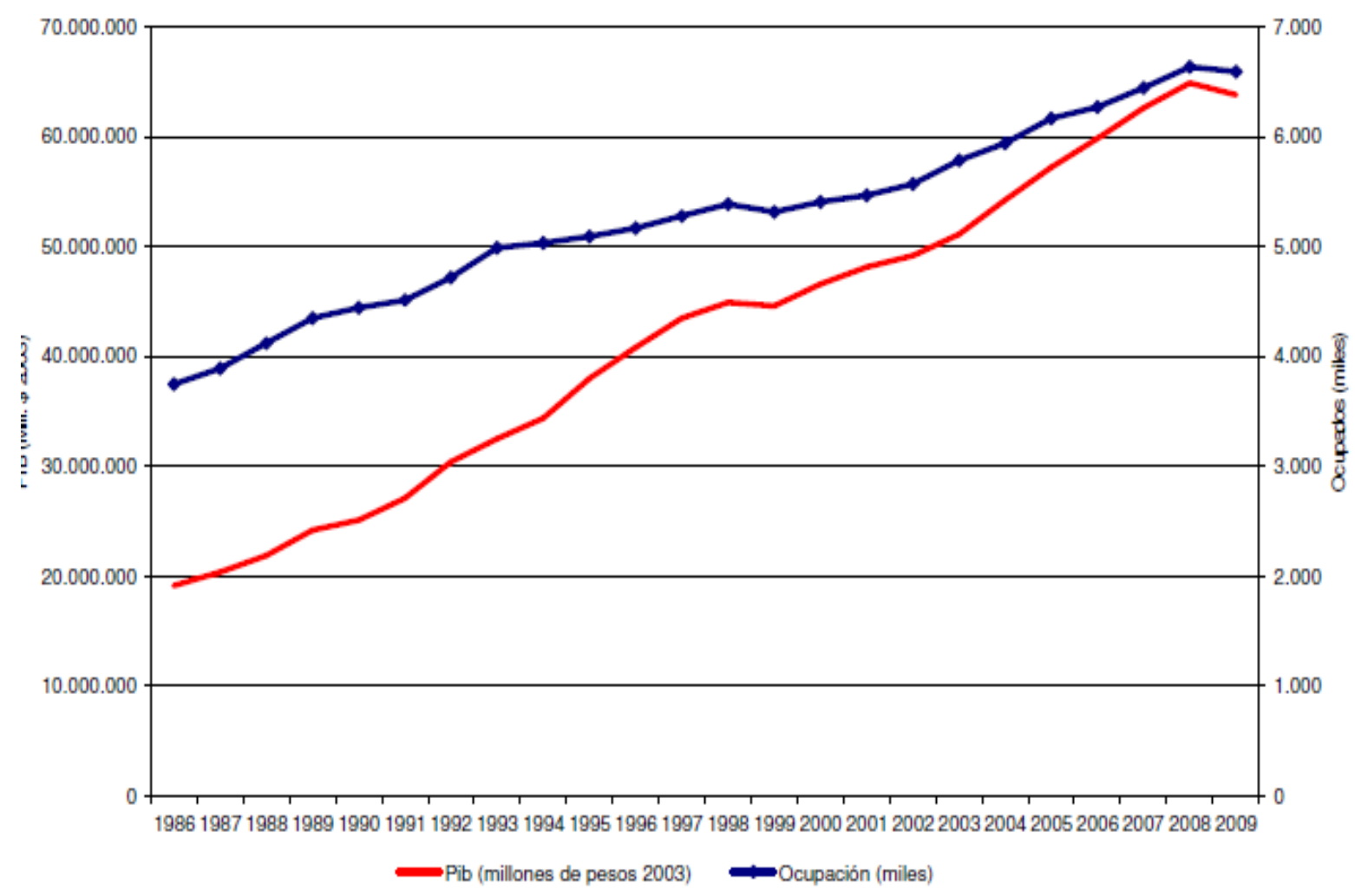

Figura 13. Producto Interno Bruto (PIB) vs. Ocupación en Chile (1986-2009). Cifras en millones de pesos Chilenos

Fuente: (Rucci, 2011, p. 1)

Chile viene experimentando un alza importante en su productividad y también en el nivel de ocupación del mercado de trabajo. Sin embargo, se ha registrado un retroceso en cuanto a producción de nuevos empleos y al nivel de calificación que poseen los trabajadores chilenos de ingresos medios y bajos, lo cual en la siguiente figura está dado por el nivel 1 (menores ingresos y el nivel 5 (mayores ingresos); estos niveles de ingreso son directamente proporcionales a los años de educación que puede conseguir un trabajador chileno y que en consecuencia le permita incrementar su nivel de ingreso en la vida laboral y posterior a ella.

Como ha sido tendencia en los países de América Latina, el comportamiento del nivel del empleo ha sido ascendente mayormente para los ingresos más elevados dada su capacidad de ingresos y el acceso a una mejor y mayor capacitación o nivel educativo; mientras que caso contrario muestran los ingresos medios y bajos puesto que no tienen un nivel educativo elevado, en muchas ocasiones los trabajadores de ingresos medios acceden a empleos en los cuales se encuentran subvalorados de acuerdo con su formación profesional y académica, y 
también puede presentarse que permanecen en trabajos temporales que no les garantizan una estabilidad económica ni profesional, tal como se puede ver en la siguiente figura.

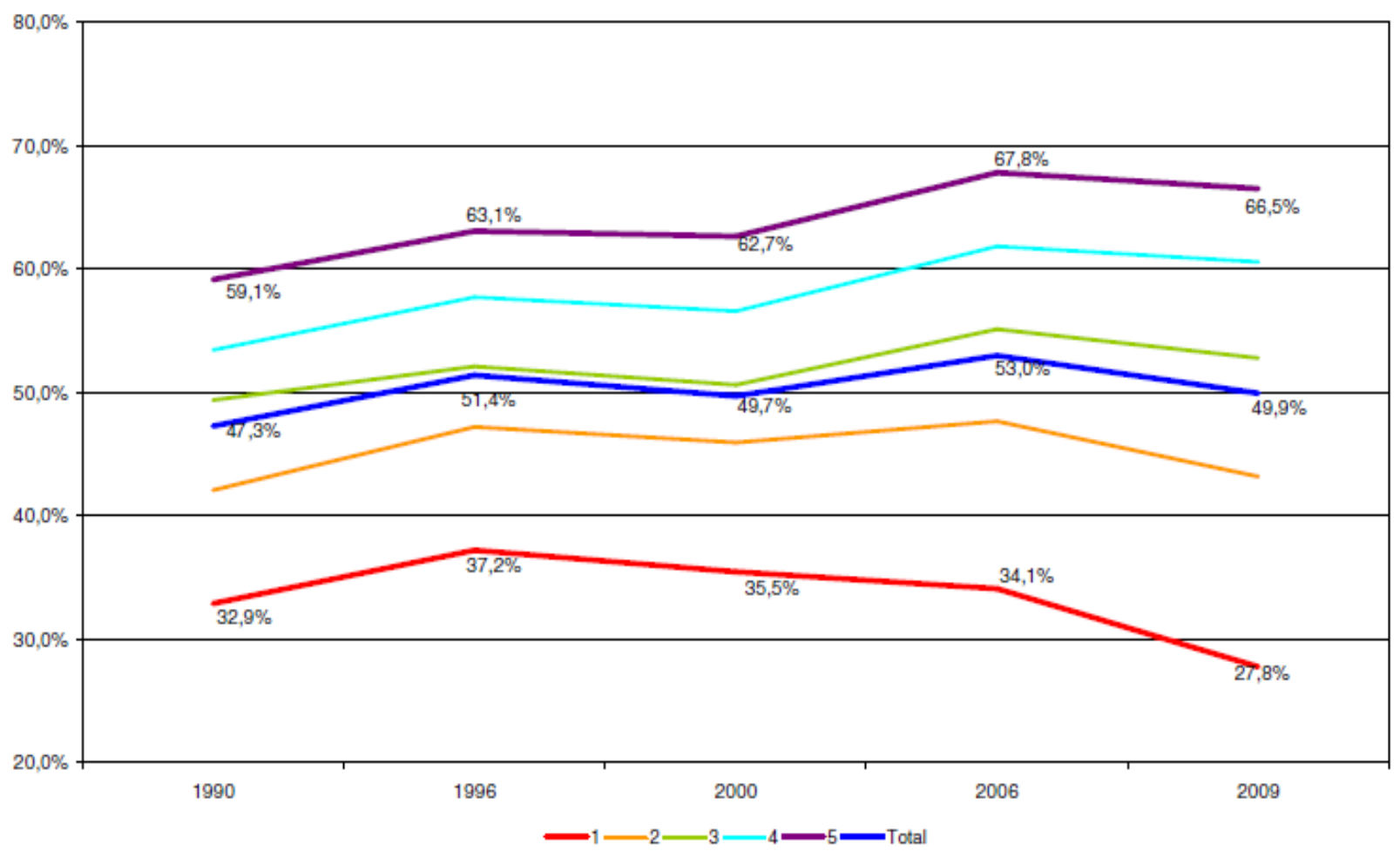

Figura 14. Evolución de Tasa de Empleo por quintil de ingreso - Chile

Fuente: (Rucci, 2011, p. 5)

En concordancia con lo anterior, los niveles de empleo por años de escolaridad adquiridos muestran exactamente el mismo panorama, tanto en los ingresos bajos, medios como en los altos. Esto a razón de que mientras más años de escolaridad se adquiera por parte de un trabajador, esto podrá beneficiarle para estar en un nivel de calificación laboral más alto y que se va a reflejar de forma directa en los ingresos que devengue, mejorando como es comprensible todo su entorno económico y social. 


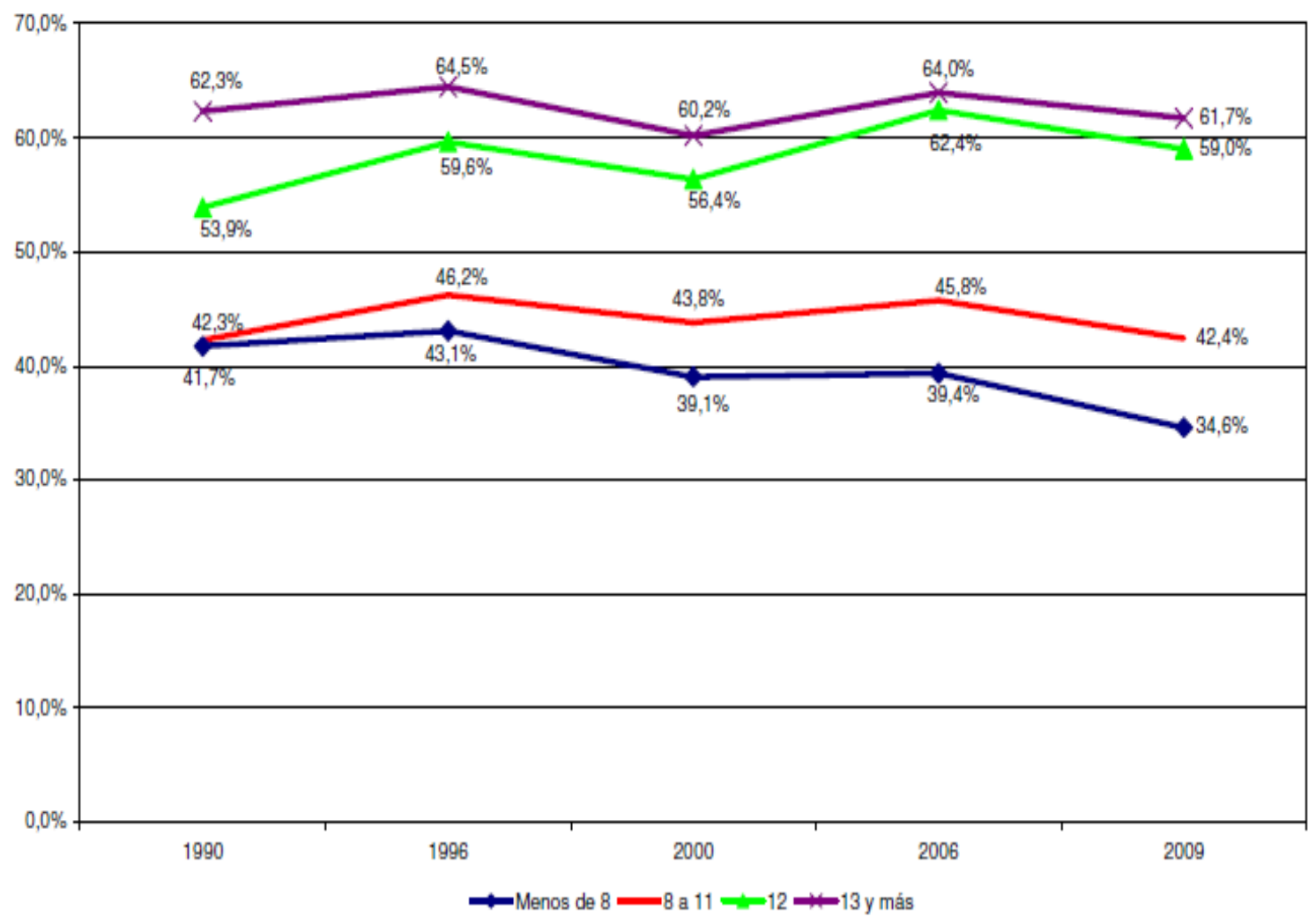

Figura 15. Evolución de Tasa de Empleo por años de escolaridad - Chile

Fuente: (Rucci, 2011, p. 6)

Ya que el mercado laboral de Chile presenta serias deficiencias para articular acciones que permitan atacar los problemas de empleabilidad que existen para poblaciones focalizadas como por ejemplo, las mujeres y los jóvenes, a continuación se presentan los rangos de salario respecto a los años de escolaridad adquiridos tanto en hombres como en mujeres; las diferencias entre uno y otro son notables aun cuando ambas personas tienen los mismos años de escolaridad, el caso más asimétrico se presenta en el umbral de mayores ingresos, en donde un hombre que cuente con 20 años de escolaridad devenga un sueldo de 11.000 por hora, mientras que una mujer con los mismos años de formación educativa gana en promedio 6.500 por hora, lo cual presenta una diferencia de un $40 \%$ en los ingresos de los dos individuos (Echeverría \& López, 2004). 


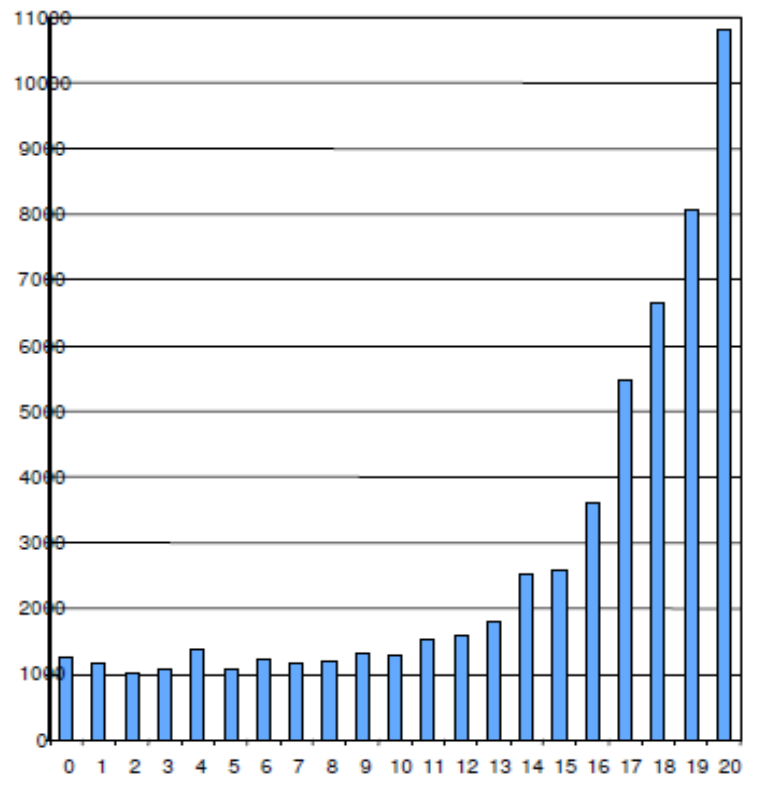

Hombres

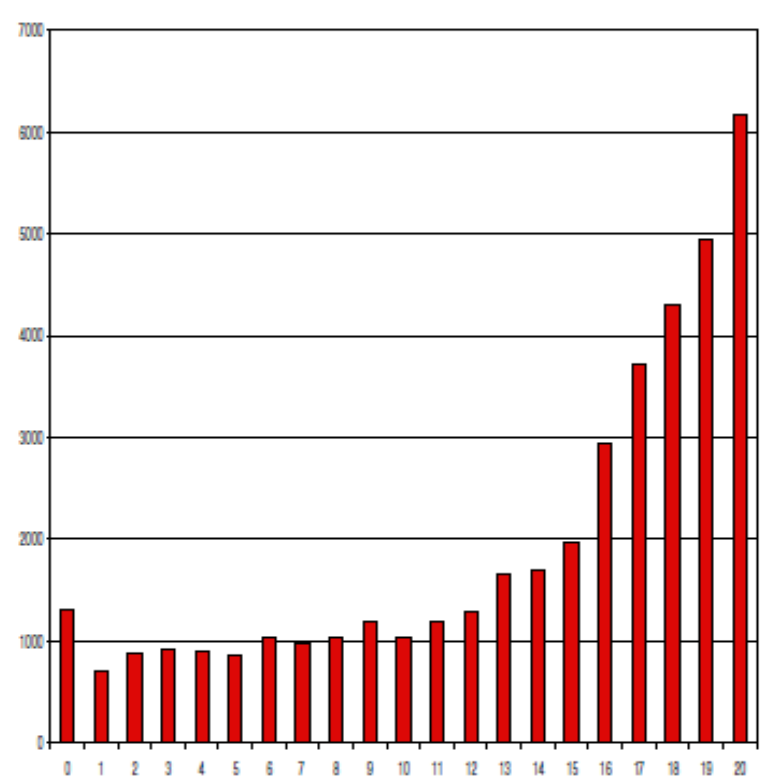

mujeres

Figura 16. Salario por hora según años de escolaridad

Fuente: (Rucci, 2011, p. 7)

Las empresas chilenas se han caracterizado por brindar amplias garantías en prestaciones sociales a sus trabajadores, sin embargo, hace falta impulsar los programas de capacitación laboral y de promoción de empleo que permitan equilibrar las condiciones de accesibilidad del trabajo y también de los niveles de salarios; este tema se aborda con mayor amplitud en la siguiente sección que trata sobre las políticas laborales que existen en Chile.

Entonces, la tasa de desempleo promedio ha venido incrementándose más aceleradamente que el nivel de empleo en Chile, sin embargo, esta situación ha sido subsanada en su mayor parte por el alto grado de crecimiento del PIB y por el auge económico presentado por Chile en los últimos diez años. Por su parte, la tasa de empleo en particular, se mantiene estable hasta el año 2004 en donde comienza a presentar una tendencia decreciente, y en contraste se da un aumento considerable en el nivel de desempleo. 


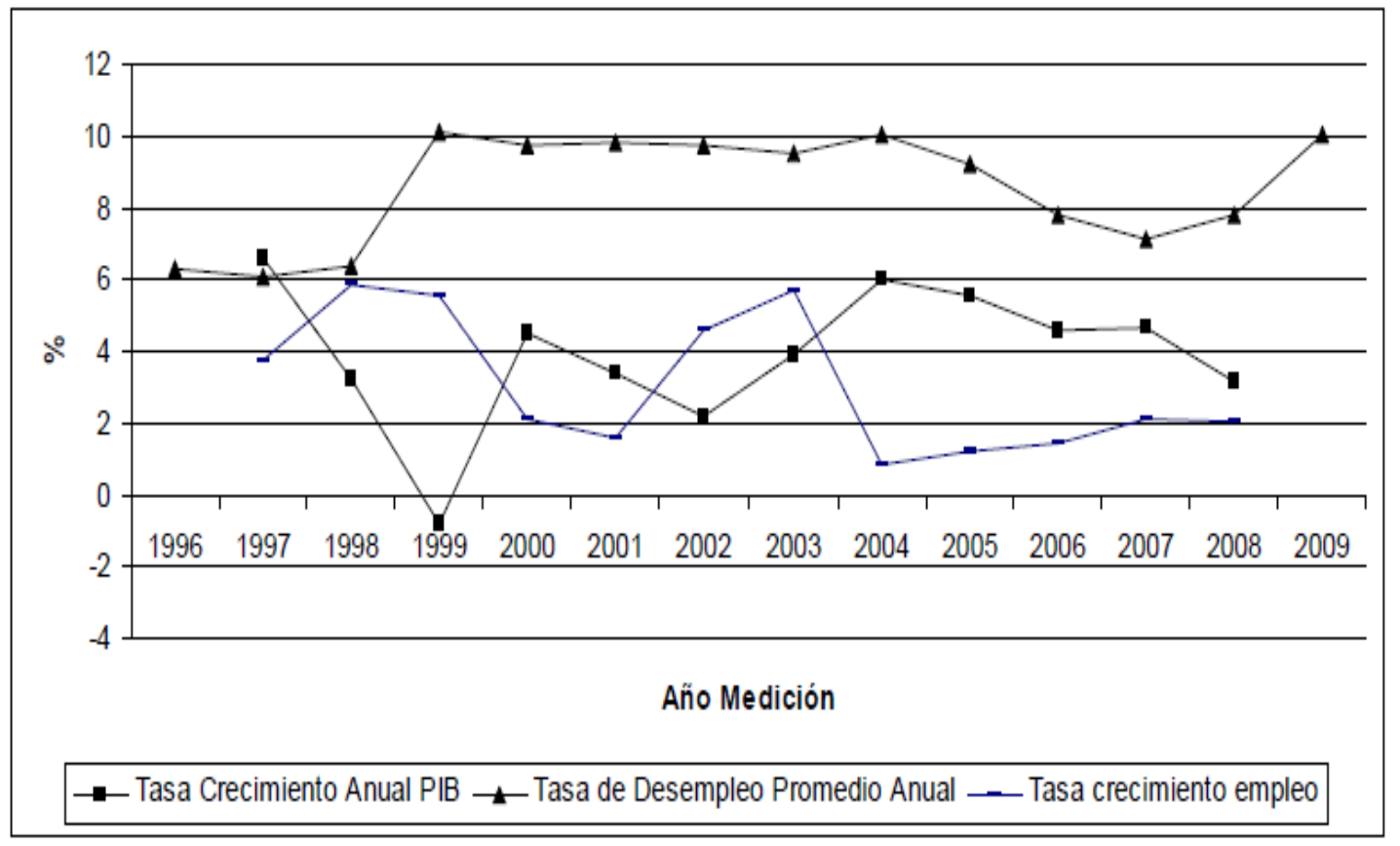

Figura 17. Evolución del PIB, Tasa de Desempleo y nivel de Empleo. Periodo 1996-2009

Fuente: (Perticara \& Celhay, 2010, p. 4)

El contexto latinoamericano del mercado laboral

La región, en su conjunto, está generando empleos a menor ritmo que en años anteriores. En los primeros tres trimestres de 2014, la tasa de ocupación en América Latina (para las urbes) fue del 55,7 \% meramente inferior a lo registrado en el año 2013 con 56,1 \%. En términos de variaciones anuales, la única vez que la tasa de ocupación cayó en la última década fue en 2009, año de la crisis financiera internacional. Para tener una idea de su magnitud, esta reducción implicó que alrededor de un millón de personas dejaron de conseguir un empleo en la región (González \& Huneeus, 2016).

De tal manera, la disminución de la demanda laboral fue contrarrestada por la reducción de la fuerza laboral, con la consecuencia de una caída de la tasa de desocupación, que pasó de 6,5 $\%$ en los primeros tres trimestres de 2013 a 6,2 \% en el mismo periodo de 2014 y 2015.

Tabla 7. América Latina y el Caribe: principales indicadores del mercado laboral urbano, 2004-2014 (porcentajes)

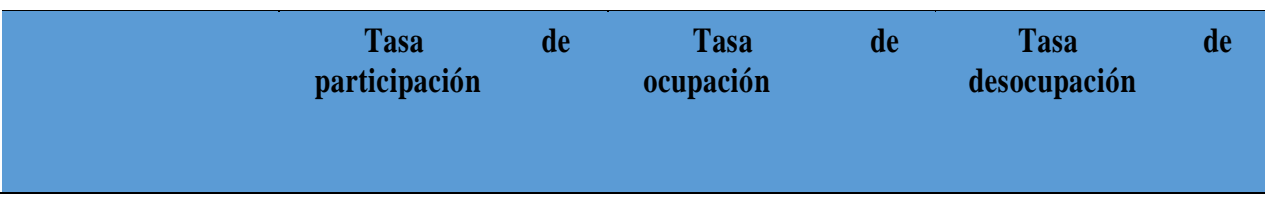




\begin{tabular}{|lrll|} 
& \multicolumn{3}{c}{ Datos anuales } \\
2004 & $\mathbf{5 9 , 6}$ & $\mathbf{5 3 , 5}$ & $\mathbf{1 0 , 3}$ \\
2005 & $\mathbf{5 9 , 2}$ & $\mathbf{5 3 , 9}$ & $\mathbf{9 , 0}$ \\
2006 & $\mathbf{5 9 , 5}$ & $\mathbf{5 4 , 5}$ & $\mathbf{8 , 6}$ \\
2007 & $\mathbf{5 9 . 6}$ & $\mathbf{5 5 , 0}$ & $\mathbf{7 , 9}$ \\
2008 & 59,7 & $\mathbf{5 5 , 4}$ & $\mathbf{7 , 3}$ \\
2009 & $\mathbf{5 9 , 7}$ & $\mathbf{5 4 , 9}$ & $\mathbf{8 , 1}$ \\
2010 & $\mathbf{6 0 , 1}$ & $\mathbf{5 5 , 6}$ & $\mathbf{7 , 3}$ \\
2011 & $\mathbf{6 0 , 3}$ & $\mathbf{5 6 , 2}$ & $\mathbf{6 , 7}$ \\
2012 & $\mathbf{6 0 , 5}$ & $\mathbf{5 6 , 6}$ & $\mathbf{6 , 4}$ \\
2013 & $\mathbf{6 0 , 3}$ & $\mathbf{5 6 , 5}$ & $\mathbf{6 , 2}$ \\
2014 & $\mathbf{5 9 , 9}$ & $\mathbf{5 6 , 2}$ & $\mathbf{6 , 1}$ \\
\hline
\end{tabular}

Fuente: elaboración propia con base en Organización Internacional del Trabajo (2014)

*Se han considerado 16 países: Argentina, Bahamas, Brasil, Chile, Colombia, Costa Rica, Ecuador, Guatemala, Jamaica, México, Panamá, Paraguay, Perú, República Dominicana, Uruguay y Venezuela (Rep. Bol. de).

Las tasas de participación y ocupación se han incrementado en los países del Caribe y América Central, estos se caracterizaron porque presentaron serias dificultades en sus mercados de trabajo en los años posteriores a la crisis internacional sucedida en el año 2008, esto debido a la fuerte relación comercial con los Estados Unidos; así mismo se han benefíciado de la recuperación (repunte) económica que tuvo este país. Una de las principales dificultades económicas se sufrió en los precios de exportación de los principales productos de los países latinoamericanos, y también en la volatilidad de su mercado accionario en el escenario internacional que afectaba indirectamente a los fondos de inversión. 


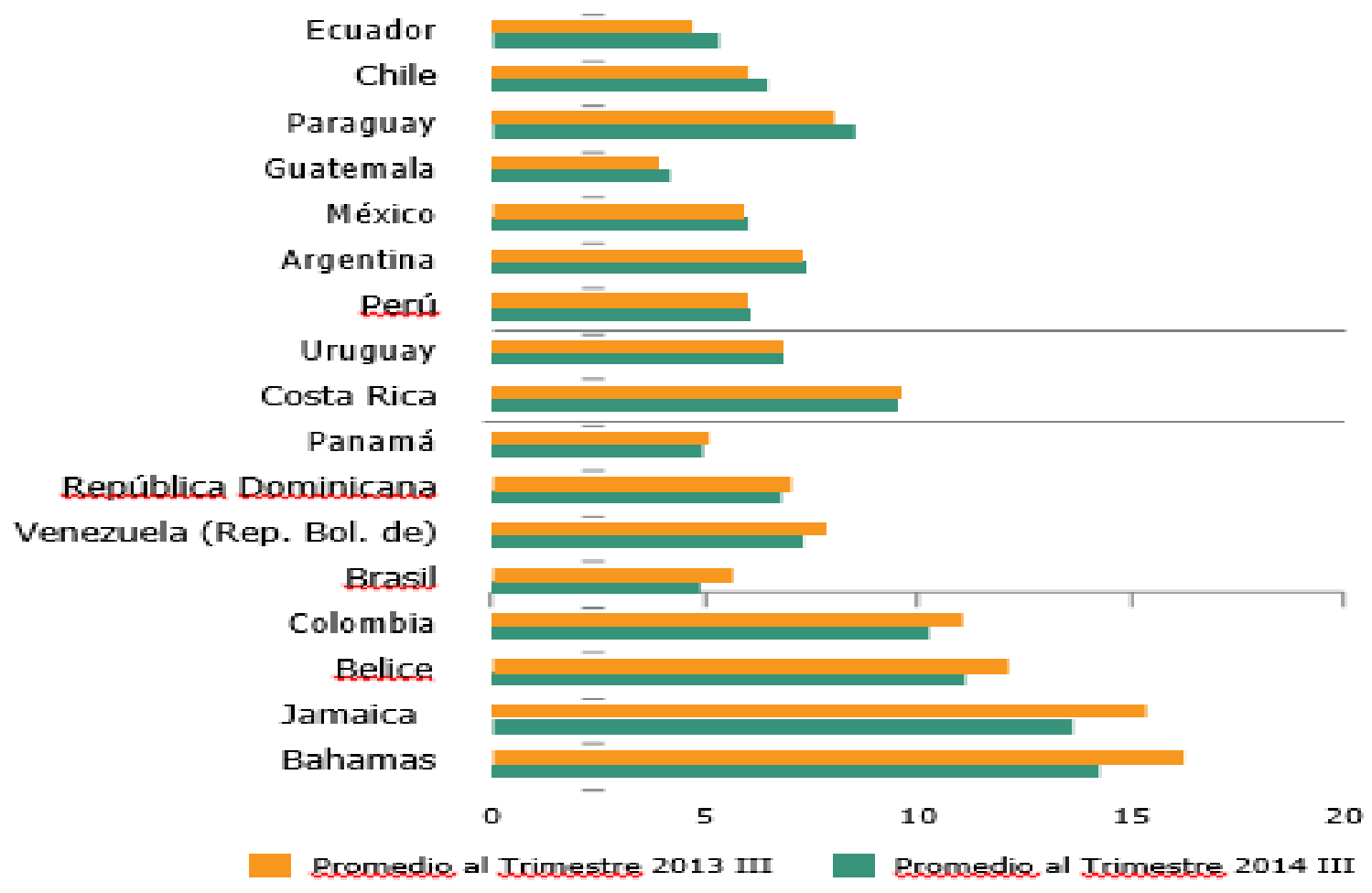

Figura 18. América Latina y el Caribe: tasa de desocupación urbana. Enero a septiembre, 2013 y 2014 (porcentajes)

Fuente: (Organización Internacional del Trabajo, 2014)

En cuanto a las tasas de ocupación se puede ver que hay una subida gradual en el año 2014 respecto al año inmediatamente anterior, esto se dio en 7 de los 17 países tenidos en cuenta: Ecuador $(+0,6 p p)$, Chile (+0,5pp), Paraguay $(+0,5 p p)$, Guatemala $(+0,3 p p)$, México $(+0.1 p p)$, Argentina $(+0,1 \mathrm{pp})$ y Perú $(+0,1 \mathrm{pp})$. En dos países -Uruguay y Costa Rica- el nivel de desempleo se mantuvo sin mayores cambios, y en ocho países el nivel de desempleo descendió, estos fueron: Panamá (-0,1pp), República Dominicana (-0,2pp), la República Bolivariana de Venezuela (-0,5pp), Brasil (-0,7pp), Colombia (-0,8pp), Belice (-1pp), Jamaica (-1,8pp) y Bahamas (-1,9pp).

Igualmente, la tasa de participación también tuvo variaciones entre diversos países. De los 16 países con cuya información se cuenta, la participación cayó en 6 de ellos: Brasil (-1,2pp), Ecuador (-0,7pp), Argentina (-0,7pp), México (-0,6pp), Perú (-0,5pp) y Jamaica (-0,3pp). En los otros 10 países aumentó la participación laboral: Paraguay (+0,2pp), Colombia (+0,2pp), Chile (+0,3pp), Bahamas (+0,4pp), República Bolivariana de Venezuela (+0,7pp), Uruguay (+1,2pp), Costa Rica (+1,3pp), Panamá (+1,4pp), República Dominicana (+1,6pp) y Guatemala 
(+1,8pp). Cabe destacar que en la mayoría de los países la participación laboral aumentó, y esto es algo favorable para la competitividad del mercado laboral pues incentiva a que los gobiernos impulsen programas de contratación a diferentes sectores de la población.

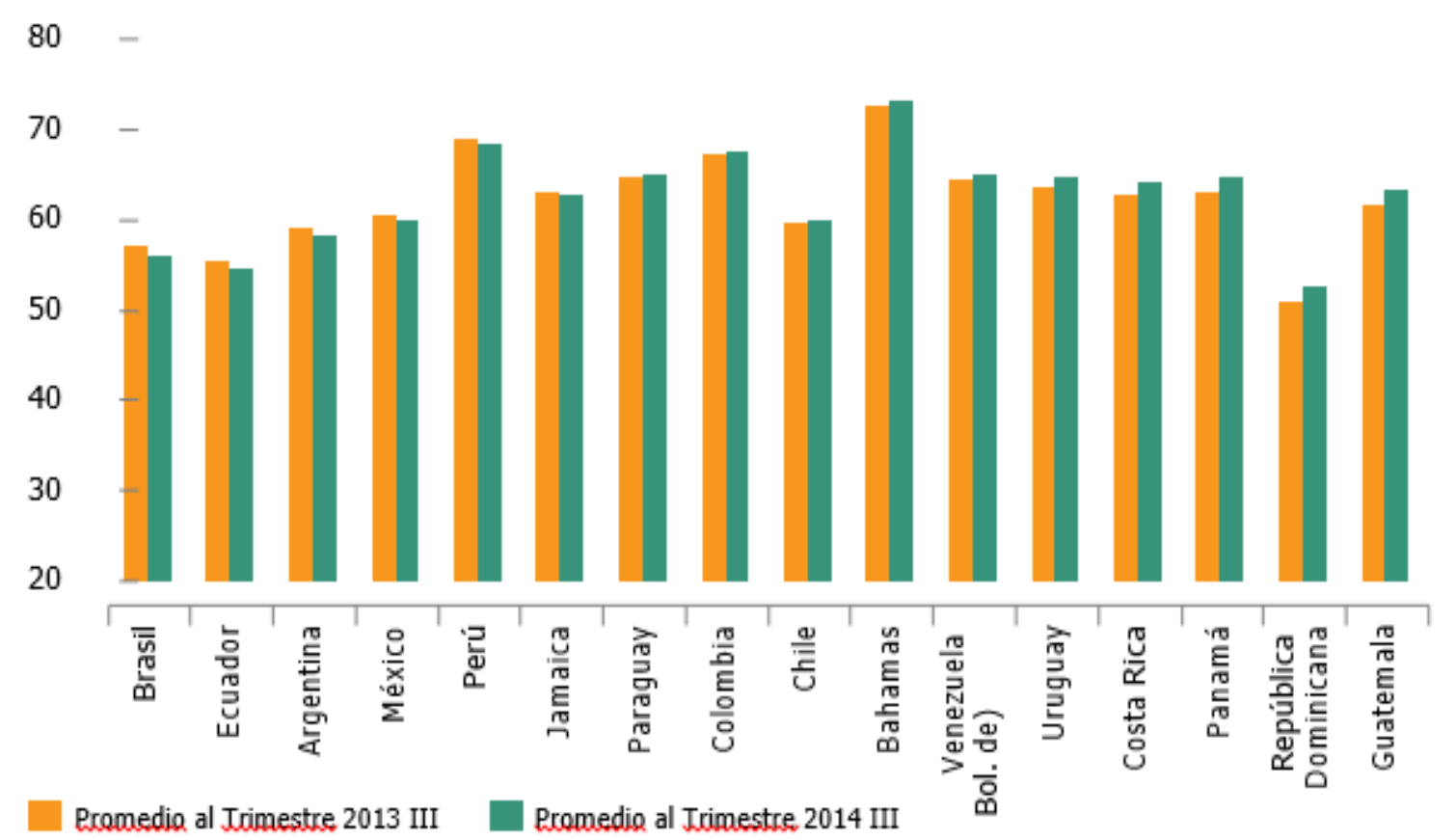

Figura 19. América Latina y el Caribe: Tasa de participación urbana. Enero a septiembre, 2014 y 2013 (porcentajes)

Fuente: (Organización Internacional del Trabajo, 2014)

La evolución de la tasa de ocupación en los países presenta un patrón similar al de la tasa de participación, es decir, va en un ascenso gradual hasta estabilizarse. Es destacable que se ha generado un reducción en el tercer trimestre de 2014, respecto del mismo periodo de 2013, en 6 países del total de naciones evaluadas: Ecuador (-1pp), Brasil (-0,8pp), Argentina (-0,7pp), México (-0,7pp), Perú (-0,5pp) y Paraguay (-0,2pp). En Chile la ocupación se mantuvo estable, mientras que en nueve países ha aumentado: Colombia (+0,7pp), Jamaica (+0,9pp), República Bolivariana de Venezuela (+1pp), Uruguay (+1,1pp), Costa Rica (+1,2pp), Panamá $(+1,4 p p)$, Guatemala (+1,6pp), República Dominicana (+1,6pp) y Bahamas (+1,7pp). 


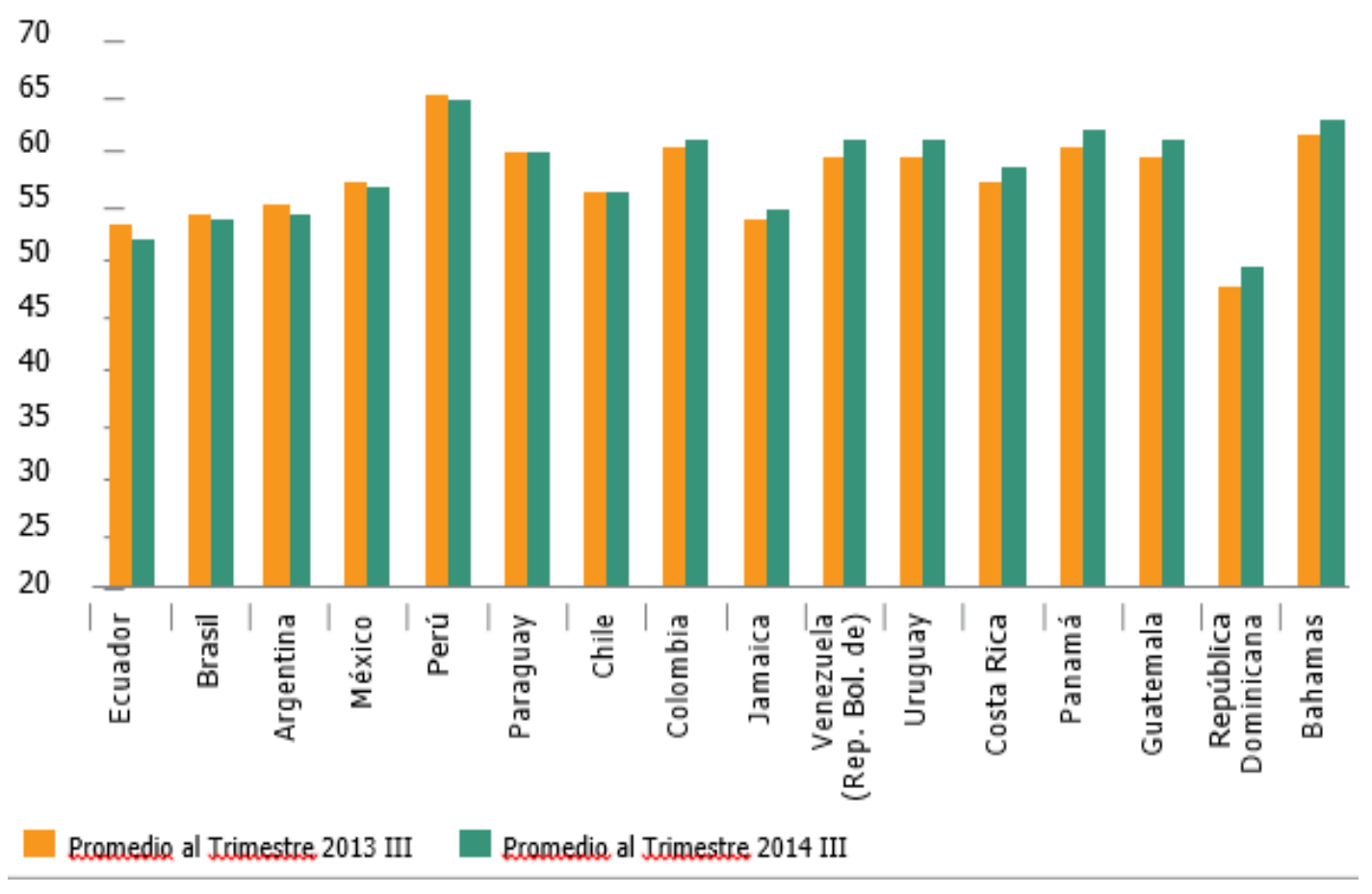

Figura 20. América Latina y el Caribe: Tasa de ocupación urbana. Enero a septiembre, 2014 y 2013 (porcentajes)

Fuente: (Organización Internacional del Trabajo, 2014)

En general, los cambios en el nivel de la desocupación son producto del resultado de dos factores esenciales, uno que se relaciona directamente proporcional a los cambios en la tasa de participación causando una presión alta a los niveles de desempleo, y otro inverso que al caer la tasa de ocupación produce alzas inmediatas en el nivel de desempleo (Organización Internacional del Trabajo, 2014).

Si se examinan estos indicadores por género y por grupos etarios, la evolución de estos indicadores ha sido diversa en cada país. Por ejemplo, en Paraguay, Panamá y Costa Rica se redujo la tasa de desocupación masculina, pero la femenina aumentó; el caso opuesto ocurrió en Perú, México y República Dominicana, donde se produjo un notorio aumento de la desocupación masculina y un decrecimiento en la femenina. Por su parte, en Ecuador y Guatemala, el aumento de la desocupación se dio tanto en los hombres como en las mujeres y no se presentó una diferencia significativa entre un género y otro.

En Ecuador, Chile y Guatemala se dio un aumento tanto en la desocupación de jóvenes como la de adultos; en Panamá y Costa Rica hay un aumento en el desempleo juvenil, pero el de adultos decreció considerablemente como se puede ver en la siguiente tabla. 
Tabla 8. América Latina: principales indicadores del mercado laboral urbano por sexo. Enero a septiembre, 2013 y 2014 (porcentajes)

\begin{tabular}{|c|c|c|c|c|c|c|c|c|c|c|c|c|c|c|}
\hline \multirow{3}{*}{ Países } & \multicolumn{4}{|c|}{ TASA DE PARTICIPACIÓN } & \multicolumn{5}{|c|}{ TASA DE OCUPACIÓN } & \multicolumn{4}{|c|}{ TASA DE DESOCUPACIÓN } & \\
\hline & \multicolumn{2}{|c|}{ Total } & Hombres & Mujer & \multicolumn{2}{|c|}{ Total } & \multirow{2}{*}{$\begin{array}{l}\text { Hombres } \\
201201 \\
\end{array}$} & \multicolumn{2}{|c|}{ Mujer } & \multicolumn{2}{|c|}{ Total } & $\begin{array}{l}\text { Hombre } \\
\text { s }\end{array}$ & \multirow{2}{*}{$\begin{array}{r}\text { Mujer } \\
2013\end{array}$} & \\
\hline & 2013 & 2014 & 2013201 & 20132014 & 2013 & 2014 & & 201 & 2014 & 2013 & 32014 & 2012014 & & 2014 \\
\hline Argentina & 58,9 & 58,2 & 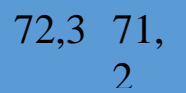 & $47,1 \quad 46,5$ & 54,6 & 53,9 & $\begin{array}{l}67,66,7 \\
5\end{array}$ & 42,9 & 42,5 & 7,3 & 7,4 & $6,6 \quad 6,5$ & 9,0 & 8,6 \\
\hline Brasil & 61,3 & 61,1 & $73,0 \quad 72$ & $50,7 \quad 50,6$ & 56,6 & 56,8 & $68,68,4$ & 45,9 & 46,3 & 7,7 & 7,0 & $6,2 \quad 5,9$ & 9,6 & 8,5 \\
\hline Chile & 59,4 & 59,7 & 71,7 71, & $47,5 \quad 48,3$ & 55,8 & 55,8 & $67,67,1$ & 44,2 & 44,9 & 6,0 & 6,5 & $5,3 \quad 6,2$ & 7,0 & 7,0 \\
\hline Colombi & 63,9 & 63,8 & $\underset{1}{74,6} \underset{1}{74}$ & $53,7 \quad 53,7$ & 57,4 & 57,8 & $\begin{array}{l}68,69,0 \\
7\end{array}$ & 46,6 & 47,1 & 10,1 & 9,4 & $7,8 \quad 7,3$ & 13,2 & 12,3 \\
\hline Costa & 62,0 & 62,7 & $75,1 \quad 76$ & $48,8 \quad 49,2$ & 56,0 & 56,7 & $68,69,9$ & 43,0 & 43,3 & 9,7 & 9,6 & $8,4 \quad 8,1$ & 11,8 & 12,0 \\
\hline Ecuador & 55,2 & 54,5 & 67,366 & $44,2 \quad 43,1$ & 52,7 & 51,6 & $64,63,5$ & 41,9 & 40,4 & 4,7 & 5,3 & $4,3 \quad 4,7$ & 5,2 & 6,2 \\
\hline Jamaica & 63,1 & 62,8 & $70,0 \quad 70$ & $56,4 \quad 55,9$ & 53,4 & 54,3 & $62,62,9$ & 45,1 & 46,0 & 15,4 & 13,6 & $11, \quad 10,2$ & 20,1 & 17,7 \\
\hline Guatemala & 61,5 & 63,3 & 80,180 & $45,4 \quad 48,8$ & 59,1 & 60,6 & $77,77,1$ & 43,4 & 46,5 & 3,9 & 4,2 & $3,7 \quad 3,8$ & 4,3 & 4,8 \\
\hline México & 58,9 & 58,6 & $76,7 \quad 76$ & $42,8 \quad 42,2$ & 56,0 & 55,6 & $72,72,8$ & 40,7 & 40,1 & 5,0 & 5,0 & $5,0 \quad 5,0$ & 5,1 & 5,0 \\
\hline Panamá & 63,0 & 64,5 & $76,7 \quad 77$ & $50,952,9$ & 59,8 & 61,2 & $73,74,3$ & 48,1 & 49,7 & 5,1 & 5,0 & $4,9 \quad 4,2$ & 5,4 & 6,1 \\
\hline Paraguay & 64,9 & 65,1 & 72,674 & $57,656,2$ & 59,7 & 59,6 & $67,69,7$ & 52,1 & 50,1 & 8,0 & 8,5 & $6,9 \quad 6,6$ & 9,5 & 10,8 \\
\hline Perú & 68,9 & 68,4 & 77,977 & $60,459,8$ & 64,7 & 64,2 & $74,73,6$ & 56,0 & 55,5 & 6,0 & 6,1 & $5,0 \quad 5,3$ & 7,3 & 7,2 \\
\hline Dominicana & 51,0 & 52,6 & $\begin{array}{c}64,1 \begin{array}{l}65 \\
0\end{array} \\
0\end{array}$ & $37,939,4$ & 47,4 & 49,0 & $\begin{array}{l}60,62,5 \\
0\end{array}$ & 34,0 & 35,6 & 7,0 & 6,8 & $5,0 \quad 5,1$ & 10,4 & 9,6 \\
\hline Uruguay & 63,5 & 64,6 & $73,8 \quad 74$ & $54,2 \quad 55,9$ & 59,3 & 60,3 & $70,70,3$ & 49,7 & 51,2 & 6,5 & 6,5 & $5,1 \quad 5,1$ & 8,3 & 8,3 \\
\hline Venezuela & 64,3 & 65,0 & $78,0 \quad 78$ & $50,9 \quad 51,4$ & 59,3 & 60,3 & $72,73,6$ & 46,5 & 47,2 & 7,9 & 7,3 & $7,3 \quad 6,8$ & 8,7 & 8,1 \\
\hline
\end{tabular}

Fuente: elaboración propia con base en Organización Internacional del Trabajo (2014) 
Tabla 9. América Latina: principales indicadores del mercado laboral urbano por grupos etarios. Enero a septiembre, 2013 y 2014 (porcentajes)

\begin{tabular}{|c|c|c|c|c|c|c|c|c|c|c|c|c|}
\hline \multirow{3}{*}{ Países } & \multicolumn{4}{|c|}{ TASA DE PARTICIPACIÓN } & \multicolumn{4}{|c|}{ TASA DE OCUPACIÓN } & \multicolumn{4}{|c|}{ TASA DE DESOCUPACIÓN } \\
\hline & \multicolumn{2}{|c|}{15 - 24 años } & \multicolumn{2}{|c|}{25 años a más } & \multicolumn{2}{|c|}{15 - 24 años } & \multicolumn{2}{|c|}{25 años a más } & \multicolumn{2}{|c|}{15 - 24 años } & \multicolumn{2}{|c|}{25 años a más } \\
\hline & 2013 & 2014 & 2013 & 2014 & 2013 & 2014 & 2013 & 2014 & 2013 & 2014 & 2013 & 2014 \\
\hline $\begin{array}{l}\text { Total } \\
\text { países b/ }\end{array}$ & 47,9 & 46,5 & 66,2 & 65,7 & 41,0 & 40,0 & 63,2 & 62,8 & 14,5 & 14,0 & 4,6 & 4,3 \\
\hline Argentina & 40,8 & 38,7 & 65,7 & 65,7 & 32,6 & 31,5 & 62,1 & 62,2 & 20,1 & 18,7 & 5,4 & 5,3 \\
\hline Brasil & 52,9 & 50,1 & 64,0 & 62,4 & 45,3 & 43,2 & 61,5 & 60,4 & 14,5 & 13,9 & 3,9 & 3,3 \\
\hline Chile & 36,2 & 36,1 & 65,5 & 65,8 & 30,5 & 30,1 & 62,5 & 62,5 & 15,7 & 16,5 & 4,6 & 5,1 \\
\hline Colombia $\mathrm{d} /$ & 62,2 & 62,3 & 69,9 & 70,2 & 50,7 & 51,3 & 64,4 & 65,1 & 18,5 & 17,7 & 7,9 & 7,2 \\
\hline Costa Rica & 48,2 & 50,2 & 67,1 & 68,0 & 36,8 & 36,8 & 62,7 & 63,8 & 23,7 & 26,5 & 6,6 & 6,1 \\
\hline Ecuador & 39,7 & 37,6 & 69,1 & 70,3 & 34,1 & 31,9 & 67,0 & 67,6 & 14,3 & 15,2 & 3,0 & 3,8 \\
\hline Guatemala e/ & 48,9 & 49,6 & 67,5 & 69,2 & 45,4 & 45,6 & 65,6 & 67,2 & 7,3 & 8,0 & 2,8 & 3,0 \\
\hline Jamaica & 34,9 & 33,3 & 74,1 & 74,4 & 21,7 & 22,0 & 65,8 & 66,9 & 37,8 & 34,1 & 11,2 & 10,0 \\
\hline México & 43,0 & 42,3 & 64,8 & 64,5 & 38,9 & 38,3 & 62,2 & 62,0 & 9,5 & 9,5 & 3,9 & 3,9 \\
\hline Panamá & 42,2 & 43,7 & 69,5 & 70,7 & 36,5 & 37,2 & 67,0 & 68,4 & 13,6 & 15,0 & 3,6 & 3,2 \\
\hline Perú & 51,5 & 49,3 & 76,7 & 77,0 & 44,7 & 42,5 & 73,7 & 74,0 & 13,2 & 13,7 & 3,9 & 3,9 \\
\hline $\begin{array}{l}\text { Rep. } \\
\text { Dominicana } \\
\text { g/ }\end{array}$ & 40,9 & 42,1 & 64,6 & 65,7 & 34,1 & 36,5 & 61,5 & 62,3 & 16,7 & 13,3 & 4,8 & 5,3 \\
\hline Uruguay & 48,8 & 48,2 & 67,5 & 69,1 & 38,8 & 38,4 & 64,6 & 66,0 & 20,4 & 20,4 & 4,2 & 4,4 \\
\hline $\begin{array}{l}\text { Venezuela } \\
\text { Rep. Bol. } \\
\text { de) } \mathrm{h} /\end{array}$ & 40,8 & 41,3 & 72,2 & 72,7 & 33,9 & 34,9 & 67,8 & 68,6 & 17,0 & 15,5 & 6,1 & 5,8 \\
\hline
\end{tabular}

Fuente: elaboración propia con base en Organización Internacional del Trabajo (2014) 
Los datos anteriores muestran que las mujeres y los jóvenes son más susceptibles a los cambios en las condiciones económicas del mercado, esto quiere decir que el impacto que genera el cambio de actividad laboral o un periodo de desempleo corto es mucho más significativo para estos grupos poblacionales. Cabe destacar que las mujeres habían venido aumentando su tasa de participación en las últimas décadas, lo que contribuye a la reducción de la pobreza, puesto que el hecho de que la mujer tenga opciones laborales incide de forma positiva en los hogares aumentando los ingresos y la calidad de vida del núcleo familiar. Esto hace suponer que la reducción en la participación laboral de las mujeres podría ser coyuntural, por lo que no debería continuar a la baja en los próximos años (Perticara \& Celhay, 2010).

Sin embargo, a pesar de la leve reducción evidenciada en 2014, la magnitud de las brechas en el desempleo para jóvenes y mujeres sigue siendo muy significativa. La tasa de desempleo de las mujeres es $30 \%$ más alta que la de los hombres, y la tasa de participación es un $30 \%$ más baja. En el caso de los jóvenes, las diferencias son muy notorias: la tasa de desempleo de la población de 15 a 24 años en los países de América Latina es entre 2 y 4,3 veces superior a la tasa de desocupación de los adultos de 25 años y más; los jóvenes desempleados representan más del $40 \%$ del total de los desempleados de la región. Esto no sería un problema grave si se considera que entre los desempleados jóvenes se encuentran tanto cesantes como personas que buscan trabajo por primera vez.

No obstante, "los prolongados y altos niveles de desempleo juvenil, así como una inserción laboral precaria, resultan en varios efectos negativos sociales y económicos" (Suárez, 2015, párr. 6).

De otro lado, los salarios de los trabajadores formales permiten analizar la evolución de las economías de la región, y aquí se presenta un pequeño repunte inflacionario que ha incidido para que haya una desaceleración del crecimiento de los salarios reales del sector formal, que aumentaron en 2014 menos vigorosamente que en 2013; claro está, contando con las excepciones de Nicaragua, Costa Rica, México y Uruguay. Los salarios formales reales se comportaron en la región así: crecieron en Brasil, Chile, Costa Rica, Nicaragua y Uruguay, en rangos que varían entre 1,6 \% y $3.1 \%$; mientras que en Colombia, México y Paraguay, el poder adquisitivo de los salarios se mantuvo prácticamente constante. 


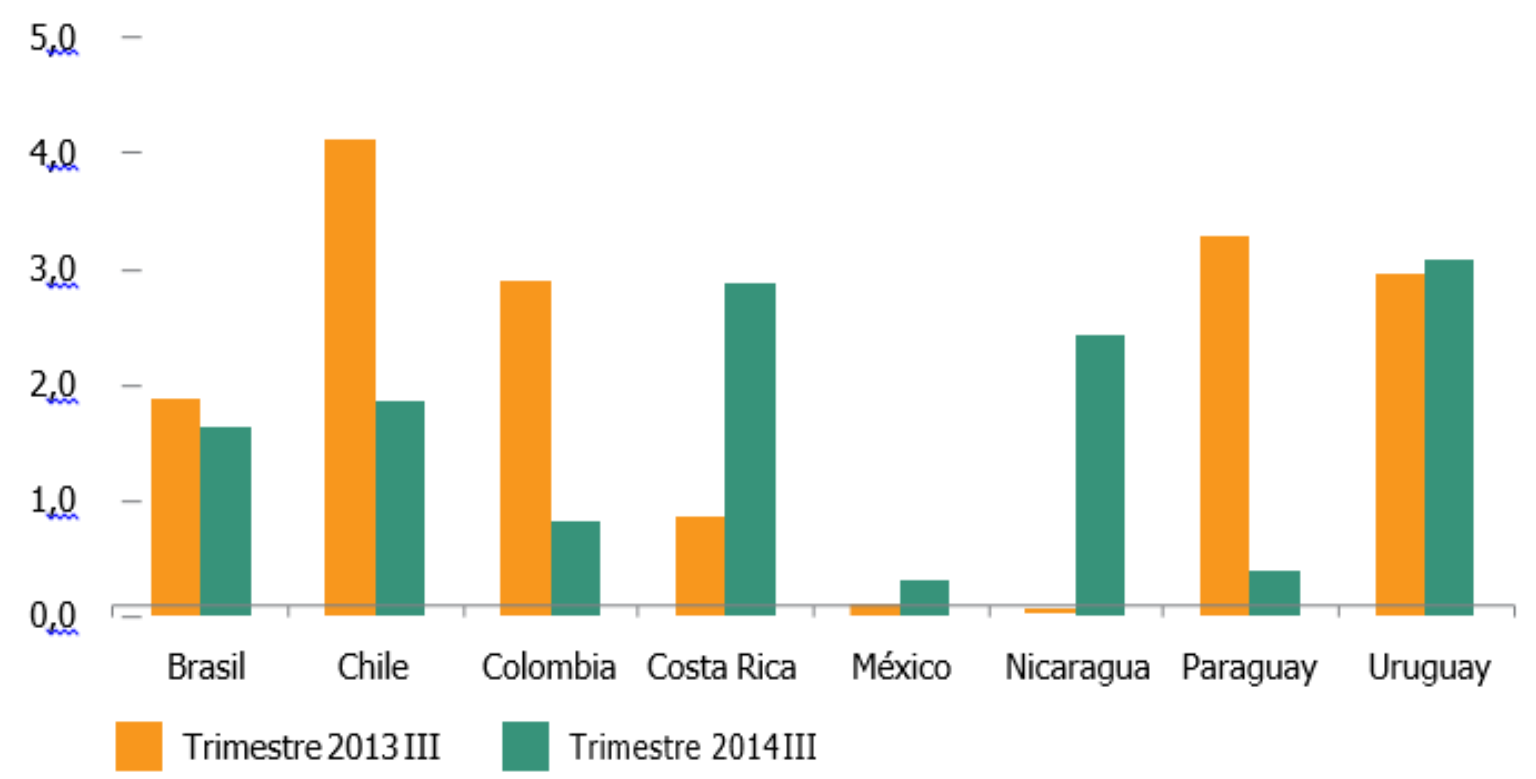

Figura 21. América Latina: variación interanual del salario real medio en el sector formal, 2013 III y 2014 III (porcentajes)

Fuente: (Organización Internacional del Trabajo, 2014)

Durante la crisis de 2008-2009 y en la fase inmediatamente posterior que significó recuperación, muchos países de América Latina utilizaron la política de salarios mínimos como medida de impulso al consumo de los hogares; esto contribuyó a generar un mayor dinamismo en los mercados laborales y en la economía en general.

Más tarde, para el año 2014 la región latinoamericana presentó un aumento en los salarios mínimos para la mayoría de países, aunque ha habido una desaceleración en el último año. Por ello se han realizado reajustes a las políticas del salario mínimo para evitar que este se vea afectado por un potencial aumento de la inflación como consecuencia del aumento de precios en los alimentos (sobre todo los de tipo exportación), lo que podría frenar el crecimiento gradual del salario. Solo en cuatro de los 17 países de la región, el salario mínimo tuvo una disminución al tercer trimestre de 2014: El Salvador, Perú, República Dominicana y Honduras. En los tres primeros casos, no se presentó ningún reajuste al salario.

Es importante destacar que las políticas orientadas a favorecer la calidad del empleo de los trabajadores dependientes se diferencian bastante de las que pretenden mejorar las condiciones salariales de los independientes, y en especial el sector agrícola familiar. En el caso de los asalariados rurales, el sistema de salarios mínimos podría ayudar a aumentar la remuneración 
de la población de menores ingresos, así como a la tasa de protección social en salud que indica una tendencia muy positiva.

Tabla 10. América Latina y el Caribe. Principales indicadores del mercado laboral por ámbito geográfico según sexo y país. Año 2013 o último año disponible (porcentajes)

\begin{tabular}{|c|c|c|c|c|c|c|}
\hline & \multicolumn{2}{|c|}{$\begin{array}{c}\text { Tasa de } \\
\text { participación }\end{array}$} & \multicolumn{2}{|c|}{$\begin{array}{l}\text { Tasa de } \\
\text { ocupación }\end{array}$} & \multicolumn{2}{|c|}{$\begin{array}{c}\text { Tasa de } \\
\text { desocupación }\end{array}$} \\
\hline & Urban & Rural & Urban & Rur & Urban & Rural \\
\hline \multicolumn{7}{|l|}{ Hombres } \\
\hline Argentina & 66,2 & $\ldots$ & 62,1 & $\cdots$ & 6,1 & $\ldots$ \\
\hline Bolivia (Estado Plur. & 69,1 & 86,4 & 66,9 & 85 & 3,1 & 0,7 \\
\hline Brasil & 69,4 & 73,7 & 65,5 & 72 & 5,5 & 2,2 \\
\hline Chile & 71,3 & $\mathbf{7 4 , 5}$ & 67,4 & 71 & 5,5 & 3,8 \\
\hline Colombia & 74,2 & 74,6 & 67,5 & 72 & 9,0 & 3,3 \\
\hline Costa Rica & 75,4 & 76,1 & 70,2 & 70 & 6,9 & 7,1 \\
\hline Ecuador & 65,1 & 69,3 & 62,5 & 67 & 4,0 & 2,2 \\
\hline El Salvador & 77,6 & 85,9 & 72,3 & 80 & 6,8 & 6,9 \\
\hline Guatemala & 79,8 & 87,2 & 76,7 & 85 & 3,9 & 1,6 \\
\hline Honduras & 66,1 & 77,2 & 62,3 & 76 & 5,7 & 1,6 \\
\hline México & 75,5 & 78,4 & 70,9 & 75 & 6,0 & 4,0 \\
\hline Nicaragua & 74,2 & 78,8 & 68,6 & 76 & 7,5 & 2,5 \\
\hline Panamá & 77,6 & 84,2 & 74,5 & 82 & 3,9 & 2,1 \\
\hline Paraguay & 70,6 & 78,3 & 66,5 & 76 & 5,8 & 2,8 \\
\hline Perú & 80,2 & 87,6 & 76,9 & 86 & 4,1 & 1,1 \\
\hline República Dominicana & 64,5 & 64,7 & 60,9 & 62 & 5,6 & 3,8 \\
\hline Uruguay & 73,4 & 76,3 & 69,4 & 74 & 5,4 & 3,0 \\
\hline \multicolumn{7}{|l|}{ Mujeres } \\
\hline Argentina & 43,8 & $\cdots$ & 40,1 & $\cdots$ & 8,5 & $\cdot$ \\
\hline Bolivia (Estado Plur. & 50,9 & 71,9 & 48,5 & 71 & 4,7 & 0,8 \\
\hline Brasil & 50,7 & 46,3 & 46,1 & 44 & 9,1 & 4,5 \\
\hline Chile & 48,8 & 39,8 & 45,4 & 37 & 7,0 & 5,8 \\
\hline Colombia & 58,1 & 39,5 & 50,8 & 35 & 12,5 & 10,9 \\
\hline Costa Rica & 49,5 & 37,1 & 44,6 & 32 & 10,0 & 12,9 \\
\hline Ecuador & 42,5 & 41,3 & 39,9 & 39 & 6,1 & 3,7 \\
\hline El Salvador & 55,1 & 38,2 & 52,8 & 35 & 4,2 & 6,0 \\
\hline
\end{tabular}




\begin{tabular}{lllllll} 
Guatemala & 46,3 & 34,4 & 44,6 & 33, & 3,7 & 3,7 \\
Honduras & 44,7 & 29,6 & 41,9 & 28, & 6,3 & 2,9 \\
México & 48,1 & 38,6 & 45,2 & 37, & 5,9 & 3,8 \\
Nicaragua & 60,9 & 55,1 & 56,5 & 52, & 7,1 & 4,7 \\
Panamá & 51,9 & 43,2 & 49,0 & 41, & 5,7 & 4,0 \\
Paraguay & 54,6 & 47,2 & 51,3 & 44, & 6,1 & 4,9 \\
Perú & 62,6 & 72,0 & 59,1 & 70, & 5,6 & 1,5 \\
República Dominicana & 40,7 & 31,7 & 36,4 & 28, & 10,6 & 9,7 \\
Uruguay & 55,3 & 49,3 & 50,8 & 45, & 8,3 & 7,9 \\
\hline
\end{tabular}

Fuente: elaboración propia con base en Organización Internacional del Trabajo (2014) 
Tabla 11. Tasa de desocupación promedio en Chile años 2006-2010

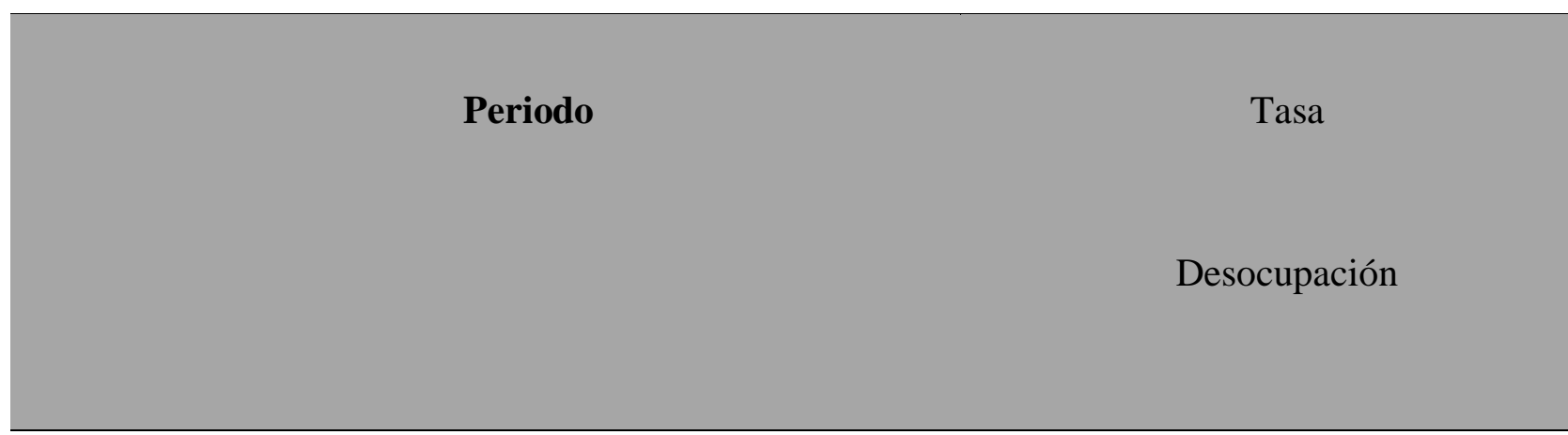

2006

Dic-Feb

7,7

2010

Dic-Feb

8,5

Fuente: elaboración propia con base en Instituto Nacional de Estadística (s.f.)

El nivel de empleo en Chile se vio afectado (en menor medida y de forma indirecta) por la crisis económica que inició en Norteamérica en el año 2008, a raíz del grave problema de endeudamiento hipotecario que enfrentó Estados Unidos.

Se tomaron estos dos periodos porque revelan el antes y el después de la Reforma Previsional de Chile ocurrida en el año 2008, y lo que hasta ahora se ha podido observar y mostrar en este documento es que los años 2006 y 2010 tienden a tener marcadas diferencias sobre todo en términos del nivel de empleo y del impacto que este tiene en las cotizaciones al sistema pensional de Chile. 
Tabla 12. Remuneración salarial mínima pagada a trabajadores 2006 - 2009

\begin{tabular}{|c|c|c|c|}
\hline \multicolumn{4}{|c|}{ REMUNERACIONES MÍNIMAS PAGADAS A TRABAJADORES } \\
\hline PERIODO & Ingreso & Ingreso mínimo & Ingreso mínimo \\
\hline & mínimo no & Imponible & Laboral \\
\hline & remuneracional & de Empleadas & Menores de 18 años \\
\hline & & de Casas Particulares & Mayores de 65 años \\
\hline 2009 & 106.435 & 131.970 & 123.176 \\
\hline 2008 & 102.558 & 119.250 & 118.690 \\
\hline 2007 & 92.897 & 108.000 & 107.509 \\
\hline 2006 & 87.697 & 101.250 & 101.491 \\
\hline
\end{tabular}

Fuente: elaboración propia con base en Instituto Nacional de Estadística (s.f.)

El aumento de los salarios mínimos en Chile ha sido gradual, no ha percibido un golpe tan fuerte como el nivel de empleo producto de los cambios económicos sucedidos entre los años 2006 y 2010. Los sectores presentados anteriormente fueron seleccionados por ser sectores que en el mercado laboral no gozan de garantías suficientes para desempeñar su labor diaria, lo cual conlleva a una alta rotación de personal en las empresas y a una constante intermitencia en los ingresos de los trabajadores. 


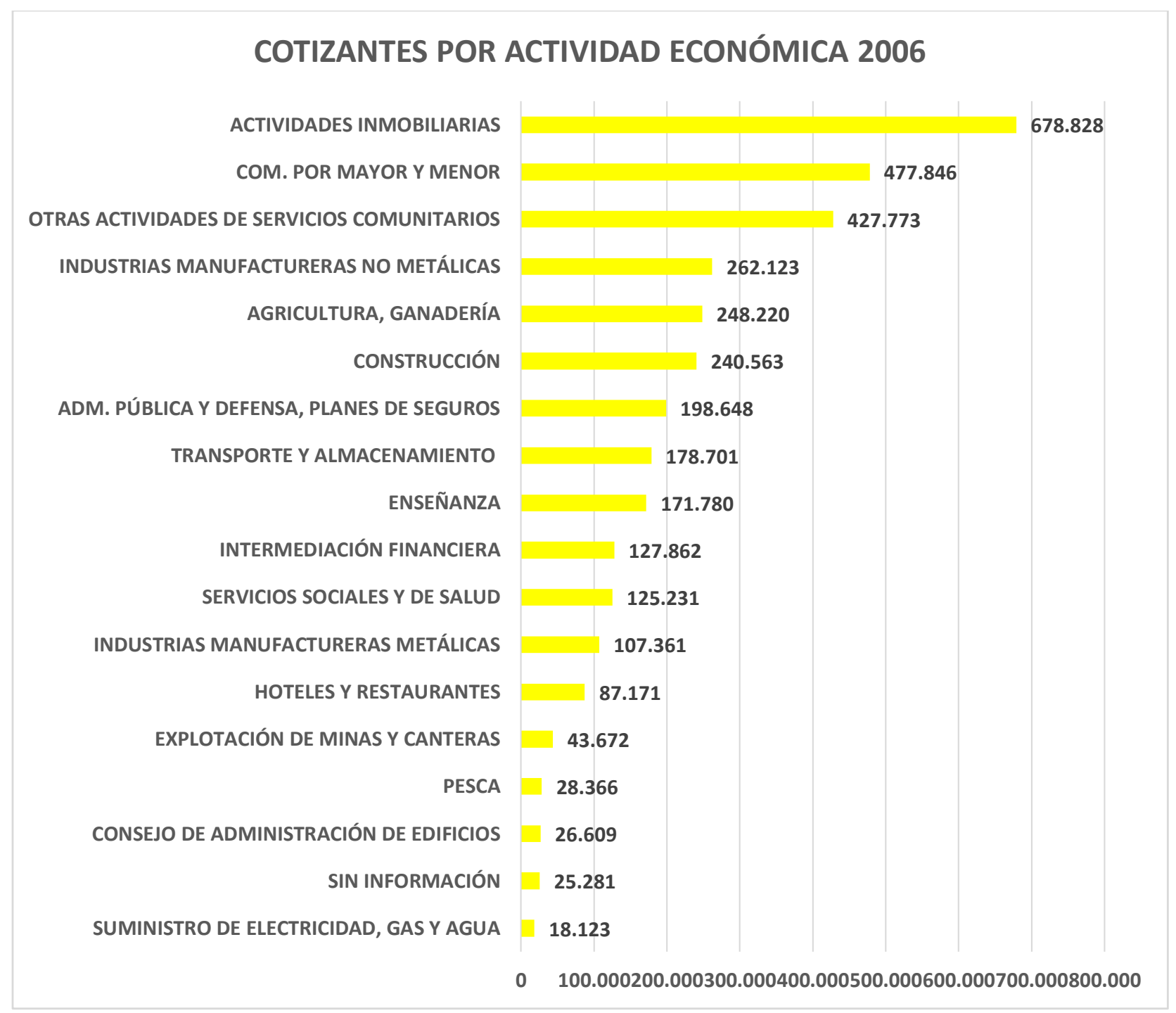

Figura 22. Cotizantes por actividad económica al sistema pensional 2006

Fuente: elaboración propia con base en Instituto Nacional de Estadística (s.f.) 


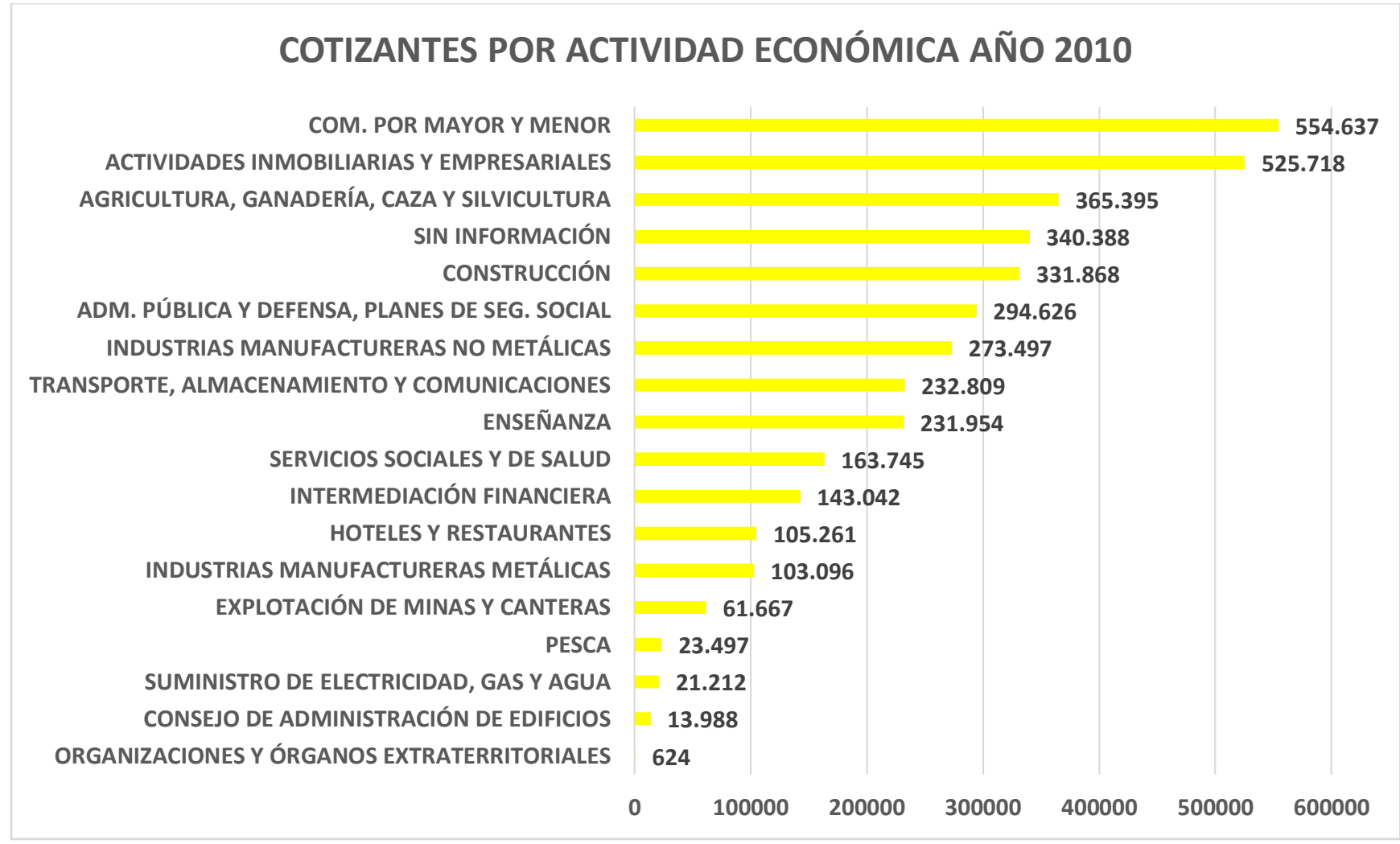

Figura 23. Cotizantes por actividad económica al sistema pensional 2010

Fuente: elaboración propia con base en Instituto Nacional de Estadística (s.f.)

\subsection{La informalidad laboral en Chile}

La informalidad en palabras de Gálvez y Díaz (2015) significa:

La precariedad laboral del siguiente modo: inserción endeble de los asalariados en el sistema productivo (producción de bienes y servicios), caracterizada por una multiplicidad de formas de manifestación, que se extiende al ámbito de la condición asalariada y por tanto no se limita a un sector determinado del aparato productivo, ni tampoco a un tamaño de empresa, ni a un grupo de población en particular. La inserción endeble se expresaría en la participación intermitente e inestable de los trabajadores en la actividad laboral, determinada centralmente por la ausencia de condiciones contractuales que garanticen una permanencia y dependencia continua: contratos de trabajo por tiempo determinado bajo 
distintas modalidades a plazo fijo, por obra o faena, por tiempos parciales, subcontratos, relaciones civiles que ocultan subordinación como el trabajo a honorarios [...]. (p. 10)

Esta precariedad contractual anula la protección jurídica al trabajador. Entre los principales prejuicios que existen están la carencia de cierto conjunto de derechos, como por ejemplo: el no poder acceder a indemnización por motivo de despido, poca o nula seguridad social y la restricción para ser partícipe de cualquier grupo sindical, y adicionalmente el poco respeto por la duración y cumplimiento de las jornadas de trabajo. Estos elementos instan al gobierno para buscar alternativas que flexibilicen la legislación laboral y refuercen los lazos de las relaciones entre patrono y empleado, y que a su vez reduzcan las condiciones de precariedad en el trabajo.

Pero el problema actual no es solo ese, sino también, en palabras de Castel (1997) como se citó en Gálvez y Díaz (2015) “el de la “desestabilización de los estables”, todos los trabajadores incluso aquellos más calificados, de empresas grandes y exitosas, que provienen de sectores dinámicos de la economía, pueden potencialmente llegar a ser precarios" (p. 11). La precariedad avanza hacia los empleos estables, dado que las condiciones que se imponen en los mercados de trabajo son de una naturaleza que busca el sostenimiento del mercado de trabajo sin procurar mantener el mismo nivel de vida para los trabajadores, este detrimento de las relaciones laborales hace que el nivel de desempleo y transición laboral aumente en forma gradual y que los beneficios a los trabajadores sean cada vez menores. Como consecuencia de esto la relación laboral entre empresa y trabajadores pasa a ser un vínculo netamente financiero, en el que el trabajador cumple sus labores únicamente con la intención de recibir su remuneración sin ningún tipo de interés en aumentar su productividad o capacitarse para tener un mayor estatus en su profesión.

De igual manera, la precarización cambia las relaciones entre el salario y las labores asignadas, el empleo de los asalariados sufre un debilitamiento considerable y los trabajadores deben aceptar (por no tener más opciones o resignación) unas condiciones contractuales cada vez más desequilibradas. Castel (1997) como se citó en Gálvez y Díaz (2015):

Habla del crecimiento de la "vulnerabilidad de masas". Define incluso la existencia de "una nueva cuestión social", con similar importancia a lo que fue el pauperismo (siglo XIX), que generó un sector de trabajadores con condiciones críticas de vida y la emergencia de desigualdades que involucró problemas para la sociedad en su conjunto. (p. 11) 
Respecto a la informalidad, el cual es un problema que se encuentra acentuado en todas las economías latinoamericanas, en lo que corresponde al año 2013:

En cifras absolutas un total de 93 millones de personas, están en el empleo informal en 16 países de la región, de estos 60 millones están en el sector informal de las empresas, 23 millones tienen un empleo informal aunque trabajan en empresas formales y los 10 millones restantes se desempeñan en el servicio doméstico. (Silva, 2013, p. 7)

Para el año 2006 en Chile se tuvo un nivel de informalidad del 35,8 \%, siendo el sector de los trabajadores independientes los que más incurren a laborar en la informalidad. Sin embargo, es destacable que a comparación de años anteriores (1998) en los que se tuvieron niveles de informalidad con más de cuatro puntos porcentuales de diferencia respecto al año 2006, existió una reducción importante de este fenómeno, pues el nivel se encontraba en un 39,5\%. Esto explicado por las maniobras de reforma que realizó el gobierno nacional para introducir en el mercado de trabajo a jóvenes y mujeres por medio de programas sociales focalizados que estaban diseñados para esa finalidad.

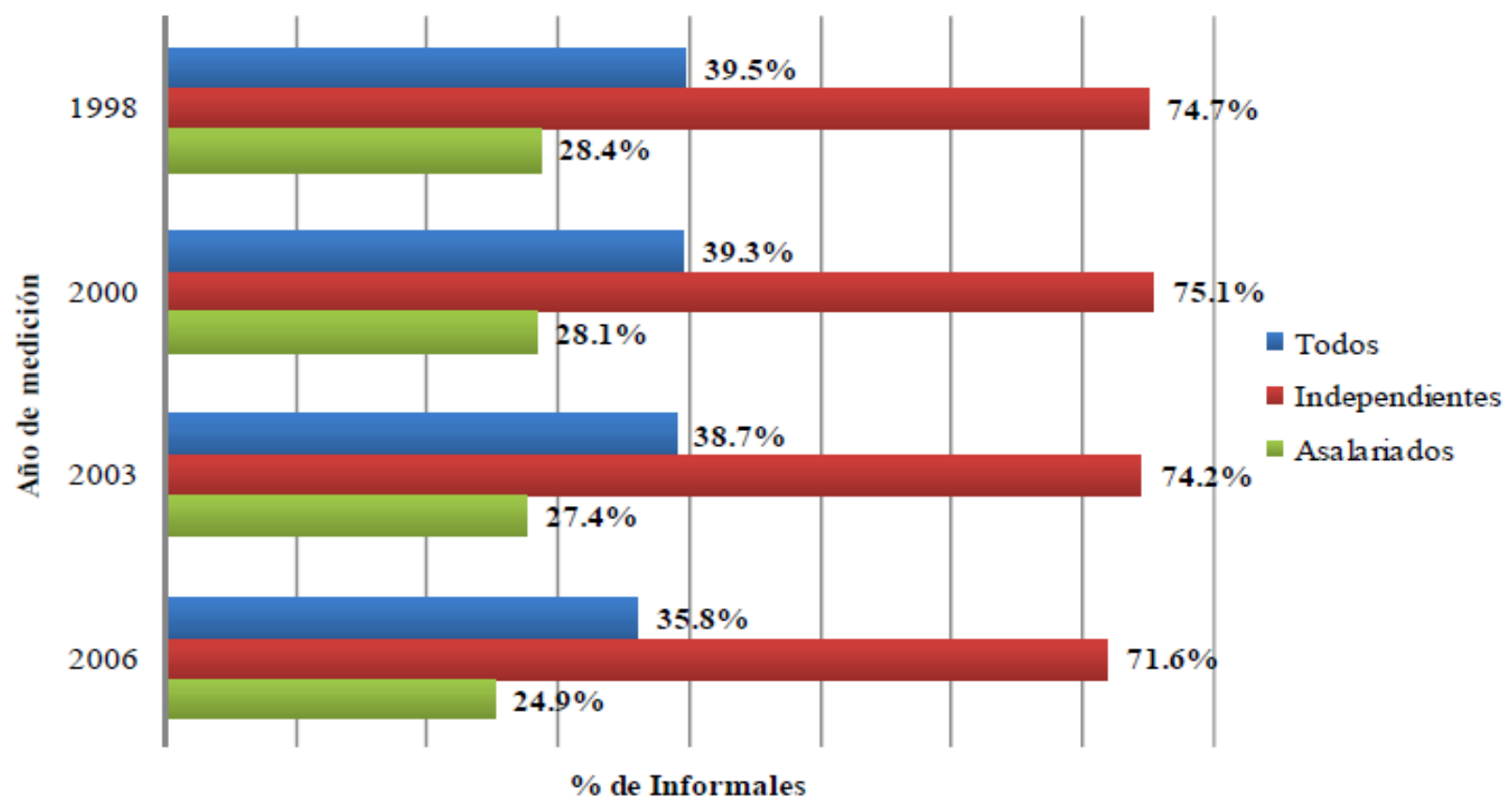

Figura 24. Evolución del nivel de informalidad laboral en el periodo 1998-2006

Fuente: elaboración propia con base en (Perticara \& Celhay, 2010, p. 6) 
Como es conocido, uno de los sectores productivos más afectados por el problema de la informalidad es el de la construcción, teniendo en cuenta el tipo de contratación que se le hace a la mayoría de trabajadores por obra o faena (obra o labor, días trabajados por periodos quincenales), el cual no les permite ni tampoco les garantiza el acceso a una protección social digna; es por esta razón principal que las personas no tienen cabida en el sistema de salud, y a su vez tampoco contribuyen monetariamente al mismo (González \& Huneeus, 2016).

Frente a esto, el sector que mayor informalidad muestra en los países de América Latina es el de "informales en empresas formales"; lo que es preocupante toda vez que sería propicio establecer la forma bajo la cual se está contratando este tipo de trabajadores y que evidentemente está ocasionando que el sector informal crezca considerablemente.

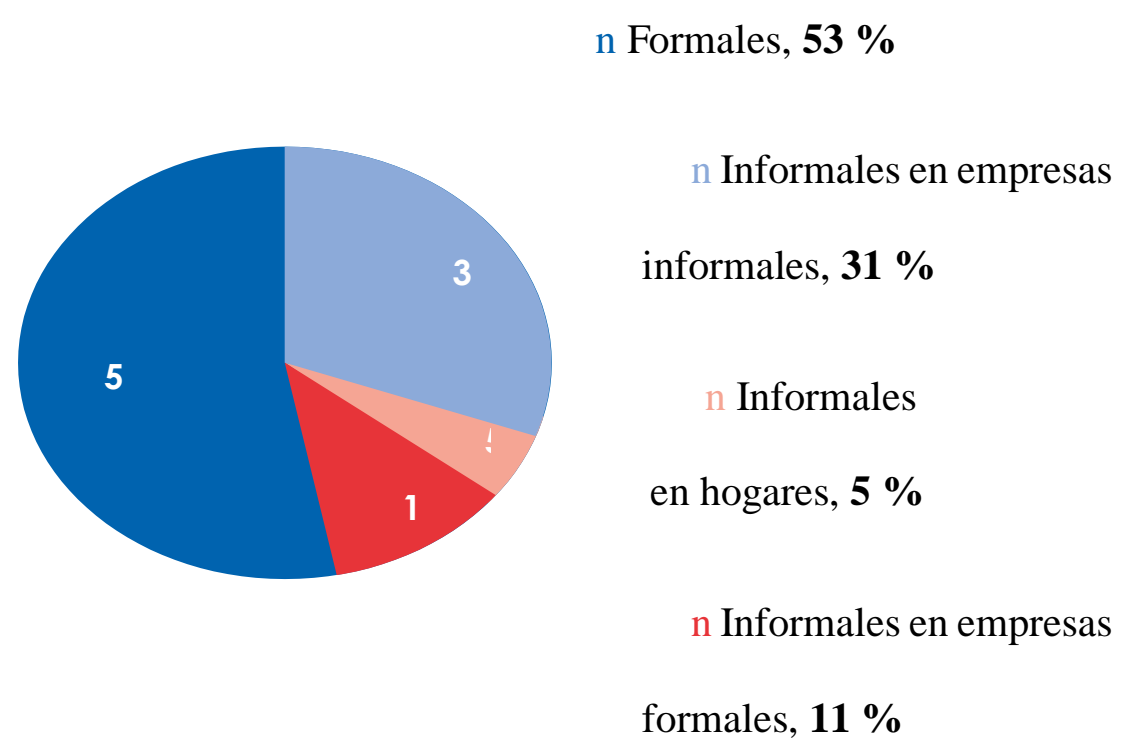

Figura 25. Formalidad e informalidad por componentes. 14 países de América Latina. Entre 2009 y 2013

Fuente: (Perticara \& Celhay, 2010) 
Finalmente, en la siguiente tabla se puede ver la diferencia que marca el sector de la construcción en términos de informalidad respecto al total nacional que lo componen los demás sectores de la economía.

En términos de ingreso en 1998, los trabajadores que se encontraban en la informalidad y que se consideraban asalariados ganaban un menor sueldo que los trabajadores a cuenta propia (independientes). En el año 2006 si bien los informales asalariados siguieron teniendo los niveles más desiguales en cuanto a ingresos, no obstante, su diferencia de ingresos (brecha) disminuye considerablemente a raíz de las políticas implementadas por el gobierno en materia de protección social; estas buscaban ampliar la cobertura de los servicios previsionales y garantizar un ingreso en la vejez para quienes realizaran aportes al sistema de pensiones de forma voluntaria.

Tabla 13. Caracterización de los trabajadores formales e informales. Definición OIT

\begin{tabular}{|c|c|c|c|c|c|c|}
\hline & \multicolumn{3}{|c|}{ Año 1998} & \multicolumn{3}{|c|}{ Año 2006} \\
\hline & Informales & Informales & No & Informales & Informales & No \\
\hline & Independie & Asalariados & Informales & Independiente & Asalariados & Informal \\
\hline$\%$ que son hombres & $70.3 \%$ & $56.5 \%$ & $65.2 \%$ & $62.3 \%$ & $53.0 \%$ & $63.8 \%$ \\
\hline Edad promedio & 43. & 35.6 & 37.7 & 45.8 & 38.2 & 39.2 \\
\hline Escolaridad & 8.9 & 9.1 & 11.5 & 9.5 & 10.1 & 11.7 \\
\hline Ingreso del trabajo & 338.361 & 118.153 & 290.688 & 353.969 & 157.355 & 340.553 \\
\hline$\% \quad$ Trabaja en & $94.3 \%$ & $59.6 \%$ & $26.8 \%$ & $95.3 \%$ & $49.7 \%$ & $23.3 \%$ \\
\hline $\begin{array}{l}\% \text { Individuos que son } \\
\text { pobres }\end{array}$ & $10.2 \%$ & $21.9 \%$ & $9.0 \%$ & $7.3 \%$ & $14.0 \%$ & $5.3 \%$ \\
\hline
\end{tabular}

Fuente: elaboración propia con base en Perticara y Celhay (2010)

Como conclusión, se evidencia que los trabajadores que pertenecen al sector informal trabajan en su mayoría en empresas pequeñas (menos de 10 trabajadores) y evidencian una mayor tasa de 
pobreza y escasez de ingresos, donde la tasa de pobreza es de $21.9 \%$ en 1998, y equivalente al 14 $\%$ en el año 2006, comparada con un $10.2 \%$ y $7.3 \%$ respectivamente, para los trabajadores informales independientes.

Tabla 14. Tasas de informalidad por género, nivel educativo y tramos de edad. Definición OIT. Año 2010

$\begin{array}{lcccccccc} & \text { Ind } & \text { A } & \text { I } & \text { A } & \text { I } & \text { A } & \text { I } & \text { Asal. } \\ & & & & & & & & \\ \text { Mujeres } & 77 . & 3 & 7 & 3 & 7 & 3 & 7 & 29.7 \% \\ \text { Hombres } & 73 . & 2 & 7 & 2 & 7 & 2 & 6 & 21.8 \% \\ \text { Básica Completa/Media } & 79 . & 3 & 8 & 3 & 8 & 3 & 7 & 32.2 \% \\ \text { Media completa/Terciaria o } & 67 . & 2 & 6 & 2 & 6 & 2 & 6 & 19.9 \% \\ \text { Universitaria completa } & 44 . & 1 & 4 & 1 & 4 & 1 & 4 & 14.0 \% \\ \text { 25 a 34 años } & 79 . & 2 & 8 & 2 & 7 & 2 & 7 & 20.5 \% \\ \text { 35 a } 44 \text { años } & 73 . & 2 & 7 & 2 & 7 & 2 & 7 & 21.2 \% \\ \text { 45 a } 54 \text { años } & 70 . & 2 & 7 & 2 & 6 & 2 & 6 & 22.7 \% \\ \text { 55 a } 64 \text { años } & 69 . & 2 & 7 & 2 & 6 & 2 & 6 & 27.4 \% \\ \text { 65 o más años } & 79 . & 5 & 8 & 5 & 7 & 5 & 7 & 53.8 \% \\ & 2 \% & 7.3 \% & 1.0 & 2.0 \% & 5.7 & 0.5 \% & 4.6 & \\ & & & \% & & \% & & \% & \\ \end{array}$

Fuente: elaboración propia con base en Perticara y Celhay (2010)

Teniendo en cuenta lo anterior, las menores tasas de informalidad se registran entre trabajadores administrativos y profesionales. En todas las categorías se pueden observar importantes descensos en las tasas de informalidad en el período 1998-2006, exceptuando a los trabajadores de mayor calificación dentro del mercado (profesionales tanto técnicos como científicos y cargos gerenciales), ya que en estos grupos la tasa de informalidad entre los asalariados crece entre un 25 $\%$ y la tasa de informalidad entre los independientes lo hace un $15 \%$. 


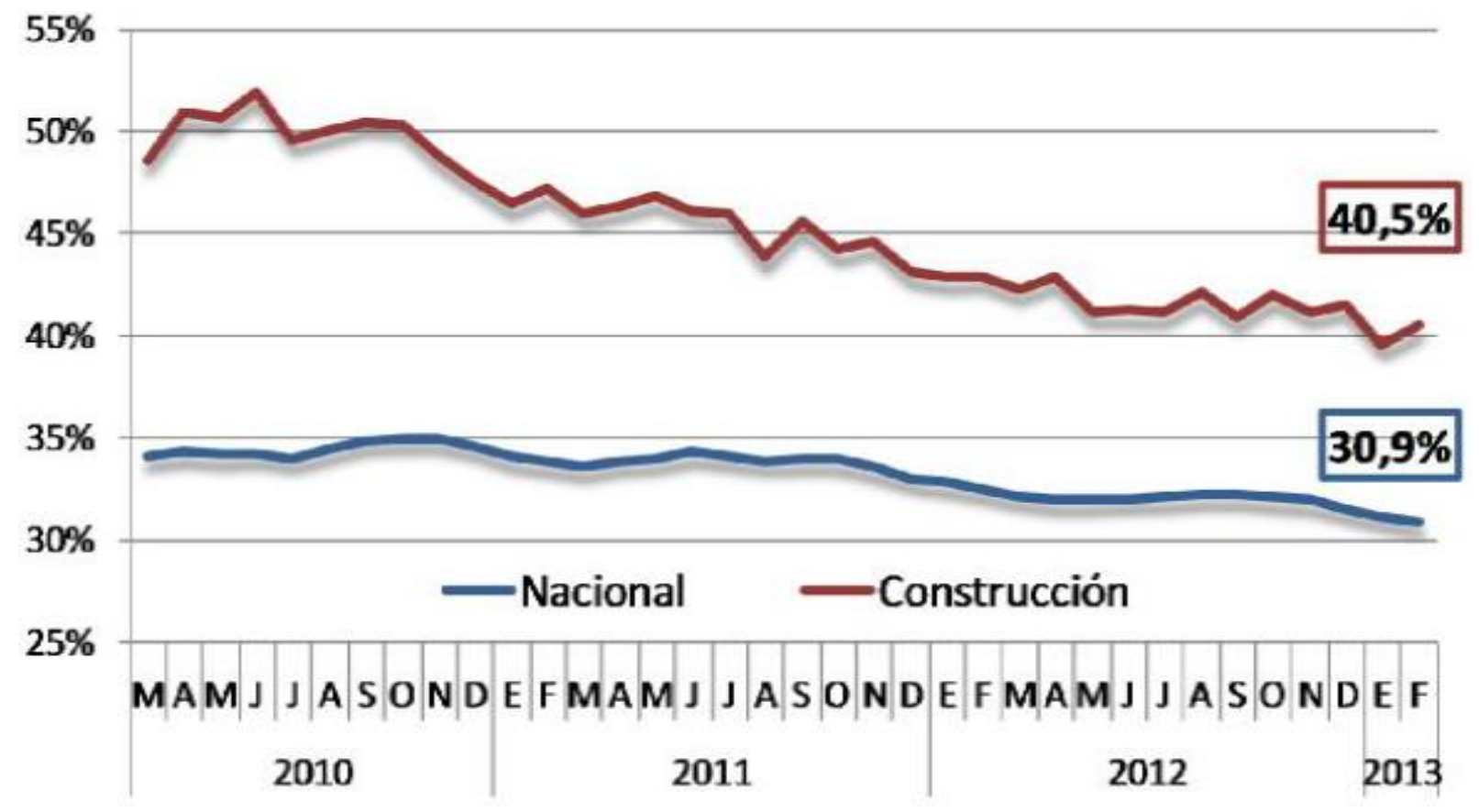

Figura 26. Informalidad en el empleo como proporción del empleo total - Total Nacional vs. Sector Construcción 2010-2013

Fuente: (Silva, 2013, p. 9)

De los datos mencionados anteriormente se puede concluir que la informalidad en Chile es menor que en otras economías de América Latina, ha tendido a reducirse en los últimos años. No obstante, donde más prevalece es en grupos específicos de la población como las mujeres, los jóvenes y las personas mayores de 65 años. La informalidad entre los trabajadores independientes tiene sus orígenes en el hecho de que hasta la Reforma Previsional del año 2009 para los independientes no era obligación cotizar o generar aporte alguno al sistema de pensiones; es importante mencionar que el sector informal siempre ha tenido un potencial para incentivar a la exclusión de los sistemas de seguridad social, y por ende también de las oportunidades para acceder a los servicios previsionales que tiene dispuesto el país para los ciudadanos. 
Así, muchas de las políticas implementadas desde que retornó la democracia generaron más cobertura, protección y una mayor cantidad de derechos adjudicados a los trabajadores, la caída de la informalidad en el último tiempo puede deberse también a la implementación de estrategias para contratación laboral, como la subcontratación, la contratación parcial, por honorarios y por obra o labor; buscando aumentar la inclusión en el Sistema Previsional a los trabajadores desde la vuelta de la democracia originaron más protección y más derechos para los trabajadores.

Ahora bien, parte de la informalidad vista en el país corresponde a factores culturales arraigados en las empresas y los trabajadores, es decir que algunos empresarios prefieren contratar personal temporal para evitar aumentar la carga prestacional de su empresa, y los trabajadores prefieren cumplir con el mínimo establecido para acceder a alguno de los beneficios disponibles que brinda el Estado, conocidos como las pensiones básicas asistenciales y otros subsidios de cuantía mínima.

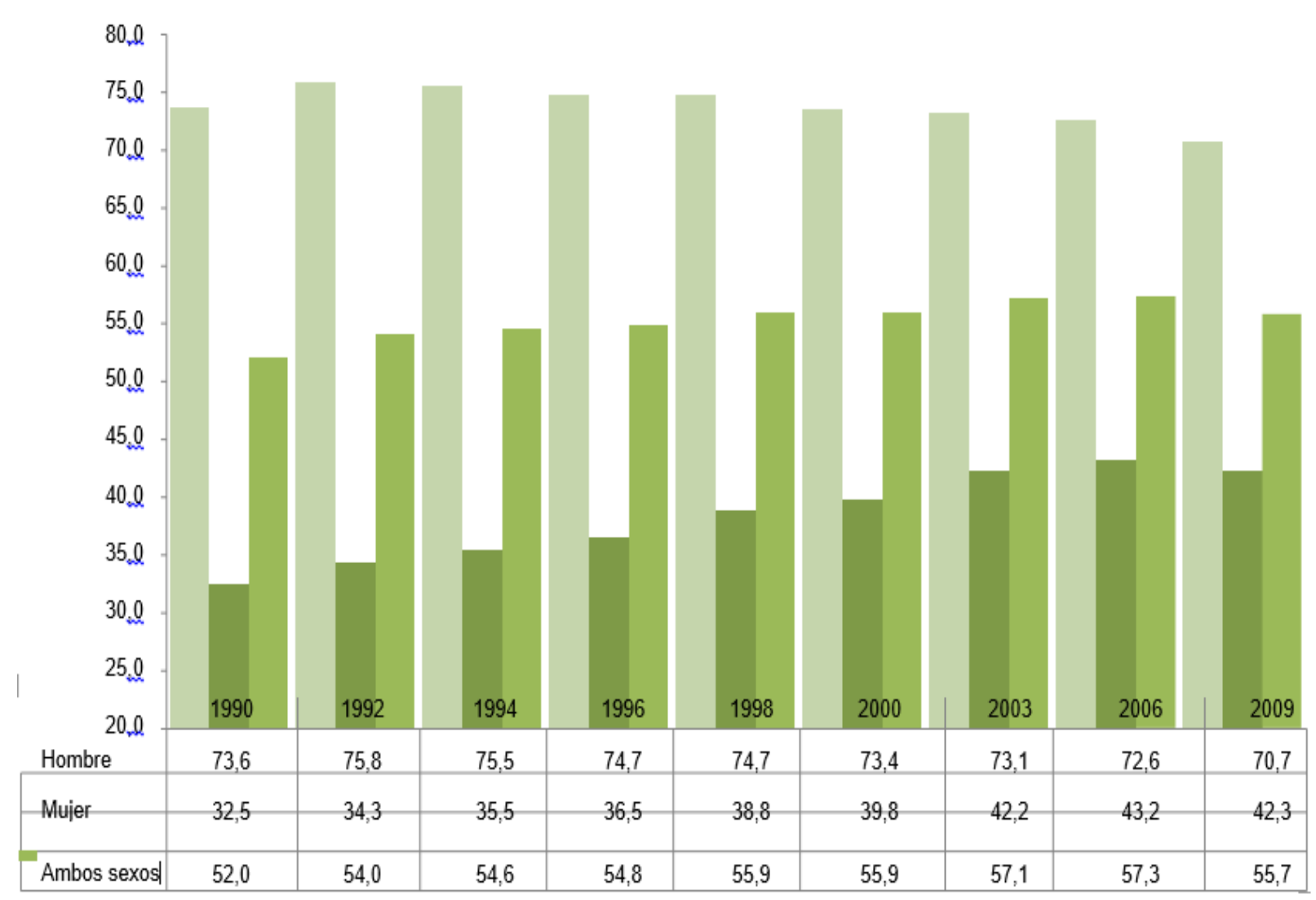

Figura 27. Evolución de la Tasa de participación por sexo 1990 - 2009

Fuente: (Ministerio de Planificación de Chile, 2010) 
La tasa de ocupación muestra un comportamiento desigual si se compara entre los hombres y las mujeres, tanto así que solo en los últimos años (2000 hacia delante) las mujeres consiguen aumentar su participación en el mercado laboral con respecto a los hombres.

Tabla 15. Evolución de la tasa de desocupación por sexo 1990 - 2006

Ambos

\begin{tabular}{|c|c|c|c|}
\hline Año & Hombre & Mujer & $\begin{array}{l}\text { Ambos } \\
\text { Sexos }\end{array}$ \\
\hline 1990 & 7,7 & 9,6 & 8,3 \\
\hline 1992 & 4,6 & 7,5 & 5,6 \\
\hline 1994 & 5,7 & 8,5 & 6,7 \\
\hline 1996 & 4,9 & 7,3 & 5,7 \\
\hline 1998 & 9,0 & 11, & 9,9 \\
\hline & & 3 & \\
\hline 2000 & 9,6 & 11 & 10 \\
\hline & & 7 & 4 \\
\hline 2003 & 8,2 & 12 & 9,7 \\
\hline & & 1 & \\
\hline 2006 & 6,0 & 9,4 & 7,3 \\
\hline 2009 & 8,9 & 12 & 10 \\
\hline & & 2 & 2 \\
\hline
\end{tabular}


Fuente: elaboración propia con base en Ministerio de Planificación de Chile (2010)

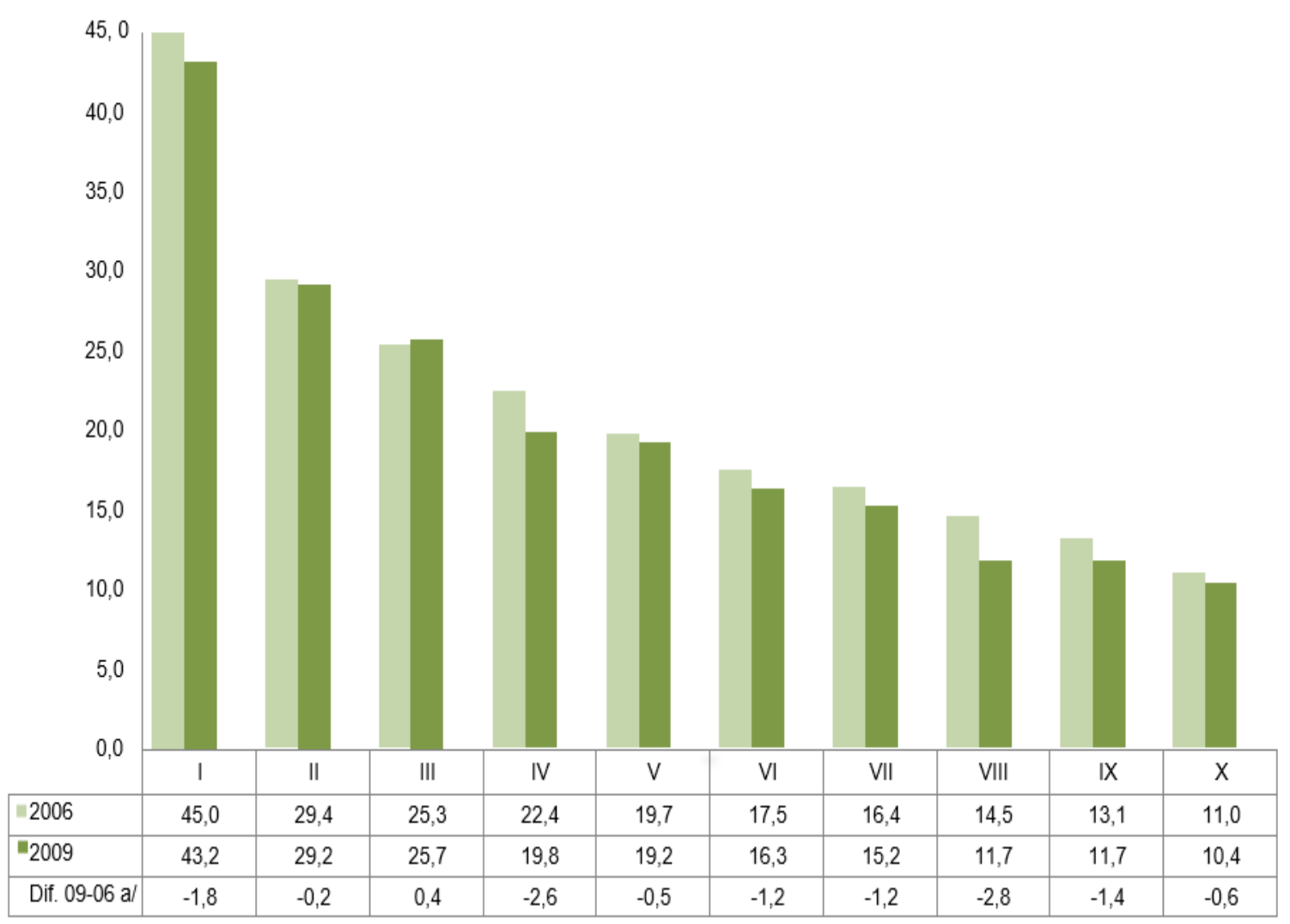

Figura 28. Evolución de la tasa de desocupación por sexo 1990 - 2006

Fuente: (Ministerio de Planificación de Chile, 2010)

La tasa de desocupación entre 2006 a 2009 estuvo marcada por una reducción gradual y poco profunda entre esos dos años, esto se debe a que las acciones tomadas por el gobierno chileno para realizar la Reforma Previsional Integral de 2008 también contaron con una fuerte protección al empleo y a los cotizantes, con el ánimo de que el sistema de seguridad social no se viera perjudicado en cuanto al recaudo. 


\begin{tabular}{|c|c|c|c|c|c|c|c|c|}
\hline $\mathrm{N}^{\circ}$ ocup & $\mathrm{N}^{0}$ ocup & $\mathrm{N}^{\circ}$ ocup & $\mathrm{N}^{\circ}$ ocup & $\mathrm{N}^{0}$ ocup & $\mathrm{N}^{0}$ ocup & $N^{0}$ ocup & $\mathrm{N}^{0}$ ocup & $\mathrm{N}^{\circ}$ ocup \\
\hline 4.419 .471 & 4.902 .939 & 5.101 .708 & 5.343 .449 & 5.378 .144 & 5.496 .444 & 5.994 .631 & 6.578 .325 & 6.493 .557 \\
\hline
\end{tabular}

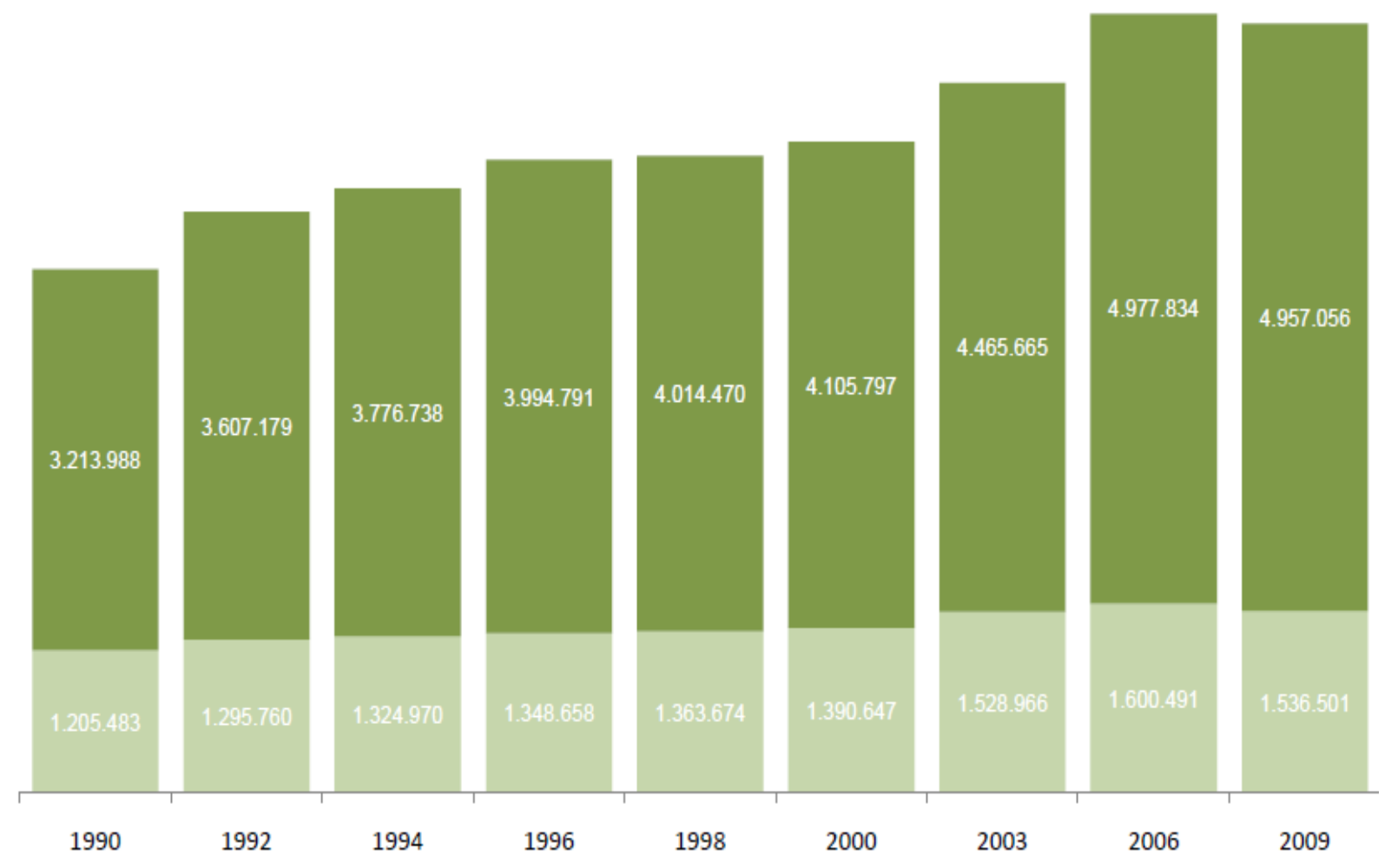

Figura 29. Total de trabajadores asalariados y no asalariados 1990 a 2009

Fuente: (Ministerio de Planificación de Chile, 2010)

Los trabajadores asalariados de Chile llegaron a ser hasta tres veces mayores en cantidad que los trabajadores no asalariados, esta condición que se ha convertido en tendencia desde años atrás ha generado importantes aumentos en los niveles de informalidad; y también en el sistema de seguridad social ha impactado como consecuencia de una abstención a aportar para pensión y otras prestaciones sociales. 


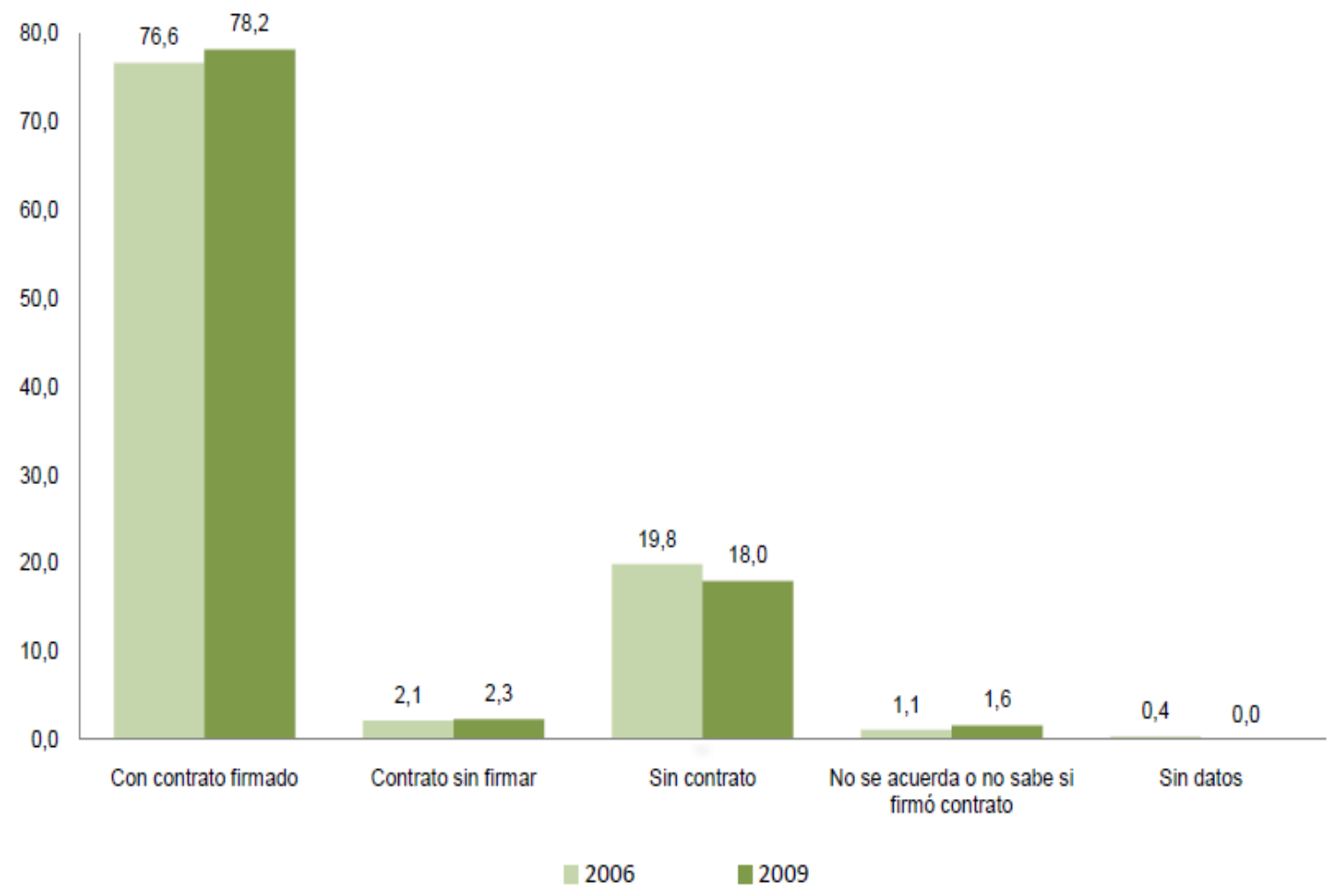

Figura 30. Asalariados según su situación contractual 2006 - 2009 (porcentaje)

Fuente: (Ministerio de Planificación de Chile, 2010)

Los trabajadores que cuentan con un contrato laboral establecido formalmente superan con amplia mayoría a quienes no tienen un contrato laboral establecido, estos últimos se ven expuestos a varios riesgos tales como desprotección total o parcial de prestaciones sociales, pocas o nulas garantías de acceso al sistema de salud y facilitan la exoneración de la responsabilidad que tiene con ellos el empleador, puesto que no existe un documento oficial que vincule dicha relación laboral. 


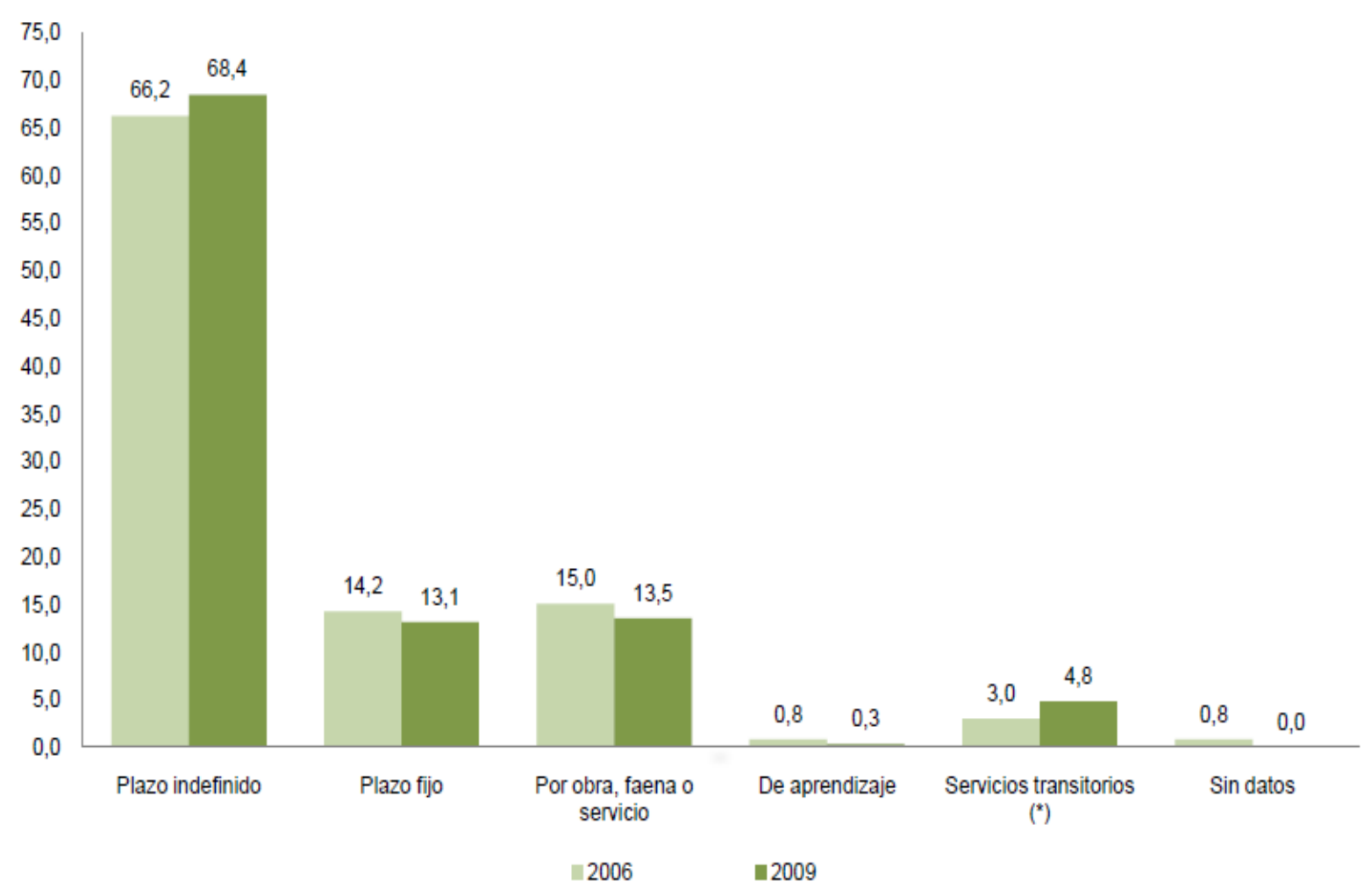

Figura 31. Asalariados según tipo de vinculación contractual 2006 - 2009 (porcentajes)

Fuente: (Ministerio de Planificación de Chile, 2010)

Los contratos a término o plazo indefinido son los que más se dieron durante los años 2006 a 2009, mientras que las demás modalidades contractuales se dieron en una cuarta parte menos que los contratos a plazo indefinido; esta condición laboral suele ser garante de beneficios prestacionales para el trabajador. Adicionalmente contribuye en gran medida a reducir la tasa de reemplazo del mercado laboral y hace posible que las cotizaciones a seguridad social sean continuas; caso contrario se vive en las otras formas de contratación puesto que ante una intermitencia de los ingresos esta se replicará también en los pagos al sistema de seguridad social.

\section{Programas que han impulsado el mercado laboral chileno durante los últimos 5 años}

Siguiendo el orden que se ha establecido en el presente capítulo, a continuación se presentan las políticas laborales que rigen en el mercado de trabajo chileno. 
Los programas de impulso al mercado laboral en Chile surgen como consecuencia de las inequidades de género, de ingresos y de oportunidades, especialmente para la población más joven, quienes tienen dificultades para estar insertos en el mercado laboral por su falta de experiencia o estudios que acrediten y garanticen ingresos que les permitan acceder al sistema de protección social por medio de las cotizaciones. La diferencia de ingresos económicos entre géneros agudizó aún más la falta de interés para cotizar al sistema de seguridad social por parte de los jóvenes; esto traía como consecuencia que se presentara una ruptura en la lógica de la solidaridad intergeneracional (Instituto Nacional de Estadística, s.f.) en materia de pensiones principalmente, a lo cual el Estado debió responder con la formulación de programas que pudieran mitigar el impacto de estas desigualdades para el sistema de protección social y que a su vez impulsaran de manera gradual el nivel de empleo en Chile.

Lo anterior se explicará de la forma más detallada posible junto con cada uno de los elementos que lo componen, haciendo la salvedad de que las políticas laborales focalizadas a un determinado grupo de población como por ejemplo mujeres o jóvenes, se ahondarán más adelante porque en esta sección lo que interesa es mostrar el contenido general que en materia de políticas contiene el mercado de trabajo chileno.

Por ello, en este apartado se hace una reseña sucinta de los programas laborales que ha implementado Chile en los últimos 5 años, pasando primero por los antecedentes históricos (1973, 1990, 2002 y entre otros) que dieron como resultado la necesidad de formular este tipo de programas recientes y que conocemos hoy en día, orientados al impulso de la educación, el empleo, el crecimiento de la productividad y la disminución del gasto de Estado.

Para empezar, tras el final del régimen militar hubo una urgente necesidad de realizar acciones que conllevaran a replantear y renegociar las condiciones de varios sectores sociales que habían sido oprimidos fuertemente por el régimen de Augusto Pinochet, especialmente el sector laboral dado que se habían limitado en gran manera las formas de negociación de derechos de los trabajadores, los ajustes salariales y la actividad sindical, entre otros. Las modificaciones más relevantes que incidieron en los mercados laboral y de pensiones se basaron en que los nuevos trabajadores que ingresaran al mercado de trabajo tenían que afiliarse por obligación al sistema de capitalización individual de pensiones, mientras que los trabajadores antiguos podían elegir quedarse en el sistema de reparto (Larrañaga, 2010). 
Tras esto, se introdujo la cotización obligatoria en salud para todos los trabajadores asalariados y pensionados, quienes tenían la opción de depositar estos recursos en un fondo público o privado, esta maniobra de elección según Larrañaga (2010) permitió que la población se inclinara en su mayoría por un seguro de salud de origen privado.

A inicios del año 2000 se dio un giro total en las políticas sociales y laborales, con el objetivo de focalizar la atención a las poblaciones que se encontraran en condiciones de vulnerabilidad, y en cuanto al mercado de trabajo se optaba por una estrategia que permitiera contrarrestar el desempleo juvenil para disminuir la afectación que esta situación le podía generar al sistema de seguridad social en conjunto. Durante el periodo de 1990 a 2006 "se tiene cuenta de aproximadamente 400 programas de focalización y 80 instituciones que los controlaban en diferentes instancias de desarrollo y ejecución".

En el año 2002 entra en vigencia la Ley 19728 que da lugar a un seguro de desempleo en Chile, el primero que se ocupa de ampliar la cobertura y que otorga beneficios significativos a los trabajadores del país. Esta ley fue muy oportuna para suplir la necesidad de un mecanismo que protegiera los ingresos de los trabajadores ante un posible desempleo temporal. El diseño del seguro en Chile se apoyó en los acontecimientos históricos internacionales que sirvieron de referencia, con el fin de evitar los potenciales problemas que se podían presentar, por ejemplo la unión de empleados y empleadores para desviar recursos para un fin común o entregar beneficios de esta naturaleza a personas que no lo necesitaran o evitar que los desempleados buscaran un nuevo trabajo a costa de permanecer amparados por este subsidio.

No obstante, "los mecanismos adoptados para evitar abusos y filtraciones de beneficios a grupos no prioritarios limitaron excesivamente los beneficios del seguro" (Larrañaga, 2010, p. 19), incentivando a que se generara una modificación importante a la ley en el año 2009; buscando aumentar así los beneficios a otorgar y ampliando la cobertura por medio de la extensión del mismo a grupos que no estaban en el radar de la ley original. A continuación, y con base en el Servicio Nacional de Capacitación y Empleo (SENCE, s.f.) de Chile se presentan listados de los programas con los que para los años 2011 y 2014 contaba el mercado de trabajo para impulsar su actividad.

\section{PROGRAMA FORMACIÓN EN EL PUESTO DE TRABAJO (2011)}


Este programa se creó para mejorar la condición laboral de aquellos grupos poblacionales con altos niveles de desempleo y que presentaban el mayor grado de restricción para ingresar al mundo laboral, y que así mismo tenían serias dificultades para mantenerse dentro del sistema, aunado esto a los bajos niveles educativos que presentaban debido a la falta de oportunidades y escasez de recursos. El objetivo general de este programa es "promover la colocación de jóvenes, mujeres y mayores de 50 años, potenciando su formación laboral en el desempeño en un puesto de trabajo y el desarrollo de competencias vinculadas a la ocupación" (SENCE, 2013, p. 3).

\section{PROGRAMA DE FORMACIÓN EN OFICIOS (2011)}

El programa Formación en Oficios busca aumentar las opciones laborales de las personas que tienen mayor dificultad para encontrar un empleo, algo particular de estos grupos es la alta deserción escolar y las competencias laborales que pueden encontrar en el programa para encontrar empleos que garanticen las prestaciones sociales exigidas por la ley. Por consiguiente el objetivo general de este programa es "generar mayores competencias laborales en jóvenes, mujeres y personas mayores de 50 años, con el propósito de fomentar una futura inserción laboral y un aumento de sus condiciones de empleabilidad".

\section{PROGRAMA BONO INTERMEDIACIÓN LABORAL (2011)}

El programa Bono de Intermediación Laboral obedece a la necesidad de disminuir el desempleo con políticas activas y pasivas de empleo, insertando a un nuevo actor privado cuyo rol sea disminuir la desconexión entre la oferta y demanda laboral en segmentos poblacionales menos calificados y vulnerables (por la dificultad para encontrar un empleo más no por ingresos). El Bono de Intermediación Laboral tiene como objetivo facilitar el acceso a la incorporación y/o reincorporación de personas desempleadas a un puesto de trabajo formal mediante la intervención de un agente u organismo privado. El Servicio de Capacitación y Empleo (SENCE) se ocupa de subsidiar los servicios prestados mediante el Bono de Intermediación Laboral, de esta manera los usuarios de este (población en condición de desempleo) reciben como beneficio la inserción en un puesto de trabajo.

\section{PROGRAMA BONO EMPRESA Y NEGOCIO (2011)}


Este programa fue diseñado para que la micro y la pequeña empresa cuenten con un acceso al actual sistema de capacitación, y además se amplíe la cobertura de los servicios previsionales para estas empresas. El objetivo principal del Bono MIPE es aumentar la competitividad y la productividad de las empresas que pertenecen a estos segmentos, a través de una capacitación focalizada y práctica para sus dueños y/o administradores.

\section{PROGRAMA BONO TRABAJADOR ACTIVO (2011)}

Este programa busca aumentar los niveles de empleo y la movilidad laboral por medio del financiamiento de los programas de capacitación laboral, para aumentar la productividad y la capacidad de conseguir un empleo de mejor calidad para el trabajador. Al programa se le incorpora un mecanismo de participación del trabajador a través del financiamiento por parte de este, y consiste en que si el trabajador lo desea puede contribuir con un dinero adicional para acceder a mayor cantidad de cursos y elementos de capacitación; esto a través de un bono del que el trabajador debe hacer un uso responsable.

\section{PROGRAMA APRENDICES 2014}

El Programa Aprendices se crea "para mejorar la condición laboral de aquellas poblaciones con altas tasas de desempleo y que presentan mayores barreras a la entrada al mundo del trabajo y dificultades por mantenerse en él, esto sumado a niveles educacionales bajos" (SENCE, 2013, p. 3). El objetivo general de este programa es generar mayores probabilidades de empleo a los aprendices y que así se contribuya a la productividad de las empresas a partir del desarrollo de competencias que le permitan a la persona enriquecer su formación profesional; para las empresas que tienen en su planta de trabajo a los aprendices se les otorga un bono que subsidia los programas de capacitación destinados a este grupo de población al interior de la empresa.

\section{PROGRAMA BECAS LABORALES 2014}

Desde el año 2013 el Programa Becas Franquicia Tributaria ejecutará dos grandes líneas de acción:

- Evaluación y Certificación de Competencias: a través del Programa Becas Franquicia Tributaria se financiarán procesos gratuitos de evaluación de competencias. 
- Capacitación Laboral: el programa otorga cursos de capacitación completamente gratuitos para los participantes que están conectados con los requisitos de los perfiles laborales que exigen las empresas y el mercado local.

\section{PROGRAMA MUJER TRABAJADORA Y JEFA DE HOGAR 2014}

El objetivo general de este programa es "mejorar la empleabilidad y las condiciones laborales de las Mujeres inscritas en el programa "Mujer Trabajadora y Jefa de Hogar", a través de los instrumentos de capacitación SENCE, en oficios con egreso dependiente o independiente." Para cumplir con el objetivo antes dispuesto se otorga una capacitación mensual durante dos años a las mujeres cabeza de hogar, con el fin de impulsar la obtención de un mejor posicionamiento en el mercado de trabajo y que a su vez incida positivamente en sus ingresos.

\subsection{Conclusiones}

\section{Posibles acciones para reducir las dificultades del mercado de trabajo en Chile}

Finalmente se presentan, a manera de reflexión y de una opinión respetuosa, algunas medidas o acciones para combatir los problemas que el mercado laboral chileno sostiene y que así mismo frenan el progreso de las instancias de la protección social para empleadores y trabajadores. Los procesos de reajuste que se tienen que llevar a cabo en el mercado de trabajo en Chile deben hacerse por medio de acuerdos que ofrezcan tanto a empresas, empleadores y trabajadores, un ambiente favorable para otorgar prestaciones sociales adecuadas a estos últimos; pero también que al aplicar esta clase de beneficios a los trabajadores, sus empleadores reciban incentivos económicos o tributarios por dar cumplimiento a este tipo de políticas que impulsan el mercado de trabajo.

A continuación se enlistan brevemente algunas conclusiones concretas que de llevarse a cabo podrían ser potencialmente de utilidad a la hora de concertar un adecuado manejo de la dinámica del mercado laboral:

- Por medio de los procesos de contratación a los jóvenes de 18 a 24 años se generan subsidios a las empresas que los vinculen, adicionalmente tienen ciertos beneficios tributarios. 
- La Ley 20.416 por la cual se fijan y amplían plazos de creación de nuevas empresas de menor tamaño, más conocida como estatuto PYME, en el que también se reducen costos para operación de las pequeñas empresas.

- Se deben realizar ajustes sobre la legislación laboral de forma gradual, esto permitiría que existiese un organismo o estatuto que vigile, dé cumplimiento a los derechos de protección a los trabajadores y que sirva de garante en la asignación de dichas prestaciones de tipo social.

- Los tipos de contrato independiente de la naturaleza que sean a plazo fijo, indefinido, por obra o por faena deben brindar (todos sin excepción) un piso base de protección social que le permita a los trabajadores obtener garantías para ejercer su profesión, y a la vez que la buena percepción que se tienen de esas garantías permita crear y ampliar la cultura de la cotización al sistema de seguridad social.

- Si se generan adecuados incentivos a los empresarios, especialmente de la pequeña y mediana empresa (PYME), esto podría impulsar la contratación de jóvenes y mujeres para ocupar puestos de trabajo operativos, técnicos y profesionales.

- Por medio del SENCE existe la posibilidad de que se implementen una serie de indicadores que permitan monitorear la calidad y la correcta recepción de los servicios de capacitación que esta entidad ofrece. Lo anterior dado que en Chile el SENCE no cuenta con indicadores que permitan medir la efectividad de su labor, por lo que en años anteriores se han tenido y aún se tienen serias dificultades para manejar la información de las personas que realmente han recibido este tipo de servicio por parte del Estado.

- Es importante prestar mucha atención a sectores como el agrario, el minero y el de la construcción, puesto que estos sectores productivos dada la forma en la cual opera su contratación permiten que haya lugar para unos niveles de informalidad sumamente altos; sus funcionarios, especialmente los de más bajos ingresos, no tienen acceso al sistema de salud y además carecen de prestaciones sociales. Lo anterior implica que en muchos casos se haga elusión y evasión al sistema de seguridad social, y en muchos otros el ámbito de la seguridad y salud en el trabajo está vulnerado y se está expuesto a riesgo constante en la actividad laboral que se desarrolla.

- Los términos de negociación colectiva y de actividad sindical deben regularse para evitar arbitrariedades tanto en el sector empresarial como en el gremio de los trabajadores, para 
que las acciones de concertación que se realicen permitan llegar a acuerdos en los que no sea posible vulnerar los derechos de ninguna de las dos partes.

\section{CAPÍTULO 3: Una Reforma Previsional Integral en medio de la crisis económica mundial}

Vista la estructura del sistema de pensiones y el mercado laboral de Chile, en el presente capítulo se ilustra de forma resumida la estructura productiva que conforma la economía chilena para el año 2014; se eligió ese año por disponibilidad de datos y para facilitar el análisis de los resultados que se observaron en materia pensional, laboral y protección social. 
La economía de Chile ha estado caracterizada por una fuerte tendencia hacia el liberalismo desde el gobierno de Augusto Pinochet (1973-1990) como se citó en Saavedra (2014), lo que implica que el desarrollo de su aparato productivo si bien ha sido fuertemente desarrollado permitiendo así un desarrollo económico gradual a través del tiempo, también ha tenido una dificultad muy seria, como lo es la exclusión social traducida en falta de oportunidades para las personas de más bajos ingresos. Este tipo de situaciones compromete seriamente el desarrollo de las políticas en materia social que incluyen dentro de sí al sector pensional y laboral, mismos que alimentan las finanzas públicas y privadas de Chile mediante su operación (Saavedra, 2014).

Ahora, el actual modelo manejado en la economía chilena le da al Estado un rol subsidiario, con una fuerte protección a los derechos de propiedad y con tendencias a la privatización de algunos sectores de servicios sociales básicos como las pensiones y la salud, entre otros. La protección social en Chile también se ha visto permeada por la problemática de la exclusión que ha sido relacionada muchas veces con la marcada desigualdad de ingresos monetarios (el coeficiente de Gini promedio en Latinoamérica se encuentra sobre el 0,52), altos niveles de desempleo e informalidad que impactan no solamente a Chile sino a toda América Latina.

Para realizar una síntesis de los diferentes sectores productivos que componen la economía chilena se presentan a lo largo del capítulo diferentes tablas y figuras que contienen las principales cifras que revelan el desempeño de la economía chilena en los últimos 4 años (2010-2014); también se recurre a mostrar el PIB (Producto Interno Bruto de Chile) para evidenciar su composición y el gasto en el cual se incurre por parte de gobierno chileno para atender los diferentes frentes de inversión del país.

En primera instancia, el PIB de Chile se encuentra compuesto por 11 grandes rubros, de los cuales tienen más relevancia los otros servicios que hace referencia al comercio de bienes, productos y servicios, los servicios empresariales (banca y seguros), la industria manufacturera (fábricas y establecimientos que utilizan materias primas) y el sector minero; con el cobre como uno de sus productos insignia en el país austral. En estos cuatro sectores reposa más del $55 \%$ del valor total del PIB chileno.

De esta manera, el sector comercial de Chile está sostenido en gran mayoría por los resultados que obtiene a partir de la venta y exportación de minerales como lo son el cobre (36 \% de la 
producción mundial de este mineral la realiza Chile), Litio y Yodo de los cuales cuenta con el 28 $\%$ de las reservas mundiales; esto le permite ser un exportador por excelencia de estos productos, traduciendo así a la actividad minera como el motor de la economía chilena.

Por otro lado, en el sector bancario de Chile se ubican 24 entidades de las cuales 18 son nacionales, cinco sucursales internacionales y el Banco Central de Chile, quien ejerce como banco rector de las otras entidades y a su vez tiene la función exclusiva de emisión de dinero, control de la inflación y las políticas monetarias entre otras. Además, en el sector agrícola se encuentran productos principales adicionales a las frutas y verduras, cereales como avena, maíz y trigo. Chile también es reconocido por su alta actividad pesquera y silvicultura, y por su industria de vinos que cuenta con prestigio mundial. Así, el PIB total de Chile para el año 2014 fue de U\$ 258.017 millones siendo el sector comercio y valor agregado el más influyente de todos.

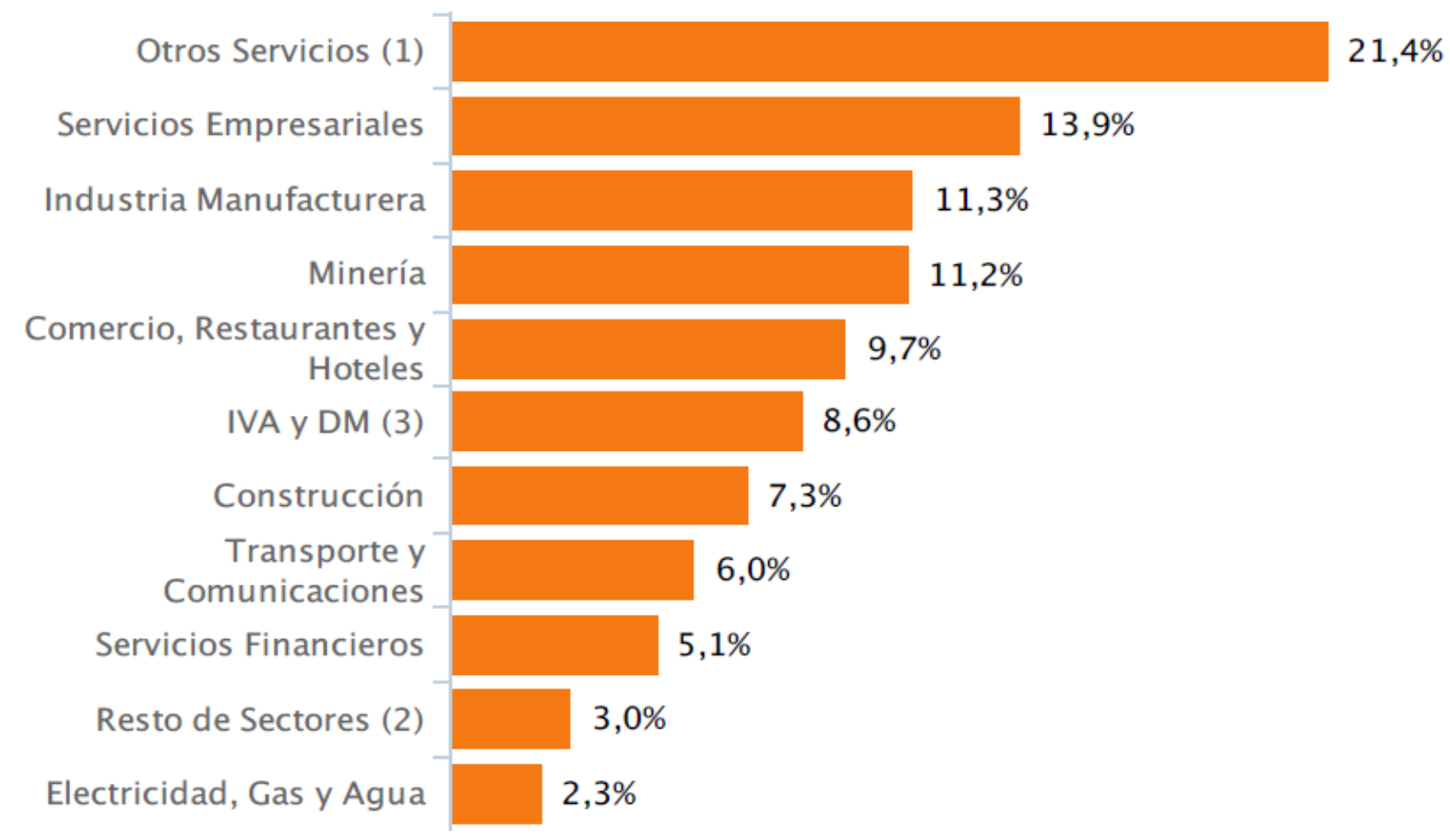

Figura 32. Estructura del PIB en Chile 2014 (porcentajes)

Fuente: (Banco Central de Chile, 2016) 
El PIB de Chile logró tener un aumento gradual durante los últimos 4 años desde 2010 hasta 2014, esto es explicado principalmente porque al tiempo en el cual se realizó la Reforma Integral del Sistema Pensional (2008) el país experimentaba un crecimiento económico importante que contagió a toda la región sudamericana, y así mismo el dólar perdió poder de compra frente a otras monedas internacionales, por lo cual los bienes importados tenían un costo reducido en sus aranceles y la brecha comercial se amplió notoriamente. En este periodo, en sus dos primeros años (2010 -2012) fue cuando Chile tuvo un mayor protagonismo económico en la región y sumado a esto el aumento en su protagonismo dentro de la OCDE, acogiendo también varias de las sugerencias que en materia pensional y sostenibilidad financiera del sistema le hacían al gobierno de Bachelet; esto permitía que las ideas planteadas por esta organización multilateral se vieran reflejadas en el modelo económico que tenía implicaciones en la reducción de la pobreza y desigualdad en el ingreso, pero también incentivos a la cotización del sistema de seguridad social.

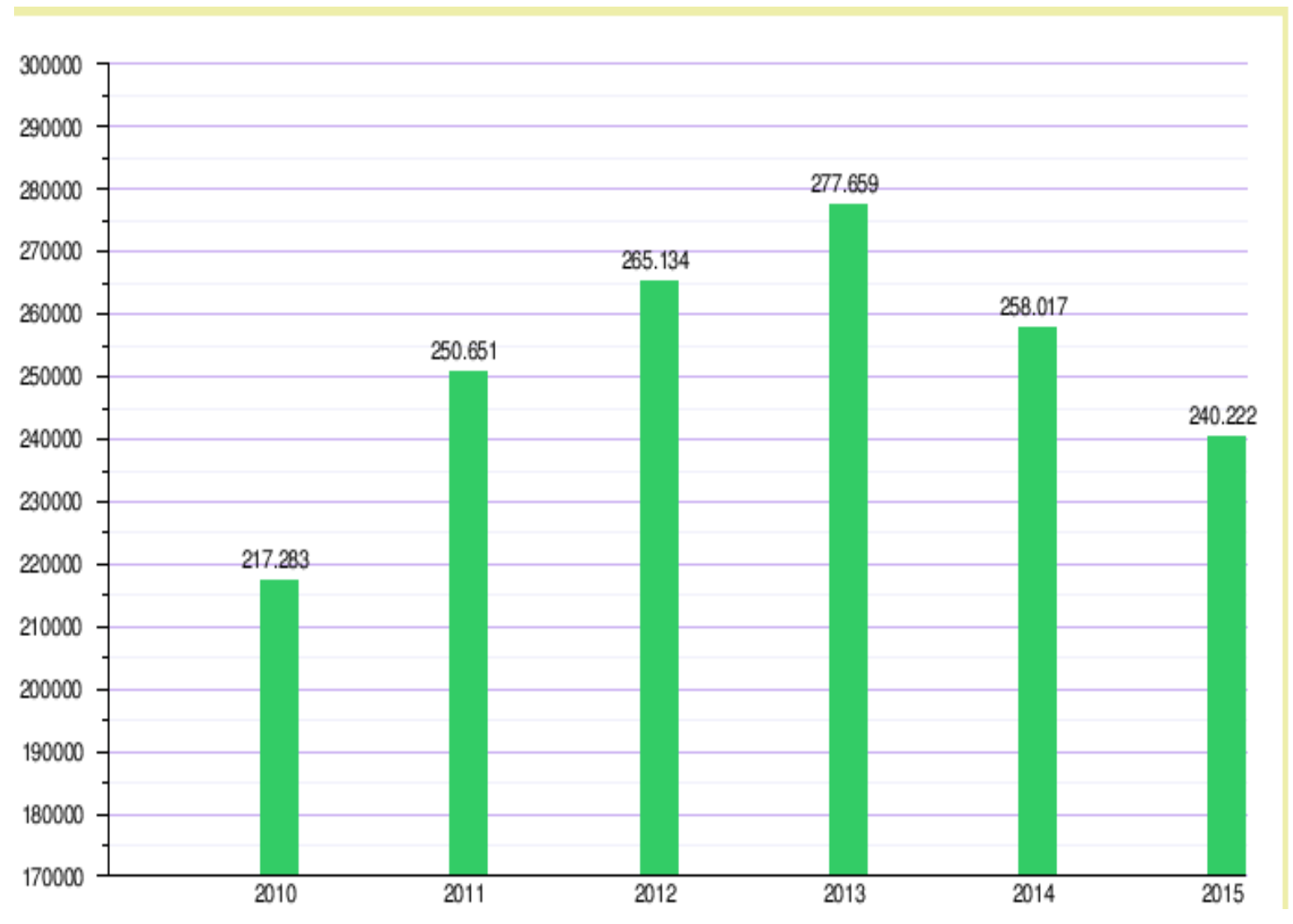

Figura 33. Evolución histórica del PIB 2010 - 2015. Cifras en millones de U\$\$. 
Fuente: (Wikipedia, s.f., párr. 32)

Entre los gastos más relevantes que presupuestariamente tiene el PIB chileno están la explotación de bienes y servicios, el consumo de los hogares, la importación y exportación de bienes y servicios y la industria, siendo el primero el que abarca más del $40 \%$ del gasto total entre todos los rubros de la economía. El sector de la construcción también toma una porción importante del gasto chileno, más exactamente en las regiones de Santiago de Chile y Valparaíso. 


\begin{tabular}{|c|c|c|c|c|}
\hline & 2011 & 2012 & 2013 & 2014 \\
\hline Demanda interna & 117.492 .992 & 129.283 .512 & 137.928.207 & 145.001.676 \\
\hline Consumo total & 88.708 .362 & 96.338 .960 & 104.638 .759 & 113.486 .866 \\
\hline Consumo de hogares e IPSFL (2) & 74.017 .752 & 80.664 .656 & 87.567 .098 & 94.532 .899 \\
\hline Bienes durables & 7.068 .948 & 7.907 .886 & 8.889 .637 & 9.181 .115 \\
\hline Bienes no durables & 30.640 .457 & 33.204 .546 & 35.902 .944 & 38.869 .191 \\
\hline Servicios & 36.308 .347 & 39.552 .225 & 42.774 .516 & 46.482 .593 \\
\hline Consumo de Gobierno & 14.690 .610 & 15.674 .304 & 17.071 .661 & 18.953 .968 \\
\hline Variación de existencias & 1.652 .597 & 1.900 .061 & 641.952 & -907.080 \\
\hline Formación bruta de capital fijo & 27.132.032 & 31.044 .491 & 32.647 .496 & 32.421 .891 \\
\hline Construcción y otras obras & 16.751 .193 & 19.097 .361 & 20.972 .672 & 21.876 .089 \\
\hline Maquinaria y equipos & 10.380 .839 & 11.947 .131 & 11.674 .824 & 10.545 .801 \\
\hline Exportación de bienes y servicios & 46.162 .810 & 44.265 .706 & 44.406 .959 & 49.715 .751 \\
\hline Exportación de bienes & 39.435 .085 & 37.905 .101 & 37.935 .198 & 43.246 .110 \\
\hline Agropecuario-silvicola-pesca & 2.397 .970 & 2.451 .848 & 2.755 .429 & 3.237 .438 \\
\hline Mineria & 23.761 .014 & 22.488 .073 & 21.701 .662 & 23.436 .304 \\
\hline Cobre & 21.628 .632 & 20.392.974 & 19.842 .291 & 21.631 .614 \\
\hline Resto & 2.132 .382 & 2.095 .098 & 1.859 .371 & 1.804 .690 \\
\hline Industria & 13.276 .100 & 12.965.180 & 13.478 .106 & 16.572 .368 \\
\hline Exportación de servicios & 6.727 .725 & 6.360 .605 & 6.471 .761 & 6.469 .641 \\
\hline Importación de bienes y servicios & 42.336 .340 & 44.521 .666 & 45.306 .182 & 47.532 .502 \\
\hline Importación de bienes & 36.181 .505 & 38.895 .889 & 39.210 .194 & 41.110 .031 \\
\hline Agropecuario-silvicola-pesca & 535.499 & 579.805 & 610.041 & 661.028 \\
\hline Mineria & 5.215 .755 & 4.848 .699 & 4.779 .545 & 5.114 .965 \\
\hline Industria & 30.430 .252 & 33.467 .385 & 33.820 .607 & 35.334 .038 \\
\hline Importación de servicios & 6.154 .835 & 5.625 .777 & 6.095 .988 & 6.422 .471 \\
\hline $\mathrm{PIB}$ & 121.319 .462 & 129.027 .553 & 137.028 .983 & 147.184 .925 \\
\hline Tasa de inversión en capital fijo & 22,4 & 24,1 & 23,8 & 22,0 \\
\hline Tasa de inversión total & 23,7 & 25,5 & 24,3 & 21,4 \\
\hline
\end{tabular}

Figura 34. Gasto del PIB por sector años 2011 - 2014. Cifras en millones de U\$\$.

Fuente: (Banco Central de Chile, 2014)

Los rubros más significativos que tiene el PIB en Chile están determinados por la actividad minera proveniente del cobre, la actividad minera de exportación de otros productos como Litio y Yodo, la industria de las manufacturas y los servicios empresariales que es donde se encuentran los servicios públicos y privados de aseguramiento principalmente; esta tendencia se ha mantenido desde el 2011 hasta el 2014 presentando un crecimiento reducido pero constante. 


Agropecuario-silvicola
Pesca
Minería
Minería del cobre
Otras actividades mineras
Industria manufacturera
Alimentos
Bebidas y tabaco
Textil, prendas de vestir, cuero y calzado
Maderas y muebles
Celulosa, papel e imprentas
Refinación de petróleo
Química, caucho y plástico
Minerales no metálicos y metálica básica
Productos met., maq. y eq. y otros n.c.p.
Electricidad, gas y agua
Construcción
Comercio
Restaurantes y hoteles
Transporte
Comunicaciones
Servicios financieros
Servicios empresariales
Servicios de vivienda
Servicios personales ( 2 )
Administración pública
PIB a costo de factores
Impuesto al valor agregado
Derechos de importación
PIB

\begin{tabular}{|c|c|c|c|}
\hline 3.357 .540 & 3.330 .408 & 3.628 .642 & 4.009 .841 \\
\hline 631.406 & 459.713 & 422.055 & 475.260 \\
\hline 18.070 .636 & 16.502 .538 & 15.429 .626 & 16.513 .795 \\
\hline 16.113 .918 & 14.621 .643 & 13.553 .776 & 14.707 .227 \\
\hline 1.956 .718 & 1.880 .894 & 1.875 .850 & 1.806 .568 \\
\hline 13.295 .316 & 13.940 .298 & 14.774 .704 & 16.614 .599 \\
\hline 3.109 .379 & 3.282 .881 & 3.660 .109 & 4.748 .574 \\
\hline 1.867 .223 & 2.080 .560 & 2.212 .296 & 2.339 .862 \\
\hline 340.929 & 355.716 & 359.712 & 316.512 \\
\hline 555.626 & 577.433 & 674.477 & 872.970 \\
\hline 1.612 .387 & 1.329 .284 & 1.436 .051 & 1.713 .243 \\
\hline 859.624 & 937.511 & 1.160 .611 & 1.367 .298 \\
\hline 1.855 .719 & 2.076 .538 & 2.049 .624 & 2.035 .003 \\
\hline 869.715 & 785.522 & 705.249 & 709.700 \\
\hline 2.224 .716 & 2.514 .851 & 2.516 .576 & 2.511 .436 \\
\hline 3.365 .933 & 3.180 .881 & 3.343 .457 & 3.438 .689 \\
\hline 8.370 .433 & 9.598 .611 & 10.432 .939 & 10.685 .846 \\
\hline 9.666 .245 & 10.618 .480 & 11.425 .027 & 11.719 .680 \\
\hline 1.811 .673 & 2.121 .415 & 2.371 .518 & 2.579 .793 \\
\hline 4.679 .459 & 5.367 .231 & 5.722 .876 & 6.225 .642 \\
\hline 2.380 .963 & 2.436 .134 & 2.576 .168 & 2.659 .935 \\
\hline 6.072 .856 & 6.716 .952 & 7.101 .259 & 7.538 .021 \\
\hline 15.451 .677 & 17.352 .440 & 19.037 .919 & 20.519 .720 \\
\hline 5.872 .699 & 6.432 .796 & 7.007 .488 & 7.582 .097 \\
\hline 13.109 .764 & 14.293 .316 & 15.852 .432 & 17.163 .608 \\
\hline 5.184 .059 & 5.617 .380 & 6.185 .159 & 6.743 .234 \\
\hline 111.320 .661 & 117.968 .593 & 125.311 .269 & 134.469 .761 \\
\hline 9.347 .631 & 10.360 .644 & 11.041 .649 & 12.001 .138 \\
\hline 651.170 & 698.316 & 676.066 & 714.026 \\
\hline 121.319 .462 & 129.027 .553 & 137.028 .983 & 147.184 .925 \\
\hline
\end{tabular}

Figura 35. Producto Interno Bruto por clase de actividad económica años 2011 - 2014. Cifras en millones de U\$.

Fuente: (Banco Central de Chile, 2014)

Los sectores que tienen una mayor participación en el gasto del PIB chileno son demanda interna, formación bruta de capital fijo e importación de bienes y servicios, este último presentando una fuerte caída después del año 2011, lo cual es explicado principalmente porque luego de 2012 Chile optó por generar grandes acuerdos comerciales (TLC) con las principales potencias económicas mundiales como China. De acuerdo a esto, la libertad arancelaria para enviar productos a otros países fue mayor, lo cual favorece sin duda los términos de intercambio de los productos provenientes de la silvicultura y la minería con productos como el salmón y el cobre, en el caso de particular del primero Chile potenció enormemente la industria pesquera hasta el punto 
de llegar a ser competidor grande en exportación de este tipo de pescado a nivel mundial junto a Noruega, que actualmente es el país que más pescado exporta a nivel mundial; y en el caso del cobre, Chile es el mayor productor de este mineral en todo el planeta.

\begin{tabular}{lcccccc}
\hline Especificación & $\mathbf{2 0 1 1}$ & $\mathbf{2 0 1 2}$ & $\mathbf{2 0 1 3}$ & $\mathbf{2 0 1 4}$ & $\mathbf{2 0 1 5}$ & $\mathbf{2 0 1 6}$ \\
\hline Demanda Interna & 9,4 & 7,3 & 3,6 & $-0,3$ & 2,0 & $\mathbf{1 , 3}$ \\
\hline Consumo Total & 7,8 & 5,7 & 5,2 & 2,8 & 2,5 & $\mathbf{2 , 8}$ \\
\hline Consumo Privado & 8,9 & 6,1 & 5,5 & 2,4 & 1,9 & $\mathbf{2 , 1}$ \\
\hline Consumo Gobierno & 2,5 & 3,5 & 3,5 & 5,1 & 5,8 & 5,9 \\
\hline $\begin{array}{l}\text { Formación Bruta Capital } \\
\text { Fijo }\end{array}$ & 15,0 & 11,6 & 2,2 & $-4,2$ & $-1,5$ & $\mathbf{1 , 9}$ \\
\hline $\begin{array}{l}\text { Exportación Bienes y } \\
\text { Servicios }\end{array}$ & 4,1 & 1,8 & 3,9 & 2,0 & $-1,8$ & 0,4 \\
\hline $\begin{array}{l}\text { Importación Bienes y } \\
\text { Servicios }\end{array}$ & 16,0 & 4,8 & 2,1 & $-5,7$ & $-2,8$ & $-\mathbf{1 , 3}$ \\
\hline \begin{tabular}{l} 
Producto Interno Bruto \\
\hline
\end{tabular} & $\mathbf{5 , 8}$ & $\mathbf{5 , 5}$ & $\mathbf{4 , 0}$ & $\mathbf{1 , 9}$ & $\mathbf{2 , 3}$ & $\mathbf{1 , 9}$ \\
\hline
\end{tabular}

Figura 36. Gasto del PIB por grandes sectores años 2011 - 2016 (porcentajes)

Fuente: Sociedad de Fomento Fabril (2016)

\subsection{Aspectos centrales de la Reforma Previsional de 2008}

Esta sección del documento tiene como propósito sintetizar para el lector los aspectos puntuales que llevaron al gobierno de Michelle Bachelet a realizar la gran Reforma Integral al Sistema Previsional de 2008; también se citan referencias de autores que muestran una crítica sólida al sistema de pensiones y a su estructuración a partir de la reforma. Finalmente se enseñan los desafíos pendientes que deja esta reforma y que de abordarse de la forma adecuada podría llevar al aumento de la cobertura y la calidad en la prestación de servicios de aseguramiento.

En esta instancia es importante destacar que las necesidades que presentaba el Sistema Previsional en el año 2008 en los diferentes sectores sociales marcó el comienzo de una serie de acciones que buscaban reducir la pobreza mediante programas de promoción del empleo, 
transferencias condicionadas y subsidios estatales que pudieran incentivar la cotización permanente al Sistema Previsional, esto último debido a que las finanzas públicas chilenas se estaban reduciendo considerablemente luego de que los jóvenes empezaran a percibir que la posibilidad de alcanzar una pensión podría ser nula; para ello el gobierno nacional optó por generar beneficios a la población joven para poder seguir constituyendo y dando cumplimiento al principio de intergeneracionalidad y a las tasas de reemplazo.

\section{El enfoque multipilar del Banco Mundial}

La descripción de la Seguridad Social en base a pilares surge de la publicación del Banco Mundial de 1994 "Envejecimiento sin crisis". En este documento se plantea que el primer pilar de la seguridad social (también llamado Pilar público) debe tener como objetivo principal aliviar la pobreza en la vejez; la contribución a este pilar debe ser obligatoria. Además, al ser financiado con impuestos generales posee una función redistributiva (solidaria); este Pilar público puede tener tres formas alternativas: un programa orientado a los ancianos pobres, con un criterio de otorgamiento que considere características como la capacidad de trabajar o las necesidades propias de la edad; una garantía de pensión mínima relacionada con el segundo Pilar de ahorro obligatorio; proveer un beneficio universal, probablemente de tamaño pequeño para así dejar espacio a los otros pilares (Cechinni \& Martínez, 2011).

El segundo pilar, también de contribución obligatoria, debe ser administrado privadamente y debe estar orientado a la suavización de consumo para toda la población; este pilar no requiere de financiamiento externo sino que es totalmente capitalizado. El hecho de ser administrado privadamente permite evitar potenciales distorsiones políticas a las que el primer pilar puede ser proclive; además este pilar puede tener dos formas alternativas: cuentas de capitalización o planes ocupacionales.

Finalmente, el tercer pilar corresponde a los planes voluntarios, el objetivo de este pilar es proveer protección adicional para las personas que desean más ingresos en su vejez.

Posteriores publicaciones, también del Gill, Packard y Yermo (2004) y Cechinni y Martínez (2011) enriquecen la definición. Así, en el caso de la primera se simplifican las definiciones de los pilares al categorizarlos solo por su objetivo más que por su financiamiento (público o privado) o administración (cuentas individuales o de reparto). Por tanto, se utiliza el término primer pilar para 
referirse a la parte del sistema de pensiones que se preocupa de evitar la pobreza en la vejez. El término segundo pilar se refiere a la parte de la seguridad social que es de contribución obligatoria y que busca ayudar a los individuos a suavizar el consumo a lo largo de todo su ciclo de vida, y así evitar una caída brusca de los ingresos al momento de pensionarse. Finalmente, el término tercer pilar identifica a las instituciones e instrumentos disponibles para los trabajadores que les permiten aumentar su ingreso en la etapa de retiro.

Igualmente, la PMG (Pensión Mínima Garantizada) y la PASIS (Pensión Asistencial) pueden conceptualizarse como un Pilar solidario del Sistema chileno de Pensiones. En primer lugar, la PMG busca garantizar un beneficio mínimo a los afiliados y haciendo que el Estado supla las posibles insuficiencias que pueda llegar a tener el fondo de capitalización individual en donde se encuentran consignados los recursos de los afiliados y que podrían incurrir en bajos márgenes de rentabilidad. La PASIS, por su parte, constituye un beneficio no contributivo y está de acuerdo al entorno social y de ingresos en condición de discapacidad que no reciben ningún tipo de ingreso. Ambas alternativas de pensión se financian con recursos fiscales y se hayan más focalizadas que cualquier otro programa previsional en el país.

En la actualidad, el valor de la Pensión Mínima alcanza valores (año 2006) de entre \$ 87.853 y \$102.492 mensuales según la edad del pensionado, en tanto que la Pensión Asistencial varía entre $\$ 44.186$ y \$ 51.503 mensual. Estos valores se reajustan automáticamente cada año sobre la base de la inflación del año anterior, pero también han sido objeto de varios reajustes especiales, el último de ellos en mayo de 2006. Dichos reajustes han incrementado el valor real de las pensiones mínimas y asistenciales en alrededor de un $75 \%$ y un $161 \%$ real desde 1989, respectivamente. Esto ha permitido que la Pensión Mínima haya mantenido una relación bastante estable con el ingreso mínimo y que la PASIS se ubique en un nivel cercano a la línea de pobreza per cápita, correspondiente a $\$ 46.917$ mensuales.

\section{Intervención y necesidad de la Reforma Previsional}

Según las encuestas CASEN (encuesta integrada de hogares realizada de forma bianual) que actúa como instrumento censal de la población chilena, existieron dos elementos que determinaron una intervención integral y profunda al sistema de pensiones chileno, estos fueron: el 
envejecimiento gradual y progresivo de la población, y la desigualdad de ingresos en los diferentes grupos etarios en el país.

A continuación se muestran los objetivos que dieron vía libre al proceso para reformar el sistema de pensiones de Chile en el año 2008 en cabeza de Michelle Bachelet como presidenta y del Consejo Asesor Presidencial para la Reforma Previsional creado mediante el Decreto Ley 336 de 2006, estos objetivos están compuestos y orientados a ser metas de cumplimiento según lo establecido por el Consejo Asesor Presidencial para la Reforma Previsional (2006):

- Optar por generar la mayor universalización posible de las garantías de cobertura de los beneficios del sistema de previsión de toda la población. Esta meta debe llevar como contraparte un alto compromiso de cumplimiento de los compromisos actuales del sistema y de una minuciosa verificación del comportamiento de las medidas que sean utilizadas a través del tiempo para lograr la universalización.

- Se deben elevar las tasas de reemplazo de las pensiones de vejez contributivas hasta ser comparables con países de un mayor desarrollo en estos temas. La tasa de reemplazo es un indicador que muestra la capacidad del sistema de pensiones de reducir los riesgos de caída del consumo al pasar de la vida laboral activa al retiro. La actual tasa de reemplazo promedio en Chile alcanza a alrededor de un $45 \%$, mientras que la tasa de reemplazo en los países de la OECD se eleva, en promedio, a un $60 \%$ para el beneficiario medio.

- Eliminar el riesgo de pobreza en la vejez, lo que requiere generar beneficios mínimos que garanticen ingresos dignos a la población. Aunque esto no quiere decir que se pueda evitar que un pensionado pertenezca a un hogar pobre, de cierta manera sí le garantiza un nivel de consumo que le permita al menos satisfacer sus necesidades básicas.

Para alcanzar los objetivos finales indicados se proponen seis objetivos intermedios que por estar más directamente asociados al funcionamiento del Sistema Previsional, permiten vincular reformas específicas en distintas áreas del funcionamiento del sistema a sus resultados finales. Los objetivos intermedios propuestos son los siguientes:

- Estructurar un Pilar solidario fuerte e integrado. Un Pilar solidario es un soporte fundamental de cualquier Sistema Previsional que aspire a lograr altos estándares de protección, equidad y cobertura. En este contexto, la dimensión solidaria se entiende referida a otorgar beneficios 
dirigidos a los sectores más desprotegidos, que en su monto y financiamiento no estén directamente ligados a los aportes realizados por el propio trabajador.

- Elevar la densidad de cotizaciones al sistema contributivo. Esta es una condición imprescindible para incrementar las tasas de reemplazo y reducir su dispersión; los elementos aportados en el diagnóstico de este informe sugieren que en Chile es posible elevar la densidad de cotizaciones en la medida en que se reconozcan las actuales realidades del mercado del trabajo y se fortalezcan los incentivos a cotizar.

- Intensificar la competencia en base a precios en la industria de servicios previsionales. El régimen de capitalización individual, al recurrir a mecanismos de mercado para asegurar eficiencia en la administración de fondos, requiere de altos niveles de competencia en la industria de servicios previsionales. La competencia es también una garantía a los afiliados de que no serán víctimas de arbitrariedades de parte de los administradores y que tendrán alternativas de elección que se adecuen a sus necesidades, dentro de las limitaciones que impone un sistema obligatorio [...]. (Consejo Asesor Presidencial para la Reforma Previsional, 2006, p. 30)

- Generar un mejoramiento en la gestión de riesgo financiero y aumentar el retorno de los aportes del trabajador, con el objetivo de producir la mayor rentabilidad posible. La esencia del régimen de capitalización individual se basa en hacer uso de los aportes del trabajador capitalizados para financiar su monto pensional a futuro; la fuerza de este mecanismo está directamente relacionada con la rentabilidad lograda en la inversión de los aportes de la cuenta individual. Los resultados vistos en el largo plazo del sistema de capitalización dependen de la rentabilidad de las inversiones de los fondos, de los riesgos que se asumen en dicho proceso, de las comisiones cobradas al afiliado como resultado de la prestación de este servicio y del costo de la renta vitalicia.

- Fortalecer el Pilar voluntario. La historia laboral de muchos afiliados al sistema de AFP incluye períodos relativamente prolongados de desempleo, de trabajo en el sector informal y, particularmente en el caso de las mujeres, fuera del mercado de trabajo. Junto con esto existe una marcada variabilidad en los ingresos que reciben algunas personas al pasar de un trabajo a otro. Por otra parte, un porcentaje creciente de afiliados reciben rentas iguales o superiores al tope imponible; a estos fenómenos se suman los efectos negativos sobre el monto de la pensión de la tendencia al aumento en la expectativa de vida de la población. El 
ahorro previsional voluntario es un instrumento particularmente apropiado para que los trabajadores que lo requieran compensen los efectos de un insuficiente monto de ahorro previsional obligatorio. Además, el ahorro previsional voluntario permite a las personas que tienen remuneraciones por sobre el tope imponible financiar pensiones que sean razonablemente proporcionales a los ingresos efectivos que tenían en actividad.

- Elevar la transparencia y predictibilidad del sistema. Un sistema obligatorio de pensiones busca subsanar los problemas de imprevisión de las personas, anticipándose a las consecuencias sociales futuras de tal comportamiento. La obligatoriedad de afiliación acarrea como contrapartida una obligación de transparencia y predictibilidad del sistema y sus administradores lo que, a su vez, resulta fundamental para lograr el objetivo de reducir la incertidumbre de las personas respecto de sus medios de subsistencia en la vejez [...]. (Consejo Asesor Presidencial para la Reforma Previsional, 2006, p. 30)

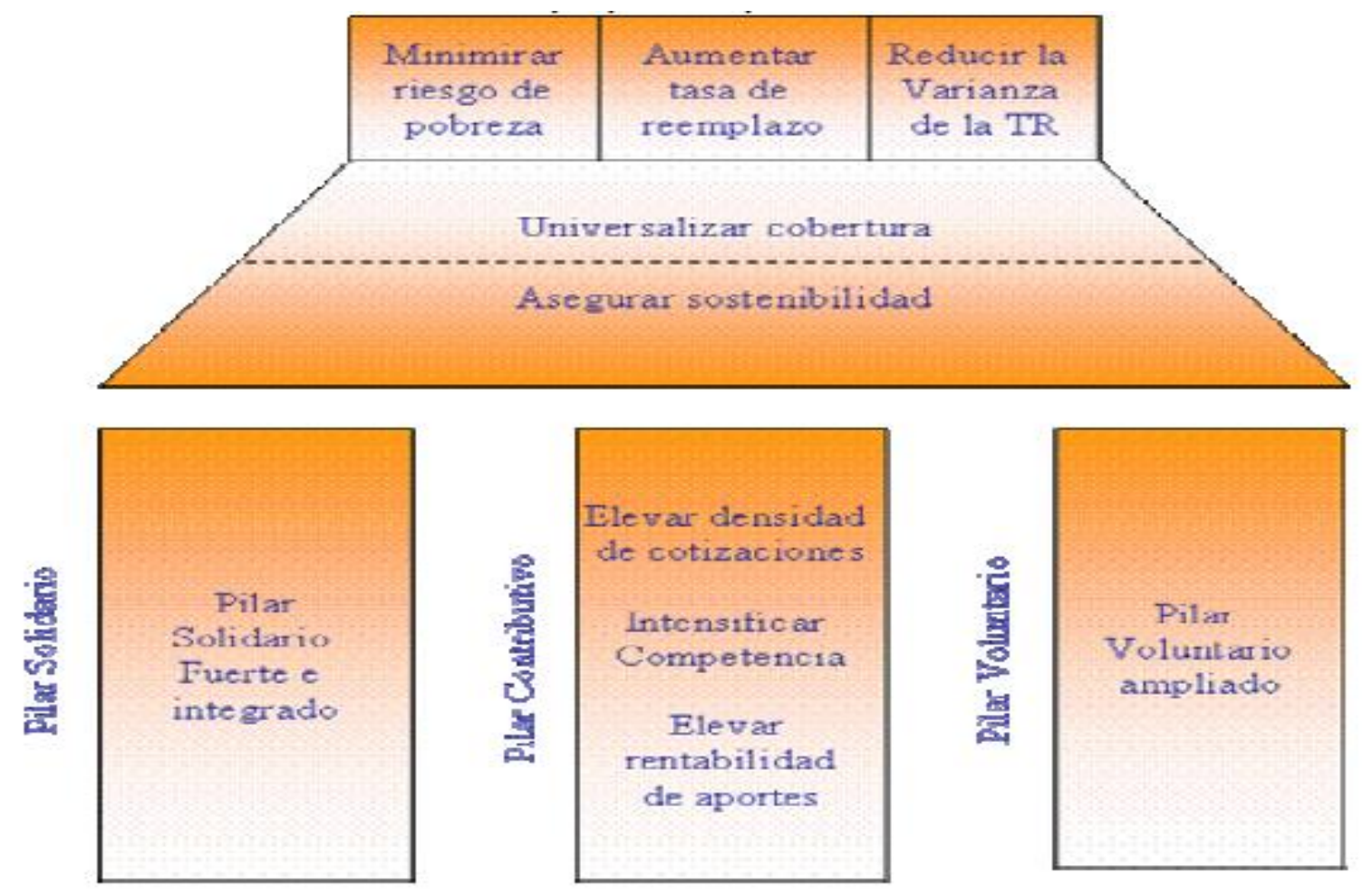

Transparencia y predictibilidad

Figura 37. Objetivos para abordar la Reforma Previsional 
Fuente: (Consejo Asesor Presidencial para la Reforma Previsional, 2006)

En consecuencia, y siguiendo las orientaciones contenidas en los acuerdos que estableció el gobierno nacional con los sectores participes de la reforma, el Consejo para la Reforma Previsional propone que la estructura del modelo previsional sea multipilar. Esto quiere decir que en lugar de hacer prevalecer un régimen sobre otro, o desarrollar sistemas paralelos e independientes, se propone consolidar el sistema con base en tres pilares: el solidario, el contributivo y el voluntario; con elementos complementarios e integrados.

Sobre la base de los criterios y objetivos anteriores, las propuestas del Consejo se ordenan en las siguientes once áreas:

1. Nuevo Pilar solidario

2. Cobertura, densidad de cotizaciones y cumplimiento del mandato de cotizar

3. Equidad de género

4. Competencia y organización de la industria de AFP

5. Competencia y precios

6. Inversión de los fondos de pensiones

7. Pensiones en el Pilar contributivo

8. Ampliación de Pilar voluntario

9. Educación e información

10. Institucionalidad

\section{Disciplina financiera}

Cada una de estas áreas tiene su propio análisis y propuestas respectivas por parte de los entes gubernamentales que permiten realizar la reforma acorde a lo establecido, teniendo en cuenta que al ser una gran reforma su aplicación debe ser gradual para evitar impactar sectores vulnerables del país.

\section{Cobertura del Pilar Solidario}


La cobertura del Pilar Solidario debe ser definida en forma cuidadosa y circunscrita al objetivo de dar una garantía para que las personas tengan una vejez digna; para ello el Estado debe actuar focalizadamente complementando los ingresos de los adultos mayores. El Nuevo Pilar Solidario presenta un diseño adecuado y tiene entre sus virtudes principales que las personas que aportan más recibirán mayores pensiones gracias a un retiro gradual del subsidio del Estado. Sin embargo, este pilar, además, debería garantizar una alta equidad horizontal y vertical (Robles et al., 2014).

Tal como está planteado actualmente, el pilar no garantiza estos principios; para evitarlo es más razonable establecer una pensión autofinanciada total que incorpore en alguna proporción otras pensiones familiares e ingresos no laborales. De esta forma aunque la persona no haya acumulado fondos tendrá, para efectos del cálculo del subsidio, una pensión autofinanciada mayor que cero. Esta modalidad de definición de la pensión autofinanciada garantizaría no solo la equidad adecuada sino también una focalización apropiada de acuerdo a la iniciativa pensional planteada.

\section{Elegibilidad para acceder al Nuevo Pilar Solidario}

Por los siguientes motivos:

- Se realiza una prueba de afluencia al momento de la jubilación.

- El sistema es de derechos individuales

- Existen seguros de invalidez y sobrevivencia

El test de afluencia (necesario para poder acceder a los beneficios del Pilar Solidario) solo puede aplicarse al momento de la edad de jubilación y no repetirse al momento del fallecimiento de uno de los cónyuges, de modo que no discrimine conforme a la capacidad de ahorro y estructura de la familia a lo largo de la vida. Ello sin perjuicio de que una persona reciba dos prestaciones del sistema.

\section{Eximir de la obligación de cotizar y rebaja de tasa de cotización}

Rebaja de tasa de cotización, especialmente por la carga que significa cotizar para las personas de bajos ingresos que no tienen capacidad alguna de ahorro y por ser un posible incentivo de formalización de aquellos trabajadores con menor calificación. Por ello: 
1. Se exime de cotizar a trabajadores, sin distinción, que perciban un ingreso igual o menor al mínimo.

2. Los trabajadores que perciban un ingreso superior al mínimo y menor o igual al $85 \%$ de dos ingresos mínimos mensuales deberán realizar cotizaciones graduales, estas irán aumentando de un $4 \%$ hasta un $8 \%$ según sea el tramo que se defina.

3. Los trabajadores que perciban ingresos superiores al $85 \%$ de dos ingresos mínimos deberán cotizar por el $10 \%$ del ingreso base de cotización.

\section{Se propone eliminar legalmente la posibilidad que se le otorgó a los empleadores de realizar una "Declaración y no pago" de las cotizaciones previsionales de los trabajadores.}

Los fundamentos de esta propuesta son los siguientes:

- Las cotizaciones previsionales son parte fundamental de la porción social del salario de los trabajadores, por lo cual no es viable que los empleadores se apropien de ellas y las utilicen para pagarlas a comodidad de ellos. Esto a vista de los trabajadores se constituye en un abuso por parte del empleador y afecta en gran medida a los trabajadores y sus familias.

- Una gran cantidad de trabajadores perdió sus cotizaciones y con ellas el tiempo o semanas cotizadas, debido a que algunas empresas que se apegaban a la medida de "declaración y no pago" entraron en bancarrota o desaparecieron del mercado, por lo que no es posible recuperar los montos que se adeudan.

- Una medida altamente efectiva para delatar a los deudores morosos es el uso masivo de las tecnologías (pagos electrónicos) para realizar los pagos al Sistema Previsional.

\section{Propuesta para igualar las edades de jubilación de las mujeres y/o acceder al Pilar} Solidario.

En opinión contraria a la propuesta de subir en cinco años la edad de la mujer para jubilar, a fin de igualar este requisito con los hombres, como una medida tendiente a resolver las diferencias de monto de pensión que la lógica contributiva de la capitalización individual requiere. En respuesta a esa misma lógica esencialmente contributiva, las mujeres deberían tener capacidad de ahorro para incrementar su saldo los cinco años que se demandan para "igualar” el cálculo de la pensión con el de los hombres. Para ello requiere generar ingresos más allá de los 60 años, cuestión que de acuerdo a las características estructurales del mercado y de la división existente entre el trabajo 
remunerado y no remunerado o doméstico que latamente da cuenta el diagnóstico absolutamente desfavorables a la mujer, no aparece como factible.

Por su parte, las mujeres han aumentado su participación en la fuerza laboral para poder mantenerse a sí y a sus familias, se han incorporado al empleo formal e informal en condiciones pocos favorables y sustancialmente volátiles, y aumentaron su trabajo doméstico no remunerado debido a la disminución de sus ingresos (Prado \& Sojo, 2010). No existe evidencia clara de que tales condiciones de desigualdad vayan disminuyendo, en equivalencia con la progresividad de aumento de edad de jubilación que se ha planteado y que esta opinión no comparte.

Por otra parte, con la lógica de "igualar edad" persiste también la diferencia en el monto de pensión entre hombres y mujeres, ya que las mayores expectativas de vida de estas impactan negativamente en el cálculo de su pensión al aplicar tablas diferenciadas por sexo. Es necesario, entonces, abordar el tema de la edad de jubilación de las mujeres desde la perspectiva del enfoque de género que debe considerar la reforma al sistema de pensiones. Una reforma no puede establecer una regla con base en una predicción incierta de la realidad social en los próximos veinte años (Salazar, 2011).

Ahora, si hay condiciones de igualdad en el futuro, una sociedad democrática como la chilena tendrá la capacidad política para discutir si se justifica o no un trato diferenciado. Con la realidad actual no solo se justifica sino que se constituye un imperativo ético para asegurar la equidad de género. Para lograr una acertada y aumentada inserción de las mujeres en el sistema pensional se sugiere lo siguiente:

- El Sistema Previsional debe optar por generar una equidad de género en la que la mujer vea posicionado su rol como cotizante activo y con normas que permitan que los beneficios sean pensados y estructurados para ambos géneros.

- En definitiva, se sugiere que la edad de jubilación se mantenga como hasta ahora, las mujeres a los 60 años incluyendo el Pilar Solidario, con mecanismos solidarios de corrección (o nivelación) que permitan retribuir el periodo de 5 años en los que la mujer por los factores genéticos (hijos) debe retirarse del mercado laboral y le cuesta mucho más reinsertarse que a los hombres. Esto desencadena un menor monto pensional obtenido al final de su vida laboral activa. 
- Generar incentivos para que la mujer ingrese a la fuerza laboral y se mantenga en ella después de los 60 años.

\begin{tabular}{|c|c|c|c|c|c|}
\hline & & \multicolumn{2}{|c|}{ Trabaja } & \multicolumn{2}{|c|}{ No trabajó nunca } \\
\hline & & Pilar Solidario & Mayores recursos & Pilar Solidario & $\begin{array}{l}\text { Mayores } \\
\text { recursos }\end{array}$ \\
\hline \multirow{2}{*}{ Casada } & Con hijos & $\begin{array}{l}\text { Pensión básica universal } \\
\text { Fondo de capitalización ind. } \\
\text { Pensión de sobrevivencia } \\
\text { Subsidio Pilar Solidario* } \\
\text { Subsidio hijo nacido vivo }\end{array}$ & $\begin{array}{c}\text { Fondo de capitalización } \\
\text { individual } \\
\text { Pensión de } \\
\text { sobrevivencia }\end{array}$ & $\begin{array}{l}\text { Pensión básica } \\
\text { universal } \\
\text { Pensión de } \\
\text { sobrevivencia } \\
\text { Subsidio hijo } \\
\text { nacido } \\
\end{array}$ & $\begin{array}{l}\text { Pensión de } \\
\text { sobrevivencia }\end{array}$ \\
\hline & Sin hijos & $\begin{array}{l}\text { Pensión básica universal } \\
\text { Fondo de capitalización ind. } \\
\text { Pensión de sobrevivencia } \\
\text { Subsidio Pilar Solidario }\end{array}$ & $\begin{array}{c}\text { Fondo de capitalización } \\
\text { individual } \\
\text { Pensión de } \\
\text { sobrevivencia }\end{array}$ & $\begin{array}{l}\text { Pensión básica } \\
\text { universal } \\
\text { Pensión de } \\
\text { sobrevivencia }\end{array}$ & $\begin{array}{l}\text { Pensión de } \\
\text { sobrevivencia }\end{array}$ \\
\hline \multirow{2}{*}{ Soltera } & Con hijos & $\begin{array}{l}\text { Pensión básica universal } \\
\text { Fondo de capitalización ind. } \\
\text { \% Pensión de sobrevivencia } \\
\text { Subsidio Pilar Solidario } \\
\text { Subsidio hijo nacido vivo }\end{array}$ & $\begin{array}{c}\text { Fondo de capitalización } \\
\text { individual } \\
\% \text { Pensión de } \\
\text { sobrevivencia }\end{array}$ & $\begin{array}{l}\text { Pensión básica } \\
\text { universal } \\
\text { Subsidio hijo } \\
\text { nacido } \\
\text { \% Pensión de } \\
\text { sobrevivencia } \\
\end{array}$ & $\begin{array}{l}\% \text { Pensión de } \\
\text { sobrevivencia }\end{array}$ \\
\hline & $\begin{array}{l}\text { Sin hijos, a } \\
\text { cargo de } \\
\text { familiares }\end{array}$ & $\begin{array}{l}\text { Pensión básica universal } \\
\text { Fondo de capitalización ind. } \\
\text { \% Pensión de sobrevivencia } \\
\text { Subsidio Pilar Solidario }\end{array}$ & $\begin{array}{c}\text { Fondo de capitalización } \\
\text { individual } \\
\% \text { Pensión de } \\
\text { sobrevivencia }\end{array}$ & $\begin{array}{l}\text { Pensión básica } \\
\text { universal } \\
\text { \% Pensión de } \\
\text { sobrevivencia }\end{array}$ & \\
\hline \multicolumn{2}{|c|}{$\begin{array}{l}\text { Sin responsabilidades } \\
\text { familiares }\end{array}$} & $\begin{array}{l}\text { Pensión básica universal } \\
\text { Fondo de capitalización ind. } \\
\text { Subsidio Pilar Solidario }\end{array}$ & $\begin{array}{c}\text { Fondo de capitalización } \\
\text { individual }\end{array}$ & $\begin{array}{c}\text { Pensión básica } \\
\text { universal }\end{array}$ & \\
\hline
\end{tabular}

Figura 38. Beneficios para las mujeres con la aplicación de la reforma

Fuente: (Consejo Asesor Presidencial para la Reforma Previsional, 2006)

La figura anterior ilustra la forma en la cual el Estado buscó incentivar la densidad de cotización de las mujeres, a partir de una estrategia que permitiera garantizar el aumento de la cobertura previsional en la población femenina vía beneficios tangibles para ellas de acuerdo a su estructura de núcleo familiar y a sus condiciones particulares de vida, según corresponda el caso. La idea es que a la par que se cotiza y se alimenta el Sistema Previsional también se incremente la posibilidad de alcanzar la jubilación con ingresos para las mujeres, mermando las diferencias con respecto a los hombres en cuanto a este sector pensional y de trabajo.

\section{Indización de renta imponible máxima}


Se ha propuesto indexar la renta imponible máxima (UF 60) a la evolución de las remuneraciones medias en el país. La imposición de cotizar se justifica por la miopía de las personas, pero este argumento no justifica un mandato ilimitado. Son los individuos quienes deben cubrirse más allá de ciertos umbrales razonables que les permitan sostener, luego del retiro, niveles de consumo superiores. Para ello pueden utilizar tanto los mecanismos de ahorro previsional voluntario que establece la regulación, como las distintas formas e instrumentos de ahorro privado disponibles en el mercado.

Cabe recordar que este Consejo ha recomendado, además, que se fortalezcan los incentivos para el ahorro previsional voluntario, incluyendo el desarrollo de planes de ahorro previsional colectivo. Por otra parte, ha propuesto que los beneficios del Pilar Solidario se indexen al índice de precios al consumidor y no a la evolución del salario medio. Por tanto, se hace inclinación por mantener la actual renta imponible en UF60. Dado que el presente informe plantea una estructura mixta del sistema al integrar el Pilar público con el contributivo, se proponen los siguientes objetivos para esta sección:

- Conciliar la capitalización individual con el principio de solidaridad.

- Destacar el carácter tripartito del financiamiento del Sistema Previsional.

En las propuestas se debe señalar:

- En los ejercicios actuariales debe considerarse el derecho de la persona a las prestaciones garantizadas, y los requisitos de elegibilidad, por sobre las consideraciones macroeconómicas.

- El nuevo acuerdo social deberá identificar y comprometer fuentes específicas de aportes al fondo solidario.

1. Se aumentarán gradualmente (por ejemplo, mediante un aumento de 0,5\% anual) las cotizaciones hasta en un $2 \%$, con cargo a los empleadores. A largo plazo, esto debería incidir en un aumento de un $20 \%$ de todas las jubilaciones, fundamentado en que dada la realidad del mercado de trabajo chileno, se considera que un $10 \%$ neto de cotizaciones es insuficiente para otorgar jubilaciones dignas. Téngase en cuenta que países desarrollados tienen tasas de cotizaciones previsionales mucho más altas: 
Alemania 19,5 \%; Suecia 18,5 \%. Estos aportes permitirán disminuir los costos fiscales para el Pilar Solidario.

2. Se trata de que los trabajadores que ganan más contribuyan solidariamente con los que ganan menos, ya que todos están insertos en el mismo sistema. La solidaridad directa es importante para generar una cultura que permita una distribución más equitativa de los ingresos en nuestra sociedad.

\subsection{Institucionalidad del Sistema Previsional chileno}

El actual sistema de pensiones chileno se caracteriza por tener dentro de sí una gran cantidad de organismos de carácter institucional, en los que cabe destacar todos o en su gran mayoría se relacionan con el Ministerio de Trabajo y Previsión Social, institución que permite el funcionamiento de las demás como un engranaje que va atado a otras instituciones de origen privado y que actúan de forma complementaria para estructurar el sistema.

Tal dispersión (gran variedad institucional) es reflejo de una dispersión de las funciones ejecutivas, normativas y regulatorias de los diversos regímenes que lo integran entre diversas instituciones públicas y privadas. Es así como en el funcionamiento de los distintos regímenes que integran el Sistema Previsional intervienen del lado público la Subsecretaría de Previsión Social, la Superintendencia de Seguridad Social (SUSESO), la Superintendencia de Administradoras de Fondos de Pensiones (SAFP), la Dirección de Presupuestos, la Tesorería General de la República, el Ministerio de Planificación (MIDEPLAN), el Instituto de Normalización Previsional (INP), las intendencias y las municipalidades (Berstein, 2010).

Dicha dispersión institucional es particularmente notoria en torno a los beneficios que otorga el Pilar Solidario. La PMG es administrada por las AFP, correspondiendo al sector público una función esencialmente de tesorería, a través, precisamente de la TGR; la PASIS es administrada por el INP, los gobiernos regionales, los municipios y más recientemente por MIDEPLAN. Por otro lado, la SAFP supervigila el funcionamiento de las AFP en la prestación de sus servicios y la administración de sus fondos, reglamenta el funcionamiento de estas, recibe reclamos y consultas del público, administra el seguro de cesantía y realiza estudios. La SUSESO tiene 
responsabilidades de regulación y reglamentación sobre variados componentes del sistema de seguridad social (Berstein, El sistema chileno de pensiones, 2010).

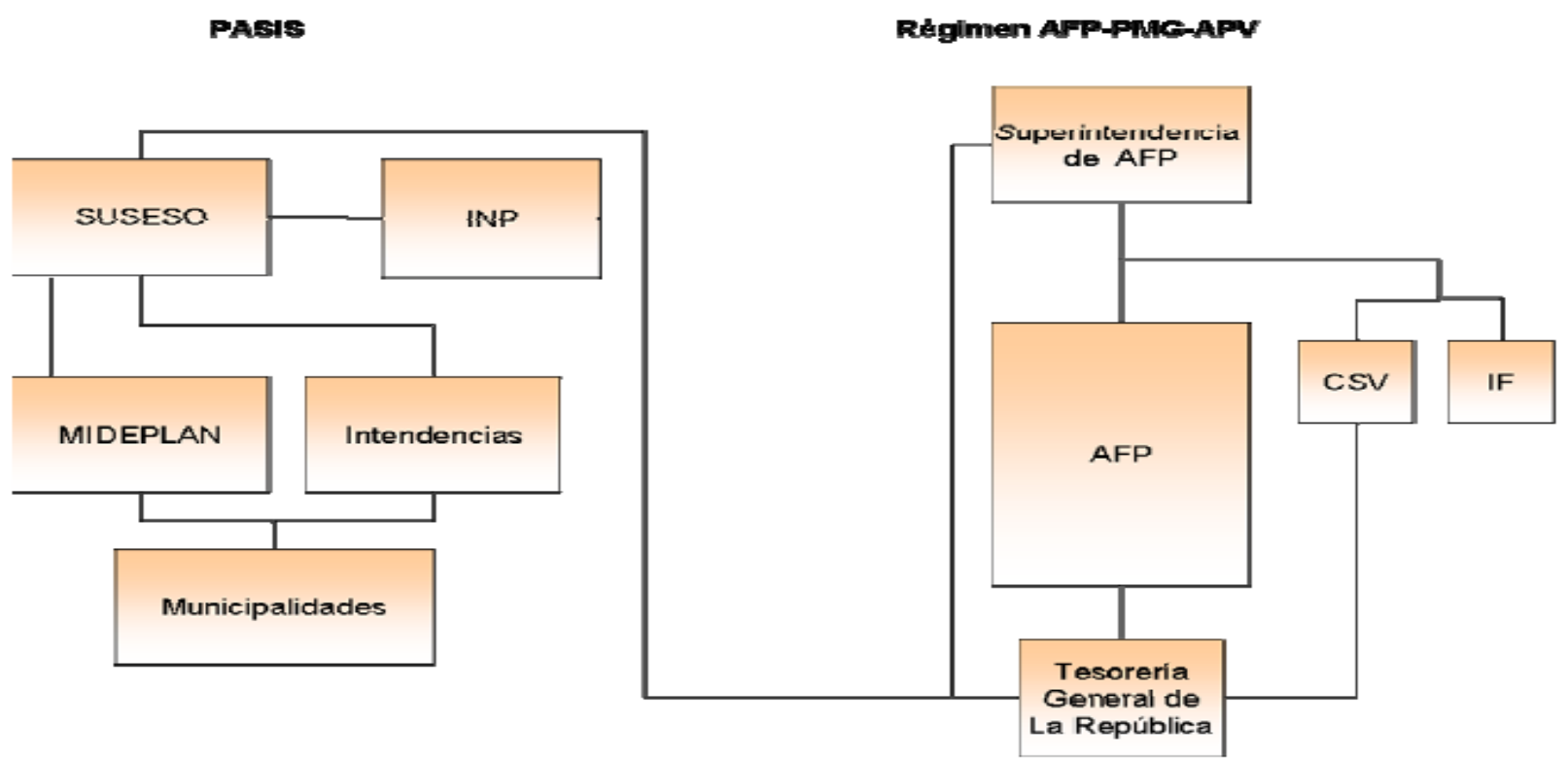

Figura 39. Estructura institucional del Sistema Previsional año 2006

Fuente: (Consejo Asesor Presidencial para la Reforma Previsional, 2006)

El INP se encarga de administrar los beneficios que otorgaba el antiguo Sistema Previsional, igualmente se encarga del recaudo de las cotizaciones para otras instituciones públicas y administra la Ley de Accidentes del Trabajo para sus afiliados. La formulación de políticas es en principio responsabilidad del Ministerio del Trabajo y Previsión Social, supuestamente a través de la Subsecretaría de Previsión, pero tiene poca capacidad analítica propia y debe apoyarse en alguno de sus organismos dependientes. En esta instancia también interviene el Ministerio de Hacienda a través de la Dirección de Presupuestos.

No obstante, estas responsabilidades institucionales se encuentran débilmente articuladas, lo que se traduce en una particular debilidad en la supervisión y conducción superior del sistema como un todo. Esta realidad parece contradictoria con el reconocimiento de la seguridad social como un derecho constitucional y explica en parte por qué ha tomado tanto tiempo plantear una 
evaluación global del funcionamiento del sistema y la elaboración de un conjunto articulado de propuestas de reforma.

Por su parte, las AFP están sujetas a la estructura de gobernabilidad corporativa aplicable a las sociedades anónimas, con normas especiales referentes al nombramiento de directores en las sociedades anónimas con participación de los fondos que administran. Pese a que el sistema de pensiones se financia íntegramente con cotizaciones de los trabajadores, en toda esta institucionalidad no existe ninguna instancia en que la voz de los afiliados pueda expresarse, más allá de los canales administrativos comunes al sector público o de procesamiento de reclamos, todo ello en una lógica estrictamente individual (Saavedra, , 2014). Con el objeto de alcanzar los objetivos propuestos de manera coherente con las propuestas de reforma del sistema, incluyendo especialmente la creación de un Nuevo Pilar Solidario, el Consejo propone un conjunto de modificaciones a la institucionalidad pública vinculada al Sistema Previsional y a su marco normativo que se detallan a continuación.

Para ello se sugiere realizar una consolidación de una sola institución pública que se haga cargo de regular los distintos pilares que componen el Sistema Previsional. Dicha instancia será responsable de resguardar los derechos de los afiliados, regular el funcionamiento de los administradores, integrar las bases de datos y promover el conocimiento del Sistema Previsional. Esa institución deberá estar investida de la autoridad y autonomía necesaria para ejercer sus funciones con consistencia y rigurosidad. Esta Superintendencia se estructurará sobre la base de la actual SAFP y de algunas funciones de la SUSESO.

La estructura de la Superintendencia de Pensiones debería contemplar intendencias especializadas en cada uno de los pilares que integrarán el sistema: el Nuevo Pilar Solidario, el Pilar Contributivo Obligatorio y el Pilar Voluntario (Saavedra, 2014). En particular, el Pilar Contributivo Obligatorio debe estar bajo la supervigilancia de una Intendencia de Fondos de Pensiones especializada en la regulación y supervisión de las inversiones de los fondos de pensiones, dado el nuevo marco propuesto en que la modificación de los límites de inversión se efectúa por decreto. A esta intendencia debería vincularse también el Consejo Técnico de Inversiones, propuesto en el área respectiva. 
De esa forma, la Superintendencia de Pensiones, en cuanto garante del funcionamiento del Sistema Previsional y los derechos de sus beneficiarios, debe contar con un marco institucional que garantice su profesionalismo y autonomía, profundizando respecto a los logros ya alcanzados por la SAFP. Para este efecto, la autoridad superior de la Superintendencia debería ser nombrada a través del Mecanismo de Alta Dirección Pública o con acuerdo del Senado y ser designada por un período predefinido de tiempo, con causales muy precisas para su remoción.

En otra instancia, el Comité de Usuarios se ocupará de expresar la percepción y opinión de los diferentes actores del Sistema Previsional y a su vez debe llevar un estricto control del cumplimiento de los objetivos y metas planteados en la Reforma Previsional, haciendo uso de diversas estrategias de comunicación y divulgación de la reforma hacia los afiliados. También sería labor del comité conocer y emitir una opinión respecto a los estudios actuariales sobre el sistema de pensiones; estudios de opinión de sus usuarios; estudios comparativos sobre costos de administración; evaluaciones externas sobre el Sistema Previsional; y proyectos de reforma.

Finalmente, con el objetivo de contar con una legislación debidamente actualizada y dinámica, el Consejo propone utilizar las facultades entregadas por la reciente reforma a la Constitución Política para fijar un comunicado coordinado y sistematizado de la legislación referente a los Pilares Solidario, Contributivo y Voluntario, siempre y cuando se hayan aprobado las modificaciones legales correspondientes a la Reforma Previsional, reemplazando de este modo el texto del DL 3.500 .

Las propuestas sobre institucionalidad permitirían contar con una institucionalidad consistente con un Sistema Previsional estructurado en torno a derechos y obligaciones universales que se ha propuesto. Adicionalmente, contribuiría a integrar la política previsional con la política de protección social. Esta nueva institucionalidad se planteó y se desarrolla actualmente en Chile (2014) de la siguiente manera: 


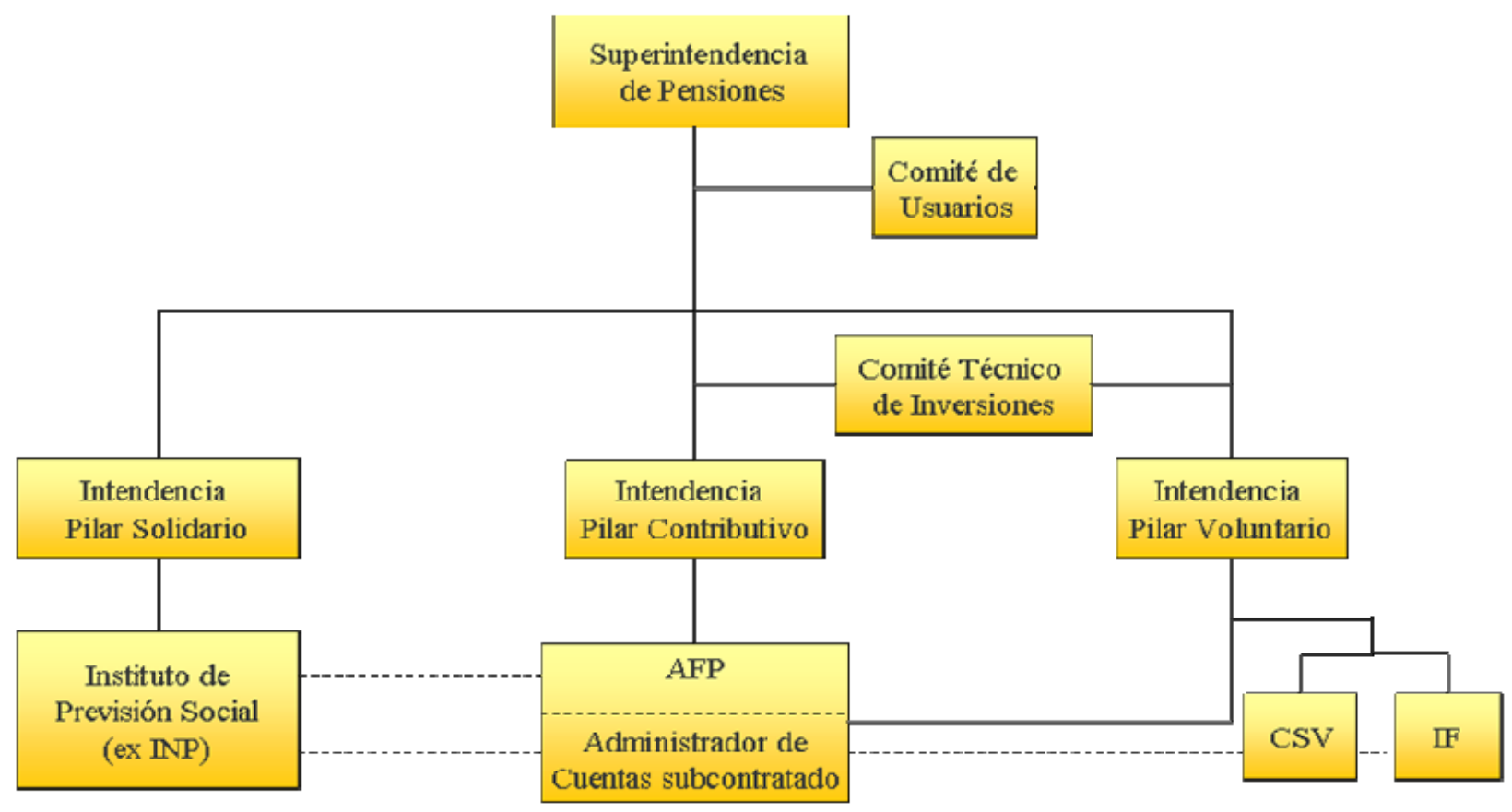

Figura 40. Estructura institucional del Sistema Previsional propuesto y aplicado en la reforma (2008) y la actualidad

Fuente: (Consejo Asesor Presidencial para la Reforma Previsional, 2006)

Este diseño institucional, al contemplar una clara distinción entre las entidades responsables de administrar las prestaciones del sistema y las encargadas de fiscalizar el respeto de los derechos de los usuarios, contribuiría a fortalecer la legitimidad del sistema ante la ciudadanía. Para los actores de la industria de administración de cuentas, inversión de fondos de pensiones y seguros, estas reformas permitirían reducir la incertidumbre regulatoria, facilitando la entrada de nuevos actores al sistema.

\section{Disciplina financiera del sistema}

La disciplina financiera es fundamental para que las promesas de la Reforma Previsional no solo se puedan realizar, sino para que se mantengan en el futuro. Para esto es necesario que el gobierno, los actores del sistema y sus beneficiarios tengan la capacidad de evaluar en cada momento la situación financiera del sistema, sus compromisos fiscales y la capacidad para solventar estos compromisos. 
Este importante aspecto que garantiza la permanencia (sostenibilidad) en el tiempo del Sistema Previsional se compone de una serie de objetivos para garantizar un acertado funcionamiento:

- Incrementar la transparencia del Sistema Previsional en relación a sus compromisos financieros a través del tiempo.

- Implantar una perspectiva de responsabilidad en la conducción del Sistema Previsional, en la determinación de beneficios, derechos y obligaciones.

- Asegurar la sostenibilidad financiera del Sistema Previsional y la viabilidad del conjunto de reformas que se proponen.

Con base en estos objetivos se esperan lograr las siguientes metas:

- Se aumentarán gradualmente (por ejemplo, mediante un aumento de 0,5\% anual) las cotizaciones hasta en un $2 \%$, con cargo a los empleadores. En el largo plazo, esto debería incidir en un aumento de un $20 \%$ de todas las jubilaciones. Esto se fundamenta en que dada la realidad del mercado de trabajo chileno se considera que un $10 \%$ neto de cotizaciones es insuficiente para otorgar jubilaciones dignas. Téngase en cuenta que países desarrollados tienen tasas de cotizaciones previsionales mucho más altas: Alemania, 19,5 \%; Suecia, 18,5 $\%$. Estos aportes permitirán disminuir los costos fiscales para el Pilar Solidario.

\subsection{Resultados esperados de la reforma}

Se propuso un conjunto de objetivos finales e intermedios para la Reforma Previsional. A continuación se presentaron una serie de propuestas de reforma distribuidas en 11 áreas de trabajo, elaboradas por el Consejo con el propósito de alcanzar dichas metas. En lo que se refiere a las metas intermedias se han presentado propuestas para estructurar un Pilar Solidario más fuerte e integrado que implica, prácticamente, duplicar en el largo plazo los compromisos fiscales con la previsión respecto de las proyecciones que se han presentado para el Sistema Previsional en su condición actual (Lo Vuolo, 2010).

Para fortalecer el Pilar Contributivo se han incluido un conjunto de propuestas para generar una mayor continuidad de los aportes de los afiliados cuando estos se encuentran trabajando como independientes, cuando están cesantes o desempeñándose como familiares no remunerados. Se 
han propuesto aportes solidarios por hijo nacido vivo y para apoyar la incorporación de nuevos trabajadores (especialmente jóvenes) al Sistema Previsional. También dentro del Pilar contributivo, este informe ha presentado propuestas para reducir las barreras a la entrada al Sistema Previsional, facilitar la incorporación de nuevos actores y traducir la mayor presión competitiva en menores comisiones para los afiliados.

De igual manera, a los esfuerzos por establecer un Pilar Solidario y fortalecer el Pilar Contributivo se debe agregar las propuestas para ampliar la cobertura del Pilar Voluntario, incorporando a trabajadores independientes y de rentas medias al actual régimen de ahorro previsional voluntario (APV), y creando un nuevo régimen de APV colectivo, con cotizaciones pactadas entre trabajadores y empleadores ejerciendo un control constante para evitar la desviación de recursos.

Las iniciativas en los tres pilares, finalmente, se pueden asentar en una institucionalidad más sólida, capaz de elevar significativamente la transparencia y predictibilidad del sistema, haciendo que los nuevos derechos y obligaciones se ejerzan a plenitud. De este modo, el conjunto de propuestas del Consejo establecen una base sólida que permite sostener la capacidad del Sistema Previsional para alcanzar los objetivos finales propuestos por el Consejo Asesor Presidencial para la Reforma Previsional (2006): universalizar cobertura, aumentar la tasa de reemplazo promedio del sistema y reducir la dispersión en torno a esta, eliminar el riesgo de pobreza en la vejez y garantizar la sostenibilidad de las metas en el tiempo.

En particular, las propuestas del Consejo involucran incluir, por derecho propio, a todos los adultos mayores en el acceso a los beneficios del sistema, garantizando un beneficio mínimo de Pensión Básica Universal para todos, significativamente superior a la línea de pobreza, independientemente de su capacidad contributiva previa. 


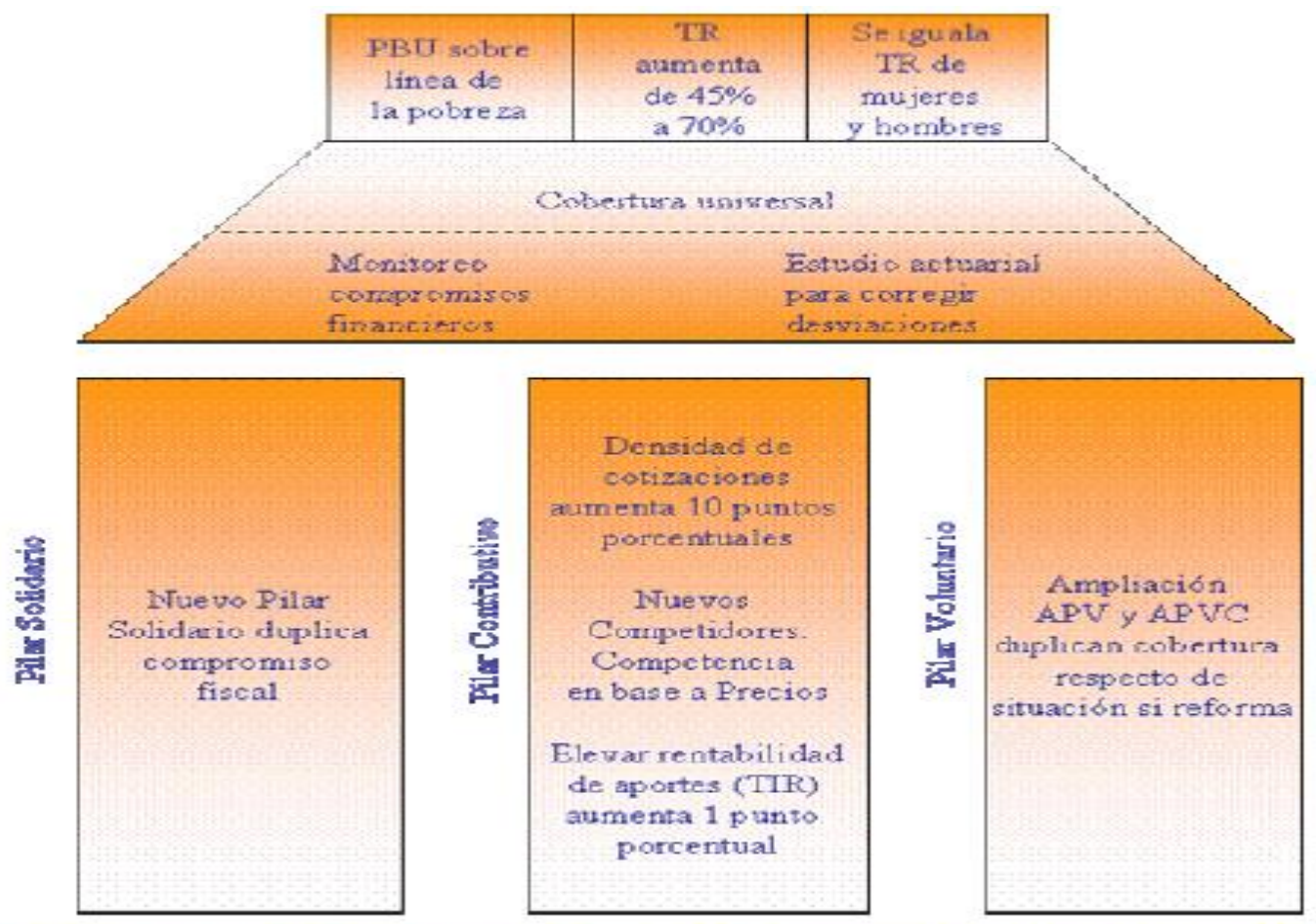

Nueva institucionalidad: Superintendencia de Pensiones, Instituto de Previsión Social, Consejo de Usuarios, Comité Técnico de Inversiones

Figura 41. Resultados esperados de la reforma

Fuente: (Consejo Asesor Presidencial para la Reforma Previsional, 2006, p. 31)

\section{Costo Fiscal implícito en la reforma}

El costo fiscal de las propuestas de reforma alcanzaría a alrededor de 1,1\% del PIB. Si de esta cifra se deducen los ahorros que se producen en el Pilar Solidario al elevarse la acumulación de fondos por efecto de los aumentos de densidad de cotizaciones y rentabilidad de los fondos, así como la tributación sobre las mayores pensiones -todo ello equivalente aproximadamente a 0,2\% del PIB — se obtiene que el costo fiscal neto de las propuestas de reforma ascendería a un 0,9\% del PIB. 


\begin{tabular}{|c|c|}
\hline \multicolumn{1}{|c|}{ Propuestas } & $\begin{array}{c}\text { Incremento costo } \\
\text { bruto anual en } \\
\text { régimen } \\
\text { (\% PIB 2025) }\end{array}$ \\
\hline $1 \quad$ Nuevo Pilar Solidario (NPS) & 0.75 \\
\hline 2 Asignaciones familiares para los trabajadores independientes & 0.02 \\
\hline $3 \quad$ Igualar tratamiento tributario para los independientes & 0.05 \\
\hline $4 \quad \begin{array}{l}\text { Subsidio a las cotizaciones pevisionales de los trabajadores } \\
\text { (jóvenes) que cotizan por primera vez }\end{array}$ & 0.08 \\
\hline 5 Bonificación devengada por cada hijo nacido vivo & 0.09 \\
\hline $\begin{array}{l}\text { Eliminar las restricciones legales y tributarias que hoy } \\
\text { impiden o desincentivan la subcontratación de servicios por } \\
\text { parte de las AFP }\end{array}$ & 0.01 \\
\hline $7 \quad \begin{array}{l}\text { Reconocer crédito de primera categoría a inversiones de los } \\
\text { fondos de pensiones }\end{array}$ & 0.01 \\
\hline 8 Ampliación APV y APVC & 0.07 \\
\hline $9 \quad$ Crear un fondo para la educación previsional & 0.01 \\
\hline $10 \begin{array}{l}\text { Establecer una instancia de inducción previsional al término } \\
\text { estatal. }\end{array}$ & 0.01 \\
\hline
\end{tabular}

Figura 42. Propuestas en materia fiscal de la Reforma previsional

Fuente: (Consejo Asesor Presidencial para la Reforma Previsional, 2006)

Tan importante como cuantificar los recursos fiscales adicionales comprometidos en la reforma es, sin embargo, evaluar la eficiencia con la que se utilizarían estos fondos. A este respecto, el informe del Consejo asesor para la Reforma Previsional resalta la necesidad de concentrar los recursos públicos (una mayor cantidad) en los sectores que requieren de un mayor apoyo solidario con el fin de impulsar este sector y garantizar la sostenibilidad del sistema (Rodríguez \& Florez, 2008).

De tal manera, el que se proyecte una reducción de los compromisos fiscales con el actual sistema de pensiones incida en que este, aunque más tarde de lo previsto, finalmente produjo ahorros de recursos fiscales, en contraste con las presiones en sentido inverso que deben sufrir muchos países con sistema de beneficio definido a medida que envejece la población. 
Esta reducción de compromisos vigentes, sin embargo, no significa que no existan para ellos usos alternativos al financiamiento de la Reforma Previsional. Particularmente relevante sería, en esta instancia, la existencia no solo de aspiraciones de otros sectores a emplear estos recursos, sino de presiones ya instaladas que pudieran disipar las holguras estimadas. Algunos candidatos a este ámbito serían el sistema de salud que se verá presionado no solo por la implantación plena del Plan AUGE, sino también por el mayor costo de la medicina curativa para una población creciente de adultos mayores. Las tendencias demográficas, unidas a la universalización de la educación secundaria, también presionarán por mayores recursos para la educación superior (Asociación Chilena de AFP, 2013).

Ante esto, el Consejo de Reforma Previsional sugirió al Ministerio de Hacienda realizar una proyección de largo plazo de ingresos y gastos fiscales que pudiera recoger estos efectos. No obstante, al cierre de este informe tal proyección aún no se encontraba disponible, por lo que al Consejo no le ha sido posible efectuar esta evaluación. Corresponderá por tanto al Ejecutivo, en el trabajo que le compete desarrollar para estructurar las propuestas definitivas de reforma que remita al Congreso Nacional, el que deba efectuar este análisis. Evidentemente, si de este análisis se desprendiera que la reducción de los actuales compromisos con la seguridad social tuviera otro destino comprometido, o si se quisiera desarrollar una transición más rápida correspondería identificar otras fuentes de financiamiento -más impuestos o menores gastos — para solventar la reforma. El Consejo ha considerado que está fuera de su mandato y de sus posibilidades efectuar un ejercicio especulativo sobre esta materia. 


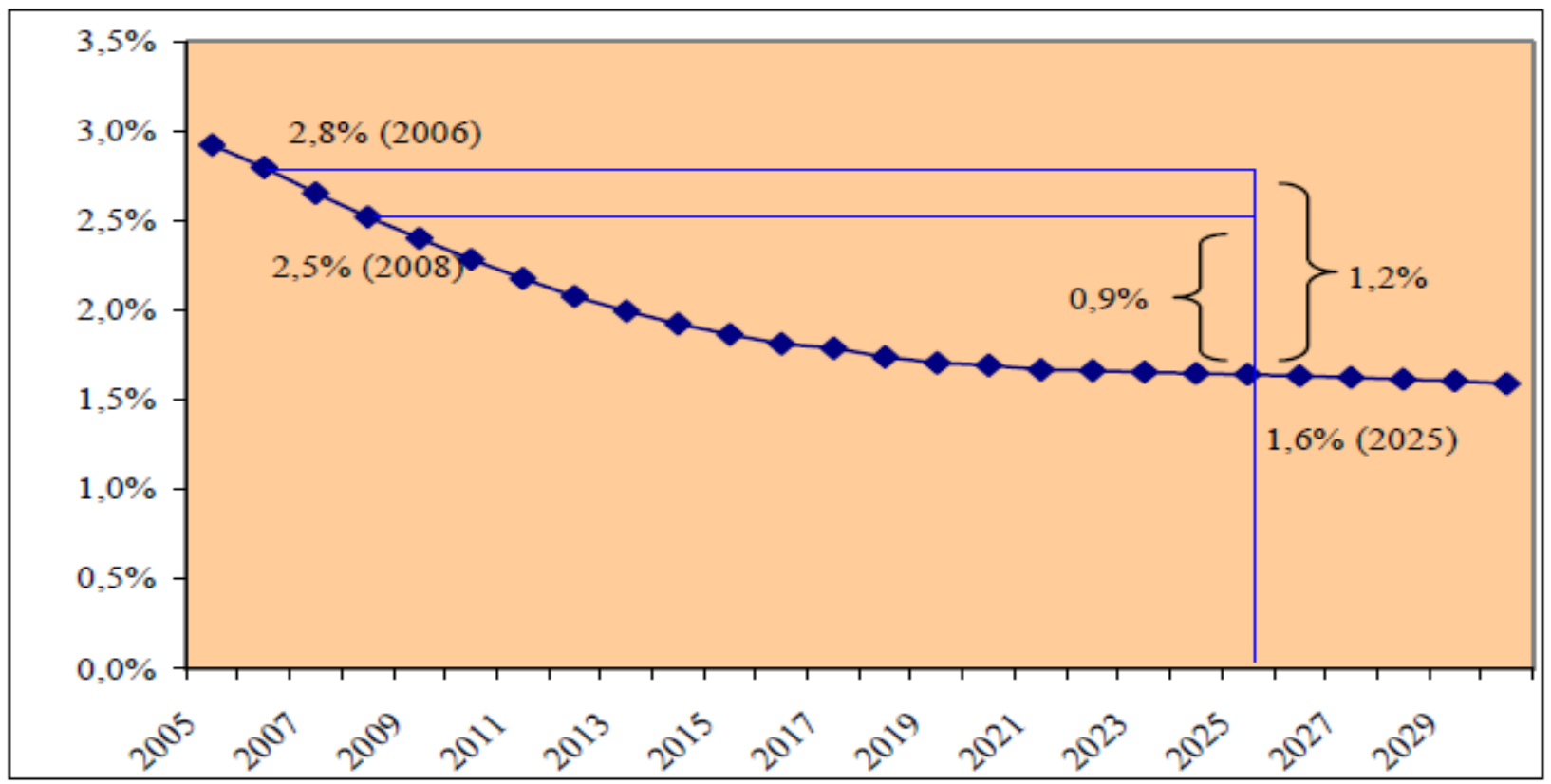

Figura 43. Compromisos fiscales con el sistema

Fuente: (Consejo Asesor Presidencial para la Reforma Previsional, 2006)

La información y el análisis desarrollado permitieron al gobierno de Michelle Bachelet:

Formular un extenso conjunto de reformas destinadas a desarrollar un Sistema Previsional capaz de responder a las demandas y aspiraciones de todos los chilenos, en la medida que todos los actores del sistema incluyendo a los propios afiliados sean capaces de aportar su cuota particular de esfuerzo, compromiso y responsabilidad.

Gran parte de estas propuestas, sin embargo, no tienen efectos inmediatos. Algunas requieren de un período gradual de implantación, otras inciden paulatinamente sobre los beneficios del sistema, muchas tienen costos fiscales y deben irse aplicando en base a las disponibilidades de financiamiento que se vayan produciendo en el tiempo. El propio proceso de discusión de estas propuestas, la elaboración de proyectos de ley y su aprobación definitiva por el Congreso Nacional también exigieron un marco de tiempo amplio para poder llevarse a cabo.

Parte importante del trabajo que se debe desarrollar para llevar la Reforma Previsional a la práctica consiste, precisamente en organizar una transición ordenada, donde la sociedad 
chilena entienda la secuencia de medidas y cómo ellas irán incidiendo sobre su bienestar. (Consejo Asesor Presidencial para la Reforma Previsional, 2006, p. 31)

En este sentido, no deben esperarse efectos inmediatos de esta propuesta. Un Sistema Previsional no opera a corto plazo, pero eso no debe ser excusa para no iniciar un proceso de reforma; el esfuerzo del Consejo para la Reforma Previsional ha estado puesto en articular un conjunto armonioso de reformas, capaz de complementarse para generar una transformación sustantiva desde un régimen de capitalización individual a un Sistema Previsional Integrado (Asociación Chilena de AFP, 2013).

\section{PROCESO DE CONCERTACIÓN Y DISCUSIÓN DE LA REFORMA}

El proceso de discusión pública que llevó a la concertación de la que finalmente sería la reforma integral al Sistema Previsional chileno de 2008 fue realizado mediante un gran número de audiencias de carácter público que principalmente se enfocaron en escuchar las opiniones y sugerencias de los diversos sectores económicos, políticos y sociales que estaban incluidos en la reforma, y que de alguna u otra forma debían manifestar su aprobación o no, ante la iniciativa de una reforma gradual y extensa en Chile para el sector previsional.

A continuación se relaciona el método de difusión que estuvo a cargo del Consejo Nacional Presidencial para la Reforma Previsional, para implementar las sesiones de audiencia pública de la reforma. La realización de audiencias tuvo por propósito enriquecer la discusión y la elaboración de propuestas de políticas por parte del Consejo. A las audiencias concurrieron organizaciones sociales, representantes del mundo laboral y empresarial, de las industrias de AFP, de seguros y bancos, de organismos internacionales, de institutos de estudio y expertos.

Con el objeto de facilitar la comprensión y difusión de los planteamientos de cada concurrente a las audiencias del Consejo se establecieron las siguientes pautas para su funcionamiento, según el Consejo Asesor Presidencial para la Reforma Previsional (2006):

A. Las audiencias tendrían una duración máxima de una hora, distribuida en una exposición inicial de los concurrentes y un tiempo dedicado a responder a las consultas de los integrantes del Consejo. Este límite de tiempo se amplió en las audiencias en que concurrió más de un invitado. 
B. Para equilibrar las diversas demandas y peticiones que surgen y ante la disponibilidad de tiempo, el Consejo se dividió en dos grupos para la realización de las audiencias, de tal modo que en estas estuviera presente su presidente y al menos la mitad de los demás integrantes.

C. Para sintetizar y articular de forma eficiente los planteamientos de los diferentes actores, se les solicitó entregar en forma previa un documento de no más de 15 páginas que contuviera su respectiva postura y opinión ante determinadas fases de discusión de la reforma.

D. Los documentos entregados se incorporarían a la página web del Consejo, quedando a disposición de la opinión pública. El Consejo se reservó el derecho de editar los documentos recibidos con objetivo de separar aquellos temas que no estuvieran estipulados dentro de las audiencias realizadas y de ajustarlos a la extensión máxima de 15 páginas.

De igual manera, el Consejo solicitó a las organizaciones y expertos invitados a las audiencias su diagnóstico, opiniones y propuestas en torno a algunos temas fundamentales, necesarios para estructurar la hoja de ruta de los problemas del actual Sistema Previsional y así abordarlos de la forma más adecuada. Estos temas fueron según el Consejo Asesor Presidencial para la Reforma Previsional (2006):

A. Beneficiarios del sistema de pensiones

- Condiciones de vida de los pensionados

- Expectativas de los trabajadores activos sobre su retiro

- Relación con el funcionamiento del mercado del trabajo

B. Aportes al sistema

- Densidad de cotizaciones

- Cobertura: incorporación de trabajadores independientes

- Brechas e inconsistencias de cotizaciones previsionales de los trabajadores, en especial de las mujeres y los jóvenes

- Morosidad provisional 
C. Magnitud, origen y soluciones a eventuales discriminaciones contra determinados grupos de trabajadores

- Mujeres

- Jóvenes

- Trabajadores de menores ingresos

- Trabajadores independientes

- Trabajadores con empleos de temporada

D. Costos del Sistema Previsional (D.L. 3.500)

- Costos de administración y nivel y estructura de comisiones

- Costo del seguro de invalidez y sobrevivencia y de rentas vitalicias

E. Competencia y eficiencia del sistema

- Rentabilidad de los fondos de pensiones

- Régimen de inversiones, riesgo y rentabilidad de los fondos

- Competencia entre fondos de pensiones, entrada de nuevos actores

- Información a los afiliados y decisiones de afiliación y jubilación

- Funcionamiento del mercado de seguros y las rentas vitalicias

F. Pilar Solidario del Sistema

- Concepto de Pilar Solidario

- Beneficios no contributivos (pensión mínima garantizada, pensión asistencial)

- Participación del Estado en el sistema de pensiones

- Costos y obligaciones fiscales

- Institucionalidad de sustento al Pilar Solidario 
G. Sustentabilidad financiera del sistema de pensiones

- Resguardo de la responsabilidad fiscal

- Efecto de fondos de pensiones sobre profundidad y eficiencia del mercado de capitales.

La siguiente figura muestra un resumen del trabajo de audiencias, destacándose el gran número de organizaciones (72) y personas (240) que asistieron para entregar su visión y propuestas sobre el Sistema Previsional (Consejo Asesor Presidencial para la Reforma Previsional, 2006).

\begin{tabular}{|l|c|c|c|c|}
\hline Día Audiencia & $\begin{array}{c}\text { Número } \\
\text { Audiencias }\end{array}$ & $\begin{array}{c}\text { Número } \\
\text { Organizaciones }\end{array}$ & $\begin{array}{c}\text { Número } \\
\text { Participantes }\end{array}$ & $\begin{array}{c}\text { Horas } \\
\text { Cronológicas }\end{array}$ \\
Lunes 3 de abril & 4 & 5 & 32 & 7 \\
Martes 4 de abril & 5 & 10 & 22 & 8 \\
Lunes 10 de abril & 5 & 8 & 17 & 8,5 \\
Martes 11 de abril & 7 & 9 & 29 & 9 \\
Lunes 17 de abril & 6 & 6 & 19 & 8,5 \\
Lunes 24 de abril & 6 & 9 & 33 & 9,5 \\
Martes 25 de abril & 6 & 10 & 25 & 9 \\
Martes 2 de mayo & 6 & 11 & 48 & 9 \\
Miércoles 3 de mayo & 4 & 5 & 17 & 5 \\
\hline TOTALES & 49 & 73 & 242 & 73,5 \\
\hline \hline
\end{tabular}

Figura 44. Balance general de audiencias públicas para la Reforma Previsional Fuente: (Consejo Asesor Presidencial para la Reforma Previsional, 2006)

Debido al ajustado tiempo disponible para llevar a cabo las audiencias, no fue posible brindar la atención requerida a todas las peticiones y solicitudes por los diferentes canales de comunicación llegaron al Consejo. En las audiencias fueron tratados todos los temas comprendidos en el mandato del Consejo, aportándose tanto diagnósticos como propuestas. Cabe destacar que los temas más citados fueron los relacionados con la densidad de cotizaciones, la inclusión de los trabajadores independientes, la equidad de género, la competencia entre fondos pensionales, beneficios de cada pilar del sistema y la participación de los asalariados, las empresas y el Estado. 


\section{Página web: medio de difusión masivo de la reforma}

La página web del Consejo fue habilitada para uso público el 12 de abril de 2006. Desde entonces fue visitada por más de 18.800 usuarios, quienes navegaron en ella principalmente para adquirir información sobre los contenidos que los distintos actores de la reforma habían consignado y fue más frecuente la visita al sitio web a medida que avanzaban las audiencias para implementar la reforma.

De forma resumida, esta página contenía: presentación, audiencias, documentos básicos de consulta, buzón de opiniones del usuario y otros banners de entidades partícipes de la reforma.

\section{Estudios de opinión: instrumento para medir percepción y conocimiento de la población sobre la realización de la Reforma Previsional}

El Consejo consideró que se debía abrir la puerta a opiniones masivas de la ciudadanía respecto a los temas de previsión social, con el fin de establecer el nivel de conocimiento que se tenía de estos. Se implementan estudios que se basan en la percepción que tiene el ciudadano de un conjunto de riesgos como ausencia de ingreso en la vejez, acceso a servicios de salud y posibilidades de jubilación mediante aportes constantes al sistema pensional.

El grupo de trabajo designado por el Consejo tuvo como misión realizar la revisión de un conjunto de encuestas y estudios cualitativos realizados en los últimos cinco años, que tienen incidencia directa e indirecta en temas previsionales. Los principales estudios revisados fueron según el Consejo Asesor Presidencial para la Reforma Previsional (2006):

- Encuestas de Protección Social 2002 y 2004

- Encuesta de Previsión de Riesgos Sociales (PRIESO 2000)

- Encuesta de Percepción de los Pensionados Respecto del Sistema de AFP

- Informes de Opinión Publica sobre las AFP, "Barómetro CERC" 2004, 2005 y 2006 (con preguntas incorporadas por solicitud de la Superintendencia de AFP)

- Estudio cualitativo sobre Trabajadores Independientes y la Superintendencia de AFP

- Estudio cualitativo "Cómo se vive la Cesantía", Superintendencia de AFP 
- Estudio cualitativo sobre "Eventos de Quiebre de Ingreso y Mecanismos de Protección Social

- Estudio en Hogares de Ingreso Medio y Bajo", encargado por el Banco Mundial a la empresa Asesorías para el Desarrollo

- Estudio cualitativo "Pooling, Savings, and Prevention: Mitigating the Risk of Old Age Poverty in Chile", Banco Mundial

- Estadísticas de diversas fuentes sobre temas de vejez, entregadas por el Servicio Nacional del Adulto Mayor

Producto de la revisión anterior, el grupo de trabajo, con el apoyo financiero del Banco Interamericano de Desarrollo (BID) acordó encargar dos estudios de opinión. El primero es un estudio cualitativo encargado a Feedeback Comunicaciones S.A., que abarcó los siguientes temas de estudio:

- Dimensionamiento acerca de la vejez, expectativas de vida y de calidad de vida

- Disposición al ahorro y a formas de captación de recursos para previsión social y la vejez

- Aspiraciones de beneficios que otorga el Sistema Previsional

- Confianza e incertidumbre en el Sistema Previsional

- Percepciones y actitudes que tiene la ciudadanía frente a una posible Reforma Previsional.

El segundo es un estudio de carácter cuantitativo encargado a la empresa Mori Chile S.A., el cual tuvo como objetivo central hacer la identificación de la percepción de la ciudadanía frente a los siguientes temas:

- Importancia y preocupación de la jubilación para los chilenos

- Expectativas sobre la vejez

- Expectativas intergeneracionales de calidad de vida

- Sistema de pensiones, derechos y obligaciones de las partes que lo componen

- Evaluación del sistema de pensiones y AFP / INP

Finalmente, el Servicio Nacional del Adulto Mayor (SENAMA) realizó un breve estudio de carácter cualitativo que consideró temas propuestos por el Consejo, particularmente orientado a 
conceptualizar, desde el discurso social de los propios adultos mayores, incluyendo visiones desde la ruralidad, perspectiva de género y sesgo étnico. Las conceptualizaciones se refieren a términos como los siguientes:

- Vejez digna

- Pensión justa

- Previsión y protección social

- Calidad de vida

\section{ACTORES SOCIALES PARTICIPANTES EN EL PROCESO DE REFORMA}

En el proceso de diseño, cobertura e implementación de la reforma integral al Sistema Previsional del año 2008 participaron entidades de todos los sectores: económicos, sociales y políticos de Chile. Por medio de audiencias, página web, estudios de opinión y actividades de corte académico se logró la participación de gran parte de la representación del pueblo chileno.

De esa forma se contó con más de 500 instituciones participantes en los diferentes escenarios que se desarrollaron para escuchar a la población chilena acerca de su percepción sobre esta reforma, entre las instituciones se encuentran: entidades públicas, entidades privadas, comités de usuarios de los diferentes servicios públicos de Chile, agremiaciones, sindicatos, centrales unitarias, cooperativas, ministerios, secretarías, juntas de acción local y comunal, uniones y movimientos por sector laboral, confederaciones, asociaciones, Organizaciones no Gubernamentales (ONG), fundaciones, programas de asistencia social y de promoción de sectores vulnerables, universidades, entidades bancarias y multilaterales.

Bajo las condiciones pactadas con el Consejo Asesor para la Reforma Previsional, cada uno de estos representantes de la estructura productiva chilena presentó sus observaciones detalladas en documentos oficiales que pretendían sugerir ajustes de acuerdo al sector que impactara la reforma; a razón de esto, el Consejo optó por llamar a la mesa de discusión a las entidades que tenían intereses comunes y que por alguna u otra razón no podían llegar a un acuerdo, estas discusiones tuvieron como objeto concertar o por lo menos alcanzar puntos medios para favorecer a los sectores implicados. 
Finalmente, como era de esperarse no todos los sectores fueron escuchados por falta de tiempo, ya que las audiencias públicas estuvieron realizadas por un lapso no mayor a dos meses, tiempo que sin duda se hace corto para discernir sobre las propuestas presentadas y analizar con detenimiento los impactos potenciales que esta reforma podría tener dependiendo el sector de la economía que se observe.

\section{Resultados esperados por el gobierno de Chile}

Según Reyes, Berstein, Castañeda y Fajnzylber (2009): "la reciente reforma de pensiones representa uno de los principales hitos en las reformas a la regulación financiera de los fondos de pensiones" (p.15). Esta reforma supone un cambio drástico dado que se pasa de un esquema de regulación un tanto rígido a una estructura institucional más flexible que saque provecho de una fuerte inversión en el mercado de capitales para inyectar fluidez a la economía, e igualmente para que el afiliado tenga más y mejores opciones de verse incluido en el sistema de pensiones.

Entonces, estos cambios favorecerán y reforzarán el cumplimiento de los compromisos financieros de las AFP para con sus afiliados y con el sistema, reduciendo en gran medida el conflicto de intereses que pudiese llegar a ocurrir a través de la fuerte competencia que se incentiva para las AFP desde el gobierno.

\section{Seguimiento a la Reforma Previsional 2016}

Con base en la información disponible a través de la Superintendencia de Pensiones de Chile para el primer semestre de 2016, a continuación se relacionan los principales cambios que se han generado en el Sistema Previsional luego de 8 años de una reforma integral en curso:

- Los beneficiarios de la Pensión Básica Solidaria (PBS) y Aporte Previsional Solidario (APS) registraron un total de a 1.342.340 personas en el primer semestre de 2016 como promedio mensual (esto representa un aumento de $1,6 \%$ respecto al semestre anterior).

- En términos de cobertura del Pilar Solidario a junio de 2016, del total de pensiones pagadas por el sistema de capitalización individual (AFP o Compañías de Seguros), el 72 \% de estas recibe el beneficio PBS o APS como remuneración a los aportes realizados al sistema.

- Durante el primer semestre del año 2016 se evidenció un aumento gradual de las solicitudes de calificación de invalidez mostrando un 4,6 \% respecto al semestre anterior. 
- La afiliación de nuevos beneficiarios (de manera voluntaria) se incrementó en el primer semestre de 2016, pasando de 341 (promedio mensual) nuevos afiliados voluntarios en el segundo semestre de 2015 a 397 en el primer semestre de 2016 (lo que se traduce en un 45 $\%$ de aumento).

- Desde agosto de 2010 a junio de 2016 se han incorporado 2.081.914 nuevos afiliados al Sistema Previsional, de los cuales 157.664 se introdujeron durante el primer semestre de 2016.

- En cuanto a la implementación del Bono por Hijo, hasta junio de 2016 se han concedido 435.050 beneficios. Durante el primer semestre de 2016, este beneficio ha significado un incremento por pago de \$9.019 y \$13.825 para pensionadas de PBS y sobrevivencia, respectivamente. Es importante destacar el control que se ha hecho de esta medida, puesto que el gobierno busca evitar que ante la implementación de un beneficio como estos, las mujeres de algunas regiones específicas del país tengan hijos en forma desmedida para acceder al beneficio.

- Como medida para incentivar la cotización al Sistema Previsional, el gobierno implementó la obligatoriedad de cotizar para los trabajadores independientes que perciben rentas gravadas por el Art. $42 \mathrm{~N}^{\circ} .2$ de la Ley sobre Impuesto a la Renta (LIR), dicha ley entró en vigencia a contar del día 1 de enero de 2012, estableciendo la opción de no cotizar hasta el año 2015 y haciendo que la cotización fuese gradual respecto de la renta que percibía el afiliado.

El número de beneficiarios por Pensión Básica Solidaria de Vejez tuvo un aumento desde el primer semestre de 2009 hasta el primer semestre de 2011, periodo en el cual alcanzó un nivel máximo de 406.674 beneficiarios mensuales. Posteriormente, y hasta el primer semestre de 2016, no ha presentado mayores cambios mostrando una cifra cercana a los 400.000 beneficiarios mensuales. Por su parte, el número de beneficiarios promedio mensual de Pensión Básica Solidaria de Invalidez ha disminuido paulatinamente desde 2012 al 2015, aumentando levemente el último semestre reportado (Subsecretaría de Previsión Social, 2013). 


\section{PBS VEJEZ}

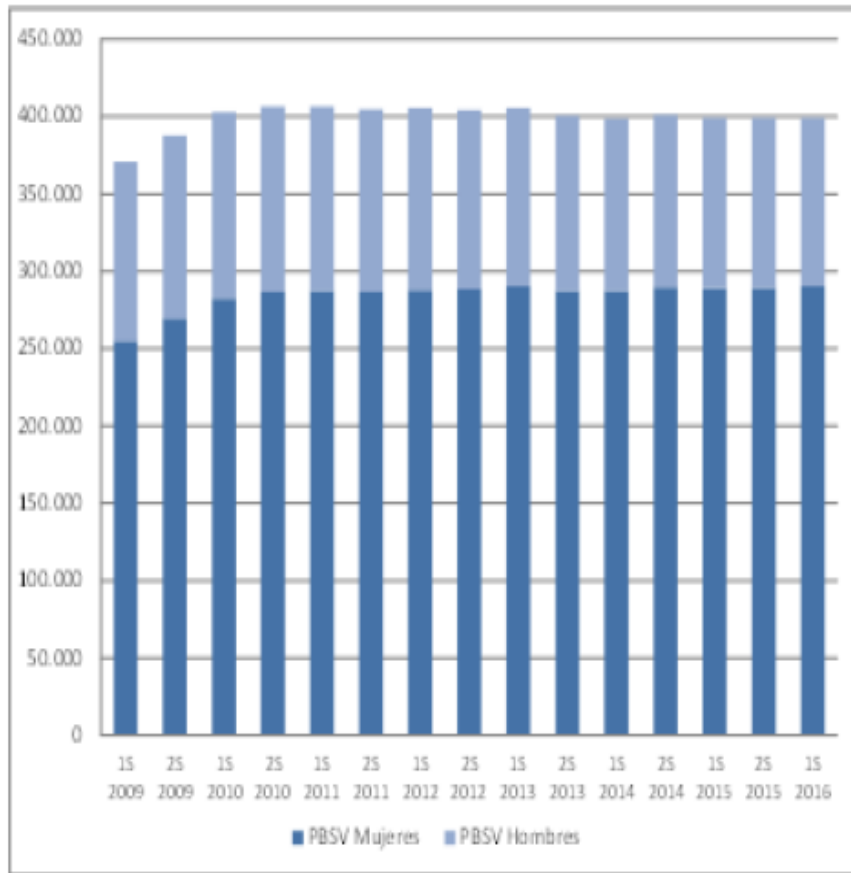

PBS INVALIDEZ

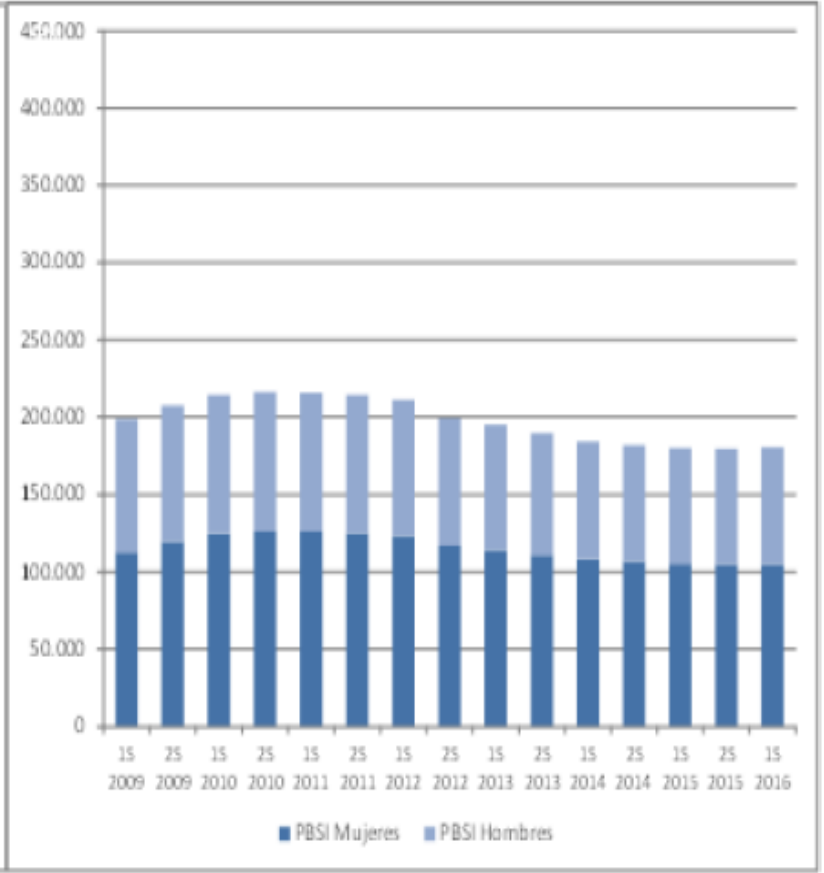

Figura 45. Número de beneficiarios por pensión básica solidaria de vejez e invalidez (2009 - 2016)

Fuente: (Superintendencia de Pensiones de Chile, 2016)

Los nuevos afiliados voluntarios continúan siendo en su mayoría mujeres, sin embargo, se observa un aumento en cuanto a la inclusión de hombres al sistema. Sin embargo, también se han registrado afiliaciones de personas jóvenes; de lo anterior surge un interés particular del Estado para hacer del Sistema Previsional algo llamativo para los jóvenes, mostrando las bondades del sistema y abriendo la puerta para obtener por parte de los trabajadores un ingreso en la vejez.

A junio de 2016 los datos del sistema evidencian un total de 16.140 afiliados voluntarios que a esta fecha tienen la condición de afiliados activos (realizan cotizaciones dos o más veces al año). 


\begin{tabular}{|c|c|c|c|}
\hline Periodo & Mujeres & Hombres & Total \\
\hline 1S 2009 & 70 & 3 & 73 \\
\hline 2S 2009 & 3.312 & 32 & 3.344 \\
\hline 1S 2010 & 4.597 & 32 & 4.629 \\
\hline 2S 2010 & 4.245 & 22 & 4.267 \\
\hline 1S 2011 & 4.074 & 8 & 4.082 \\
\hline 2S 2011 & 2.402 & 9 & 2.411 \\
\hline 1S 2012 & 1.410 & 30 & 1.440 \\
\hline 2S 2012 & 739 & 82 & 821 \\
\hline SS 2013 & 564 & 89 & 653 \\
\hline 2S 2013 & 371 & 74 & 446 \\
\hline 1S 2014 & 304 & 52 & 356 \\
\hline 2S 2014 & 294 & 55 & 349 \\
\hline 1S 2015 & 287 & 46 & 332 \\
\hline 2S 2015 & 291 & 50 & 341 \\
\hline 1S 2016 & 316 & 81 & 397 \\
\hline
\end{tabular}

Figura 46. Afiliados voluntarios según periodo de afiliación y género 2009 - 2016

Fuente: (Superintendencia de Pensiones de Chile, 2016)

En cuanto a los hombres que reciben pensión por concepto de viudez, se puede ver que el número de beneficiarios de esta modalidad ha crecido en forma gradual y continúa desde su implementación arrojando las siguientes cifras: al primer semestre de 2016 se otorgaron 5.982 pensiones (crecimiento de 8,3\% respecto al semestre anterior). Sin embargo, el número de pensiones de viudez recibida por mujeres es considerablemente mayor en igual semestre (80.952); esto si se tiene en cuenta que la expectativa de los hombres es menor y que un grupo de las actividades laborales que desempeña el hombre representa un riesgo de muerte mayor, como por ejemplo la industria minera, metalúrgica y de construcción. 


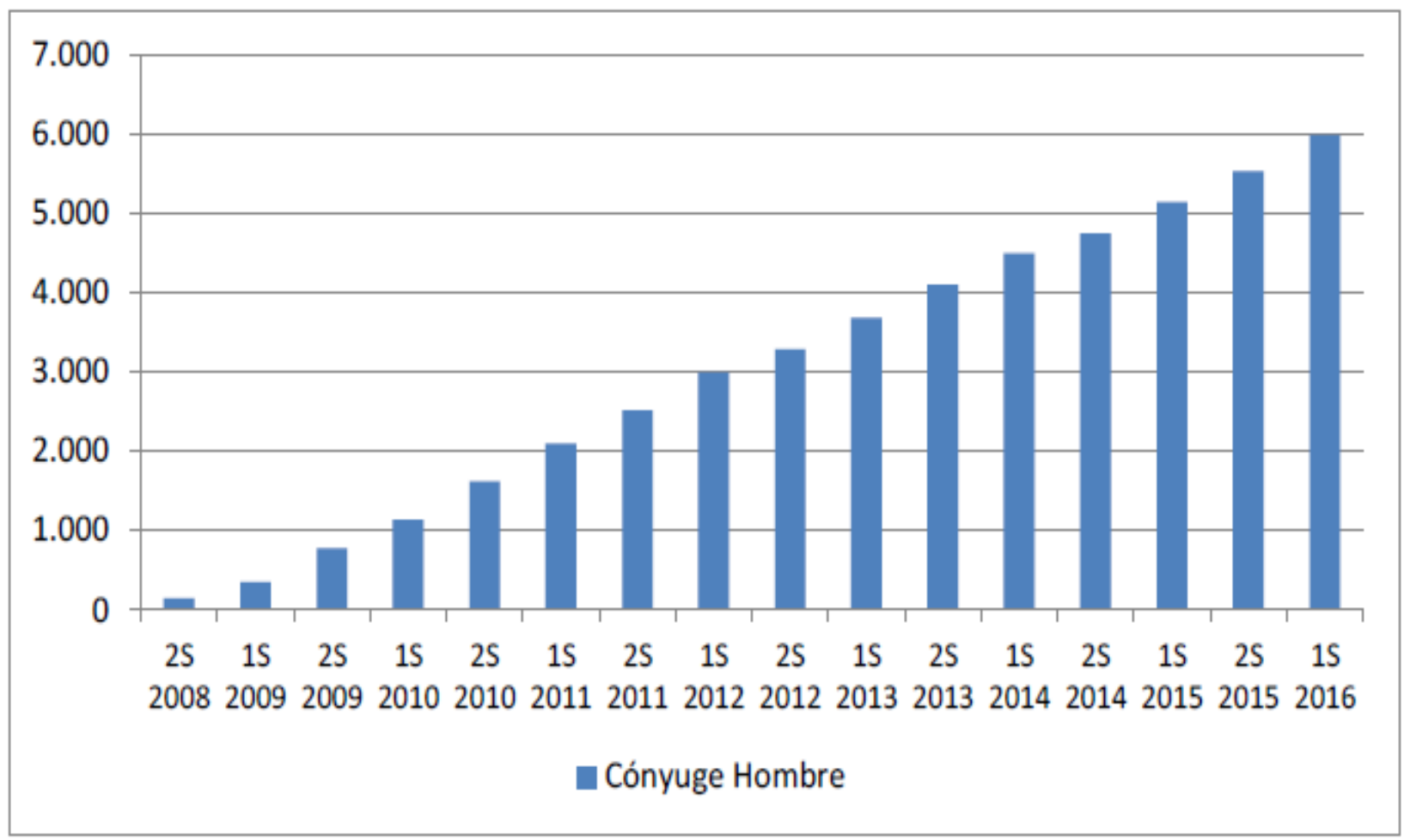

Figura 47. Número de pensiones de viudez pagadas a cónyuges hombres (2008 - 2016)

Fuente: (Superintendencia de Pensiones de Chile, 2016)

La Ley del Sistema Previsional menciona que no están obligados a cotizar aquellos trabajadores que al 1 de enero de 2012 tenían 55 años o más, para el caso de los hombres, y 50 años o más, en el caso de las mujeres. También se encuentran exentos de cotización los trabajadores independientes afiliados a algunas de las instituciones de previsión del régimen antiguo administradas por el IPS o a la Dirección de Previsión de Carabineros de Chile, o a la Caja de Previsión de la Defensa Nacional; siendo estos últimos regímenes especiales de cobertura previsional.

Esta ley de obligatoriedad entró en vigencia a partir del 1 de enero de 2012 de manera gradual, estableció la posibilidad de renunciar hasta el año 2015 y haciéndose obligatorio (sin excepciones) a partir de la declaración de renta e impuestos del año 2016. Por tal motivo, en enero de 2016 se aprobó una iniciativa legal que hace extensiva la obligatoriedad de cotizar hasta el año 2018 (Ley 20.894 que obliga a cotizar el $7 \%$ del ingreso imponible a salud a todos los independientes). Esta 
medida incide positivamente en la densidad y cuantía de aportes que se hacen al Sistema Previsional de manera mensual.

\begin{tabular}{|c|c|l|}
\hline Periodo & $\begin{array}{c}\text { \% sobre la renta imponible anual } \\
\text { respecto de la cual se calcularán } \\
\text { las cotizaciones }\end{array}$ & \multicolumn{1}{|c|}{ Obligatoriedad } \\
\hline 2012 & $40 \%$ & $\begin{array}{l}\text { Obligado a cotizar, salvo que expresamente } \\
\text { manifieste lo contario }\end{array}$ \\
\hline 2013 & $70 \%$ & $\begin{array}{l}\text { Obligado a cotizar, salvo que expresamente } \\
\text { manifieste lo contario }\end{array}$ \\
\hline 2014 & $100 \%$ & $\begin{array}{l}\text { Obligado a cotizar, salvo que expresamente } \\
\text { manifieste lo contario }\end{array}$ \\
\hline $2015-2017 *$ & $100 \%$ & $\begin{array}{l}\text { Obligado a cotizar, salvo que expresamente } \\
\text { manifieste lo contario }\end{array}$ \\
\hline 2018 & $100 \%$ & Obligado a cotizar sin excepciones \\
\hline
\end{tabular}

Figura 48. Porcentaje de obligatoriedad de cotización a los trabajadores independientes

Fuente: (Superintendencia de Pensiones de Chile, 2016)

\section{Leves cambios producidos en el Sistema Previsional chileno como respuesta a la reforma}

Se genera una ampliación de las alternativas de inversión en Chile para obtener mayor rentabilidad para los fondos de pensiones, esto se logra por medio de la flexibilización del régimen de inversiones para las AFP pasando de invertir del $34 \%$ al $45 \%$. También, los seguros de invalidez y Sobrevivencia (SIS) generan modificaciones en su legislación de forma gradual y en sus beneficios, como por ejemplo, el incluir al beneficiario cónyuge hombre para obtener la mesada pensional por este concepto.

Un aspecto negativo de estos cambios fue el proceso de tercerización (subcontratación) que emprendieron las AFP para la administración de los recursos de los afiliados con el fin de que dicha administración fuese más rentable para ellas.

\section{Fomento al Ahorro Previsional Voluntario}


Se da origen a un mecanismo de ahorro colectivo para que los ahorros realizados por los trabajadores sean complementados por sus respectivos empleadores. Se mantuvo el actual beneficio tributario al APV, pero adicionalmente se implementa un ahorro previsional para los estratos medios que busca beneficiar a los trabajadores que devenguen un salario de máximo 1,5 millones mensuales. Se estima que esta medida podría potencialmente beneficiar a 250 mil trabajadores. Esta medida, que podría beneficiar a cerca de 250 mil personas, consiste en destinar un $15 \%$ del monto ahorrado por el trabajador al mes.

A. Se creó el Instituto de Previsión Social (IPS), responsable de la administración del SPS, de los regímenes previsionales que administra el INP y de los Centros de Atención Previsional Integral. Estos Centros están destinados a prestar servicios de tramitación de beneficios del Pilar Solidario, así como garantizar la prestación de servicios esenciales de información del sistema de pensiones para todos los usuarios

B. También se fortaleció en el papel una Superintendencia de Pensiones, con facultades fiscalizadoras para resguardar el correcto funcionamiento del sistema, incluida la posibilidad de designar un "inspector delegado" que resguarde la seguridad de los Fondos de Pensiones ante eventos que los pongan en riesgo. (Hormazábal, 2008, p. 49)

Se crea la Comisión Nacional de usuarios, organismo que se ocupó de acaparar a los principales actores de la reforma para plasmar la percepción del ciudadano respecto a los cambios que se realizarían en el Sistema Previsional.

\subsection{Desafíos pendientes posteriores a la reforma}

A partir de este diagnóstico el Consejo Asesor para la Reforma Previsional (CARP) sugirió que se evidencia una inequidad en cuanto a las pensiones del Pilar Solidario, dado que la pensión de quienes siempre han cotizado iba a ser siempre mayor a la de quienes lo hicieron de forma intermitente. Por lo anterior se debería plantear una alternativa que subsane esta diferencia evitando ahondar en la inequidad de ingresos entre afiliados. Igualmente, se debe incentivar la cotización en todos los sectores de la economía con el fin de incentivar al incremento en la densidad de la cotización, procurando que esta iniciativa sea la que garantice e impulse el sostenimiento del sistema a través del tiempo. 
En cuanto al Pilar Voluntario se hacen cambios que pretenden la inclusión de los trabajadores de clase media al sistema, con el fin de brindar cobertura a los trabajadores y brindar una alternativa garantizada y rentable de ingreso en la vejez para ellos. Se invita a las empresas para invertir en capacitación y formación para los empleados, mientras que a la par se fidelizan estos últimos al Sistema Previsional.

Además, la modalidad de retiro programado sufre un ajuste respecto a la longevidad del afiliado, lo que permite que más personas accedan a este beneficio realizando un aporte adicional; situación similar presentó el segmento de pensión por invalidez y sobrevivencia en el que las comisiones, y juntas médicas que otorgaban el aval para autorizar esta modalidad pensional se dieron a la tarea de incluir mediante herramientas censales a una mayor cantidad de población.

Así, la disminución de barreras de entrada para los afiliados al Sistema Previsional supone una desconfianza para las AFP respecto a los riesgos de mercado e inversión en el sistema, sin embargo, la competitividad (en términos de costos operacionales, calidad de servicio y en márgenes de rentabilidad) introducida en el sistema por parte del gobierno hizo que estas instituciones buscasen mejores maneras para invertir y captar un mayor número de afiliados. La implementación de estas medidas hacen que se genere una flexibilización en las posibilidades de inversión que tienen las AFP, no obstante, también implica que dichas maniobras financieras requieran una mayor responsabilidad para estas instituciones, con miras a garantizar el monto pensional para los afiliados y así mismo el grado de compromiso que deben mostrar frente al funcionamiento del Sistema Previsional.

Esta reforma se traduce, entonces, en avance de bastante relevancia en términos de brindar protección a las personas de la tercera edad y garantizando el funcionamiento del sistema. En términos de calidad de las pensiones la responsabilidad reposa en cada uno de los actores del Sistema, asegurándose de que cada uno contribuya a un mejor funcionamiento del sistema.

El Estado tiene en el nuevo sistema de pensiones el rol fundamental de proveer recursos a través del Pilar solidario, administrado por el Instituto de Previsión Social (IPS), y la fiscalización del sistema, tanto público como privado, por parte del organismo regulador, la Superintendencia de Pensiones (SP). El cumplimiento de este rol exige de un IPS eficiente y que a través de sus redes de atención, los Centros de Atención Previsional Integral (CAPRI) logren atender consultas en 
general, recibir solicitudes de pensión y canalizar estas para su resolución en forma adecuada. A su vez, el organismo Supervisor debe enfrentar apropiadamente la tarea de supervigilar el sistema como un todo para lo cual un importante desafío será la implementación de un esquema de Supervisión Basada en Riesgos (Berstein, 2011).

A su vez, las contribuciones a seguridad social deben ser un garante de bienestar para los trabajadores, de aquí la importancia de que los empleadores paguen sus obligaciones de seguridad social en los plazos establecidos y así evitar posibles afectaciones a los ahorros comunes, como por ejemplo el ahorro previsional voluntario colectivo (APVC) en el que se mezclan recursos de ambas partes y es un impulsador importante del Pilar Solidario del Sistema Previsional. En el caso de las Compañías de Seguros el desafío que enfrentan es el de los riesgos de inversión y la población a que deban prestar servicios con la modalidad de rentas vitalicias, entre más personas accedan, más restrictivo se comportará el fondo para poder pagar a sus afiliados dichos montos hasta el final de su vida.

Con la reforma se establece la licitación del seguro a estas entidades, las que cubrirán estos riesgos para el conjunto de la población en forma íntegra (Cecchini, Filgueira, Martínez, \& Rossel, 2015). Esto aunado a una serie de maniobras que pretenden perfeccionar el seguro al que se tiene acceso, erradicando así el riesgo moral y las posibles inequidades que surgen a través del tiempo. Todas estas medidas buscan reforzar el sistema planteado por la actual reforma y ajustar lo que se considere en cuanto al rol de cada uno de los actores del Sistema Previsional buscando siempre el sostenimiento, cobertura y una mejor prestación de servicios dentro de este.

\section{CRÍTICAS AL SISTEMA PREVISIONAL}

A pesar de que Chile ha demostrado ser una economía fuerte y en cierta medida desarrollada, muestra unos niveles de cobertura previsional menores a los esperados. Lo anterior no es exclusiva responsabilidad de las AFP, sino también un hecho conjunto de las medidas que en dado momento procuraron mantener rígido el sistema de pensiones, ahora en este periodo de transición se busca que la cobertura aumente y esto se traduzca en mayor bienestar para los adultos mayores. El diseño del sistema tiene una estructura en la que se hubiese pensado en un escenario en el cual el trabajador no tuviera momentos de cesación o búsqueda de nuevo empleo y la cotización estuviera constante y permanente, adicionalmente se debió contemplar en mayor medida la inclusión de los 
trabajadores no calificados (que son parte importante de incluir a cotizar) en el Sistema Previsional que planteó la reforma desde un inicio.

Existen dos factores que vale la pena destacar, el primero refiere a la maternidad, el cual siendo un estado natural en la vida de la mujer debe ser fuertemente respaldado por el Estado y las empresas en materia de aportes al sistema, porque esta condición no debería ser un factor que aísle o reduzca las posibilidades de la mujer para permanecer (cuando esté en condiciones de hacerlo) en el mercado laboral. El segundo factor corresponde al impacto que tiene la reforma en la sociedad, es decir, en la manera en la cual los ciudadanos confían en el sistema y en la promesa de que les va a ser garantizado un ingreso en la vejez que les permita obtener un nivel de vida digno en sus últimos años, respecto a este factor las percepciones son variadas, pero sí existe un cierto nivel de desconfianza por los montos que se deben acumular por parte del trabajador para alcanzar este tipo de beneficios

El Estado debe prestar especial al manejo del ámbito fiscal del Sistema Previsional dado que este se encuentra en "una etapa comprendida entre la entrada en vigencia del nuevo sistema (1981) y su funcionamiento en régimen (cuando ya no existan beneficiarios del antiguo sistema de pensiones, momento estimado en alrededor de 20357)" (Guardia, 2012, p. 9) y esto hace que los imprevistos y cambios en el mismo estén a la orden del día.

Los compromisos fiscales derivados del sistema de pensiones tienen cinco componentes básicos a saber:

- Déficit operacional del antiguo sistema (ya que entraba en liquidación sus saldos y obligaciones sufren una transición que genera altos costos para el gobierno).

- El pago del bono de reconocimiento cuando el afiliado se cambia desde el sistema público al esquema de AFP (puesto como incentivo para aglomerar a todos los afiliados en el nuevo sistema y así ir eliminando gradualmente el antiguo).

- El subsidio otorgado a los pensionados a fin de obtener una pensión mínima (para suplir la imposibilidad o carencia de ingresos para cotizar al sistema).

- El financiamiento de las pensiones asistenciales (otorgadas por el Estado)

- La operación del esquema previsional de las Fuerzas Armadas y Carabineros, que corresponden a un régimen especial. 
El sistema de beneficios que obtienen por pensión los miembros de las fuerzas armadas es uno de los elementos que más peso tienen en el déficit global y que produce un déficit creciente, con una obligación anual para el Fisco de un 1,3\% del PIB (1100 millones de dólares al 2006). Parte de ello se explica porque los montos de las cotizaciones actuales no alcanzan a cubrir el total de beneficios brindados a los pensionados, esta diferencia año tras año debe ser cubierta con dineros del presupuesto nacional designado para defensa y las fuerzas militares.

Otro compromiso que tiene un peso importante es la garantía de pensión mínima (para quienes alcanzaron a acogerse a este beneficio) pues el compromiso del Estado en cuanto a este debe ser permanente y de estricto cumplimiento, de ahí el interés y el énfasis que se hace por aumentar la densidad de cotización sea vía legal o por incentivos para los trabajadores, con el fin de liberar un poco la presión que tiene el Estado y los recursos que esto implica.

Por otro lado, las pensiones de un menor monto corresponden a los sectores y trabajadores que poseen un menor rango de calificación, ante esta situación se hace necesario que cualquier sistema de pensiones se plantee la idea de instaurar un fuerte componente de solidaridad con el fin de equiparar (en la medida de lo posible) las remuneraciones en la vejez y la equidad para recibir las mismas.

La esencia del nuevo sistema de pensiones chileno que opta por un régimen de capitalización individual lleva a pensar que los esfuerzos del Estado van encaminados a la sostenibilidad y rentabilidad del sistema, generando una exclusión para los trabajadores de escasos recursos o que no pueden alcanzar un beneficio pensional en la edad de jubilación, a pesar de que el sistema contiene un Pilar solidario, no es suficiente para cubrir la población que lo requiere, esto sería “socializar las perdidas y privatizar las ganancia" (Guardia, 2012, p. 17), ya que en busca de la rentabilidad y para asegurar las menores pérdidas posibles se redistribuyen estas en la población y en los diferentes actores, realizando maniobras como el alza a los impuestos y las cotizaciones.

Entonces, es apropiado controlar la rentabilidad que pueden obtener las AFP instaurando una competencia que las equipare puesto que de no hacerse, se incurrirá en una inserción masiva de afiliados para tener un mayor margen de inversión y así aumentar la rentabilidad sin que esto represente un servicio de calidad para los afiliados. En lo anterior radica la importancia de un regulador público que genere un control adecuado a estas instituciones. 


\subsection{Conclusiones}

La Reforma Previsional como eje modificador del sistema de pensiones y de las políticas del mercado laboral orientadas a mejorar el sistema de protección social, deja cierto nivel de incertidumbre sobre la población chilena y sobre sus principales sectores productivos, esto porque semestralmente se hace un seguimiento minucioso al proceso de reforma (lo cual es acertado) y del cual se podría (en caso de que el gobierno de Chile así lo considere) hacer la cantidad de modificaciones que se estimen convenientes para seguir garantizado la sostenibilidad financiera del sistema, y afectando lo menos posible el sistema de pilares que se instauró como recomendación especial del Banco Mundial.

Vista la estructura de cada sistema y estructura que se encuentra inmiscuida en los temas pensionales de Chile, se presentan a continuación una serie de conclusiones y recomendaciones de acuerdo al tema de la investigación y a los objetivos planteados, desarrollados y cumplidos a lo largo de este trabajo:

- El mercado laboral de Chile debe realizar un mayor control de la destinación de los dineros que se asignan para apoyar los programas focalizados que van a beneficiar a ciertos grupos de población, esto a raíz de que en muchos casos los beneficiarios no logran recibir (todos) la capacitación o impulso laboral planeado a razón de las modificaciones que en el camino va sufriendo un determinado programa, lo cual afecta directamente a sus beneficiarios.

- El programa que más éxitos significó para el gobierno chileno en cuanto a políticas laborales fue "Chile trabaja", el cual también ayudó a aumentar la cotización al sistema de seguridad bajo la condición de que toda persona beneficiaria del programa debía acogerse a los pagos que en seguridad social establece la ley, y a al ser el programa más grande (por recursos y beneficiarios) en Chile logró una acogida importante que impulsó la sincronía y armonía entre pensiones y empleo que años atrás estaba buscando fallidamente el Estado, y que al fin se pudo lograr en cierta forma a través de este programa.

- La aplicación de la Reforma Previsional deja un desafío pendiente con la población más joven, porque si bien de cierto modo se están generando incentivos para que este sector de la población se motive a contribuir al sistema de pensiones, todavía se hace necesaria y urgente una mayor articulación entre el mercado laboral y el sistema de pensiones que 
permita una continua inserción de los jóvenes en un empleo estable, para que esto alimente el sistema de pensiones a través de los salarios garantizando su sostenibilidad.

- El sistema pensional debe adaptarse (o en la medida de lo posible) a los cambios y transiciones demográficas a los cuales está expuesta frecuentemente la población, esto a razón de que muchos países, incluido Chile, se encuentran inmersos en un envejecimiento progresivo que a su vez se suma a la abstención de contribuir al sistema pensional por parte de una porción importante de trabajadores; esto genera como resultado final un incremento en el compromiso fiscal del Estado, el cual debe responder por las mesadas pensionales de aquellos que no pudieron o no quisieron cotizar al sistema de pensiones cuando debían hacerlo.

- Un eventual incremento en el gasto y los compromisos fiscales del Estado, implica también un mayor gasto social y una destinación elevada de recursos para subsanar la falta de ingresos de los adultos mayores de los sectores más vulnerables.

- La desigualdad en ingresos sigue siendo un aspecto a trabajar para reducir el impacto que esta tiene en el sistema de pensiones y en la economía general de Chile, debido a que si los trabajadores carecen de un flujo constante de ingresos se verá afectado el monto de su mesada pensional en el largo plazo, y tampoco podrán acceder a beneficios de retiro programado o vejez anticipada, que son dos de las modalidades por la cuales cotizar al sistema pensional se hace atractivo para los afiliados.

- Se dio una acertada inclusión y participación a los diferentes actores en la Reforma Previsional del año 2008, esto sirvió como instrumento de difusión de las políticas sociales que se iban a llevar a cabo y también para hacer equitativo el proceso de discusión para el país, dando como resultado el acuerdo más aterrizado al que pudieron llegar tras las medidas implementadas. Sin embargo, es claro que el tiempo de discusión de los acuerdos fue corto en comparación a lo extensa que es la estructura productiva de Chile, y por ello es el único aspecto pendiente en cuanto a la discusión pública de la reforma.

- A lo largo de este documento, se pudo ver la forma en la cual se desarrolló la Reforma Previsional, tomando como base los instrumentos de participación pública de manera masiva, aunque este proceso no es ajeno a objeciones, conjeturas y desafíos pendientes que quedan en el camino y que solo se pueden observar una vez desarrollado la reforma al completo. 
Estas recomendaciones son una opinión personal del autor y no constituyen ni comprometen los planteamientos ideológicos ni las opiniones de las instituciones nombradas en este trabajo de investigación. En materia de políticas de protección social.

\section{Recomendaciones aplicables al caso de Colombia}

Las recomendaciones de cara a mejorar el funcionamiento del sistema pensional y su cobertura son las siguientes:

- El sistema de pensiones debe estar diseñado pensado en la satisfacción de los afiliados, porque si bien no son la única fuente de ingresos para el sistema, si se constituye en la más importante con los aportes que realizan como consecuencia de la obtención de un ingreso por el desempeño de alguna actividad laboral y económica.

- Es propicio permitir la movilidad libre entre fondos de pensiones de los afiliados, sin restringir la escogencia del mismo por largos periodos, como en el caso de los jóvenes que recién empiezan a contribuir al sistema y solamente se pueden trasladar de AFP pasados cinco (5) años después de haberse afiliado. Esto quiere decir, que la movilidad que hay en el Sistema de Salud sea replicada en el Sistema de Pensiones.

- No es viable dejar el sistema pensional, sin un componente público definido que conlleve a una privatización total del sistema, puesto que el Estado debe ser un actor esencial del sistema en cualquier Nación.

- Las tasas de reemplazo deben ser impulsadas en los fondos privados, dado que actualmente la remuneración que en la edad futura recibir un trabajador de entre 30 y 35 años será considerablemente más baja en la vejez, porque no existen incentivos fuertes para hacer que los más jóvenes contribuyan al sistema.

- Es aconsejable generar la creación de Organismos Estatales (como en el caso chileno) que funcionen como control y vigilancia; por ejemplo, Superintendencias para las Administradoras de pensiones y para el propio sistema y que dependan del Ministerio de Trabajo, con el fin de articular mejor la relación salarial con la Protección social en el Mercado laboral. 
- Se deben utilizar masivamente los instrumentos de difusión pública para invitar a la población a participar del proceso de articulación del sistema en caso de que se plantee una posible reforma, manejando tiempos prudenciales de mínimo 6 meses o 1 año, en los cuales se generen audiencias de discusión pública que permitan acoger a todos los sectores y actores que son parte de la reforma.

- El mercado laboral debe servir de conector entre los ingresos y el sistema pensional, implementando medidas que permitan la inclusión de la población joven y de las mujeres, garantizando a estos un ingreso mensual respaldado por incentivos en pensiones que permitan alcanzar un ingreso en la vejez a las personas.

- Mientras más personas puedan alcanzar su pensión y se les cumpla con lo pactado a través de las cotizaciones hechas a lo largo de su vida laboral, más atractivo será el sistema de pensiones para la población y de este modo podrá incrementarse la cobertura del sistema.

- Los programas de promoción al empleo deben contar con un sólido respaldo por parte de las empresas, para favorecer la inserción laboral de las personas, de este modo se logra que los programas focalizados que implementa el gobierno nacional sean utilizados por la población para la cual iban dirigidos y no quede en el simple hecho de aplicar los programas cuando muchos de los beneficiarios, por un lado no les corresponde hacer uso de este beneficio o por otro, no se logran asentar en el mercado laboral. Y esto restringe todo tipo de contribución al sistema de protección social.

- La informalidad laboral puede ser atacada desde la perspectiva de hacer obligatoria la contribución a pensiones por parte de cualquier trabajador, ligando este aporte como un requisito para desarrollar cualquier actividad económica. El hecho de ligar el aporte pensional a la autorización para desempeñar cualquier actividad económica, reduciría la evasión de aportes y el uso inadecuado de figuras de cotización que permitan al afiliado pagar un menor valor de aporte pensional del que le corresponde.

- Se debe mantener el principio de solidaridad intergeneracionalidad en miras de garantizar la sostenibilidad el sistema y a que se brinden por parte de este las prestaciones sociales, como producto de unos requisitos previamente establecido de cotización. Esto es de suma importancia, ya que los jóvenes quienes cuentan con toda la capacidad productiva son los que deben renovar el sistema de protección social, en favor de los adultos mayores que durante sus años laborales aportaron juiciosamente al sistema. 
- La generación de empleo debe ser orientada a todos los sectores de la población, sin dejar de lado la atención prioritaria que merecen las personas de bajos recursos, dicha atención puede llegar bajo la creación de oportunidades laborales que permitan a este grupo poblacional obtener un ingreso mensual y que de él se desprenda un ahorro previsional; independientemente si es mucho o poco el monto ahorrado, sin duda es un monto que al ser replicado en masa en los sectores vulnerables alivia la presión del Estado como actor paternalista y generador de ingresos (mediante subsidios) a los más necesitados.

\subsection{Reflexiones del autor}

La reforma integral hecha al Sistema Previsional chileno en el año 2008 buscó aumentar la cobertura y el acceso a una pensión digna a los trabajadores a través de generar incentivos de cotización al sistema por parte de los más jóvenes en el mercado de trabajo esto para intentar mantener la tendencia de solidaridad intergeneracional y la viabilidad de las tasas de reemplazo en el mercado laboral.

Los resultados presentados acerca de la reforma evidencian que el incremento en las cotizaciones y en el número de afiliados ha sido poco pero gradual año tras año desde que se implementó la reforma. Existe un mejor panorama para las pensiones asistenciales (PASIS) y para los programas focalizados al sector pensional que fueron creados para asistir socialmente a la población que por sus condiciones de ingreso o vulnerabilidad no podrían acceder a la garantía de una pensión. Lo anterior mostró un incremento (a partir del 2010) en el número de pensiones otorgadas por concepto de viudez, bonos por hijo para mujeres de escasos recursos y básica solidaria; como consecuencia de una mayor cantidad de pensiones aprobadas se generó un mayor gasto social y compromiso fiscal para el gobierno nacional.

De igual manera, la mejoría en el Sistema Previsional chilena se empezó a hacer visible posterior al año 2010, antes no se produjo a razón de la reciente crisis económica internacional que padecían los más importantes mercados internacionales, dicha mejoría se evidenció con la mayor inclusión de trabajadores para alcanzar la pensión, aplicando estrategias que permitieran que los aportes fueran compensados por un equilibrio en la unidad de fomento (UF) que el Estado utiliza para medir la asignación de la porción social del salario correspondiente a pensión; también la competitividad en las AFP fue impulsada por un mayor control a través de la creación de la 
Superintendencia de Pensiones, organismo que vigila el proceder de cada una de estas entidades y que a la actualidad cuenta con una sólida base y estructura de información que contribuye al adecuado funcionamiento del Sistema Previsional chileno (Maldonado \& Palma, 2013). Sin embargo, dentro de los más grandes desafíos que aún se encuentran pendientes para el sistema de pensiones de Chile está reducir las diferencias que persisten para los afiliados por ingresos puesto que la desigualdad de ingresos supone la barrera más importante para disminuir la falta de ingresos tanto en materia pensional como en materia social y económica de la población chilena.

También, sería de gran utilidad continuar generando incentivos a la cotización en seguridad social para la población, ya que según la cifras presentadas a lo largo de este trabajo alrededor de un $23 \%$ de la población hace evasión de obligatoriedades a la seguridad social, lo que afecta el desempeño del sistema gravemente pues de las cotizaciones depende garantizar la continuidad y sostenibilidad del sistema a través del tiempo. Se destaca la iniciativa del gobierno de Chile por hacer una reforma en la que se escucharan a los diversos sectores de la población para generar redes articuladas que permitieran llegar a un consenso sobre la aplicación de la reforma. No obstante, el tiempo de aplicación de las audiencias públicas específicamente fue muy corto (a pesar de la cantidad que se hicieron) tal como lo manifestó el Consejo Asesor Presidencial para la Reforma Previsional mencionando que no a todos los sectores participantes se les escuchó bajo el lapso de tiempo que se hubiera deseado.

Finalmente, el control que se impuso a los empleadores fue correcto en la medida en que permite evitar que se evadan de la responsabilidad de pagar los aportes que les corresponden como consecuencia de la actividad laboral que desempeñan. Antes de la reforma se encontró que la evasión por parte de los empleadores estuvo cercana al $11 \%$, especialmente en los sectores mineros y agrícolas en los cuales las formas de contratación permitían este tipo de arbitrariedades para los trabajadores, por lo que este es sin duda un punto a favor para el buen funcionamiento del sistema de pensiones en Chile (Jiménez \& Cuadros, 2003). La cobertura en términos generales ha aumentado gradualmente pero no en los niveles deseados, ante esto Chile ha optado por hacer un minucioso seguimiento a la reforma desde su aplicación y hasta la actualidad con el fin de hacer cambios necesarios pero no drásticos con la intención de generar un impacto negativo o inesperado para el sistema pensional actual que en América Latina es uno de los mejores en cuanto a garantía de pensiones y prestaciones de servicio. 


\section{BIBLIOGRAFÍA}

AFC Chile. (s.f.). ¿Qué es Seguro de Cesantía? Obtenido de Seguro de Cesantía: https://www.afc.cl/descripcion-del-seguro/

Arellano, J. (1980). Sistemas alternativos de Seguridad Social. Un análisis de la experiencia Chilena. Santiago de Chile: CIEPLAN.

Arellano, J. (1991). El sistema de pensiones en Chile: Una experiencia en seguridad social. Santiago de Chile: CIEPLAN.

Arenas, A. (2010). Historia de la reforma previsional chilena: Una experienca exitosa de política pública en democracia. Santiago de Chile: OIT.

Asociación Chilena de AFP. (2013). Gasto Fiscal en Pensiones: Habrá holguras para reparar el daño prevsional Estatal a empleados públicos. Serie de Estudios de la Asociación de AFP. (86), $1-5$.

Asociación de Auditores Externos de Chile. (s.f.). Superintendencia de Seguridad Social (SUSESO). Obtenido de Auditoría: http://aechile.cl/superintendencia-de-seguridad-socialsuseso/

Banco Central de Chile. (2014). Cuentas Nacionales de Chile: Evolución de la actividad económica 2014. Santiago de Chile: BCC.

Banco Central de Chile. (2016). Cuentas nacionales de Chile: Evolución de la actividad económica en el año 2016. Santiago de Chile: BCC.

Banco Mundial. (2014). Informe de desarrollo de América Latina. Santiago de Chile: Banco mundial.

Berstein, S. (2010). El sistema chileno de pensiones. Santiago de Chile: Superintendencia de Pensiones. 
Berstein, S. (2011). Documento de trabajo No45: Implementación de la Reforma Previsional en Chile. Santiago de Chile: Superintendencia de Pensiones.

Bertranou, F. (2001). Cobertura previsional en Argentina, Brasil y Chile. Santiago: OIT.

Biblioteca del Congreso Nacional de Chile. (2005). El sistema Previsional de Chile. Biblioteca del Congreso Nacional de Chile. Santiago de Chile: Departamento de Estudios.

Castel, R. (1997). La metamorfósis de la cuestión social. Una crónica del salariado. Buenos Aires: Paidós.

Cecchini, S. (2016). Protección social con enfoque de derechos para la América Latina del siglo XXI. Opera. (18), 11-33.

Cecchini, S., Filgueira, F., Martínez, R., \& Rossel, C. (2015). Instrumentos de protección Social: Caminos latinoamericanos hacia la universalización. Santiago de Chile: CEPAL.

Cechinni, S., \& Martínez, R. (2011). Protección social inclusiva en América Latina: Un enfoque integral, un enfoque de derechos. Santiago de Chile: CEPAL.

CEPAL. (2012). Heterogeneidad estructural, empleo y protección social. Santiago.

CEPAL. (2014). Panorama Fiscal de América Latina y el Caribe 2014: Hacia una mayor calidad de las finanzas públicas. Santiago de Chile: CEPAL.

CEPAL. (2015). Sistemas de pensiones en América Latina: Una perspectiva comparada. Santiago de Chile: CEPAL.

CEPAL. (2016). Panorama social de América Latina. Santiago de Chile: CEPAL.

Coloma, F., \& Rojas, P. (2012). Evolución del mercado laboral en Chile: Reformas y resultados. En F. Larraín, \& R. Vergara, La Transformación Económica de Chile (págs. 491-540). Santiago de Chile: Centro de Estudios Públicos.

Comisión técnica de asignaciones familiares. (2008). Prestaciones familiares: Políticas, prácticas y lucha contra la pobreza en América Latina. Montevideo: Banco de Previsión social del Uruguay. 
Congreso Nacional de Chile. (1972). Ley 17.594 del 4 de enero de 1972. [Por la cual se concede personalidad jurídica de la CUT y mecanismos de financiamiento de sus actividades]. Santiago de Chile, Chile.

Congreso Nacional de Chile. (2008). Ley 20255 del 4 de marzo de 2008. [Por la cual se Establece Reforma Previsional]. Santiago de Chile, Chile.

Consejo Asesor Presidencial para la Reforma Previsional. (2006). El Derecho a una vida digna en la vejez: Hacia un contrato social con la previsión en Chile. Santiago de Chile: Presidencia de la República.

Departamento Nacional de Planeación. (2012). Sistemas pensionales y solidarios de Chile, Irlanda, Polonia Brasil y Perú. Bogotá: Direccíon de Estudios económicos (DNP).

Echeverría, M., \& López, D. (2004). Flexibilidad laboral en Chile: Las empresas y las personas . Santiago de Chile: Centro de Estudios sobre Mercado de Trabajo.

Equipo Observatorio Social. (2013). Cartilla de síntesis: sistema de pensiones chileno. Observatorio Social. Santiago de Chile: Fundación Sol.

Filgueira, F. (2014). Hacia un modelo de protección social universal en América Latina. Santiago de Chile: CEPAL.

Gálvez, T., \& Díaz, E. (2015). Taller de Coyuntura: Informalidad laboral: conceptos y mediciones. Parte 1. Santiago de Chile: Dirección del Trabajo.

Gill, I., Packard, T., \& Yermo, J. (2004). Keeping the promise of Social Security in Latin America. Washington, D.C.: Banco Mundial.

González, S., \& Huneeus, C. (2016). Dinámica laboral en Chile 2009 - 2015. Santiago de Chile: Ministerio de Trabajo y Previsión social.

Guardia, A. (2012). El sistema chileno de pensiones puesto en cuestión. Santiago de Chile: Friedrich Ebert Stiftung.

Helmsdorff, L. (2008). Ampliación de la cobertura del sistema pensional colombiano y atención al adulto mayor. Bogotá, D.C.: Departamento Nacional de Planeación. 
Holzmann, R., \& Hinz, R. (2006). Una perspectiva internacional de los sistemas de pensiones y de sus reformas. Bogotá, D.C.: Banco Mundial.

Homazábal, R. (2011). El gran engaño 30 años del sistema de AFP. Santiago de Chile: Instituto de Asuntos Públicos / Universidad de Chile.

Hormazábal, R. (2008). La Reforma Previsional: Promesas y Concreciones. Agenda pública. VI (11), 42-52.

Instituto de Previsión Social. (s.f.a). Quiénes somos. Obtenido de Conózcanos: http://www.ips.gob.cl/servlet/internet/inicio/conozcanos/quienes-somos

Instituto de Previsión Social. (s.f.b). Acerca del Instituto de Seguridad Laboral. Obtenido de Portada : https://www.isl.gob.cl/inicio/acerca-isl-portadilla/

Instituto Nacional de Estadística. (s.f.). Inicio. Obtenido de http://www.ine.cl/

Jiménez, F., \& Cuadros, J. (2003). Ampliación de la cobertura de los sistemas de pensiones en América Latina. Revista de la CEPAL. (79), 117-132.

Jordana, J. (2006). Las políticas de regulación social y la creación de mercados en los sectores sociales de América Latina. Santiago: BID.

Larrañaga, O. (2010). Las nuevas Políticas de Protección Social en Perspectiva Histórica. Santiago de Chile: PNUD.

Libertad y Desarrollo. (2014). Reforma laboral: Los reales desafíos en el mercado de trabajo. Temas públicos. (1.186), 1-8.

Lo Vuolo, R. (2005). La protección social en América Latina: los límites de la revisión. Buenos Aires: CIEPP.

Lo Vuolo, R. (2010). Documento de Trabajo $N^{o} 76$ : Las perspectivas de ingreso ciudadano en América Latina. Buenos Aires: CIEPP.

Maldonado, C., \& Palma, A. (2013). La construcción de pactos y consensos en materia de política social: apuntes para un marco de análisis. Santiago de Chile: CEPAL. 
Marcel, M., \& Tapia, W. (2010). Efectos de la crisis financiera sobre las pensiones en Amérca Latina. Washington, D.C. : Banco Interamericano de Desarrollo.

Mesa, C. (2004). Evaluación de un cuarto de siglo de reformas estructurales de pensiones en América Latina. Revista de la CEPAL. (84), 59-81.

Ministerio de Planificación de Chile. (2010). Encuesta Casen. Santiago de Chile: Comisión de Técnicos.

Ministerio del Trabajo y Previsión Social. (1980). Decreto Ley 3500 del 4 de Noviembre de 1980. [Por la cual se establece nuevo sistema de pensiones]. Santiago de Chile, Chile.

Narbona, K. (2015). Antecedentes del Modelo de Relaciones Laborales Chileno. Santiago de Chile: Observatorio Social / Fundación SOL.

Observatorio social de Chile. (2015). Antecedentes del modelo de relaciones laborales chileno. Santiago.

OCDE. (2015). Panorama de las pensiones: América Latina y el Caribe. París: OCDE / Banco Mundial / BID.

Organización Internacional del Trabajo. (2014). Panorama Laboral de América Latina y el Caribe 2014. Ginebra: OIT.

Organización Internacional del Trabajo. (s.f.). Salario mínimo. Obtenido de Guías en Español: http://libguides.ilo.org/minimum-wages-es

Organización Mundial de la Salud. (2010). La financiación de los sistemas de Salud: el camino hacia la cobertura universal. Ginebra: OMS.

Ortiz, F., \& Moreno, Á. (2010). Economía política de la reforma del sistema colombiano de pensiones. Revista de Economía Institucional. 12 (22), 167-192.

Perticara, M., \& Celhay, P. (2010). Informalidad Laboral y Políticas públicas en Chile. Santiago: Universidad Alberto Hurtado.

Piñera, J. (1990). La Revolución laboral en Chile. Santiago de Chile: Zig-Zag. 
Prado, A., \& Sojo, A. (2010). Envejecimiento en América Latina: Sistemas de pensiones y protección social integral. Santiago de Chile: CEPAL.

Reyes, G., Berstein, S., Castañeda, P., \& Fajnzylber, E. (2009). Chile 2008: Una reforma previsional de segunda generación. Santiago de Chile: Superintendencia de pensiones de Chile.

Robles, C. (2013). Sistemas de protección social en América Latina y el Caribe: Chile. Santiago de Chile: CEPAL.

Robles, C., Cecchini, S., \& Filgueira, F. (2014). Sistemas de protección social América latina y el caribe: Una perspectiva comparada. Santiago de Chile: CEPAL.

Rodríguez, J., \& Florez, L. (2008). Protección del gasto público social a través de la política fiscal: el caso de chile. Santiago de Chile: CEPAL.

Rofman, R., \& Lucchetti, L. (2006). Sistemas de pensiones en América Latina: Conceptos y mediciones de cobertura. Santiago de Chile: Banco Mundial.

Rofman, R., Apella, I., \& Vezza, E. (2013). Más allá de las de las pensiones contributivas: Catorce experiencias en América Latina. Buenos Aires: Banco Mundial.

Rucci, G. (2011). Mercado laboral en Chile: Nota técnica sectorial. Santiago de Chile: Banco Interamericano de Desarrollo.

Saavedra, E. (2014). El Modelo económico-político de Chile: Desarrollo social en la encrucijada. Economía y política. 1 (1), 115-146.

SAFP. (2010). El sistema de pensiones Chileno. Santiago de Chile: Superintendencia de Pensiones.

Salazar, E. (2011). Cobertura y acceso a la garantía de pensión minima en el sistema de pensiones. Cuadernos de contabilidad. 12 (31), 491-520.

SENCE. (2013). Programa Formación en el Puesto de Trabajo . Santiago de Chile: Unidad de Estudios SENCE. 
SENCE. (s.f.). Inicio. Obtenido de http://www.sence.cl/portal/

Silva, J. (2013). Informalidad en el empleo en Chile. Federación Interamericana de la Industria de la Construcción (págs. 1-13). Montevideo: FIIC.

Suárez, Á. (2015). Juventud precarizada: desempleo, flexibilización laboral y trabajo precario. Obtenido de Juventud: http://www.laizquierdadiario.com/Juventud-precarizadadesempleo-flexibilizacion-laboral-y-trabajoprecario?id_rubrique $=2653$ ?utm_source $=$ newsletter\&utm_medium $=$ email\&utm_campaig $\mathrm{n}=$ Newsletter

Subsecretaría de Previsión Social. (2013). Situación de las pensiones (de vejez) en el Sistema de AFP. Santiago de Chile: Subsecretaría de Previsión Social.

Subsecretaría de Previsión Social. (s.f.). La experiencia chilena. Obtenido de Sistema de Pensiones: https://www.previsionsocial.gob.cl/sps/organizaciones/organizacionesterritoriales-y-sociales/sistema-de-pensiones/la-experiencia-chilena/

Superintendencia de Pensiones de Chile. (2016). Seguimiento a la reforma previsional. Satiago de Chile: Superintendencia de Pensiones.

Superintendencia de Pensiones. (s.f.). La institución. Obtenido de Quiénes somos: https://www.spensiones.cl/portal/institucional/594/w3-propertyvalue-5990.html

UNICEF. (2013). Informe anual sobre programas sociales en América Latina. Oslo: Naciones Unidas.

Uthoff, A. (2002). Mercado de trabajo y sistemas de pensiones. Revista de la CEPAL. (78), 39-53.

Uthoff, A. (2006). Brecha del Estado de Bienestar y reformas a los sistemas de pensiones de América Latina y el Caribe. Santiago: CEPAL.

Uthoff, A. (2011). La reforma del sistema chileno de pensiones. Santiago de Chile: CEPAL / ASDI.

Wikipedia. (s.f.). Economía de Chile. Obtenido de https://es.wikipedia.org/wiki/Econom\%C3\%ADa_de_Chile 
